\title{
Design and Testing for a New Thermosyphon Irradiation Vehicle
}

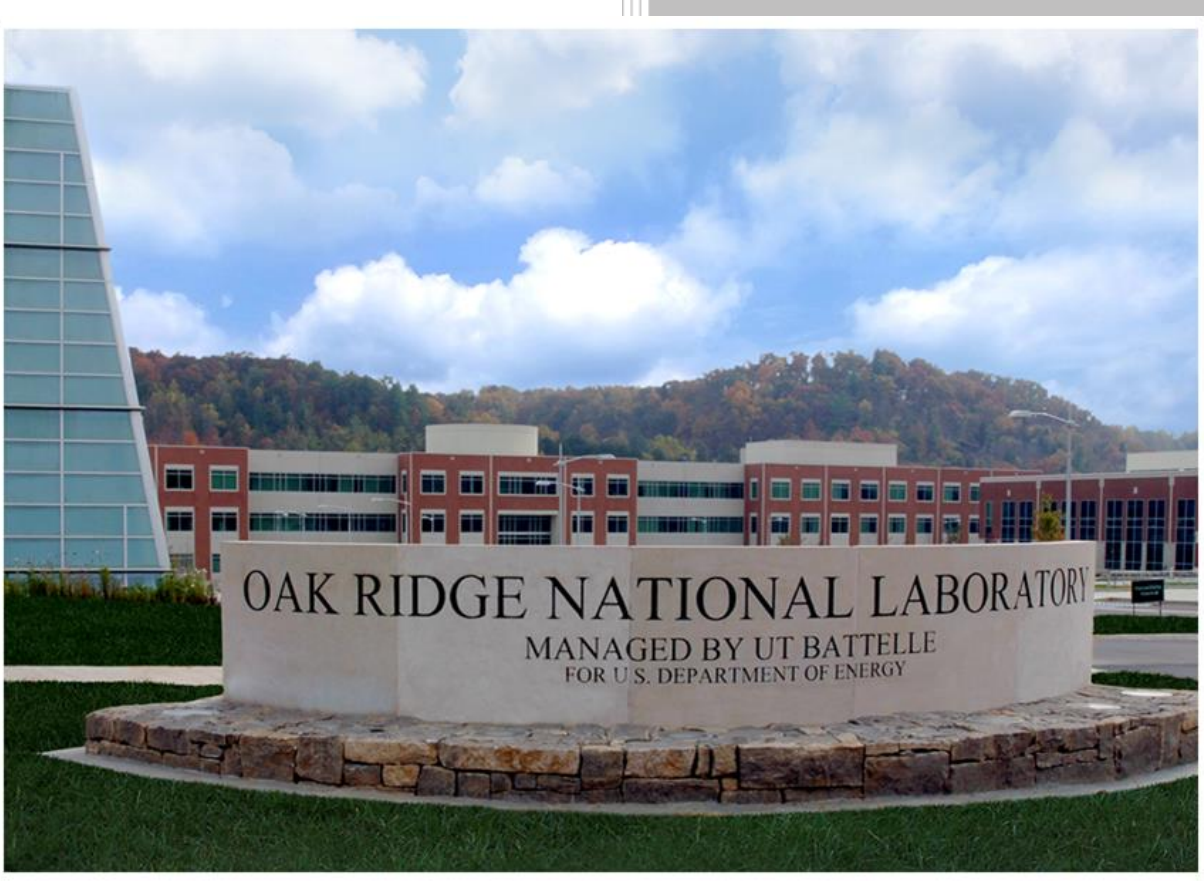

Approved for public release. Distribution is unlimited.

Joel McDuffee

Dave Felde

Juan Carbajo

September 2017 


\title{
DOCUMENT AVAILABILITY
}

Reports produced after January 1, 1996, are generally available free via US Department of Energy (DOE) SciTech Connect.

Website http://www.osti.gov/scitech/

Reports produced before January 1, 1996, may be purchased by members of the public from the following source:

\author{
National Technical Information Service \\ 5285 Port Royal Road \\ Springfield, VA 22161 \\ Telephone 703-605-6000 (1-800-553-6847) \\ TDD 703-487-4639 \\ Fax 703-605-6900 \\ E-mail info@ntis.gov \\ Website http://www.ntis.gov/help/ordermethods.aspx
}

Reports are available to DOE employees, DOE contractors, Energy Technology Data Exchange representatives, and International Nuclear Information System representatives from the following source:

Office of Scientific and Technical Information

PO Box 62

Oak Ridge, TN 37831

Telephone 865-576-8401

Fax 865-576-5728

E-mail reports@osti.gov

Website http://www.osti.gov/contact.html

This report was prepared as an account of work sponsored by an agency of the United States Government. Neither the United States Government nor any agency thereof, nor any of their employees, makes any warranty, express or implied, or assumes any legal liability or responsibility for the accuracy, completeness, or usefulness of any information, apparatus, product, or process disclosed, or represents that its use would not infringe privately owned rights. Reference herein to any specific commercial product, process, or service by trade name, trademark, manufacturer, or otherwise, does not necessarily constitute or imply its endorsement, recommendation, or favoring by the United States Government or any agency thereof. The views and opinions of authors expressed herein do not necessarily state or reflect those of the United States Government or any agency thereof. 
Reactor and Nuclear Systems Division

\section{Design and Testing for a New Thermosyphon Irradiation Vehicle}

Joel L. McDuffee

David K. Felde

Juan J. Carbajo

Date Published: September 2017

Prepared by

OAK RIDGE NATIONAL LABORATORY

Oak Ridge, TN 37831-6283

managed by

UT-BATTELLE, LLC

for the

US DEPARTMENT OF ENERGY

under contract DE-AC05-00OR22725 



\section{CONTENTS}

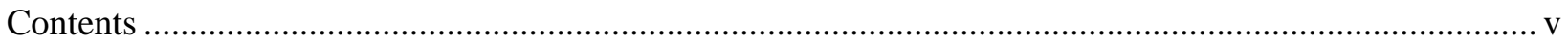

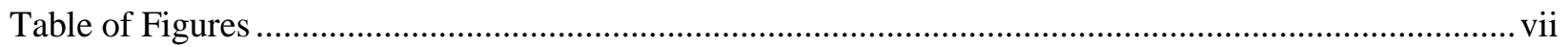

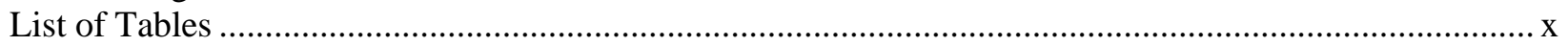

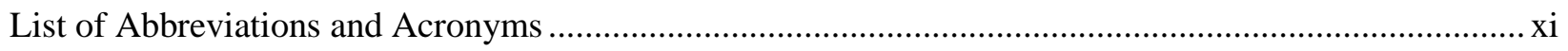

Abstract

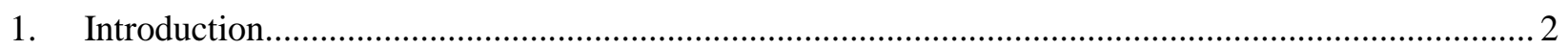

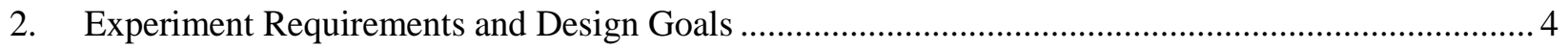

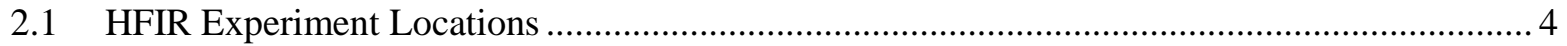

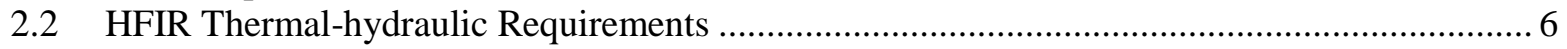

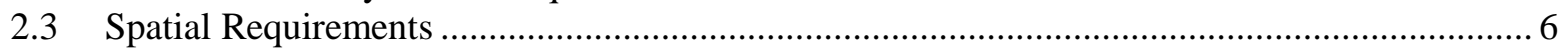

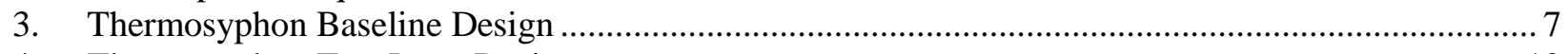

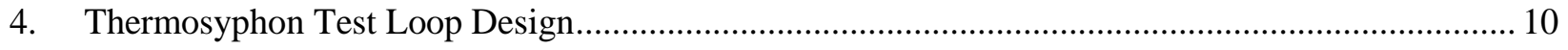

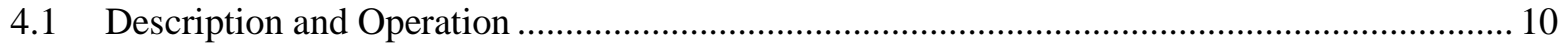

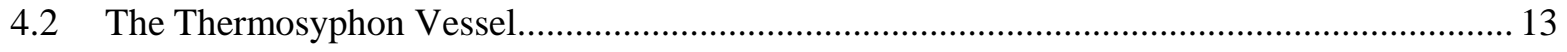

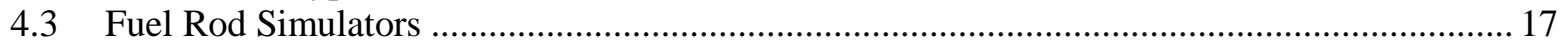

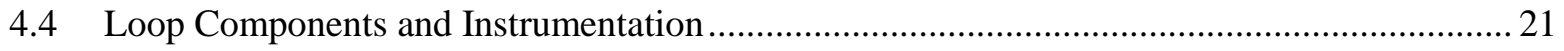

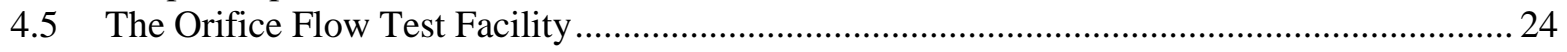

5. Thermosyphon test loop experiment Operation.................................................................. 28

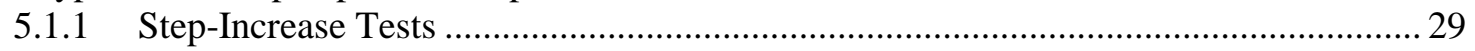

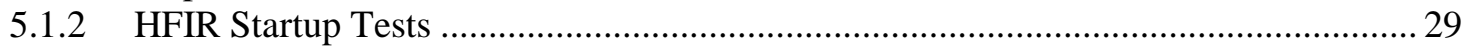

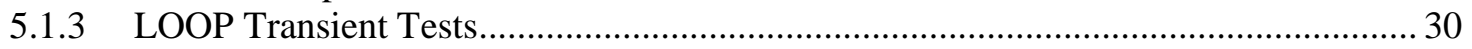

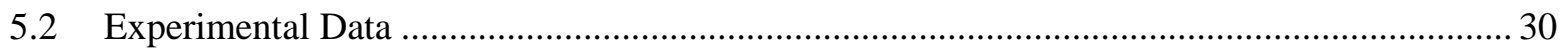

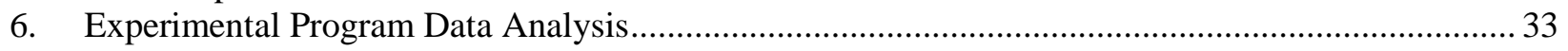

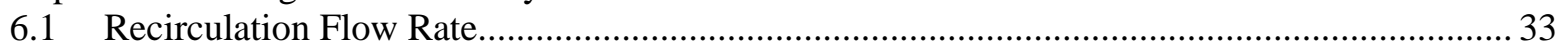

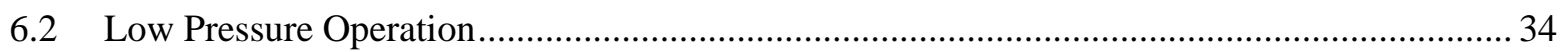

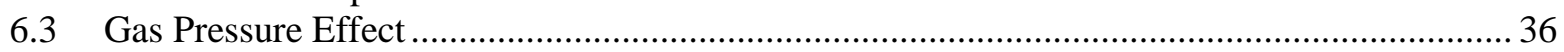

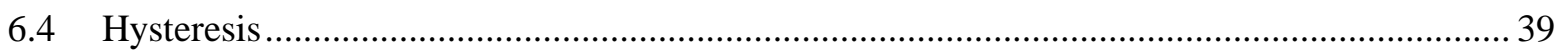

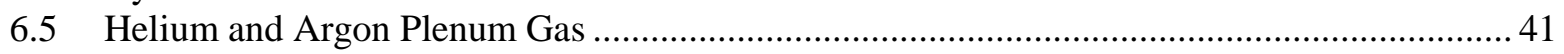

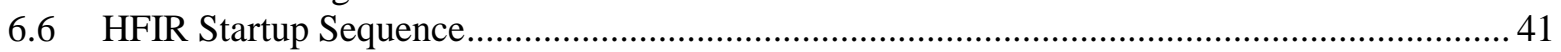

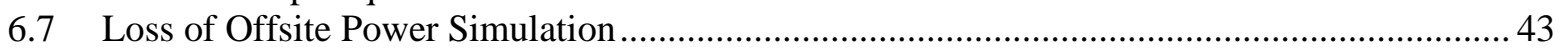

7. Comparison of Experimental Data With Computer Code Results ............................................... 46

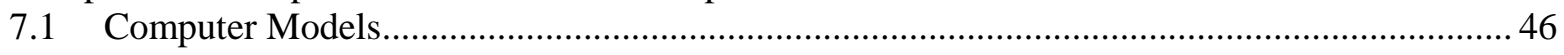

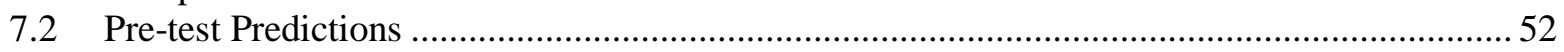

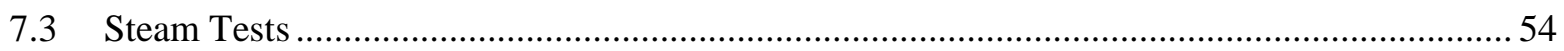

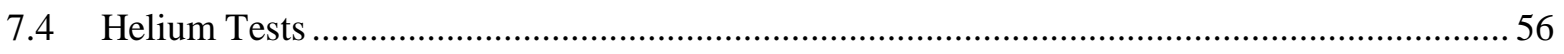

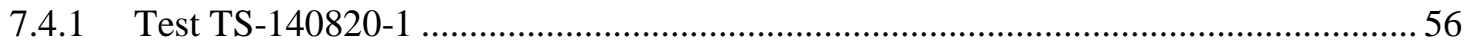

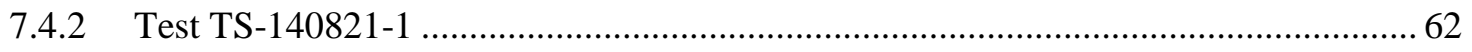

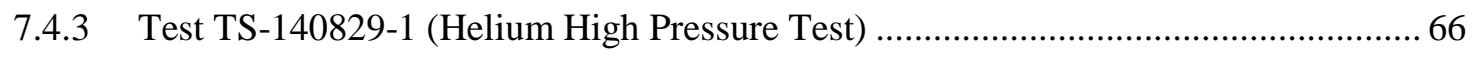

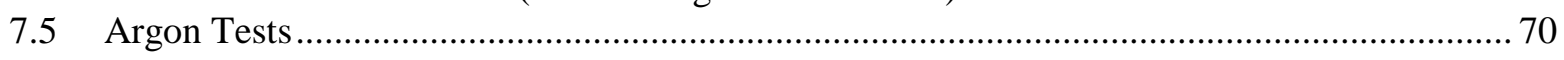

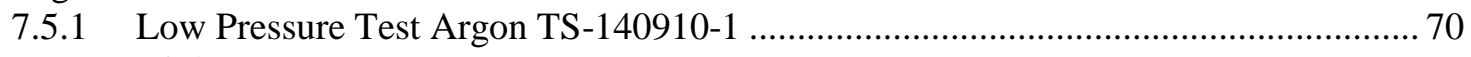

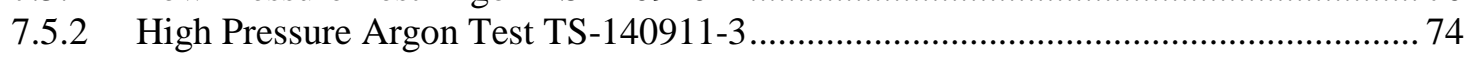

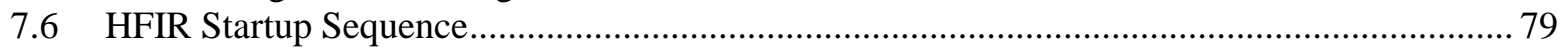

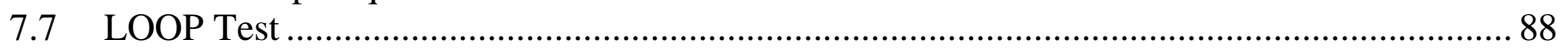

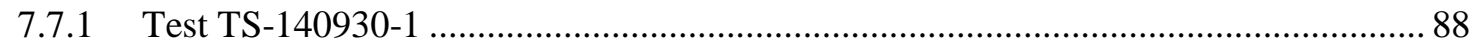

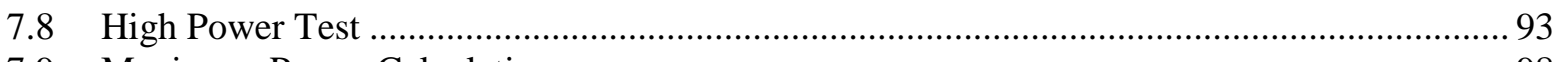

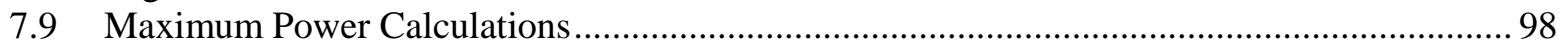


7.10 Condenser performance

7.11 RELAP5-3D and TRACE Differences

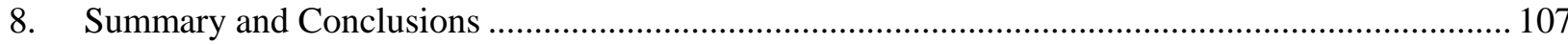

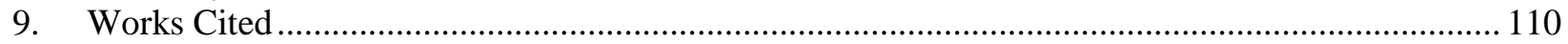

Appendix A. Thermosyphon Drawings 


\section{TABLE OF FIGURES}

Figure

Figure 2-1. Reactor core fuel plates and primary irradiation facilities.

$\underline{\text { Page }}$

Figure 2-2. HFIR's primary experimental sites

Figure 3-1. Schematic of the Thermosyphon Irradiation Facility (left, not to scale) and a CAD

representation of an out-of-reactor experimental assembly (right).......................................... 7

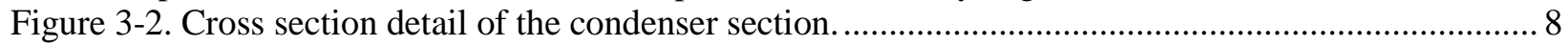

Figure 3-3. Cross section detail of the evaporator and liquid return sections........................................... 8

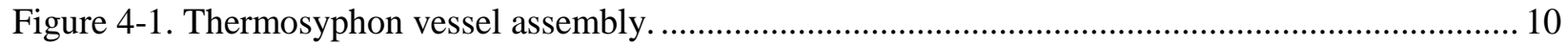

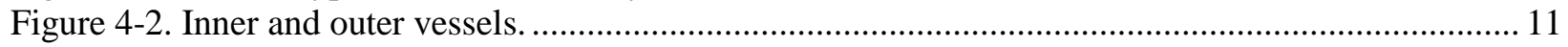

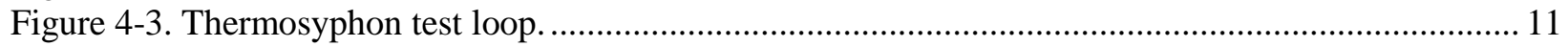

Figure 4-4. Thermosyphon test loop installed in ORNL Thermal Hydraulics Laboratory........................ 12

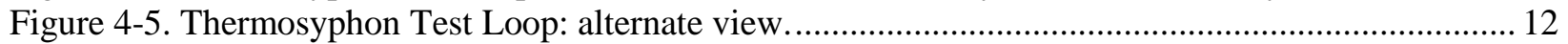

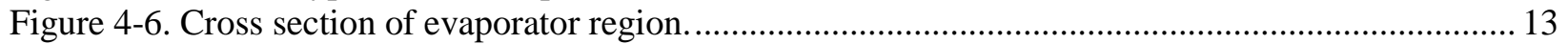

Figure 4-7. Internal baffle assembly defining the internal flow geometry............................................. 14

Figure 4-8. Eight flow orifices in lower flow separator providing flow stability (4 each at two

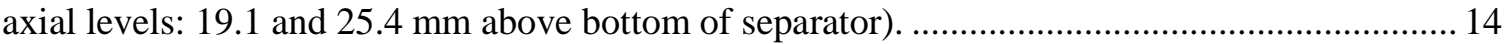

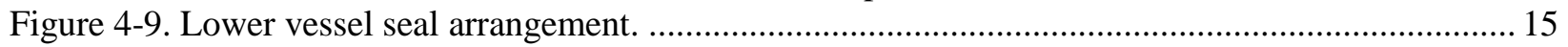

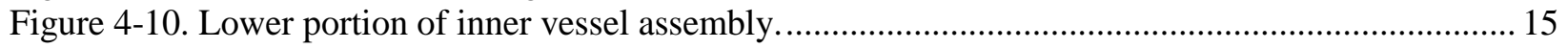

Figure 4-11. A swirl device is used to separate liquid droplets from vapor above the boiler region.......... 16

Figure 4-12. View looking down at swirl device installed in the upper baffle assembly........................ 16

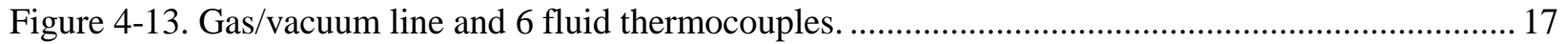

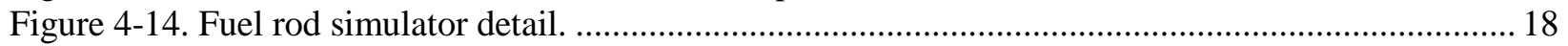

Figure 4-15. Lower thermosyphon assembly with power and instrument connections.......................... 20

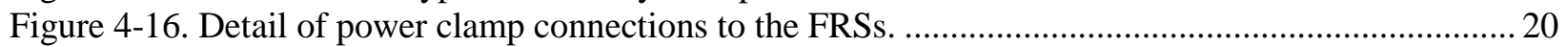

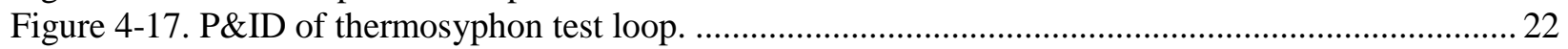

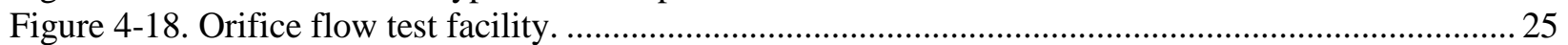

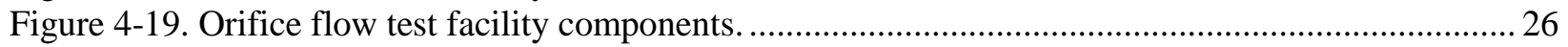

Figure 4-20. Orifice flow test facility as installed in the water test loop............................................26

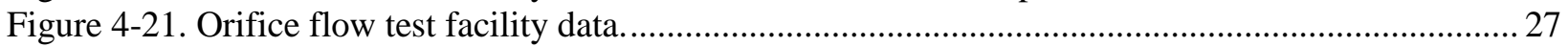

Figure 5-1. Relative heights of key features in the thermosyphon vessel (measuring from the

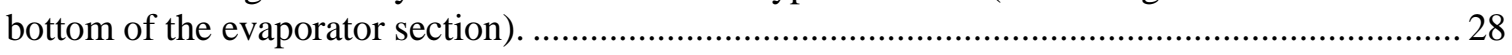

Figure 6-1. Flow separator detail showing lower flow orifice (in inches) ........................................... 33

Figure 6-2. Pressure drop through the lower orifice for several tests. ................................................... 34

Figure 6-3. Temperature trace for the top three heater thermocouples in test TS-140818-2

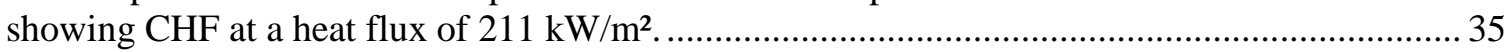

Figure 6-4. Maximum heater temperature for a series of tests at different condenser pressures............... 36

Figure 6-5. Condenser thermocouple traces showing clear separation of the steam and helium

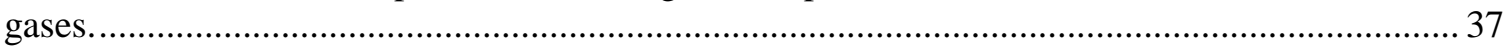

Figure 6-6. Condenser pressure for various starting helium gas blanket pressures. ................................ 38

Figure 6-7. Condenser saturation temperature for various starting helium gas blanket pressures.............. 38

Figure 6-8. Evaporator working temperature range for two gas blanket pressures $(0.01 \mathrm{MPa}$ and

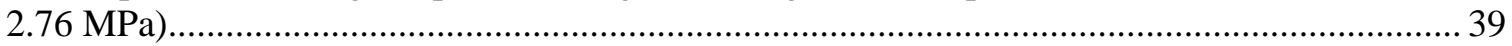

Figure 6-9. Maximum heater temperature for TS-140821-3 showing little or no hysteresis..................... 40

Figure 6-10. Condenser pressure for rising and falling power on multiple test days showing little

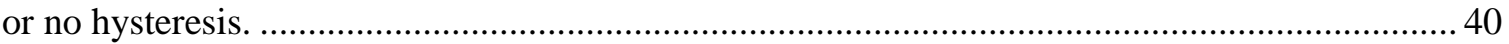

Figure 6-11. Condenser temperature profile using helium and argon gas. .............................................. 42

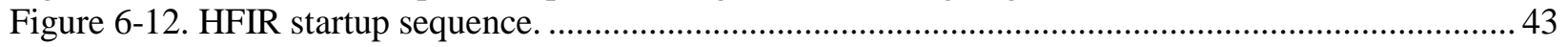

Figure 6-13. Thermocouple time trace after a $17 \mathrm{~kW}$ power increase ................................................... 43 
Figure

Figure 6-14. Mass flow and power profile during a LOOP simulation. ................................................. 44

Figure 6-15. Internal temperatures during a LOOP simulation. .............................................................. 45

Figure 6-16. Subcooling in the primary coolant during a LOOP simulation.............................................45

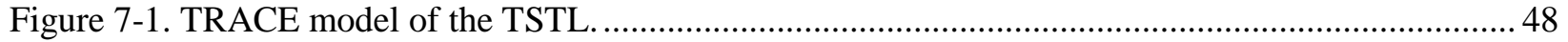

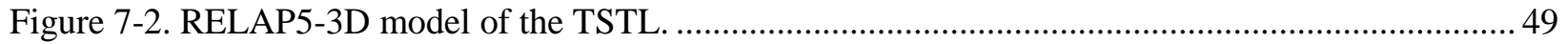

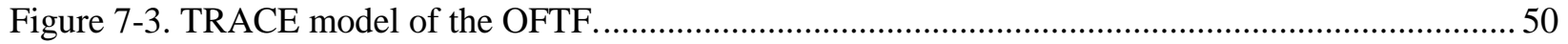

Figure 7-4. Comparison of OFTF data with calculations by the codes RELAP5-3D and TRACE........... 51

Figure 7-5. Effect of the water temperature in the OFTF calculated mass flow rates............................ 51

Figure 7-6. TSTL calculated pressures by RELAP5-3D and TRACE with only steam.........................52

Figure 7-7. Vapor and liquid temperatures calculated by TRACE and RELAP5 ..................................5 53

Figure 7-8. Heater surface temperatures calculated by TRACE and RELAP5 . ..................................... 53

Figure 7-9. Radial temperatures calculated by TRACE inside a heater at full power (Test TS-

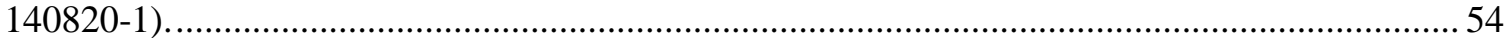

Figure 7-10. RELAP5-3D and TRACE calculated pressure for test TS-140820-1 ............................ 56

Figure 7-11. Pressure and power $(\mathrm{kW})$ for helium test TS-140820-1 ................................................ 57

Figure 7-12. TRACE calculated pressure for Test TS 140820-1 .................................................. 57

Figure 7-13. Measured data and TRACE-calculated condenser pressure ..............................................58

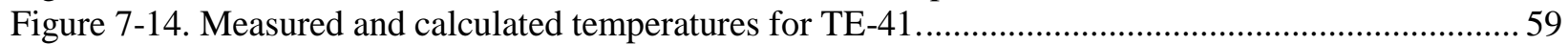

Figure 7-15. Measured and calculated temperatures for TE-42 ........................................................ 59

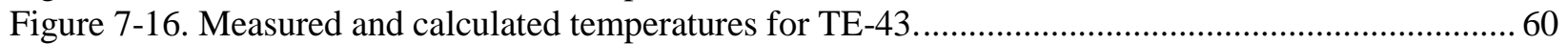

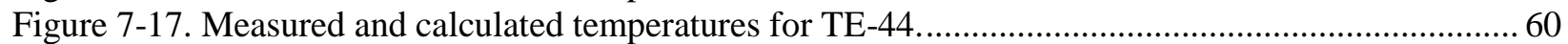

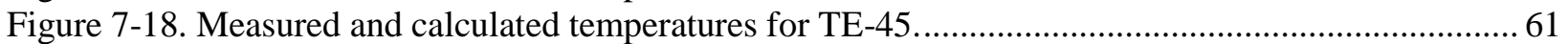

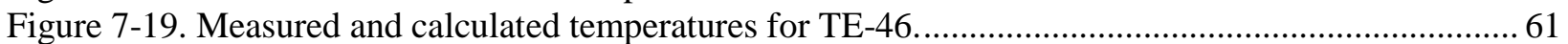

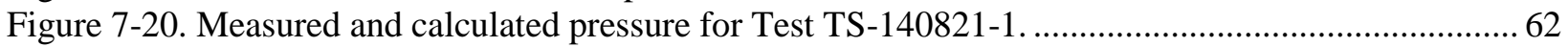

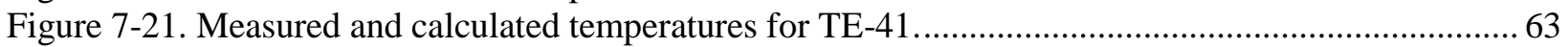

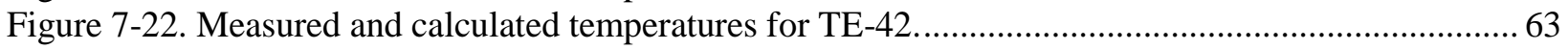

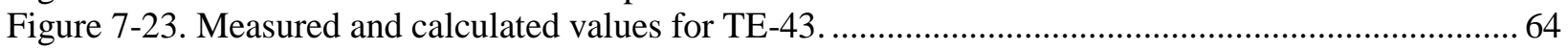

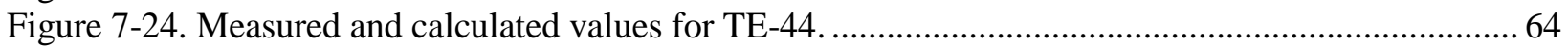

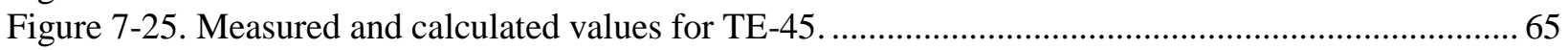

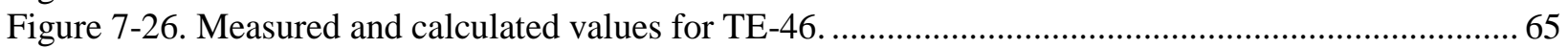

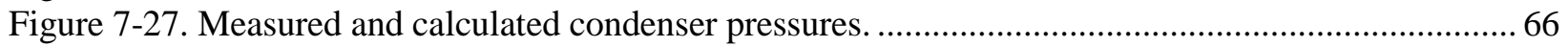

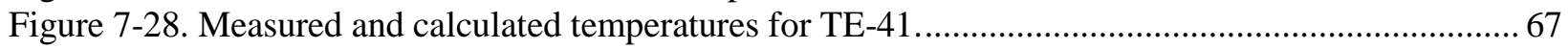

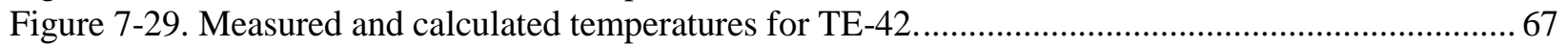

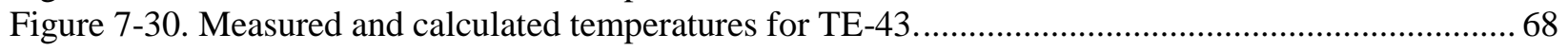

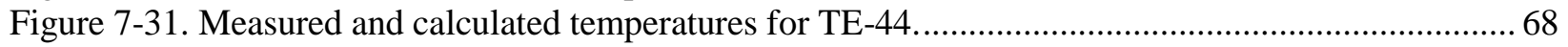

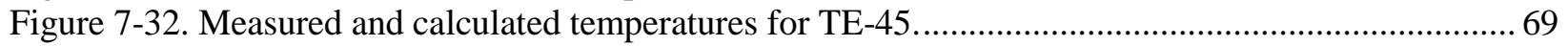

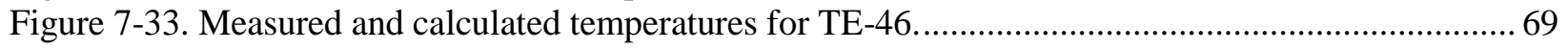

Figure 7-34. TRACE calculated pressures with increasing amounts of helium. ....................................... 70

Figure 7-35. Measured and calculated pressure for argon test TS-140910-1 ........................................ 71

Figure 7-36. Measured and calculated temperatures for TE-41 ......................................................... 71

Figure 7-37. Measured and calculated temperatures for TE-42 ......................................................... 72

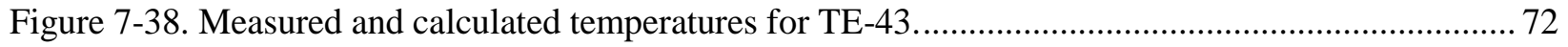

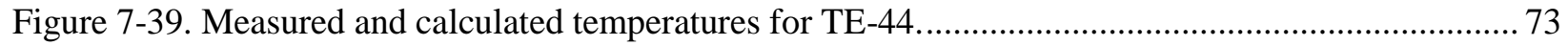

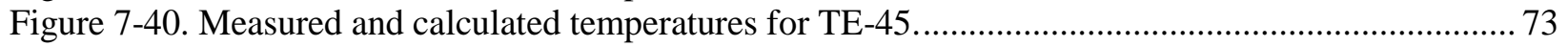

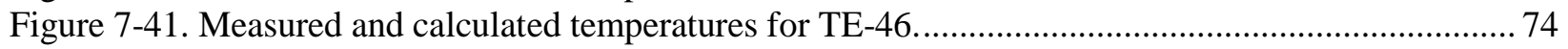

Figure 7-42. Measured and calculated pressures for test TS-140911-2 ............................................. 75

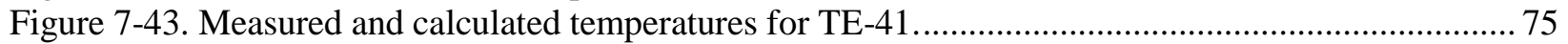

Figure 7-44. Measured and calculated temperatures for TE-42 ........................................................... 76

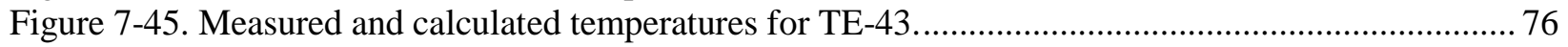

Figure 7-46. Measured and calculated temperatures for TE-44 ............................................................ 77 
Figure

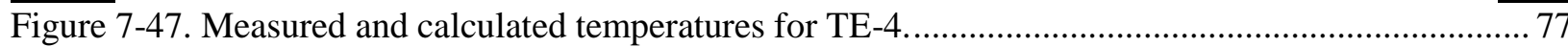

Figure 7-48. Measured and calculated temperatures for TE-4 ...................................................... 78

Figure 7-49. Calculated pressures for tests with different amounts of noncondensable gases. .................. 78

Figure 7-50. Power sequence for test TS-140925-1, HFIR startup sequence......................................... 80

Figure 7-51. Primary inlet and outlet temperatures measured for test TS-140925-1 ............................. 80

Figure 7-52. Comparison of experimental and TRACE input power to the heaters................................ 81

Figure 7-53. Experimental and TRACE-calculated primary outlet/inlet temperature difference.............. 81

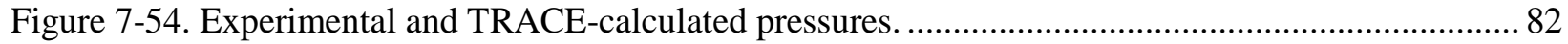

Figure 7-55. Experimental and calculated pressure differential across the entrance orifices................... 83

Figure 7-56. Experimental and calculated liquid and steam temperatures. ........................................... 83

Figure 7-57. Experimental and calculated temperatures inside the condenser at three elevations. ............ 84

Figure 7-58. TRACE-calculated helium masses in different condenser nodes....................................... 85

Figure 7-59. Steam and helium inside the condenser under no power and power conditions....................86

Figure 7-60. Experimental and TRACE-calculated temperatures for the three heaters............................ 87

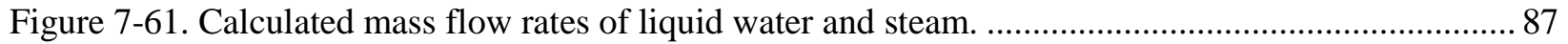

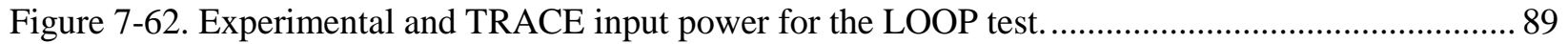

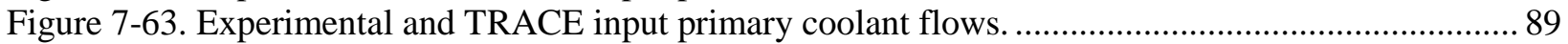

Figure 7-64. Experimental primary inlet and outlet temperatures (uncorrected test times)..................... 90

Figure 7-65. Measured and calculated pressures for the LOOP transient............................................... 90

Figure 7-66. Measured and calculated steam and water/liquid temperatures .......................................... 92

Figure 7-67. Measured and calculated pressure differential across the entrance orifice. ......................... 92

Figure 7-68. Calculated mass flow rates of water and steam in the boiler/evaporator - LOOP

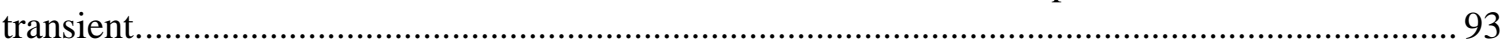

Figure 7-69. Power employed in the experiment and in the TRACE input..........................................94

Figure 7-70. Primary inlet and outlet temperatures - experiment and TRACE simulation...................... 95

Figure 7-71. Primary coolant temperature difference - experiment and TRACE simulation. .................. 95

Figure 7-72. Measured and TRACE-calculated pressures for Test TS-140930-2 .............................. 96

Figure 7-73. Measured and calculated liquid and vapor temperatures. ..............................................96

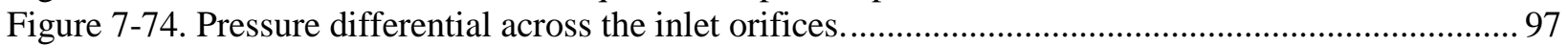

Figure 7-75. TRACE-calculated liquid ad vapor mass flow rates. ...................................................... 98

Figure 7-76. System power employed in maximum power calculations. ............................................. 99

Figure 7-77. Calculated pressures for the maximum power calculations. ......................................... 100

Figure 7-78. Calculated temperature for the surface of one heater (HS-1104) ................................... 100

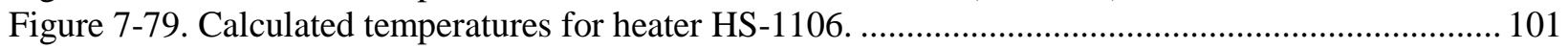

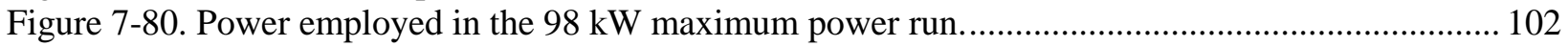

Figure 7-81. Pressure calculated for the $98 \mathrm{~kW}$ maximum power run. ............................................... 102

Figure 7-82. Heater surface temperatures calculated for the $98 \mathrm{~kW}$ maximum power run................... 103

Figure 7-83. Heat removed by the condenser and downcomer for a case with pure steam..................... 104

Figure 7-84. Heat removed by the condenser and downcomer with helium added. ..............................105

Figure 7-85. Heat removed by the condenser and downcomer for different cases analyzed................... 105

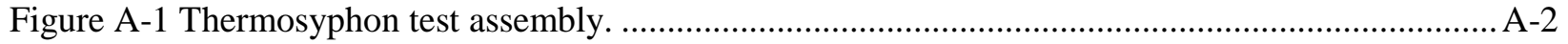

Figure A-2. Lower portion detail of the thermosyphon test assembly ....................................................3

Figure A-3. Middle portion detail of the thermosyphon test assembly ................................................. A-3

Figure A.4. Upper portion of the thermosyphon test assembly. ........................................................ A-3 


\section{LIST OF TABLES}

Table

Page

Table 4-1. General requirements for single-ended heater rods and thermocouple specifications ...............19

Table 4-2. Primary instrumentation list for the thermosyphon test loop ..............................................2 23

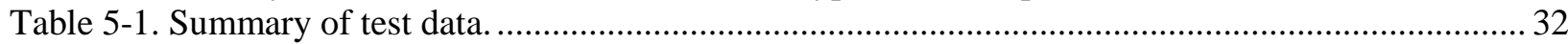

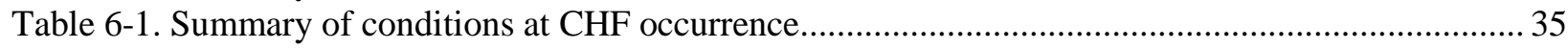

Table 7-1. Tests modeled with the TRACE Code ….............................................................................5

Table 7.2. RELAP5-3D and TRACE calculated results for only steam .............................................. 106 


\section{LIST OF ABBREVIATIONS AND ACRONYMS}

$\begin{array}{ll}\text { CAD } & \text { computer-aided design } \\ \text { CHF } & \text { critical heat flux } \\ \text { DAS } & \text { data acquisition system } \\ \text { DC } & \text { direct current } \\ \text { DPT } & \text { differential pressure transmitter } \\ \text { FRS } & \text { fuel rod simulator } \\ \text { FS } & \text { full scale } \\ \text { FT } & \text { flow transmitter } \\ \text { h } & \text { heat transfer coefficient } \\ \text { HB } & \text { high beam } \\ \text { HFIR } & \text { High Flux Isotope Reactor } \\ \text { HT } & \text { hydraulic tube } \\ \text { ID } & \text { inner diameter } \\ \text { IT } & \text { current transmitter } \\ \text { LANL } & \text { Los Alamos National Laboratory } \\ \text { LOOP } & \text { loss of offsite power } \\ \text { LT } & \text { level transmitter } \\ \text { NC } & \text { non-condensable (gas) } \\ \text { OD } & \text { outer diameter } \\ \text { OFTF } & \text { orifice flow test facility } \\ \text { ORNL } & \text { Oak Ridge National Laboratory } \\ \text { P } & \text { pressure } \\ \text { P\&ID } & \text { process and instrumentation drawing } \\ \text { PLC } & \text { programmable logic control } \\ \text { Pow } & \text { total power to the TSTL }(3 \text { heaters) }=3 \times \text { pow } \\ \text { pow } & \text { power to one heater }=\text { Pow/3 } \\ \text { PT } & \text { pressure transmitter } \\ \text { PTP } & \text { peripheral target position } \\ \text { RB* } & \text { removable Be } \\ \text { RTD } & \text { resistance temperature detectors } \\ \text { T } & \text { temperature } \\ \text { TC } & \text { thermocouple or } \\ \text { TE } & \text { thermocouple element } \\ \text { TFF } & \text { test flow facility } \\ \text { TS } & \text { test section } \\ \text { TSTL } & \text { thermosyphon test loop } \\ \text { TT } & \text { temperature transmitter } \\ \text { VDC } & \text { volts direct current } \\ \text { VFD } & \text { variable frequency drive } \\ \text { VXF } & \text { vertical experimental facility } \\ \text { VT } & \text { voltage transmitter } \\ & \end{array}$




\begin{abstract}
The High Flux Isotope Reactor (HFIR) at the Oak Ridge National Laboratory (ORNL) requires most materials and all fuel experiments to be placed in a pressure containment vessel to ensure that internal contaminants such as fission products cannot be released into the primary coolant. It also requires that all experiments be capable of withstanding various accident conditions (e.g., loss of coolant) without generating vapor bubbles on the surface of the experiment in the primary coolant. These requirements are intended to artificially increase experiment temperatures by introducing a barrier between the experimental materials and the HFIR coolant, and by reducing heat loads to the HFIR primary coolant, thus ensuring that no boiling can occur.
\end{abstract}

A proposed design for materials irradiation would remove these limitations by providing the required primary containment with an internal cooling flow. This would allow for experiments to be irradiated without concern for coolant contamination (e.g., from cladding failure of advanced fuel pins) or for specimen heat load.

This report describes a new materials irradiation experiment design that uses a thermosyphon cooling system to allow experimental materials direct access to a liquid coolant. The new design also increases the range of conditions that can be tested in HFIR. This design will provide a unique capability to validate the performance of current and advanced fuels and materials. Because of limited supporting data for this kind of irradiation vehicle, a test program was initiated to obtain operating data that can be used to (1) qualify the vehicle for operation in HFIR and (2) validate computer models used to perform design- and safety-basis calculations. This report also describes the test facility and experimental data, and it provides a comparison of the experimental data to computer simulations.

A total of 51 tests have been completed: four tests with pure steam, 12 tests with argon, and 35 tests with helium. A total of 10 tests were performed at subatmospheric pressure, and four of these were performed with pure steam. One test was conducted at a high power of $92.7 \mathrm{~kW}$, six tests were HFIR startups, and two tests were HFIR loss of offsite power (LOOP). Pressures up to $10 \mathrm{MPa}$, vapor temperatures up to 583 $\mathrm{K}\left(310^{\circ} \mathrm{C}\right)$, and heater temperatures above $600 \mathrm{~K}\left(327^{\circ} \mathrm{C}\right)$ have been reached in these tests. Two computer programs, RELAP5-3D and TRACE, have been used to simulate the tests. The TRACE code has shown good agreement with the test data and has been used to model a variety of tests. This experimental facility has been very useful in demonstrating the viability of this new type of irradiation facility. 


\section{INTRODUCTION}

HFIR is designed so that all components (flux trap, core, removable and permanent reflectors, and all irradiation facilities) are cooled by a single flow system that is distributed to many parallel channels. Because of this flow configuration, the thermal limit for all irradiation facilities is a flow excursion. A flow excursion can happen if boiling occurs in any single channel of a parallel flow system. Another consequence of the single flow system is that any accidental release of radioactive parts or byproducts from an experiment will be quickly distributed throughout the coolant.

As a result of these design elements, all fuel and materials irradiation experiments must show that (1) no external boiling will occur in the HFIR primary coolant, even under severe accident conditions, and (2) pressure-vessel standards are applied to the experiment's primary containment to avoid contamination of the primary coolant with any experimental materials. These restrictions are severely limiting for full-scale fuel/cladding experiments because the experimental claddings can rarely meet pressure-vessel standards. Therefore, the cladding must be placed inside primary containment of a more standard structural material such as stainless steel to artificially increase the internal temperatures of the experiment over the desired experimental range. For irradiation experiments with nonfuel materials, these requirements (1) limit specimen loadings to reduce the total heat load, (2) raise the minimum irradiation temperature for experiments, and (3) limit the kinds of specimens that can be irradiated while exposed to coolant. Some materials of experimental interest (e.g., copper) may be corrosive to other HFIR components and therefore are not allowed in contact with the primary coolant.

The goal of this project is to design and test a relatively simple, hydraulically isolated irradiation experiment platform that can be used for performing full-scale materials and fuel/cladding experiments. The new design will use a thermosyphon arrangement to transfer the experiment heat load to the primary coolant. A thermosyphon is similar to a heat pipe except that it uses gravity to return the condensate to the evaporator section instead of a wicking action and therefore requires a vertical orientation.

The great advantage of a thermosyphon is that it requires no pumps, valves, or other active equipment. Flow is established primarily by the boiling and condensation cycle and secondarily by natural circulation. A more typical external loop with pumps, valves, external heat exchanges, etc., would require a reactor design modification and probably would necessitate additional calculations such as a seismic analysis.

Other advantages of a thermosyphon-cooled experiment include the following.

- The entire assembly is in a sealed containment with no moving parts, so reliability is very high.

- The thermosyphon offers near isothermal operating conditions as long as the working temperature is in a region in which the saturation curve is sufficiently steep. The working temperature can be controlled by balancing the heat input to the system and the available surface area for condensation. There is no need to rely on very small gas gaps to control temperature, so machining tolerances and irradiation swelling are not as important to obtaining reliable results.

- Larger experiment heat loads are allowable because the heat is transferred to HFIR coolant through the much larger heat transfer area in the condenser.

Very few heat-pipe-cooled irradiation experiments have been conducted in the past. J. E. Deverall (Los Alamos National Laboratory [LANL]) and H. E. Watson (Naval Research Laboratory) performed some early design work in the 1970s using sodium as the working fluid [1] [2]. In 1982, Keddy and Martinez of LANL established the thermal limits associated with heat-pipe-cooled irradiation experiments [3]. The 
most recent example found in the literature was a 1986 experiment conducted in the KNK II reactor in Karlsruhe, Germany [4].

All of these historical experiments were similar in design, they all represent attempts to achieve very high working temperatures that are most typical of liquid metal fast reactors, and most of them used sodium as the working fluid. Also, these experiments were all designed with a self-contained thermosyphon that extended through the axial center of the experiment rather than being an integral part of the experiment itself.

In the proposed design, the thermosyphon would allow fuel/cladding experiments to be irradiated with a secondary coolant (not the HFIR primary coolant) flowing directly on the outside of the cladding, a feature not currently possible in HFIR for most experimental cladding materials. This design would also expand the range of temperatures that could be achieved by lowering the minimum irradiation temperature. Most importantly, it should allow for the removal of much greater experiment heat loads than currently possible. 


\section{EXPERIMENT REQUIREMENTS AND DESIGN GOALS}

\subsection{HFIR EXPERIMENT LOCATIONS}

HFIR is a beryllium-reflected, pressurized, light-water-cooled and moderated flux-trap-type reactor. The core consists of aluminum-clad involute-fuel plates, and the core currently uses highly enriched ${ }^{235} \mathrm{U}$ fuel at a power level of $85 \mathrm{MWt}$.

The reactor core, illustrated in Figure 2-1, consists of two concentric annular regions, each approximately $61 \mathrm{~cm}$ in height. The flux trap is $\sim 12.7 \mathrm{~cm}$ in diameter, and the outer fueled region is $\sim 43.5 \mathrm{~cm}$ in diameter. The fuel region is surrounded by a beryllium annular reflector approximately $30.5 \mathrm{~cm}$ thick. The beryllium reflector is in turn backed up by a water reflector of effectively infinite thickness. In the axial direction, the reactor is reflected by water. The reactor core assembly is contained in a $2.44 \mathrm{~m}$ diameter pressure vessel which is located in a $5.5 \mathrm{~m}$ diameter cylindrical pool of water. As shown in Figure 2-2, material and fuel irradiation experiments are typically performed in one of five facility types: flux trap, removable Be $\left(\mathrm{RB}^{*}\right)$, inner small vertical experimental facility (VXF), outer small VXF, and large VXF.

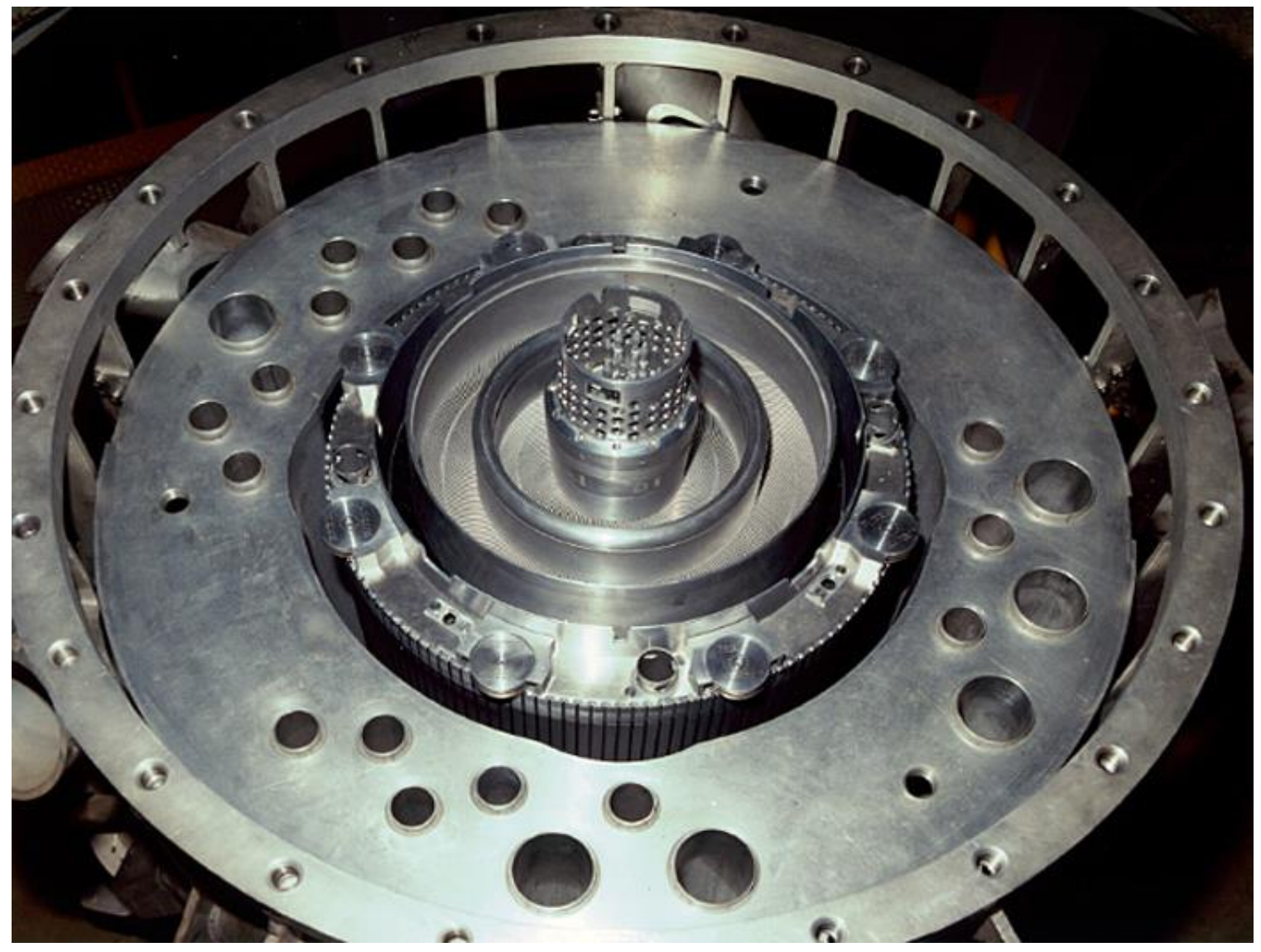

Figure 2-1. Reactor core fuel plates and primary irradiation facilities. 


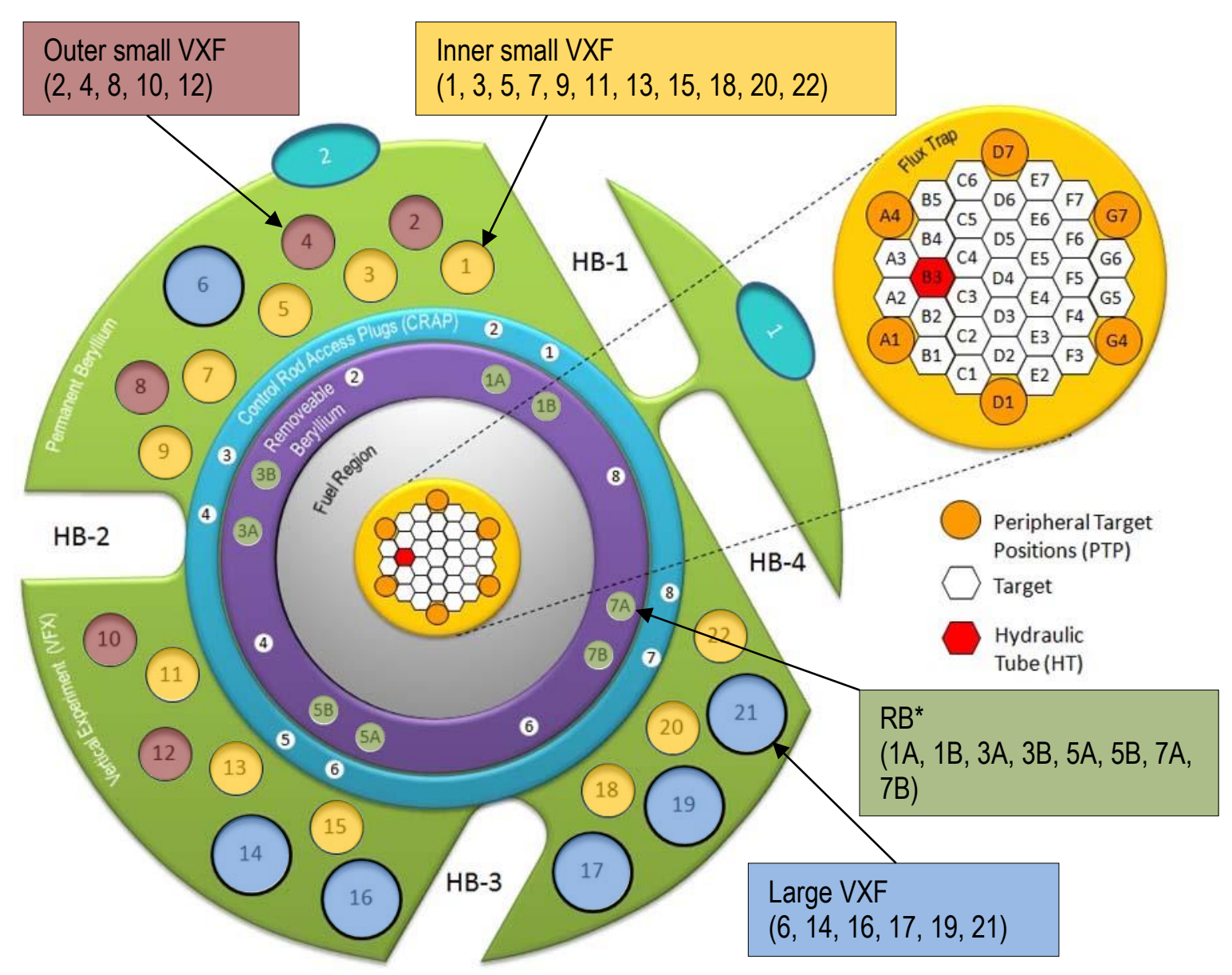

Figure 2-2. HFIR's primary experimental sites.

There are 37 flux trap positions located in the center of the reactor. These are the highest flux positions in the reactor $\left(1.2 \cdot 10^{15} \mathrm{n} / \mathrm{cm}^{2} \cdot \mathrm{s}, \mathrm{E}>0.1 \mathrm{MeV}\right.$ and $2.5 \cdot 10^{15} \mathrm{n} / \mathrm{cm}^{2} \cdot \mathrm{s}$ thermal flux $)$, but they are limited in size to approximately $12.7 \mathrm{~mm}$ in diameter. The eight RB* positions located in the reactor's RB*region are 46 $\mathrm{mm}$ in diameter and have the advantage of being easily instrumented. The fast flux in these positions is about $5.3 \cdot 10^{14} \mathrm{n} / \mathrm{cm}^{2} \cdot \mathrm{s}(\mathrm{E}>0.1 \mathrm{MeV})$. Because of the high fast neutron flux, the flux trap and $\mathrm{RB}^{*}$ positions are best suited for material irradiation experiments in which radiation damage is key.

Moving out from the core, the permanent reflector region contains the inner small VXF, the outer small VXF, and the large VXF facilities. The fast flux is significantly reduced in this region, so these facilities are best suited for fuel experiments in which fuel burnup is the driving force. The inner and outer small VXF positions are all $40.2 \mathrm{~mm}$ in diameter, while the large VXF has a working diameter of $72 \mathrm{~mm}$. The thermal flux ranges from $4 \cdot 10^{14} \mathrm{n} / \mathrm{cm}^{2} \cdot \mathrm{s}$ to $8 \cdot 10^{14} \mathrm{n} / \mathrm{cm}^{2} \cdot \mathrm{s}$ in this region.

The physics of the thermosyphon cycle are not affected by the size of the facility, but some evidence suggests that the critical heat flux limit may be affected by the phenomena of flooding. This occurs when the vertically upward flowing vapor bubbles prevent the downflow of liquid to the heated region.

Therefore, there is some advantage for providing sufficient space around the heated section to allow liquid to flow back down to the bottom of the experiment. Also, as discussed in the introduction above, a 
thermosyphon irradiation facility provides for containment of fission products for fuel experiments, which are best located in the permanent reflector region.

The two considerations detailed above indicate that using the large VXF as the initial target irradiation facility will maximize the possibility of a successful experiment by providing the largest possible experiment space while also being very applicable to one of the primary uses for such a facility.

\subsection{HFIR THERMAL-HYDRAULIC REQUIREMENTS}

Under normal operating conditions, the upper plenum operates at $2.9 \mathrm{MPa}(420 \mathrm{psig})$ at $49^{\circ} \mathrm{C}\left(120^{\circ} \mathrm{F}\right)$, and the lower plenum operates at $2.2 \mathrm{MPa}(320 \mathrm{psig})$. Typically, the total flow rate through an experiment is controlled by an orifice at the bottom of the assembly. Flow rates are not limited physically or administratively, but it is best practice to limit flow velocities to less than $\sim 10 \mathrm{~m} / \mathrm{sec}$ to avoid problems with vibrations.

\subsection{SPATIAL REQUIREMENTS}

An aluminum liner fits into the large VXF with an inner diameter (ID) of $71.98 \mathrm{~mm}$ (2.834 in). However, the liner is dimpled in three axial locations so that the maximum experiment size which can fit into the liner is $69.57 \mathrm{~mm}$ (2.739 in). This leaves a nominal primary coolant gap of about $1.19 \mathrm{~mm}$ between the experiment and the liner.

Both the reflector and core regions are $610 \mathrm{~mm}$ (24 in) in height, while the fueled portion is only $508 \mathrm{~mm}$ (20 in). The bottom of the liner lines up with the bottom of the reflector, with a $12.7 \mathrm{~mm}$ high shoulder resting on top of the reflector.

A cross bar running underneath the large VXF position is $95.3 \mathrm{~mm}$ (3.75 in) below the bottom of the reflector. The space above the reflector is relatively empty up to the bottom of the HFIR top cover. For practical purposes, the top of any experiment should not reach higher than the shroud flange to avoid the strong cross flow that exists between the shroud flange and the top cover. The shroud flange is located about 1,100 $\mathrm{mm}$ (42 in) above the top of the reflector. Therefore, the spatial limits above and below the reflector are $1,100 \mathrm{~mm}$ (42 in) and $95.3 \mathrm{~mm}$ (3.75 in), respectively.

All of the large VXF positions are located on a diameter of $925.5 \mathrm{~mm}$ (36.438 in) from the core axis. The nearest objects to the large VXF sites are the inner small VXF sites, which are located on a diameter of $784.2 \mathrm{~mm}$ (30.875 in). There is a $9^{\circ}$ angle between the centerlines of the large and neighboring small VXF. Converting to Cartesian coordinates, the centerline of the large VXF site is at ( $462.8 \mathrm{~mm}, 0 \mathrm{~mm})$, and the centerline of the inner small VXF is at $(387.3 \mathrm{~mm}, 61.3 \mathrm{~mm})$. The resulting distance between the two centerlines is $97.3 \mathrm{~mm}$. Assuming an effective diameter of a small VXF experiment or plug to be $63.5 \mathrm{~mm}(2.5 \mathrm{in})$, the largest possible diameter of a large VXF assembly in the above-core region is 131 $\mathrm{mm}(5.2 \mathrm{in})$. 


\section{THERMOSYPHON BASELINE DESIGN}

An overall schematic (not to scale) and a CAD representation of a thermosyphon assembly are shown in Figure 3-1, and cross sections at the top and bottom of the facility are shown in Figure 3-2 and Figure 3-3. Light water coolant is used inside the thermosyphon and in the outer primary region.

The heat source will be fuel rods in the actual irradiation experiment, or in the case of the test loop, the heat source will be electric heater rods. Either way, the rods are designed to be a standard size with an OD of $9.53 \mathrm{~mm}(0.375 \mathrm{in})$. The active rod length is the same as the active fueled region of HFIR-508 $\mathrm{mm}$. The evaporator is designed to have a small unheated section above the rods to ensure coolant coverage. The depth of this unheated section can be varied to tune the performance of the thermosyphon.

The primary performance variable is the surface area of the condenser. The condenser's diameter range is somewhat limited due to the presence of neighboring experimental sites. In practice, the diameter is set to about $101.6 \mathrm{~mm}$ as a compromise between the desirability for more condensation surface area and the available space. Therefore, the condenser length is the primary variable of interest.
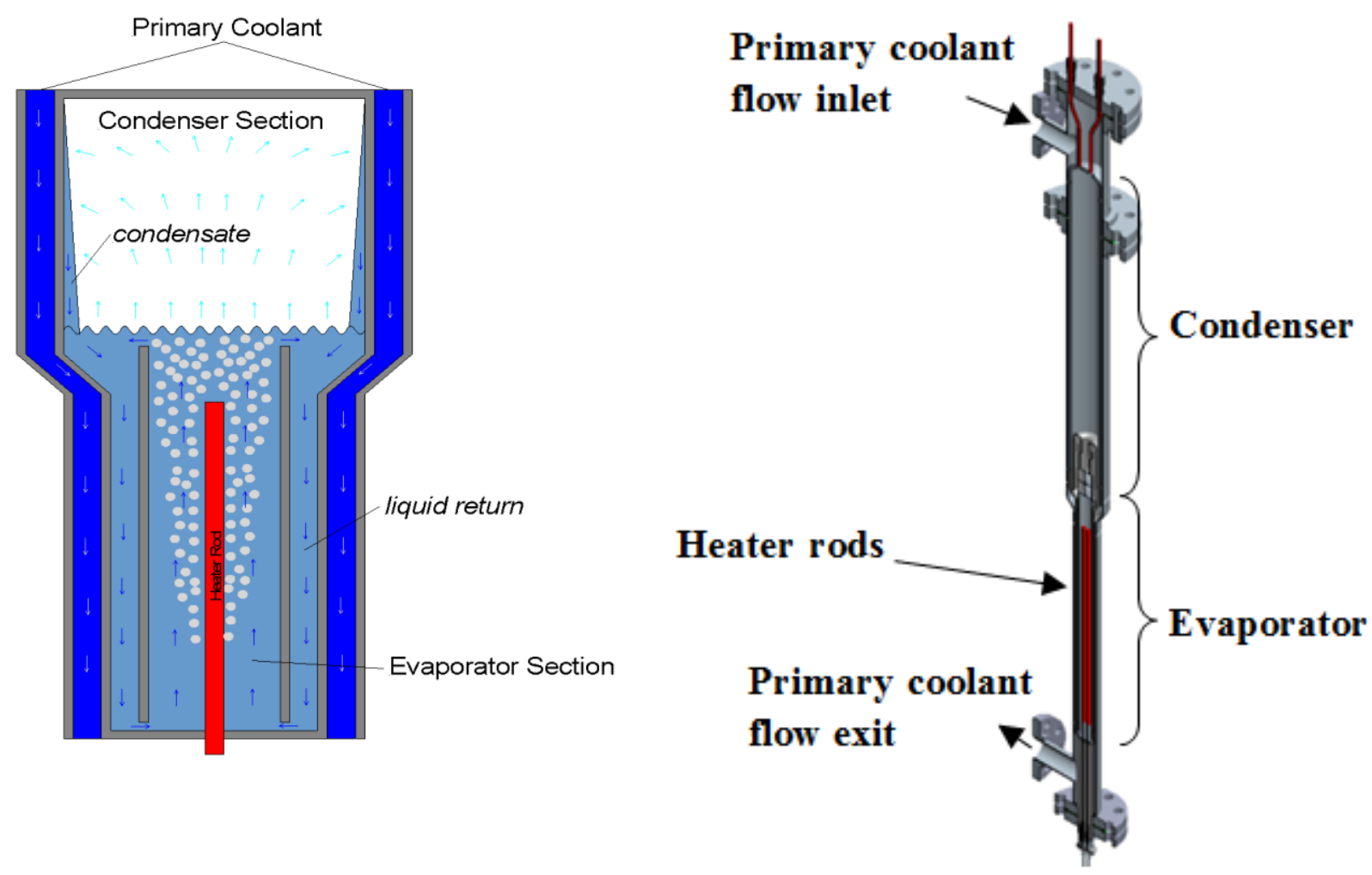

Figure 3-1. Schematic of the Thermosyphon Irradiation Facility (left, not to scale) and a CAD representation of an out-of-reactor experimental assembly (right). 


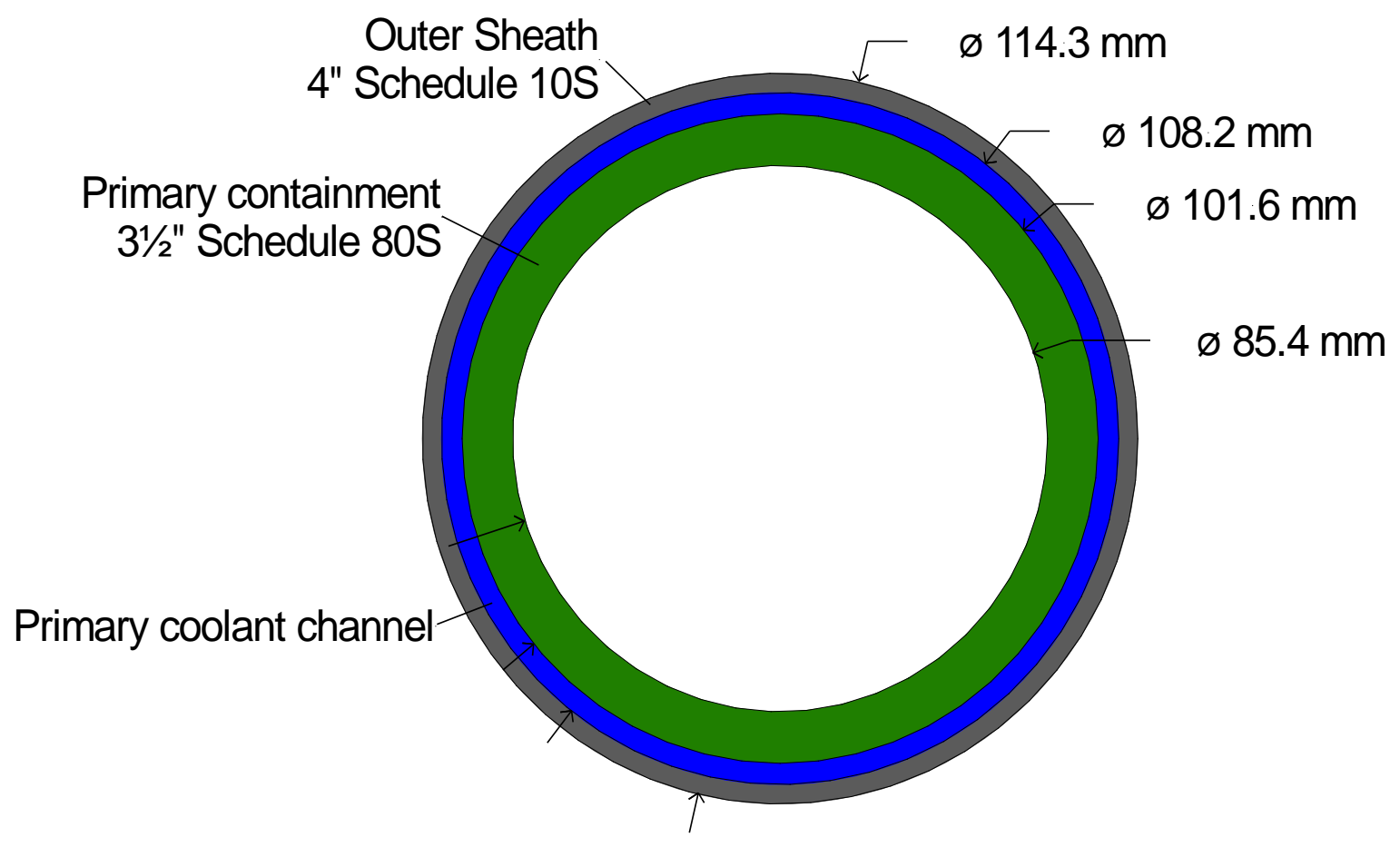

Figure 3-2. Cross section detail of the condenser section.

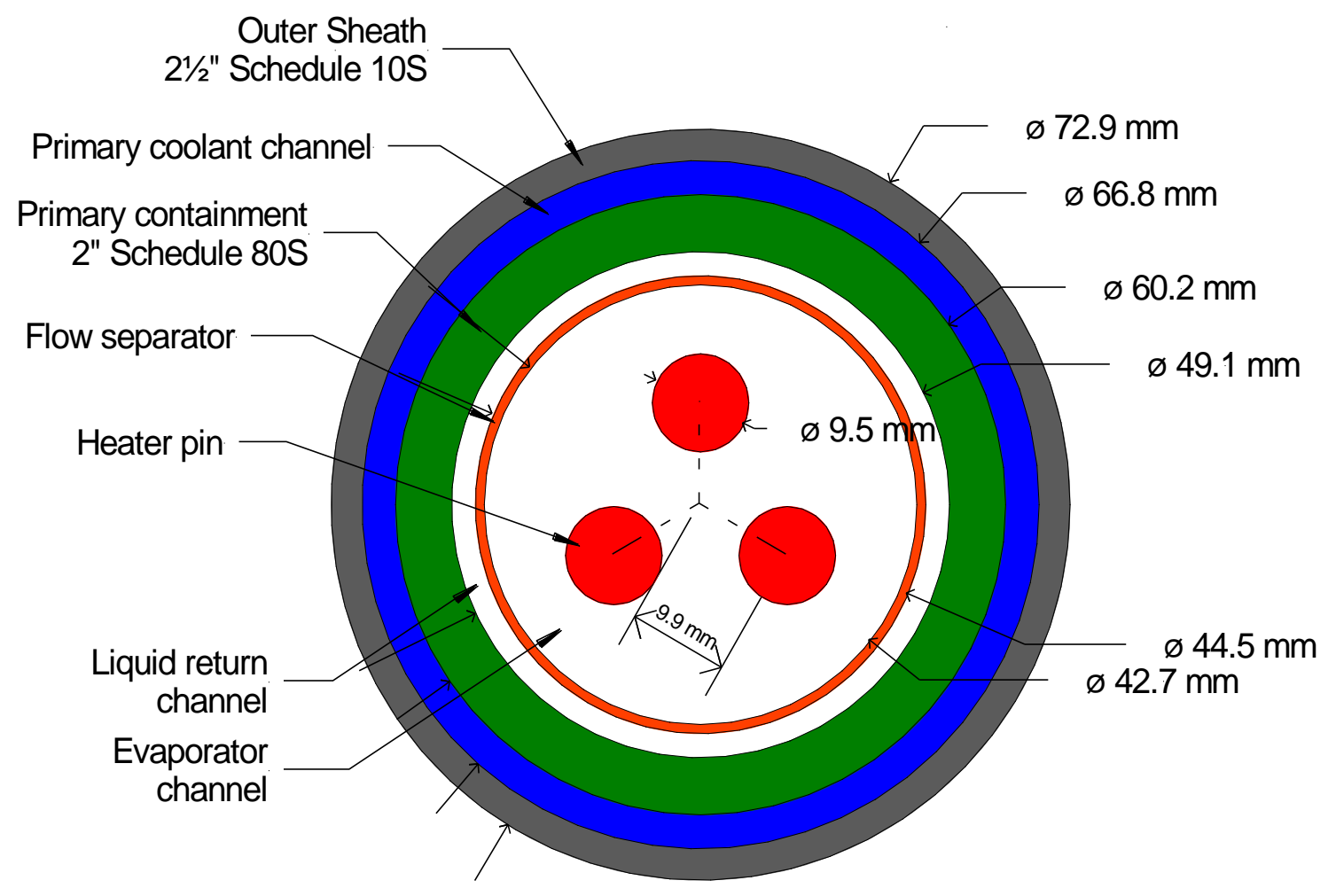

Figure 3-3. Cross section detail of the evaporator and liquid return sections. 
During construction, the thermosyphon will be evacuated, and then a metered volume of water will be introduced. Once the liquid volume is established, a prescribed gas pressure will be inserted into the condenser, and then the system will be seal-welded closed.

HFIR primary coolant serves as the heat sink for the system, flowing in the outermost annulus between the outside of the evaporator section and the inside of the VXF position.

Specimens such as fuel rods are located in the evaporator in the bottom central region. When heat is applied (by gamma or fission heating in the reactor or simulated by electrical heater rods in the laboratory), the vapor generated by the experiment rises into the condenser. Initially there is no temperature difference between the steam and the outer heat sink, so no condensation can occur. Without condensation, the vapor mass in the condenser will increase, causing the pressure to rise. As pressure rises, so does the saturation temperature, which creates a driving temperature difference for condensation. Eventually the pressure and saturation temperature will increase to the point at which the condensation is equal to the vapor production in the evaporator.

Once condensed, the condensate drains down the side walls and is circulated via a downcomer back into the bottom of the evaporator. 


\section{THERMOSYPHON TEST LOOP DESIGN}

\subsection{DESCRIPTION AND OPERATION}

The thermosyphon is made up of a pressure vessel containing three electrically heated fuel rod simulators (FRSs) in the lower section and a condensing region in the upper section. This pressure vessel will generally be operated at pressures of 7.5-8.5 MPa at full operating power, although it is designed for operation up to 16.6 MPa. A lower pressure secondary vessel (piping and flange assembly) surrounds the thermosyphon pressure vessel, and cooling water flowing in the annulus between the two vessel walls provides the heat sink for the thermosyphon. A drawing of this assembly is shown in Figure 4-1, with the loop cooling water flow inlet and outlet flange interfaces indicated. A photo of the installed thermosyphon assembly is shown in Figure 4-2.

The loop components are designed to provide cooling water to the inlet at HFIR pressure and flow conditions. An isometric diagram of the test loop is shown in Figure 4-3, and photos are provided in Figure 4-4 and Figure 4-5. The loop is designed to operate at a nominal pressure of $2.9 \mathrm{MPa}$ at the inlet to the thermosyphon assembly and at a flow rate of $1.2 \mathrm{l} / \mathrm{s}$. Cooling water is provided by a centrifugal pump with variable frequency drive (VFD). A heat exchanger with building-chilled water on the secondary side is used to remove heat from the system. A water supply tank with an argon cover gas is used to control the secondary loop operating pressure. The following sections will provide a more detailed description of the thermosyphon vessel and its major functional regions, as well as the loop components and instrumentation.

Fuel Rod Simulators $508 \mathrm{~mm}$ Heated Length

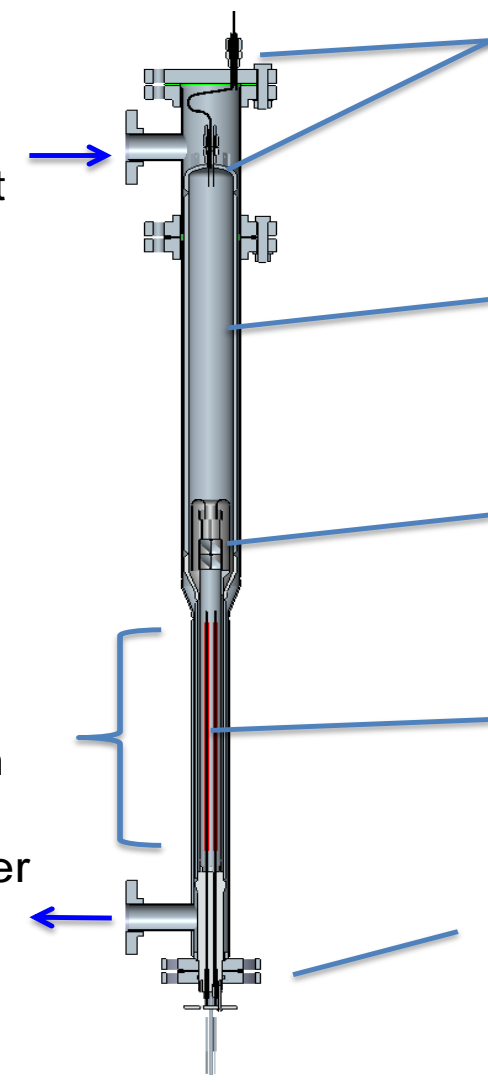

Gas injection line/ thermocouple feedthroughs

Condenser Section

Liquid/Vapor Separator Section

Evaporator Section

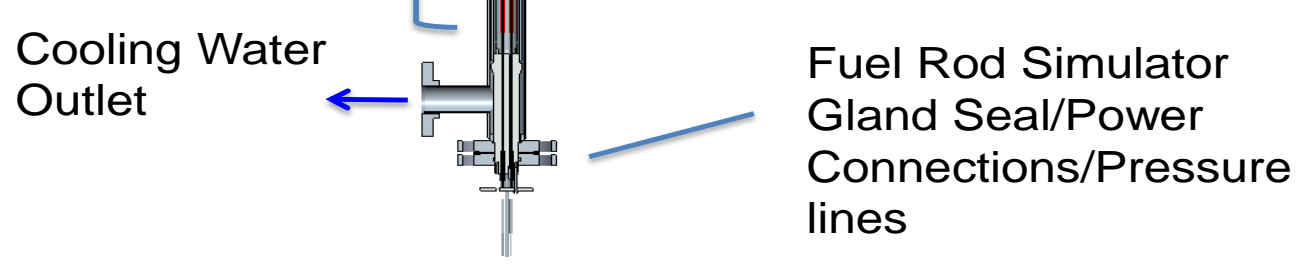

Figure 4-1. Thermosyphon vessel assembly. 


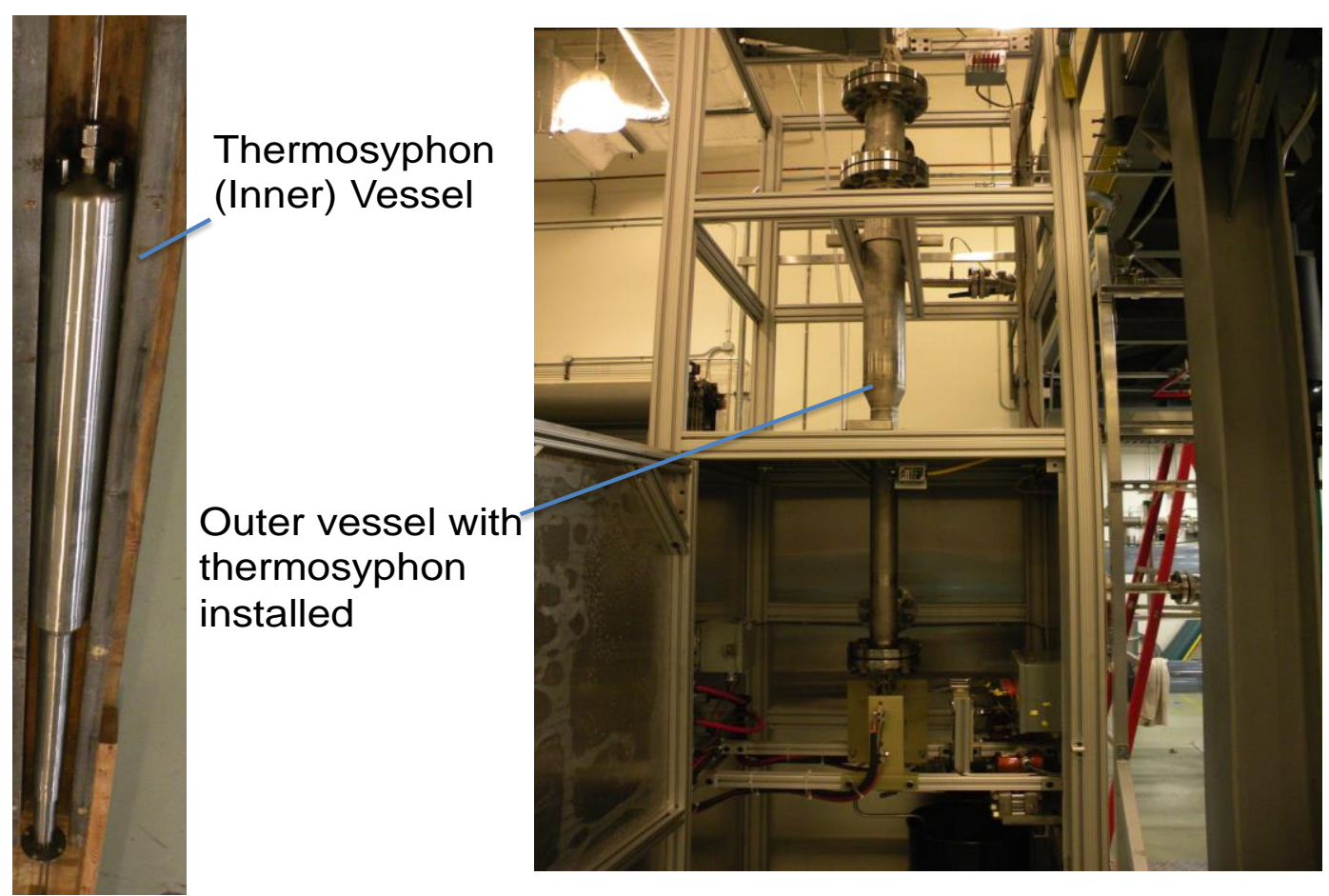

Figure 4-2. Inner and outer vessels.

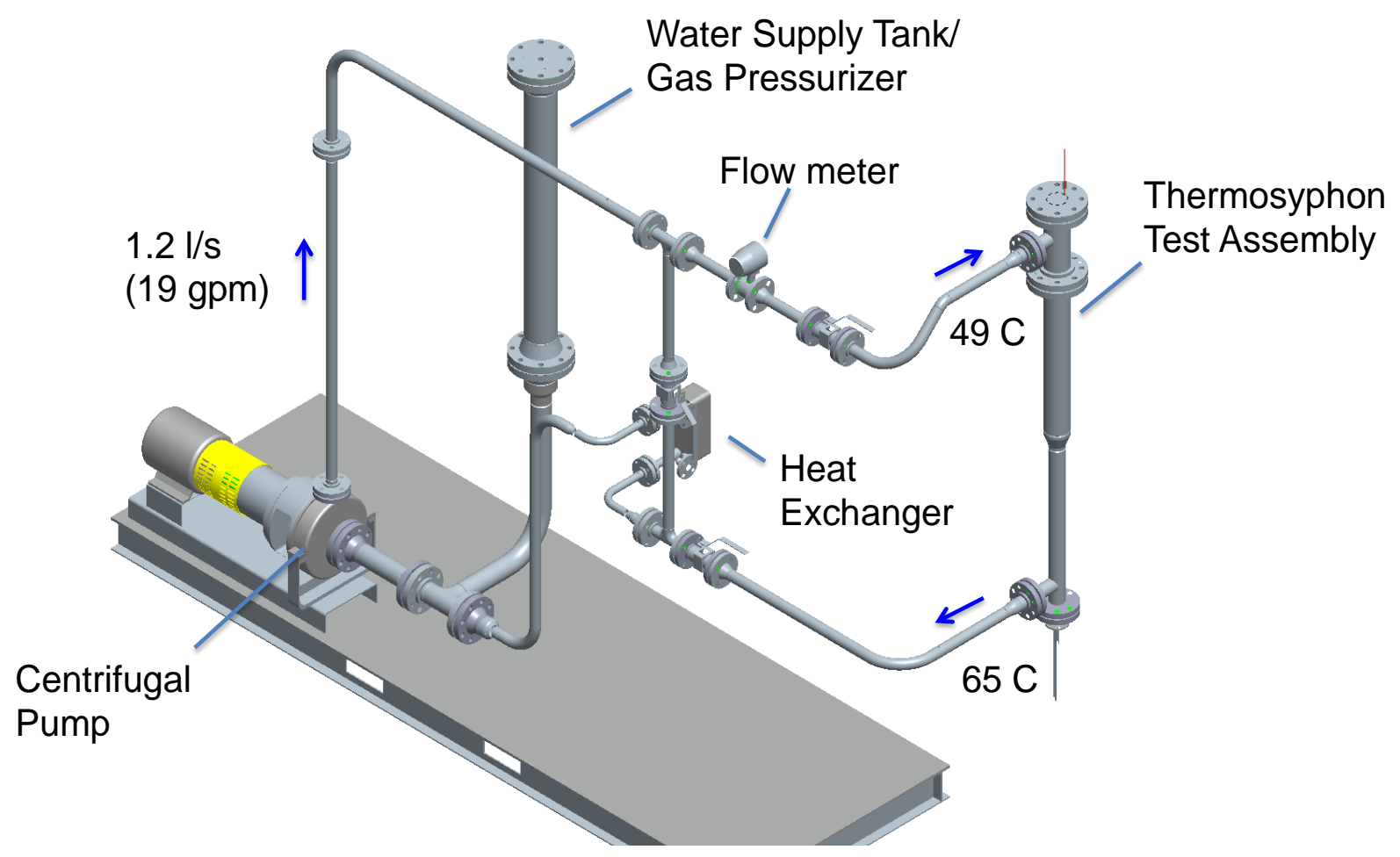

Figure 4-3. Thermosyphon test loop. 


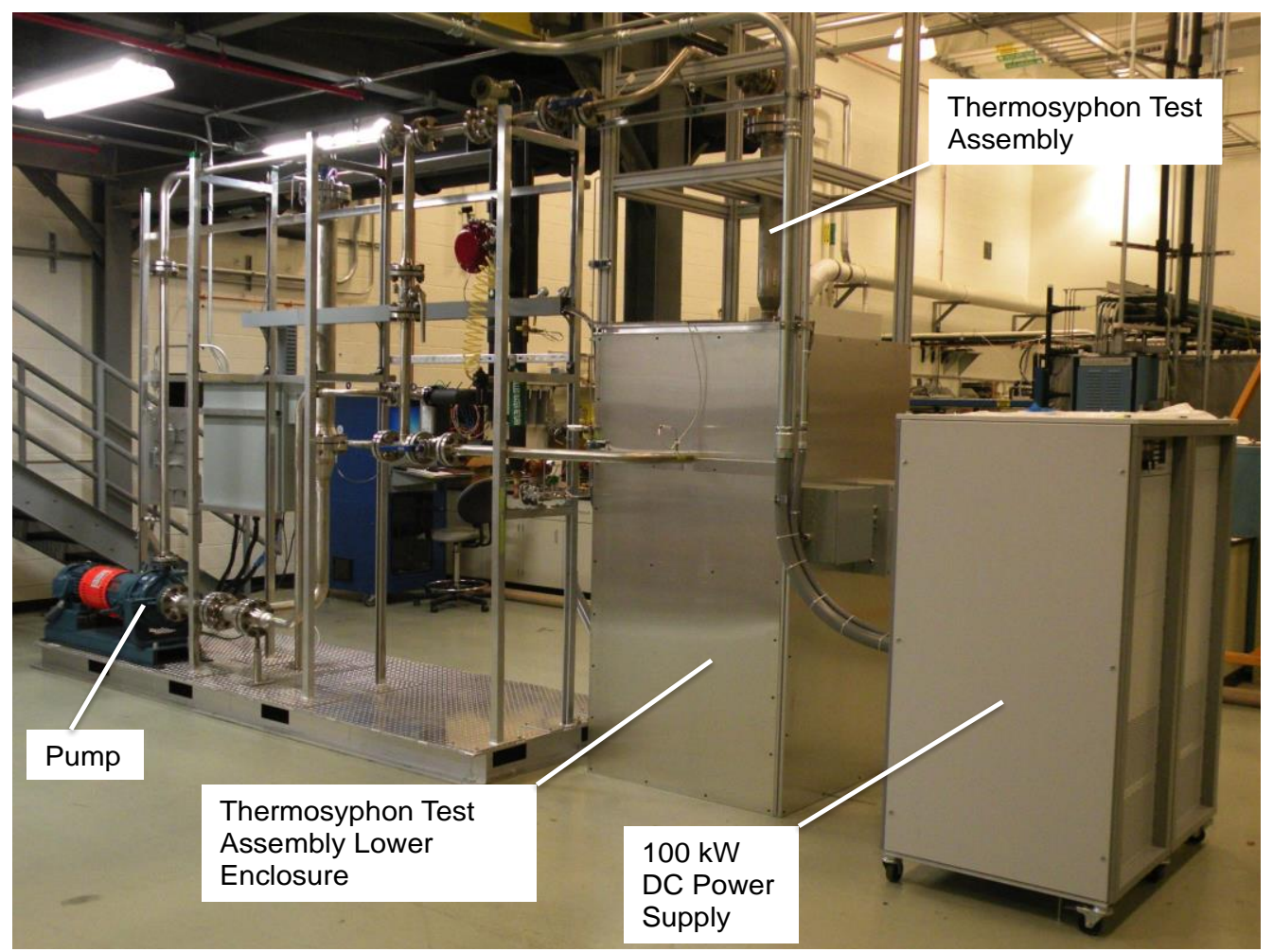

Figure 4-4. Thermosyphon test loop installed in ORNL Thermal Hydraulics Laboratory.

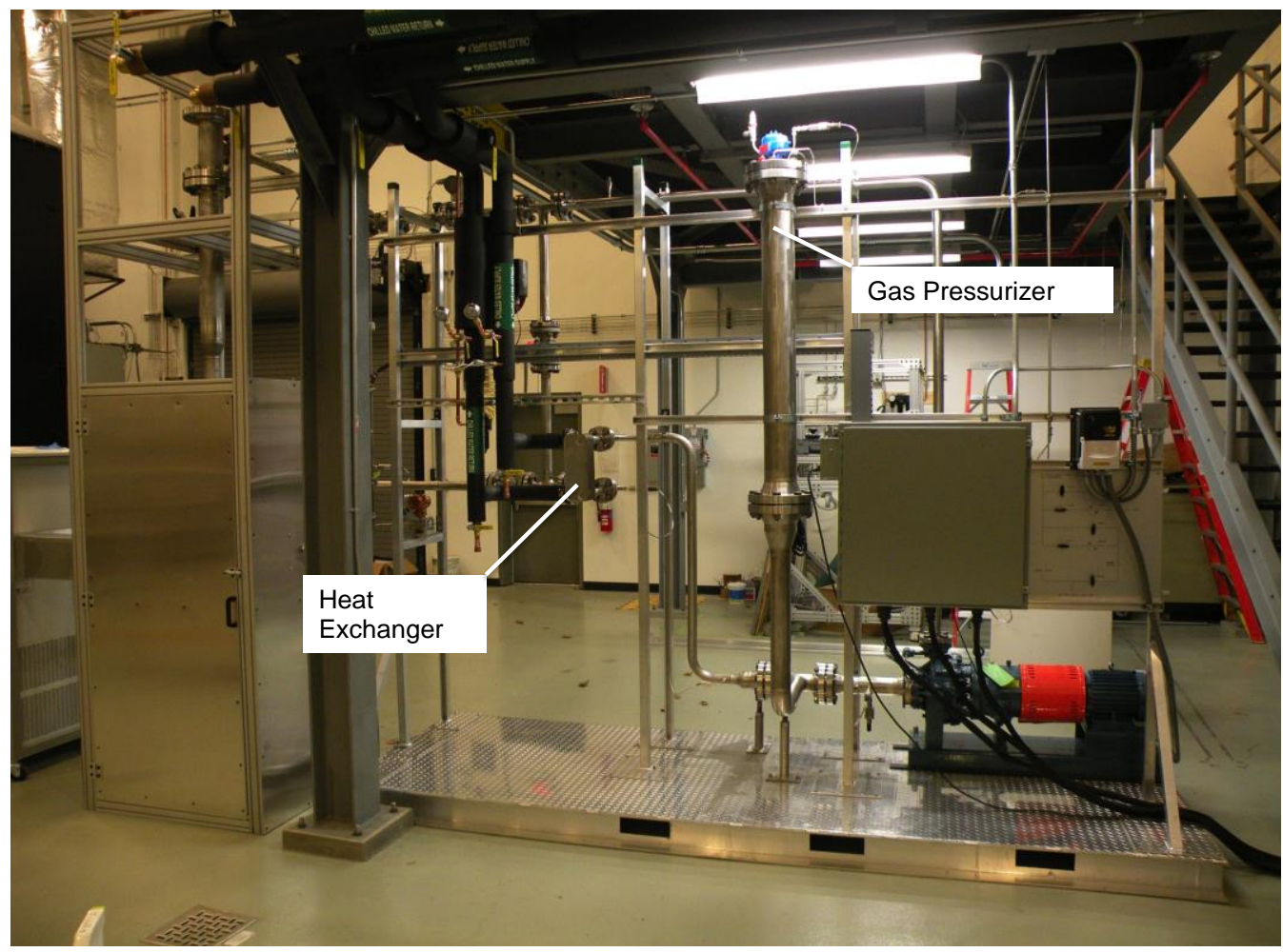

Figure 4-5. Thermosyphon Test Loop: alternate view. 


\subsection{THE THERMOSYPHON VESSEL}

The thermosyphon vessel was designed using ProE CAD software. The descriptive figures that follow are views created from these CAD models. Additional drawings with dimensions are provided in Appendix A. The system is fabricated per the American Society of Mechanical Engineers (ASME) Boiler and Pressure Vessel Code, Section VIII, Div. 1, and where possible, standard 316L stainless steel pipe and butt-weld fittings are used. The loop piping connecting to the outer vessel was built per the ASME B31.3 process piping code.

The evaporator section shown in Figure 4-1 contains the $508 \mathrm{~mm}$ heated length of the FRSs and provides the driving force for the thermosyphon mechanism. A cross section of the vessel(s) in this evaporator region is shown in Figure 4-6. Cooling water from the loop flows between the inner and outer vessel walls. An inner flow separator divides the region around the fuel rod simulators where steam is created and the condensate flowing back along the inside of the inner vessel wall.

The inner flow separator is part of an inner baffle assembly that defines much of the internal flow geometry. This assembly is shown in Figure 4-7 and includes a liquid/vapor separator region at the top and a flow orifice section at the bottom. A more detailed view of the bottom section is shown in Figure 4-8. There are 8 orifices of $4.6 \mathrm{~mm}$ diameter in the inner flow separator, 4 each spaced around the circumference at two axial levels. The orifices allow condensate flow to enter the lower evaporator section. The heated length of the FRSs begins above these holes as indicated by the red region in Figure 4-8. The bottom of the evaporator section is just below these holes.

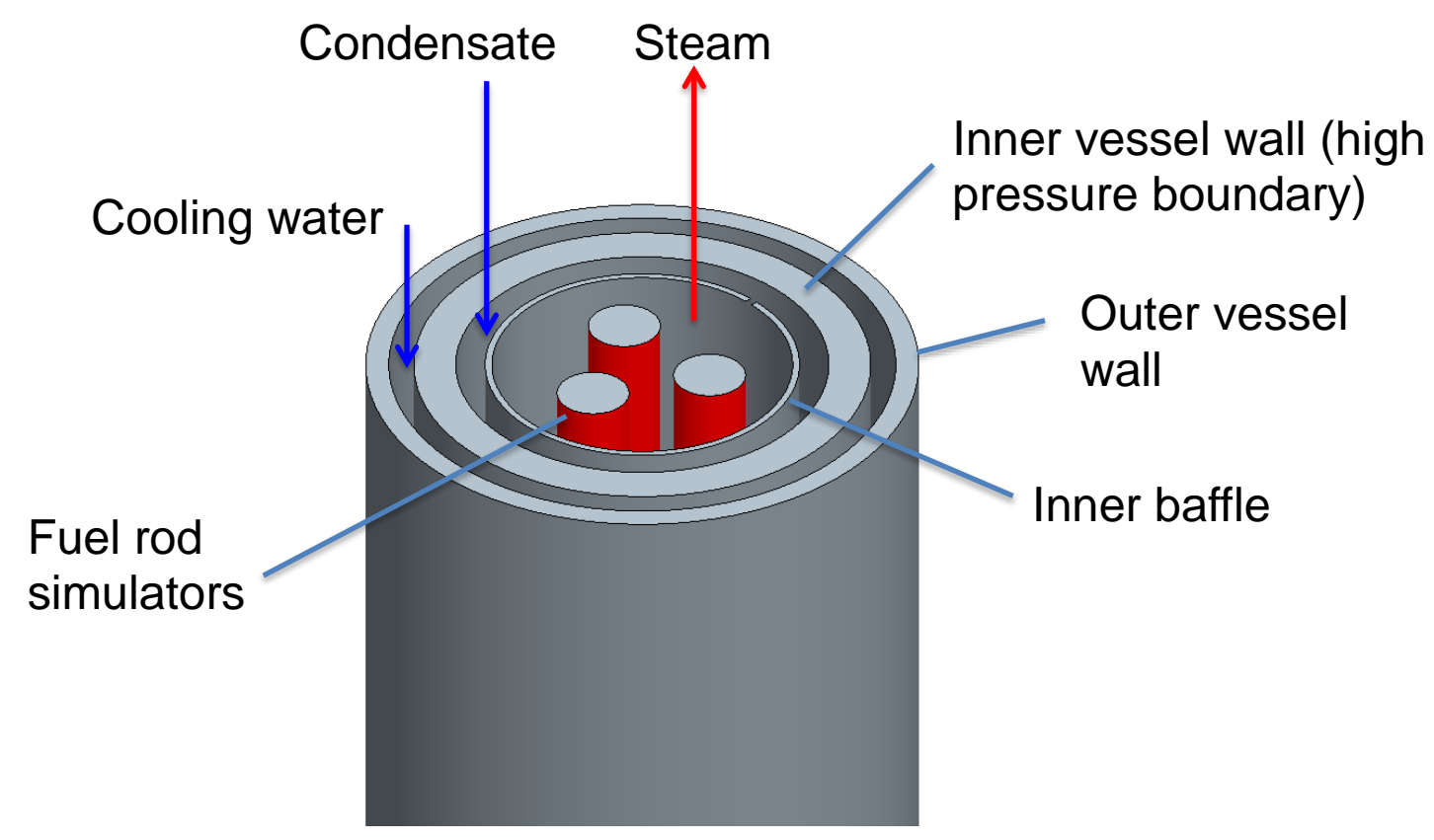

Figure 4-6. Cross section of evaporator region. 


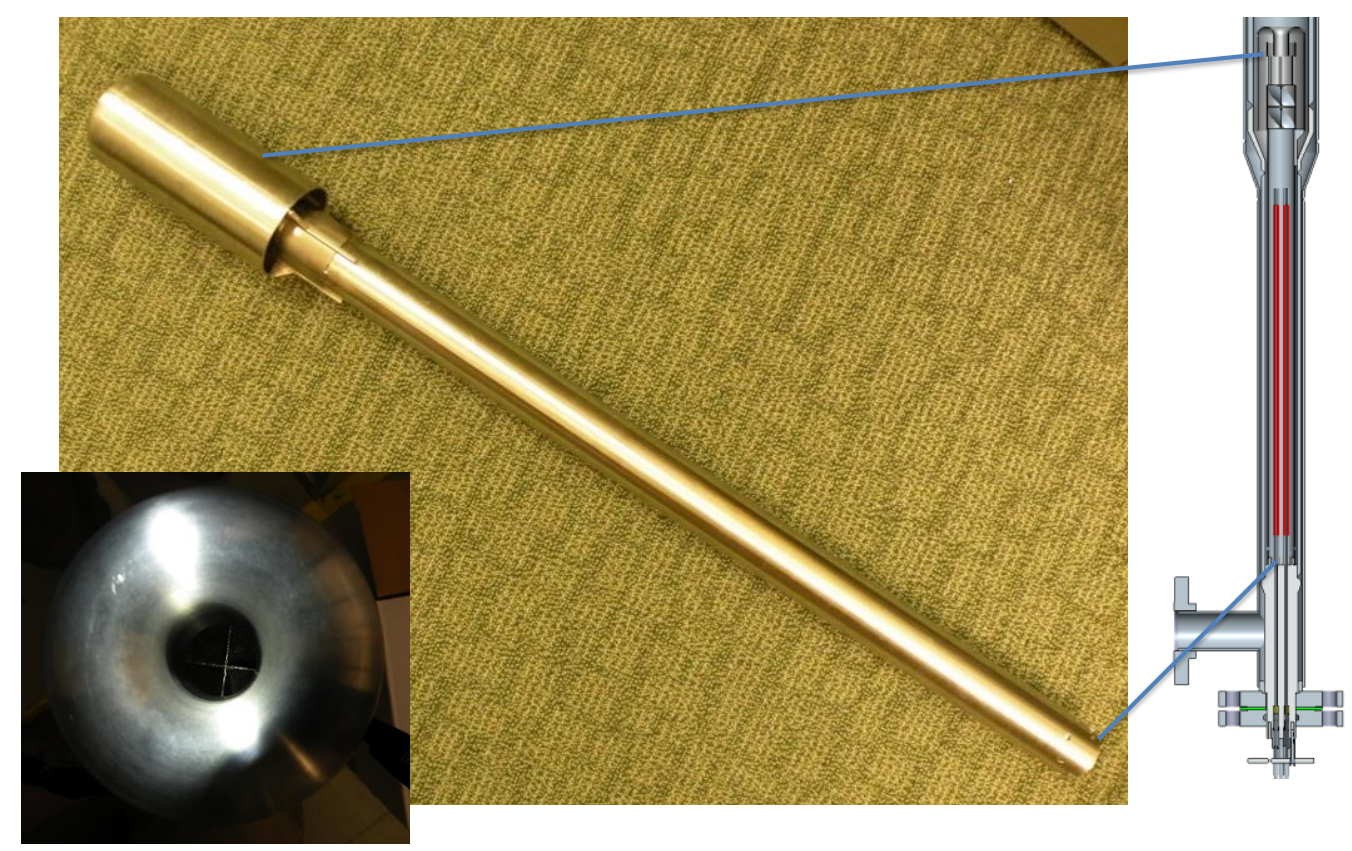

Figure 4-7. Internal baffle assembly defining the internal flow geometry.

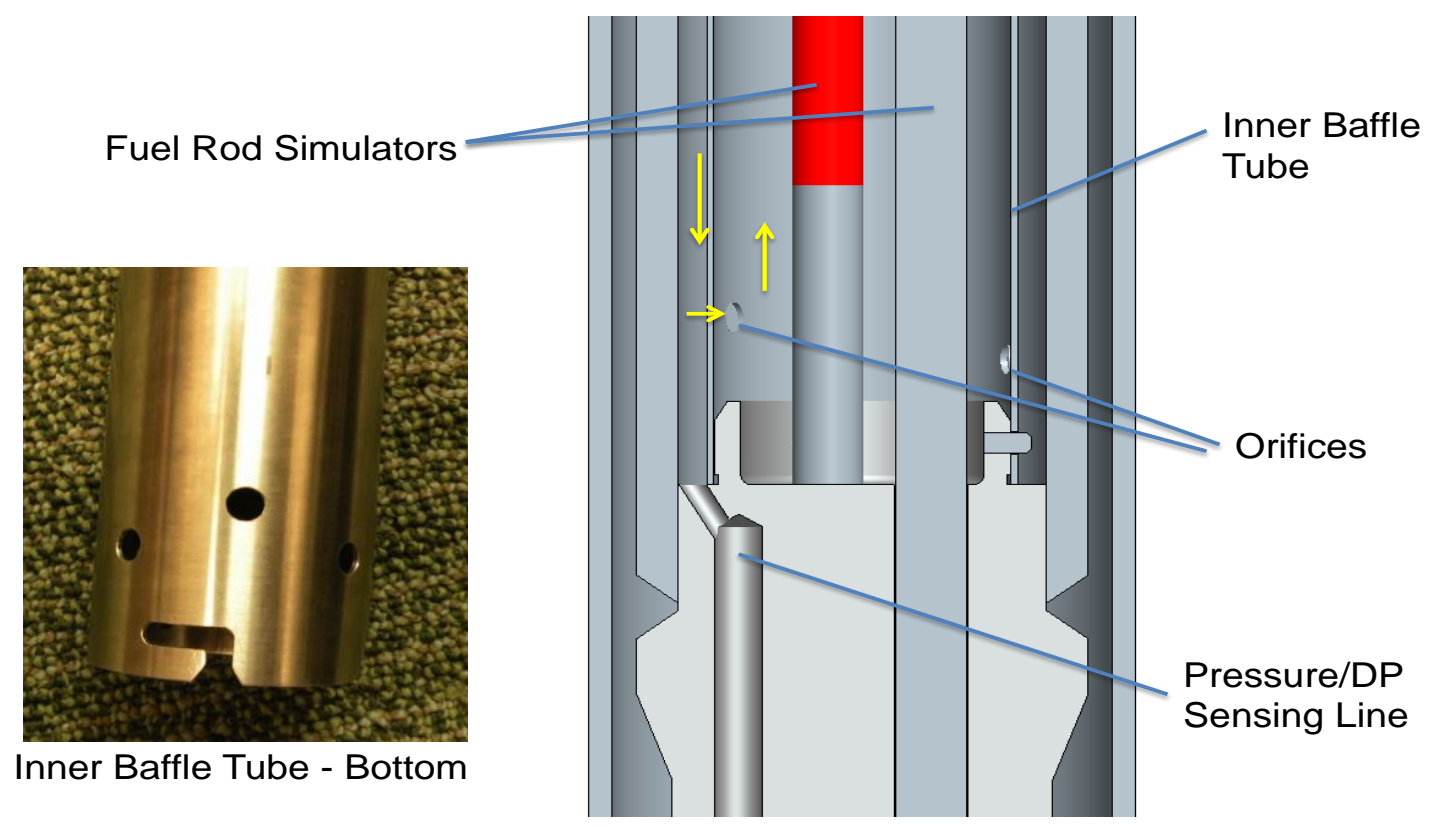

Figure 4-8. Eight flow orifices in lower flow separator providing flow stability (4 each at two axial levels: 19.1 and $25.4 \mathrm{~mm}$ above bottom of separator).

An extended solid section provides for feed-through of the unheated length of the three FRS's and pressure sensing lines to the outside of the vessel(s). This solid section extends through the outer vessel via a gland seal and allows feed-through of the FRS's to the outside. The seal arrangement is shown in Figure 4-9. The three instrumented fuel rod simulators are sealed via a graphite packing gland in the bottom of the high pressure assembly. A photo of this region of the thermosyphon vessel is shown in Figure 4-10. Dummy FRS's that were used for an initial hydrotest and $6.35 \mathrm{~mm}$ outer diameter (OD) pressure sensing lines are shown extending from the bottom of the assembly. 


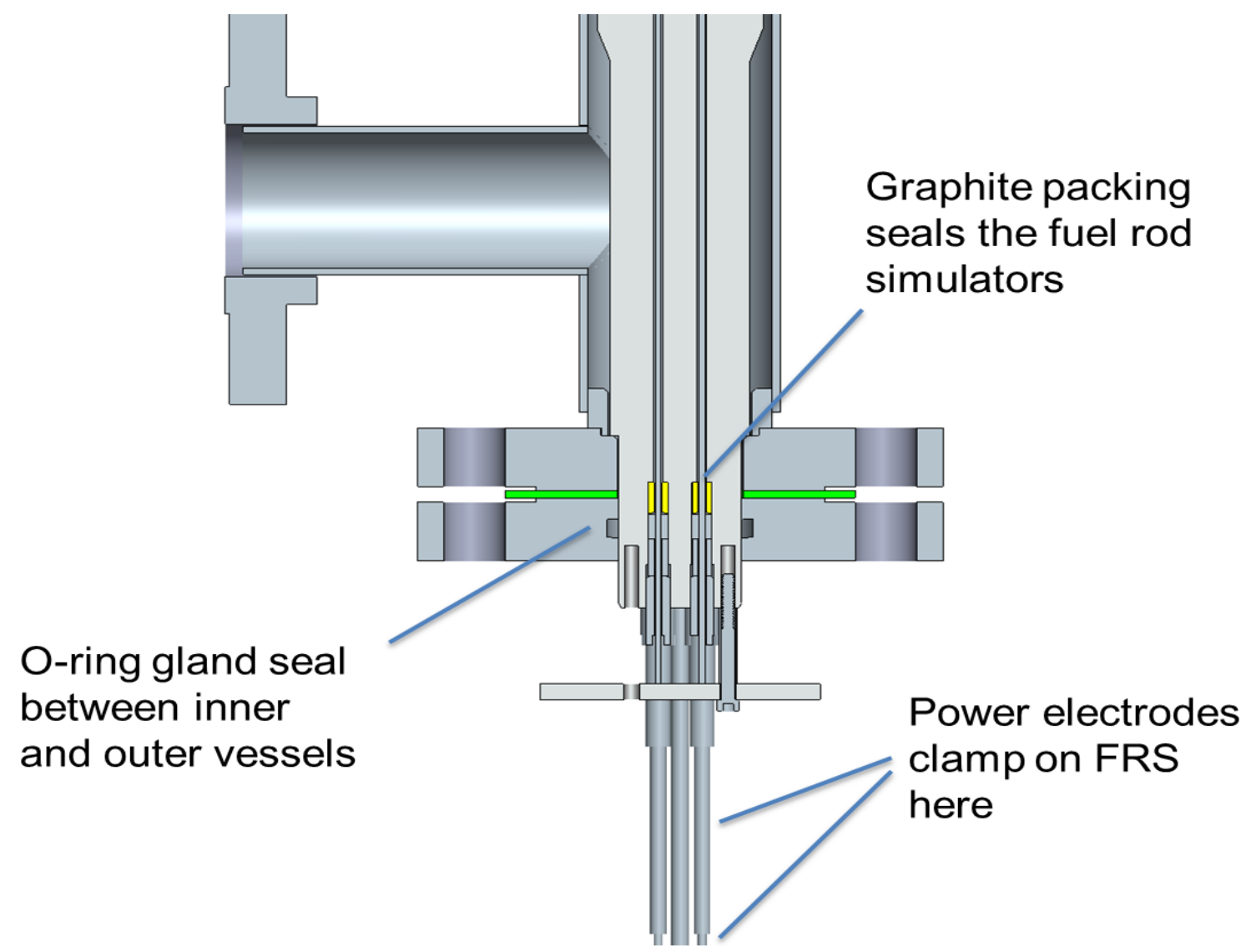

Figure 4-9. Lower vessel seal arrangement.

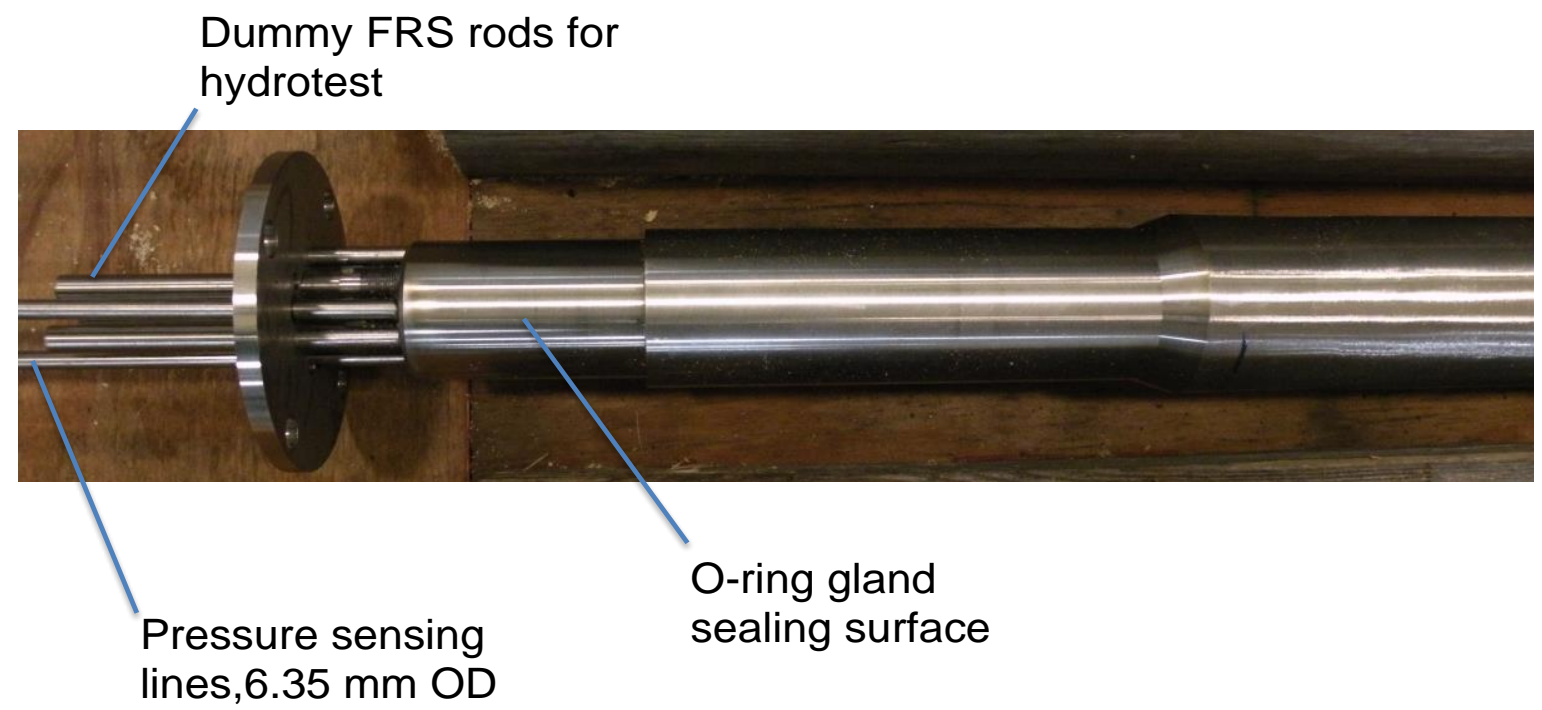

Figure 4-10. Lower portion of inner vessel assembly.

The upper end of the internal baffle assembly contains a liquid/vapor separator region as shown in Figure 4-11. A swirl device acts to sling water droplets to the outer wall where they can flow out through slots into the condensate channel. The swirl device was made from titanium using 3D printing. Figure 4-12 shows a view looking down into the tube at the swirl device before the upper portion was attached. The 
slots where the water droplets flow out can be seen in the photo. Condensate flowing down outside the slots from the separator joins with condensate from the upper condenser region, as shown in Figure 4-11. The fuel rod simulators have a $25 \mathrm{~mm}$ unheated length at the top (gray in the cutaway view) that is an artifact of the FRS fabrication process.

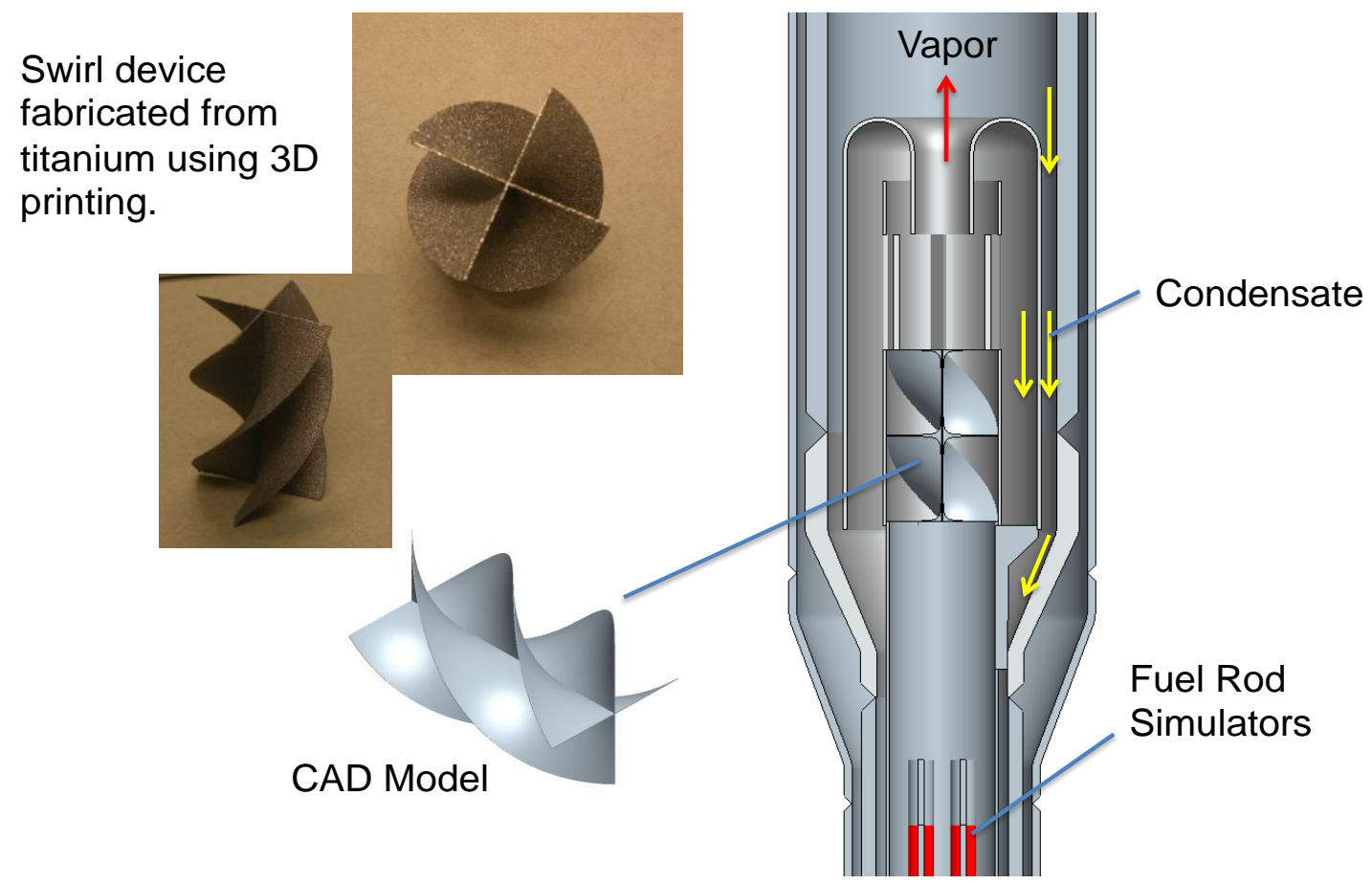

Figure 4-11. A swirl device is used to separate liquid droplets from vapor above the boiler region.

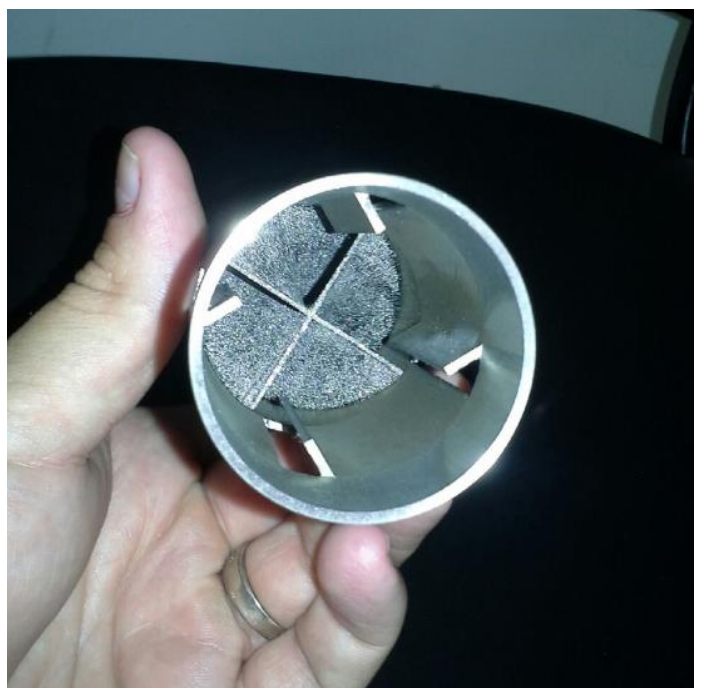

Figure 4-12. View looking down at swirl device installed in the upper baffle assembly.

The condenser region that extends above the liquid/vapor separator section is empty except for six $1 \mathrm{~mm}$ diameter fluid thermocouple leads twisted into a bundle, extending through the center of the condenser. Three of the leads terminate at different axial positions in the condenser, and the other three terminate at different axial positions in the evaporator section. The 6 thermocouples penetrate the thermosyphon vessel and the outer vessel via Conax fittings, as shown in Figure 4-13. A $3.2 \mathrm{~mm}$ diameter vent line 
shown in red also penetrates the inner and outer vessels through the same Conax fittings and is used to charge gas into the thermosyphon vessel. Thermocouples in green are not shown completely; they actually extend from outside the outer vessel into the condenser and evaporator regions. The photo on the right shows the region in the space above the thermosyphon vessel with thermocouple leads and vent line extending from the Conax fitting.

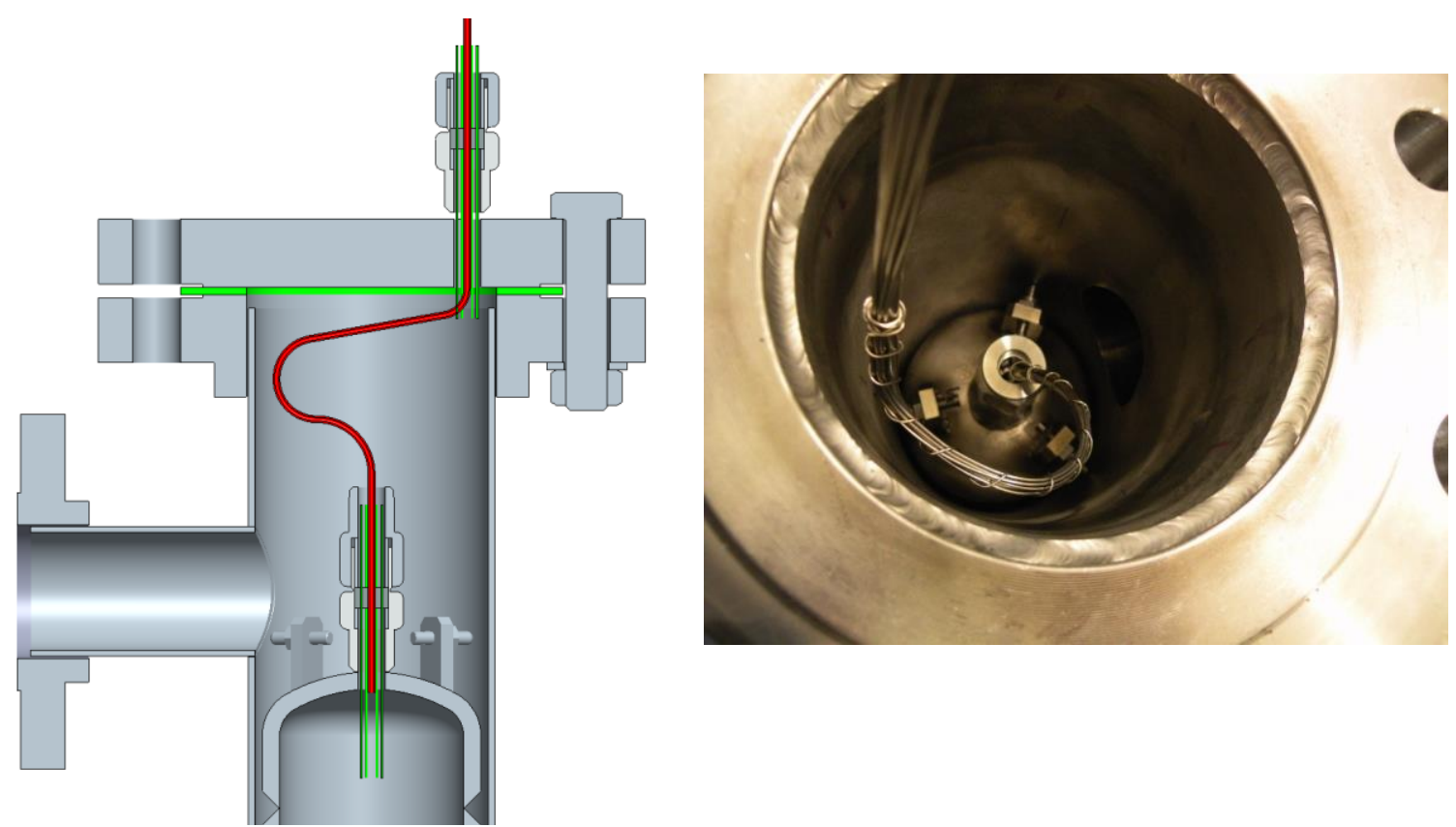

Figure 4-13. Gas/vacuum line and 6 fluid thermocouples.

\subsection{FUEL ROD SIMULATORS}

The FRSs were fabricated by Stern Laboratories, Inc., of Hamilton, Ontario. They are an indirectly heated, single-ended design, $9.5 \mathrm{~mm}$ (0.375 in) diameter with a $508 \mathrm{~mm}$ heated length and uniform axial power profile designed to provide $26.7 \mathrm{~kW}$ at $150 \mathrm{VDC}$. The simulators include 6 internal sheath thermocouples spaced over the axial length and at 60 degrees circumferentially. The FRSs were made with three different axial thermocouple arrangements to stagger the temperature measurements over the heated length. A schematic of the fuel rod simulator construction is shown in Figure 4-14. The table embedded in Figure 4-14 shows an example of the variation in axial thermocouple positions for the 5 FRSs that were specified. The as-built locations were provided in the fabrication documentation for each of the FRSs. General requirements for the single-ended heater rods and thermocouple specifications are shown in Table 4.1. 


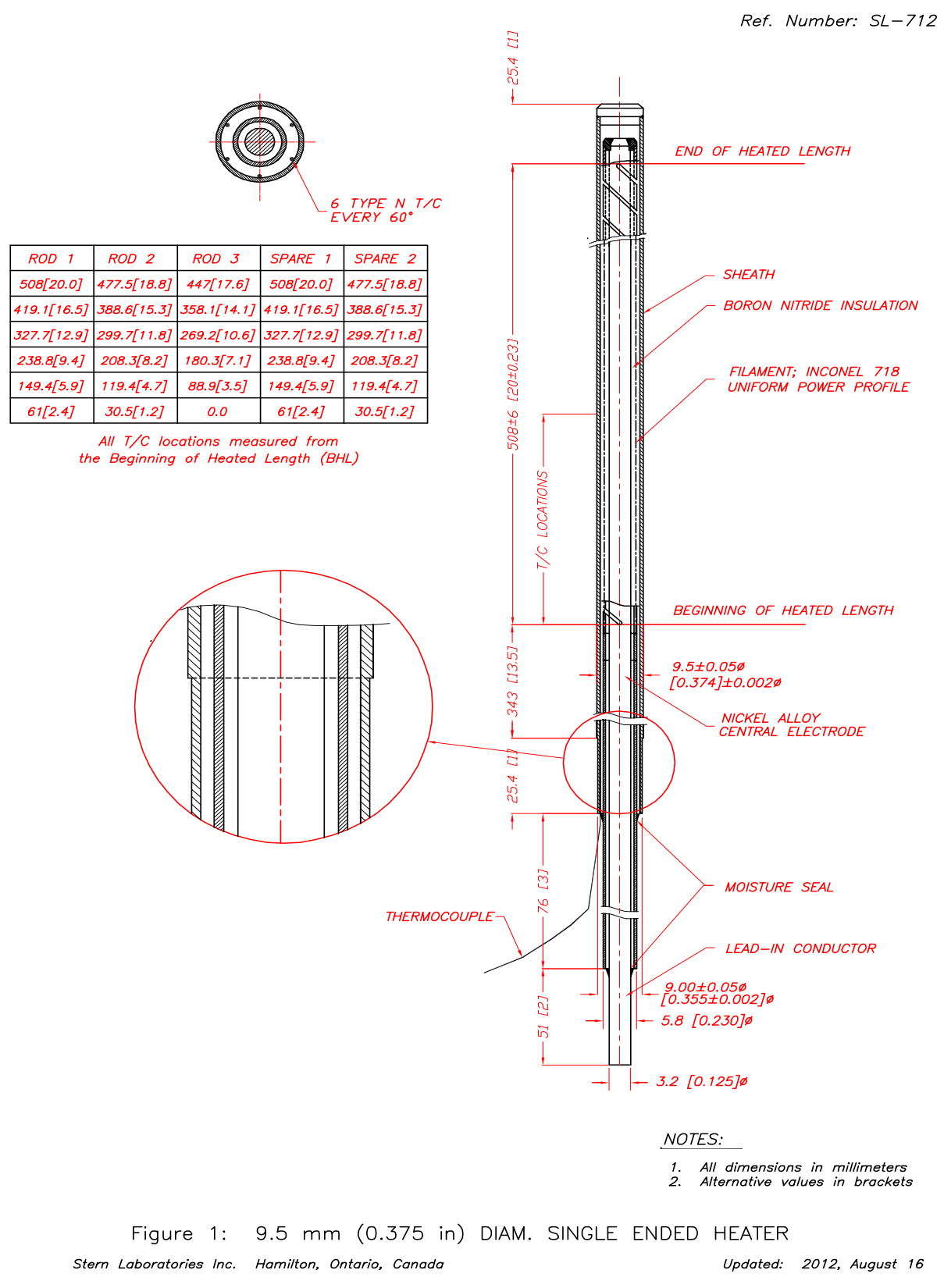

Figure 4-14. Fuel rod simulator detail. 
Table 4-1. General requirements for single-ended heater rods and thermocouple specifications

\begin{tabular}{|c|c|}
\hline Parameter & Requirement \\
\hline Operating pressure & $15.5 \mathrm{MPa}$ \\
\hline Operating temperature & $320^{\circ} \mathrm{C}$ \\
\hline Power (design maximum) & $26.7 \mathrm{~kW}$ \\
\hline Operating Voltage (maximum) & $150 \mathrm{VDC}$ \\
\hline Nominal current & $178 \mathrm{~A}$ \\
\hline Axial power profile & Uniform linear profile \\
\hline Linear power & $52.5 \mathrm{~kW} / \mathrm{m}$ \\
\hline Heat flux & $176 \mathrm{~W} / \mathrm{cm}^{2}$ \\
\hline Full diameter/extension diameter & $9.50 \pm 0.05 \mathrm{~mm}$ \\
\hline Heated length & $508 \pm 6 \mathrm{~mm}$ \\
\hline Sheath length (full diameter) & $876 \mathrm{~mm}$ \\
\hline Overall length & $1,029 \mathrm{~mm}$ \\
\hline \multicolumn{2}{|c|}{ Electrode length } \\
\hline Electrical resistance $\left(20^{\circ} \mathrm{C}\right)$ & $0.82 \Omega \pm 5 \%$ \\
\hline Electrical resistance $\left(600^{\circ} \mathrm{C}\right)$ & $0.84 \Omega \pm 5 \%$ \\
\hline Sheath surface finish & As swaged $(3.2 \mu \mathrm{m}$ or better $)$ \\
\hline Sheath to filament resistance & $>1,000 \mathrm{M} \Omega \bullet \mathrm{m} @ 1,000 \mathrm{VDC}$ \\
\hline Current leakage & <10mA @1,000 VDC \\
\hline Coolant medium & Water \\
\hline \multicolumn{2}{|c|}{ Thermocouple specifications } \\
\hline Type & Premium grade ANSI Type $\mathrm{N}$ \\
\hline Diameter & $0.5 \mathrm{~mm}$ \\
\hline Sheath & Inconel 600 \\
\hline Insulation & $\mathrm{MgO}$ \\
\hline Junction & Ungrounded, BN backfilled \\
\hline Length (varies) & $2400 \mathrm{~mm}(\max )$ \\
\hline Resistance, lead to sheath & $60 \times 10^{6} \Omega \bullet \mathrm{m}$ at $\pm 50 \mathrm{~V}$ \\
\hline Length beyond heater sheath & $1,000 \mathrm{~mm}$ \\
\hline
\end{tabular}

Stern Laboratories, Inc., Hamilton, Ontario, Canada

The FRSs have an unheated length that extends through the bottom of the evaporator section and out of the packing seal at the bottom of the thermosyphon vessel as shown in Figure 4-9. Power clamps are attached to the FRSs in this region, and the sheath thermocouples are connected to a connector strip as shown in Figure 4-15 and Figure 4-16. The power clamps attached to the three FRSs are connected in parallel to a common bus on the back of the power supply.

The two $6.35 \mathrm{~mm}$ pressure sensing lines that extend from the bottom of the evaporator can also be seen (with black electrical insulation) in Figure 4-16. These lines are connected to pressure and differential pressure transmitters and also serve as water fill/drain lines for the thermosyphon vessel. One of the lines is connected to the annulus carrying condensate (between the thermosyphon vessel wall and the flow separator) at the bottom of the separator region as shown in Figure 4-8, and the other is connected to the region inside the flow separator, also at the bottom of the separator region. The differential pressure transmitter connected between these two lines provides an indication of flow across the orifices. 


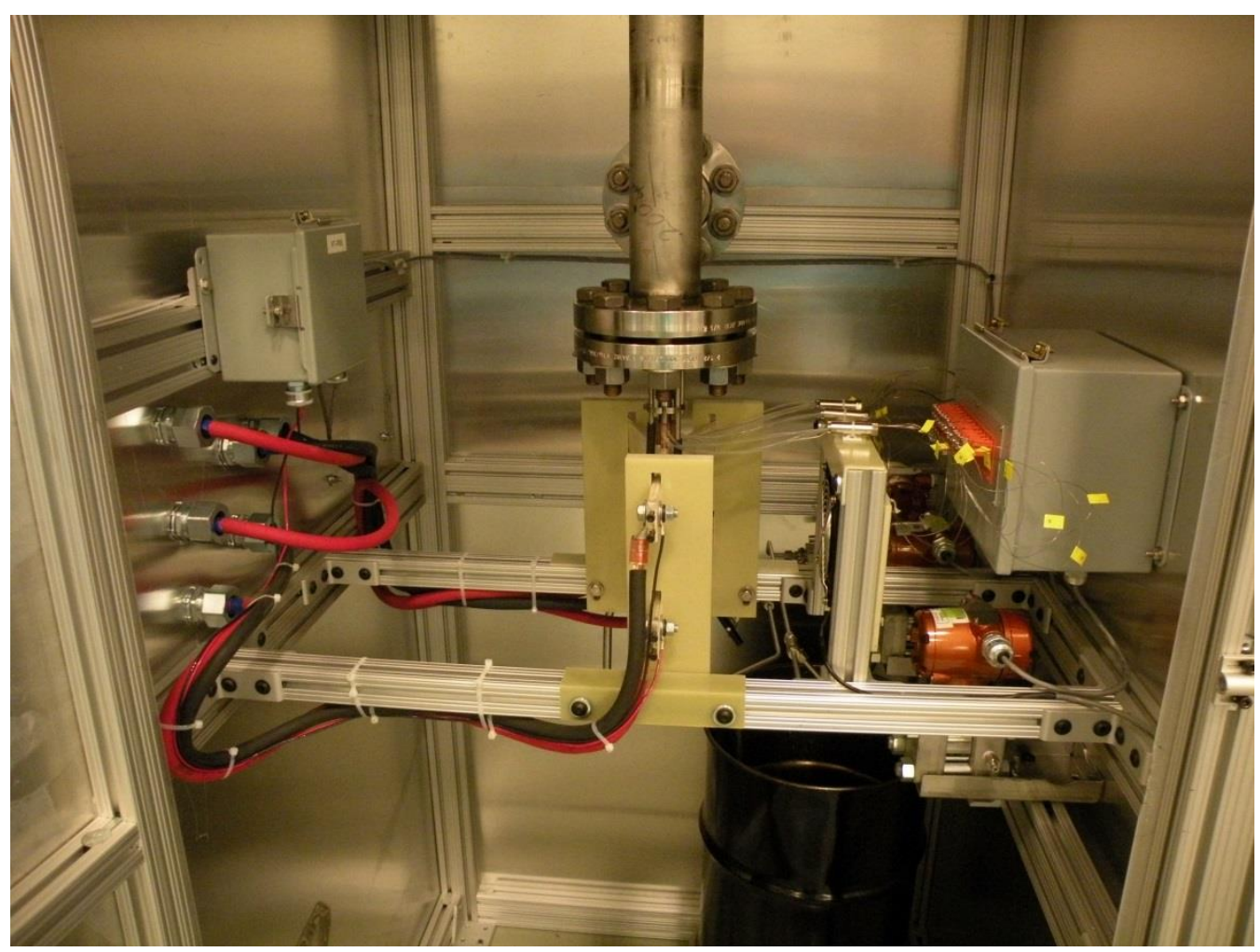

Figure 4-15. Lower thermosyphon assembly with power and instrument connections.

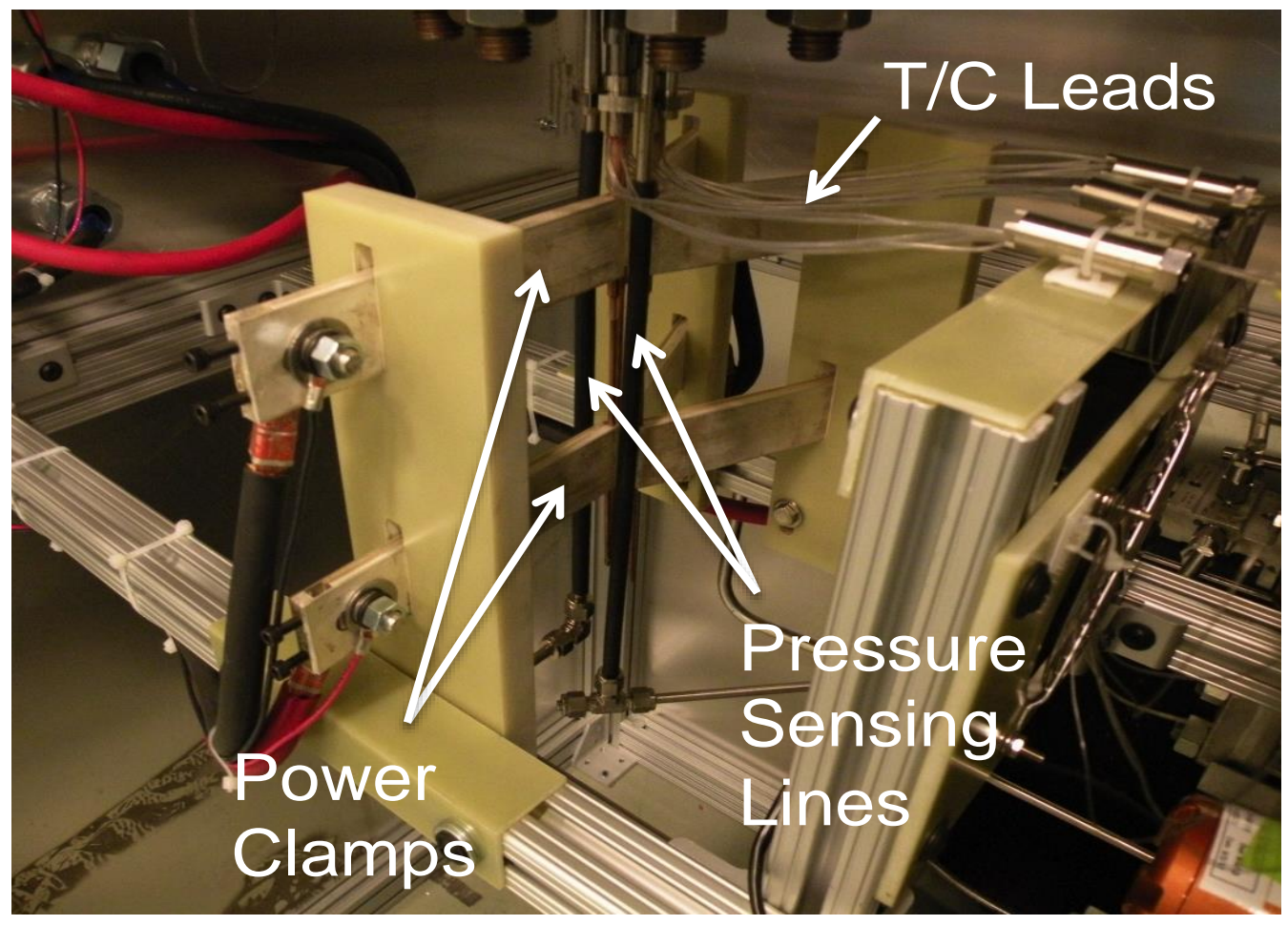

Figure 4-16. Detail of power clamp connections to the FRSs. 


\subsection{LOOP COMPONENTS AND INSTRUMENTATION}

A process and instrumentation drawing (P\&ID) is shown in Figure 4-17. A Dean R-4140 pump with a variable frequency drive can provide from $0.63-1.89 \mathrm{l} / \mathrm{s}$ of water with a total developed head of $24 \mathrm{~m}$. Discharge from the pump flows through an Azbil model MTG18A electromagnetic flow meter before entering the test section assembly. Return from the test assembly flows through an Alfa Laval plate heat exchanger, model AlfaNova $27-40 \mathrm{H}$, before returning to the pump suction. A bypass line connects the upstream side of the flow meter to the upstream side of the heat exchanger and is provided to facilitate loop checkout and optional pump operating conditions available by using the variable frequency drive. A water supply tank is connected on the suction side of the pump. The supply tank with argon cover gas also acts as a gas pressurizer, allowing the system to operate at the nominal inlet pressure of $2.9 \mathrm{MPa}$.

The system is controlled by an Allen Bradley 1756 Controllogix system. The system provides programmable logic control (PLC) and measurement of system operating parameters. Process instrumentation includes pressure, differential pressure, flow, level, and fluid temperature sensors located around the loop. Loop water temperatures are measured using platinum resistance temperature detectors (RTDs) inserted into the flow stream. Fluid temperatures in the thermosyphon vessel are measured with Type $\mathrm{N}$ thermocouples. A list of instruments with corresponding measurement ranges and uncertainties is provided in Table 4-2.

A gas regulator, in combination with solenoid valves on the gas supply and vent lines, is used to control the cover gas pressure in the supply tank. A Magnetrol model $82 \mathrm{CE}$ RF level transmitter is used to monitor level in the tank. A relief valve on the gas supply line prevents overpressure of the supply tank due to regulator failure.

A Magna Power MTD160-620 $100 \mathrm{~kW}$ power supply provides DC power to the three fuel rod simulators. The power supply can be controlled locally or remotely via the graphic display on the Controllogix system. The power supply and load are protected by overcurrent and overvoltage trips, as well as external interlocks from the PLC, based on loop and FRS operating parameters. The power supply is capable of operating using either current control or voltage control with automatic crossover. Since the FRSs are connected in parallel, the power supply was operated using voltage control (by setting the current set point above the operating point) to provide similar power to each FRS.

Interlocks are used to protect the $100 \mathrm{~kW}$ power supply, the FRSs, and loop components from abnormal conditions. The circulating pump will shut down in the event of low water tank level, high suction pressure, and high inlet temperature. The power supply will be shut down on loss of the pump, low water flow, overcurrent, overvoltage, high water tank level, low water tank level (above the pump shutdown level), high inlet pressure, or high inlet temperature (loop water) to the thermosyphon, high inlet pressure or high inlet temperature to the heat exchanger, high thermosyphon pressure, high chilled water exit temperature from the heat exchanger, and high sheath thermocouple temperature (all 18 thermocouples). The sheath temperature limits are generally set $50-75^{\circ} \mathrm{C}$ above the expected maximum temperature for a given test. 


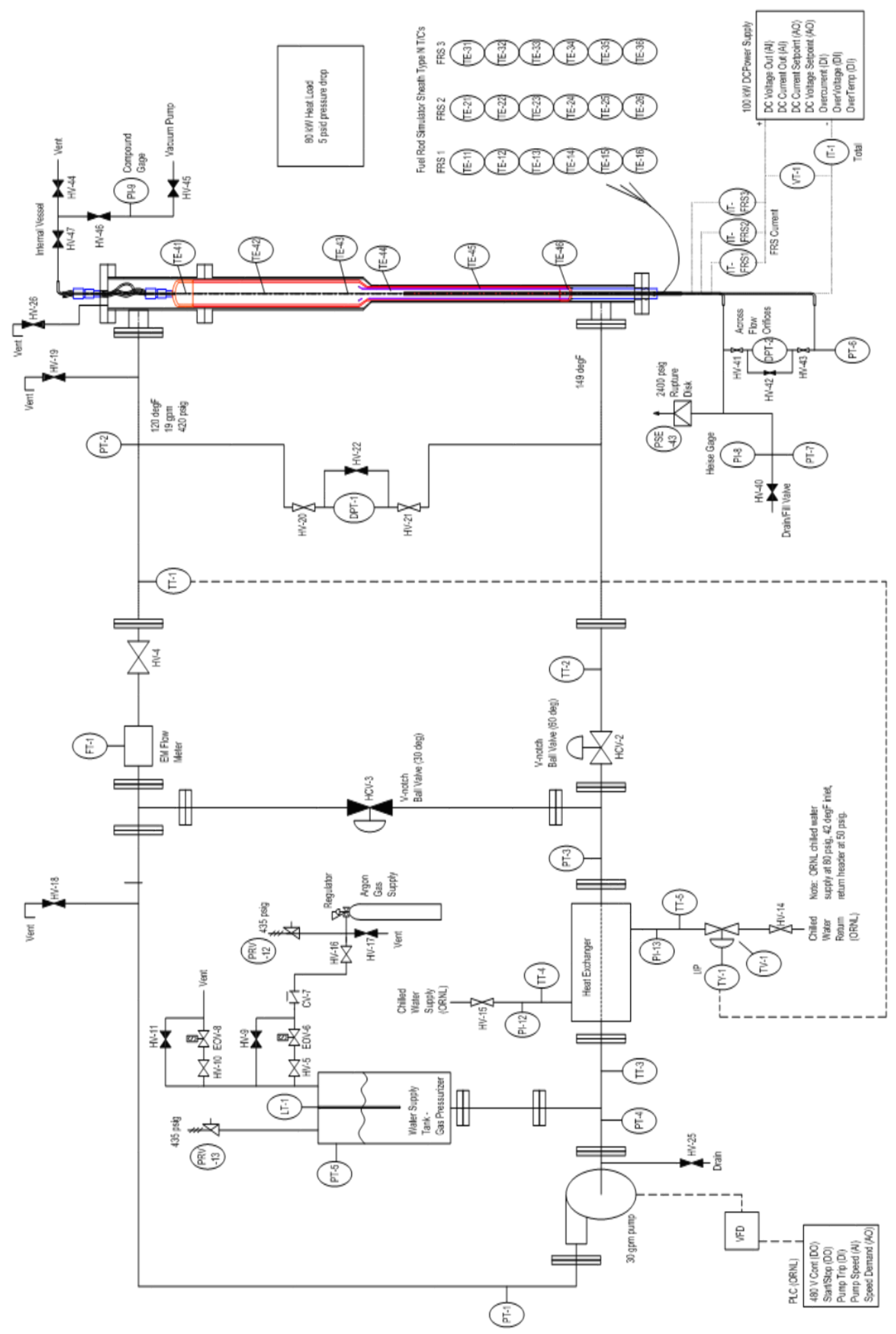

Figure 4-17. P\&ID of thermosyphon test loop. 
Table 4-2. Primary instrumentation list for the thermosyphon test loop

\begin{tabular}{|c|c|c|c|}
\hline $\begin{array}{l}\text { Instrument } \\
\text { application number }\end{array}$ & $\begin{array}{l}\text { Range } \\
\text { (normal } \\
\text { operation) }\end{array}$ & Uncertainty estimates & $\begin{array}{l}\text { Manufacturer } \\
\text { (model) }\end{array}$ \\
\hline PT-1 thru PT-5 & $\begin{array}{l}0-3.45 \mathrm{MPa} \\
(\sim 2.8 \mathrm{MPa})\end{array}$ & $\begin{array}{l}+/-1 \% \text { of FS } \\
\text { (due to calibration/ } \\
\text { scaling input error) } \\
\text { Mfg: }+/-0.25 \% \text { of FS }\end{array}$ & $\begin{array}{l}\text { Honeywell } \\
\text { (FPG pressure transmitter) }\end{array}$ \\
\hline PT-6, PT-7 & $\begin{array}{l}0-17.3 \mathrm{MPa} \\
(<8.5 \mathrm{MPa})\end{array}$ & $\begin{array}{l}+/-0.15 \% \mathrm{FS} \text { for } \mathrm{P} \geq \\
7.0 \mathrm{MPa} \\
(0.05+0.1 \times 1015 / \mathrm{P}) \% \\
\text { for } \mathrm{P}<7.0 \mathrm{MPa}\end{array}$ & $\begin{array}{l}\text { Azbil } \\
\text { (GTX82G pressure transmitter) }\end{array}$ \\
\hline TT-1 thru TT-5 & $0-100{ }^{\circ} \mathrm{C}$ & $\begin{array}{l}\text { RTD element :+/- } \\
0.35{ }^{\circ} \mathrm{C} \\
\text { interchangeability } \\
\text { Transmitter: }+/-0.1 \% \\
\text { of calibrated span or } \\
+/-0.25 \mathrm{mV}, \text { whichever } \\
\text { is greater }\end{array}$ & $\begin{array}{l}\text { Omega } \\
\text { (Pt RTD DIN Class A/Acromag } \\
\text { 250T-RBP1-DIN-NC transmitter) }\end{array}$ \\
\hline DPT-1 & $0-100 \mathrm{kPa}$ & $\begin{array}{l}\text { Max. } 0.5 \mathrm{kPa} \text { error over } \\
5.6-100 \mathrm{kPa} \text { range } \\
\text { (in-situ calibration) }\end{array}$ & $\begin{array}{l}\text { Azbil } \\
\text { (GTX31D differential pressure } \\
\text { transmitter) }\end{array}$ \\
\hline DPT-2 & $0-7.5 \mathrm{kPa}$ & $\begin{array}{l}\text { +/- } 0.015 \mathrm{kPa} \max \\
\text { (in-situ calibration) }\end{array}$ & $\begin{array}{l}\text { Azbil } \\
\text { (GTX31D differential pressure } \\
\text { transmitter) }\end{array}$ \\
\hline FT-1 & $0-3.8 \mathrm{l} / \mathrm{s}(1.2 \mathrm{l} / \mathrm{s})$ & $+/-0.5 \%$ of FS & $\begin{array}{l}\text { Azbil } \\
\text { (MTG18A electromagnetic flow } \\
\text { transmitter) }\end{array}$ \\
\hline IT-1 & 0-620 Amps & & $\begin{array}{l}\text { Magna Power } \\
\text { (MTD160-620 } 100 \mathrm{~kW} \text { power } \\
\text { supply current output) }\end{array}$ \\
\hline $\begin{array}{l}\text { IT-FRS1, IT-FRS2, IT- } \\
\text { FRS3 }\end{array}$ & $\begin{array}{l}0-250 \text { Amps } \\
(\sim 200 \text { Amps at } \\
\text { FRS design } \\
\text { power })\end{array}$ & $\begin{array}{l}+/-0.5 \% \text { of FS } \\
\text { (Max error from in-situ } \\
\text { check with calibrated } \\
\text { meter of } 0.64 \% \text { of FS) }\end{array}$ & $\begin{array}{l}\text { Powertek } \\
\text { (CTH/250A/4-20/TH/24Vdc) }\end{array}$ \\
\hline LT-1 & $\begin{array}{l}0-762 \mathrm{~mm}(457 \\
\mathrm{mm})\end{array}$ & $+/-0.25 \%$ repeatability & $\begin{array}{l}\text { Magnetrol } \\
\text { (82 CE RF level transmitter) }\end{array}$ \\
\hline TE-11-TE-16 & $0-1,300^{\circ} \mathrm{C}$ & TCs: & Type $\mathrm{N}$ thermocouples \\
\hline $\begin{array}{l}\text { TE-21-TE-26 } \\
\text { TE-31-TE-36 }\end{array}$ & & $\begin{array}{l}\text { Electronic (DAS): } \\
+/-1.5^{\circ} \mathrm{C}\end{array}$ & \\
\hline TE-41 thru TE-46 & $0-1,300^{\circ} \mathrm{C}$ & $\begin{array}{l}\mathrm{T} / \mathrm{Cs}:+/-0.5^{\circ} \mathrm{C} \text { for } \\
\text { range } 0-350{ }^{\circ} \mathrm{C} \\
\text { (ORNL Metrology) } \\
\text { Electronic (DAS): } \\
+/-1.5^{\circ} \mathrm{C}\end{array}$ & $\begin{array}{l}\text { Type } N \text { thermocouples, } 1 \mathrm{~mm} \\
\text { (0.04 in) OD }\end{array}$ \\
\hline VT-1 & $0-160 \mathrm{VDC}$ & & $\begin{array}{l}\text { Magna Power } \\
\text { (MTD160-620 } 100 \mathrm{~kW} \text { Power } \\
\text { Supply bus voltage output) }\end{array}$ \\
\hline VT-FRS & $\begin{array}{l}0-200 \text { VDC } \\
(150 \text { VDC at } \\
\text { FRS design } \\
\text { power })\end{array}$ & $\begin{array}{l}+/-0.5 \% \text { of FS } \\
\text { (Max error of } 0.06 \\
\text { VDC from in-situ check } \\
\text { with calibrated meter) }\end{array}$ & $\begin{array}{l}\text { CR Magnetics } \\
\text { (CR5320-200 DC Voltage } \\
\text { Transducer) }\end{array}$ \\
\hline
\end{tabular}




\subsection{THE ORIFICE FLOW TEST FACILITY}

A separate facility was built to measure pressure drop vs. flow characteristics across the orifices connecting the downcomer with the boiler/evaporator. This facility is isothermal. A schematic of the Orifice Flow Test Facility (OFTF) is shown in Fig. 4-18. This facility was installed in the water test loop located in the same laboratory as the thermosyphon test loop (TSTL).

The flow orifices in the lower region of the actual test section vessel are shown in Fig. 4-8. The OFTF duplicates the flow geometry of this lower region of the TSTL. An outer vessel made from $5.08 \mathrm{~cm}(2-$ inch) Sch 80 pipe provides the TSTL vessel's outer wall geometry. The details of this region shown in the original CAD drawings were machined onto a plate that forms the bottom flange of this orifice flow test assembly. A spare inner baffle tube from the original thermosyphon fabrication was available and used for this assembly. These components are shown in Fig. 4-19. To simulate the fuel rods, three $9.5 \mathrm{~mm}$ (OD) rods were threaded into the bottom plate. The bottom plate assembly with inner baffle tube is installed into the $5.08 \mathrm{~cm}$ ( 2 in) pipe assembly. Flow enters from the side, flows down the simulated downcomer annulus between the outside pipe and the inner baffle tube, goes through the orifices, and then goes upward through the inside of the inner baffle tube, which includes the three dummy fuel rods simulating the boiler. The top of the inner baffle tube was shortened slightly and welded to a reducer section and then to a $2.54 \mathrm{~cm}$ ( 1 in) tube. The tube exits the outer pipe assembly via a Swagelok boredthrough fitting and connects back to the water loop return piping. A photograph of this facility installed in the water loop is shown in Fig. 4-20. The total height of the OFTF is $0.98 \mathrm{~m}$ (38.5 in).

Differential pressure across the orifices was measured using ports machined into the bottom plate as in the TSTL. Two $6.35 \mathrm{~mm}$ tubes are welded to the bottom plate and connected to an Azbil GTX31D differential pressure transmitter. The same model and range was used as in the thermosyphon facility (see DPT-2 in Table 4-2). Water flow was measured using a Hoffer flow controls turbine-meter (model number HO1/2X3/8-3-9-BP-1MX-NPT-X) with a range of 0.02 to $0.57 \mathrm{~L} / \mathrm{s}(0.3$ to $9 \mathrm{gpm})$. From a calibration report, the error of this instrument is $+/-0.78 \%$ over this range. Inlet pressure was measured in the plenum formed above the entrance to the annulus between the outer vessel and the inner baffle tube via a pressure tap through the upper flange of the outer housing. An Omega Model DPG409-100G pressure transmitter was used (with the manufacturer's accuracy of $+/-0.08 \%$ ).

Measurements were taken over a range of water flow rates by adjusting a metering valve located between the turbine flow-meter and the inlet to the test assembly. Flows were varied between 0.04 and $0.22 \mathrm{~L} / \mathrm{s}$, and the measured pressure drops were between 0.1 and $2.2 \mathrm{kPa}$. The inlet water temperature was $\sim 293 \mathrm{~K}$ $\left(20^{\circ} \mathrm{C}\right)$, and the inlet pressure was slightly above atmospheric pressure $(<104 \mathrm{kPa})$. All the data taken in the OFTF are shown in Fig. 4-21. 


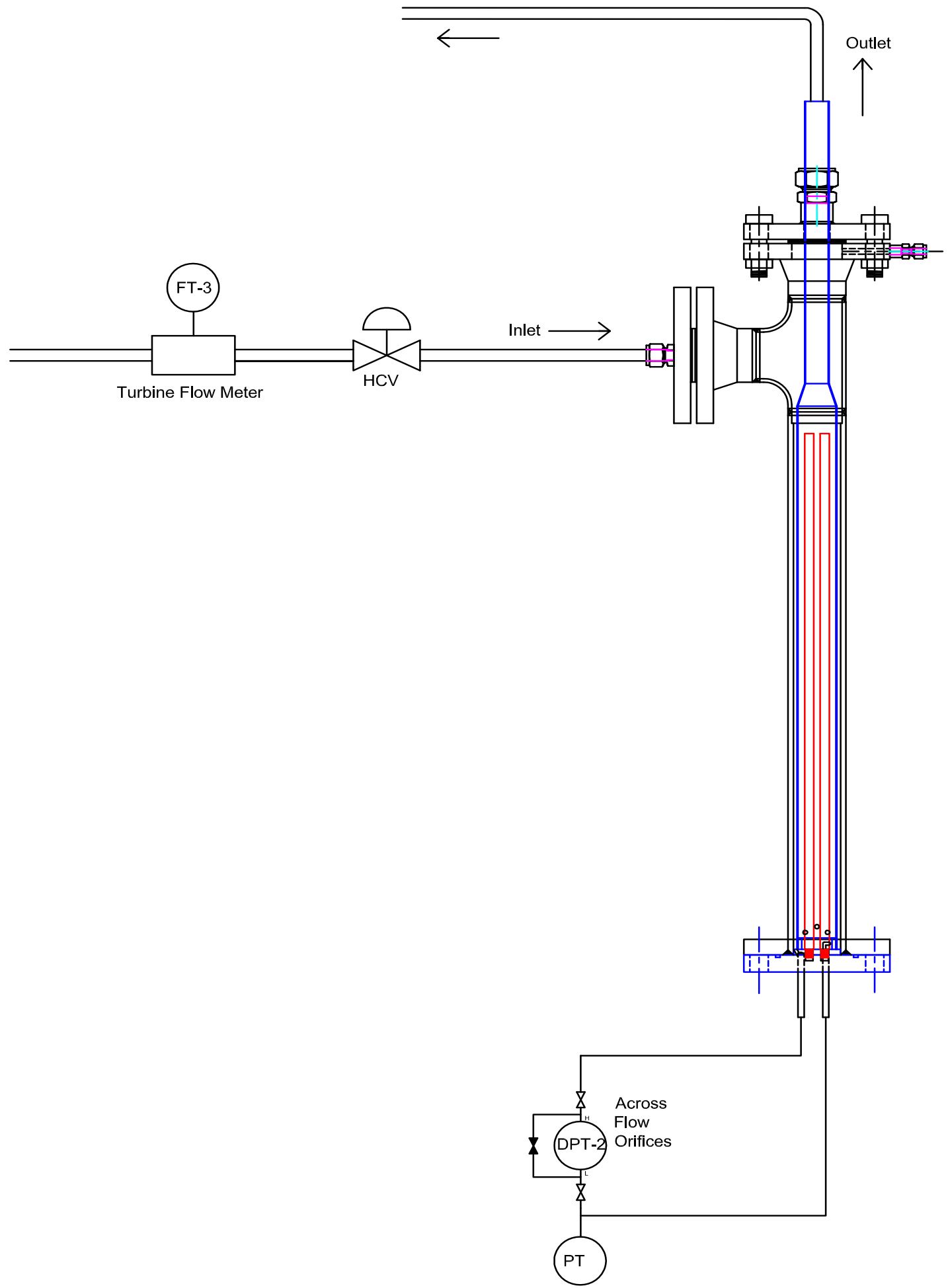

Figure 4-18. Orifice flow test facility. 


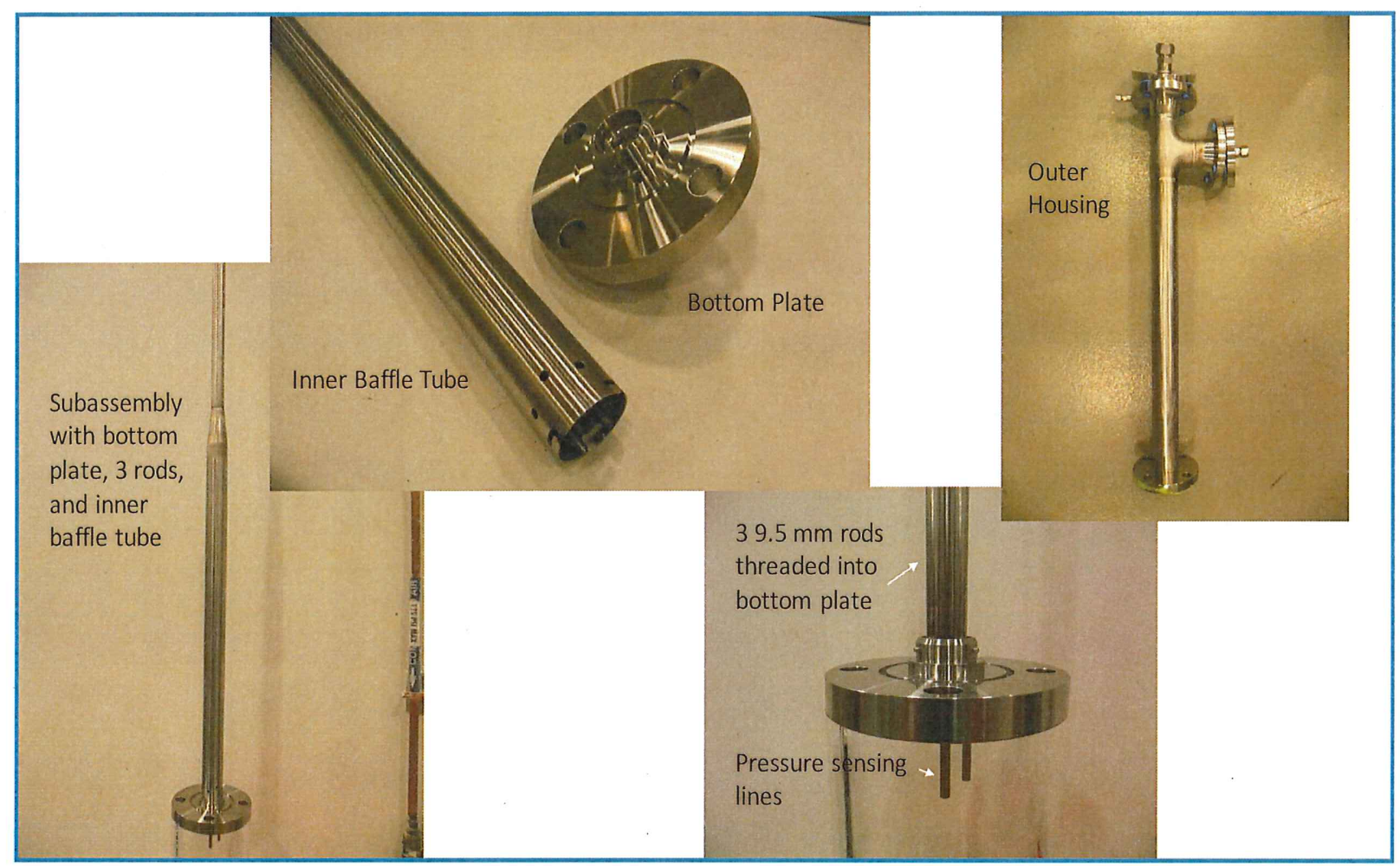

Figure 4-19. Orifice flow test facility components.

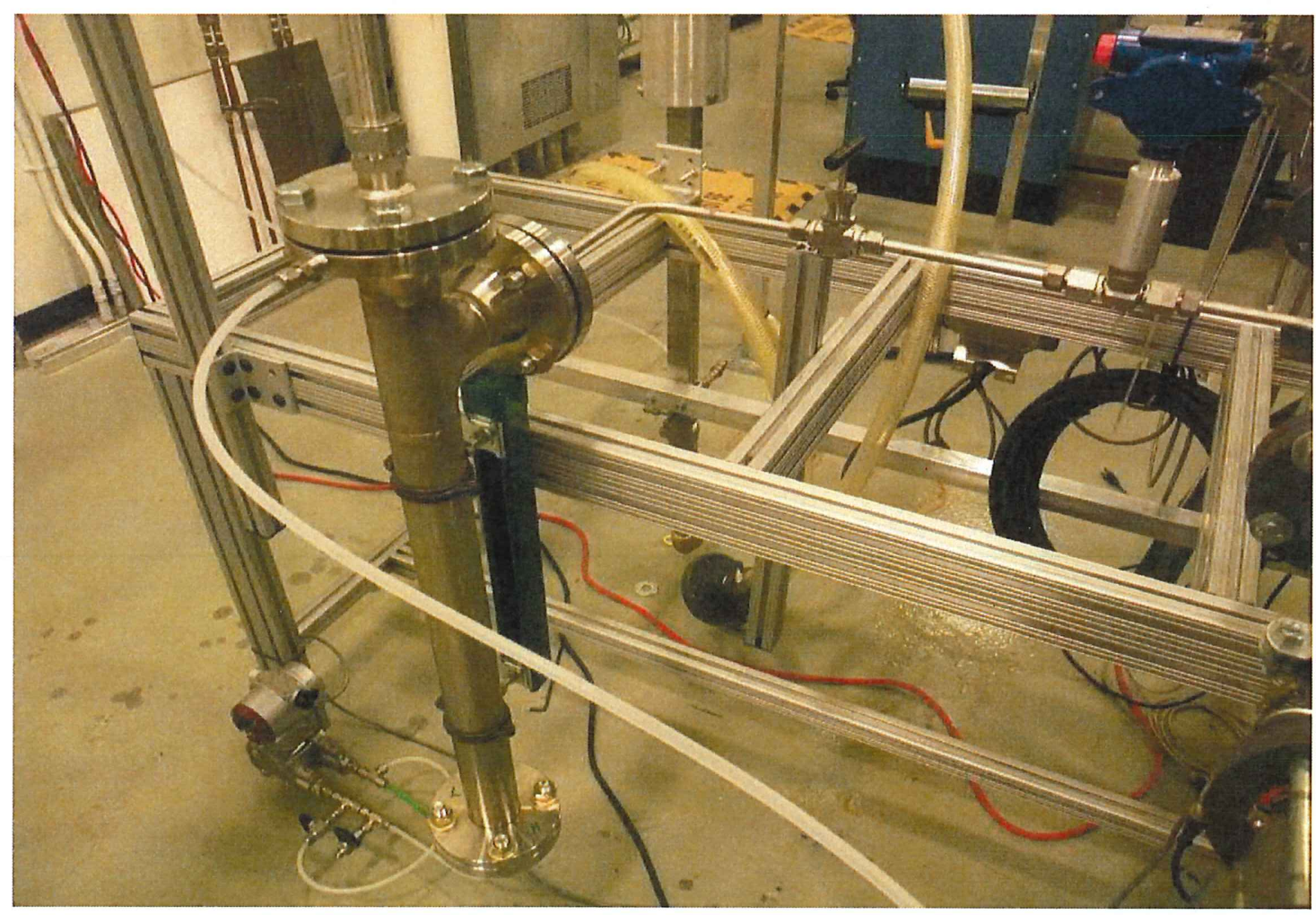

Figure 4-20. Orifice flow test facility as installed in the water test loop. 


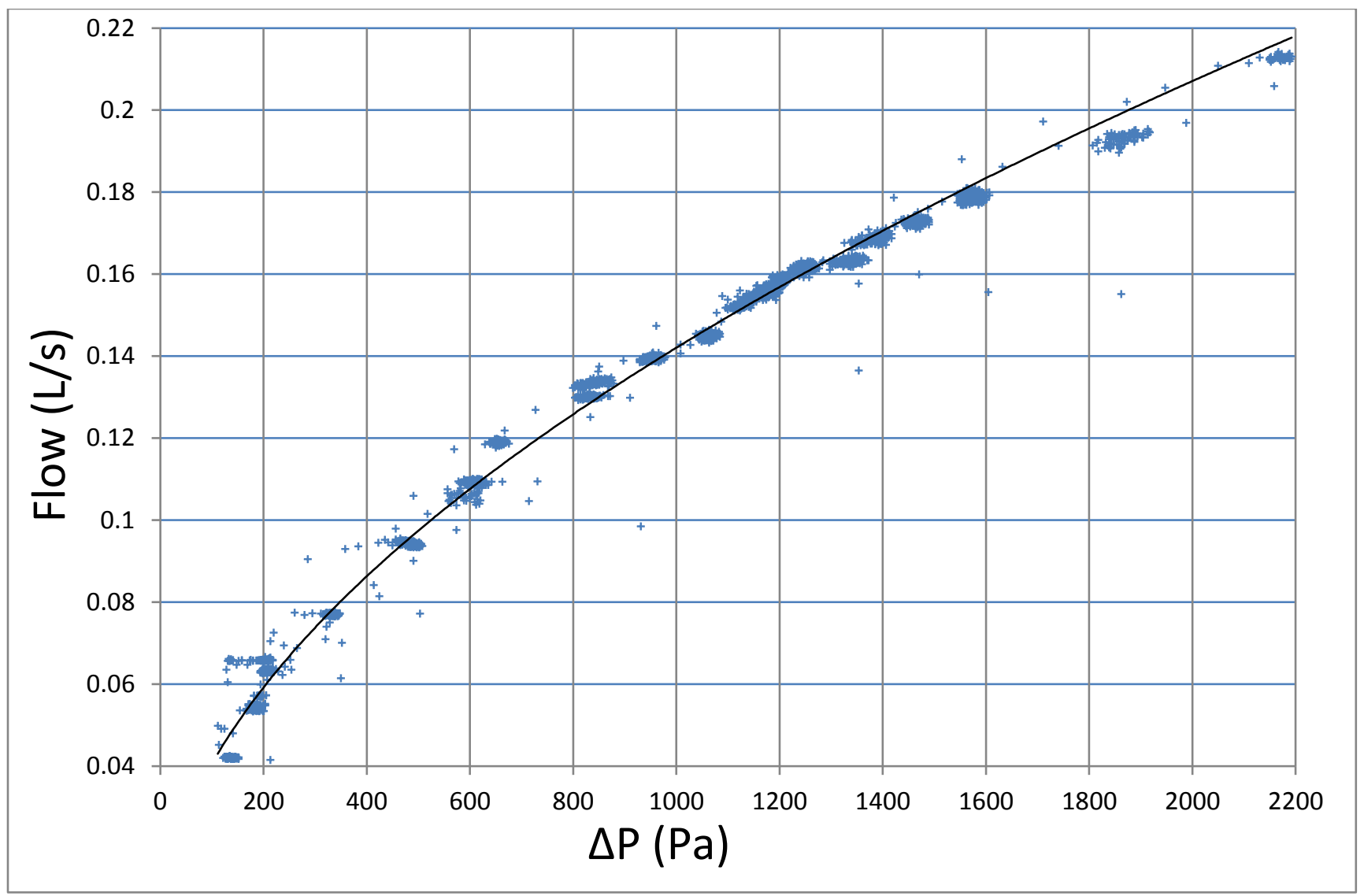

Figure 4-21. Orifice flow test facility data. 


\section{THERMOSYPHON TEST LOOP EXPERIMENT OPERATION}

The thermosyphon vessel is operated as a closed system. An initial charge of demineralized water is introduced through the lower pressure sensing lines with the vessel under vacuum. A water container is placed on a scale, and the water is injected using a peristaltic pump. A clear level tube was connected in parallel with the thermosyphon in a separate measurement to correlate mass of water to liquid level in the cold condition. For most of the tests, the cold water level was approximately $643-645 \mathrm{~mm}$ above the bottom of the evaporator region, which is $23-25 \mathrm{~mm}$ below the bottom of the swirl separator (for a fill of 1,113 to $1,117.2 \mathrm{~g}$ of water). The variance is due to the fill process, with water-added values from actual before-and-after scale measurements of the source water container. Figure 5-1 shows the heights of key features of the thermosyphon vessel relative to the bottom of the evaporator.

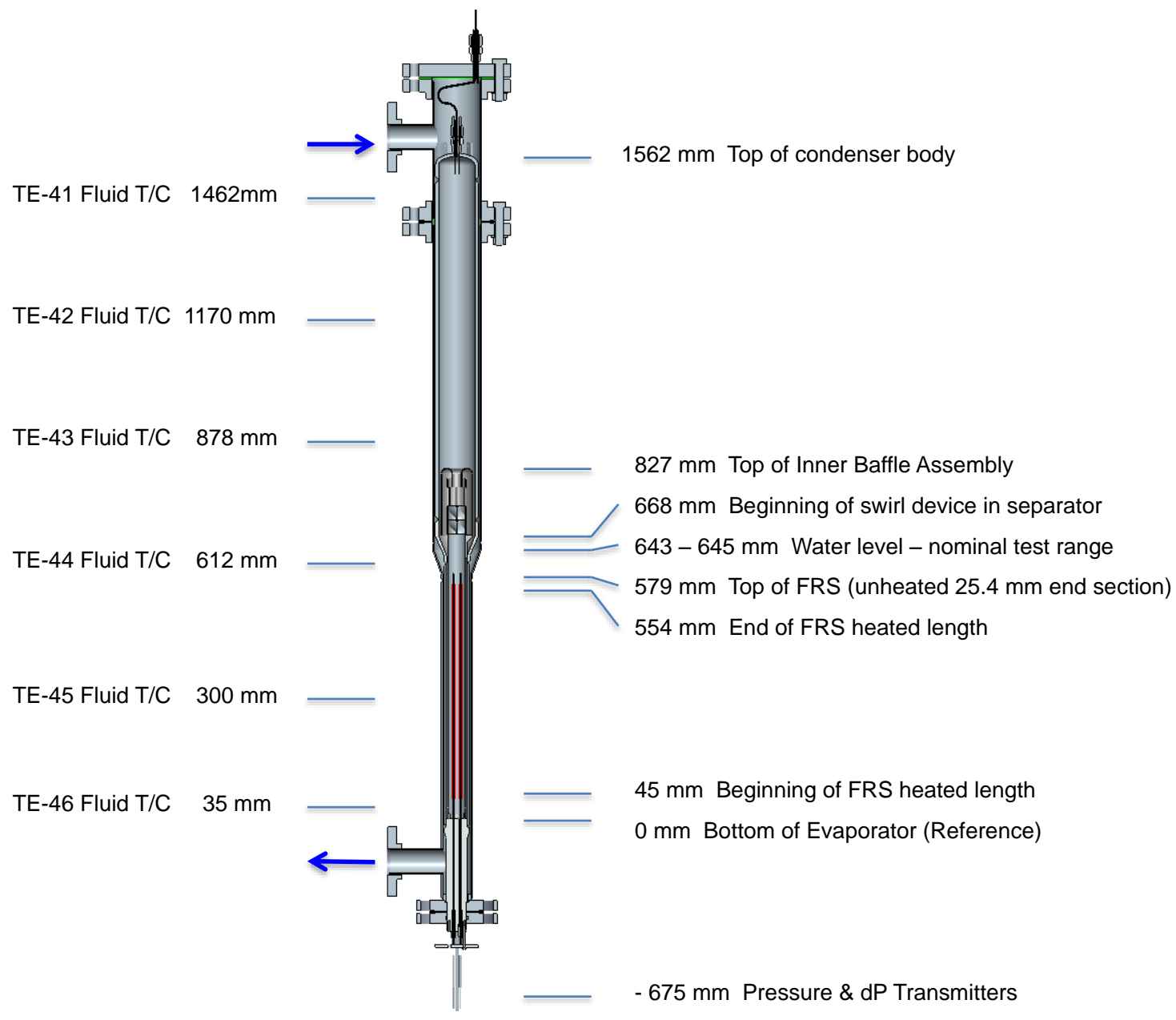

Figure 5-1. Relative heights of key features in the thermosyphon vessel (measuring from the bottom of the evaporator section).

After loading with water, gas is charged into the top of the vessel to a specified pressure. Measurements of the thermosyphon vessel's internal volume have been made so that the mass of gas charged into the system can be calculated from the initial pressures and temperatures. Volume measurements were made using a calibrated tank with known volume and gas pressure. The thermosyphon internal volume was determined by opening a valve between the calibrated tank and thermosyphon vessel and measuring the subsequent pressure at equilibrium. This measurement gave a total internal thermosyphon vessel volume of $5,981 \mathrm{~cm}^{3}$, including sensing and vent line volumes in the closed system. Using these data, the free gas 
space under cold conditions can be calculated by subtracting the water volume from the total internal volume. Pressure is measured in the thermosyphon from transmitters located below the vessel and connected by water-filled lines when operating. For cold conditions, the height of the water above the transmitter - nominally $1,319 \mathrm{~mm}$ of $\mathrm{H}_{2} \mathrm{O}(12.9 \mathrm{kPa})$ - should be subtracted from the pressure reading to get the actual cover gas pressure.

To perform a test of the thermosyphon, the loop circulating pump is turned on, and the flow rate is set to a specified value, usually $1.2 \mathrm{~L} / \mathrm{s}$. Loop pressure is increased by adding gas to the headspace of the gas pressurizer. Valves to the chilled water supply on the heat exchanger are opened, and the temperature control is placed in automatic mode with a set point of $49^{\circ} \mathrm{C}$. Power from the thermosyphon is required to bring the loop inlet temperature up from room temperature conditions to $49^{\circ} \mathrm{C}$. The power supply is turned on and FRS power increased to $\sim 6-8 \mathrm{~kW}$ and held until the loop inlet temperature reaches the set point temperature.

Several different types of tests were performed to characterize thermosyphon performance. Some tests involved stepping up the FRS power in increments of a few $\mathrm{kW}$, holding until steady state temperatures were reached, and then repeating this sequence until a total power of $\sim 80 \mathrm{~kW}$ was reached. Other tests involved using an automatic ramp/soak program in the control system to mimic a HFIR-type startup, where a series of power increases are followed by hold periods at constant power level as the reactor is brought to full power. For these tests, the power ramp rate is set to match the HFIR case, but the hold periods are shortened for convenience (since the thermosyphon reaches steady state fairly rapidly). A HFIR loss of offsite power (LOOP) transient was also simulated to assess performance under this limiting condition. A summary of tests performed is shown in Table 5-1. The initial thermosyphon water fill and gas type/pressure conditions are listed, along with a brief description of the type of test. Many initial tests were step increase tests to allow the thermosyphon to be characterized while power was slowly increased. Temperature limits were set on the FRS sheath thermocouples relatively close to the expected maximum temperatures to protect the FRSs in the event of a critical heat flux (CHF) temperature excursion.

The first few tests were performed with a vacuum on the system and resulted in CHF at relatively low power. The water level was increased as a variation on the initial conditions, but similar results were obtained. Adding cover gas provided a solution to the CHF issue and was the focus of extensive parametric variations during the testing sequence. Helium and argon were both used as a cover gas, and initial pressure was varied for both types. Near the end of the testing program, the level of vacuum required to produce $\mathrm{CHF}$ in the thermosyphon was also investigated.

\subsubsection{Step-Increase Tests}

Many tests involved making step increases in power while observing the thermosyphon vessel's response. These were generally steps of $5 \mathrm{~V}$ on the power supply or a few $\mathrm{kW}$ in power, depending on the control mode of the power supply being used. After the increase, the fluid and sheath temperatures were monitored, along with the differential pressure across the flow orifices (DPT-2). Once steady state values were observed, the power would be stepped up again. The loop conditions were maintained automatically by the control system to provide constant flow rate and inlet temperature, so the input power to the FRSs was the only parameter being changed. Cover gas pressure was only modified under cold non-powered conditions.

\subsubsection{HFIR Startup Tests}

The HFIR reactor is started up in multiple power steps and hold periods. For the thermosyphon, it was of interest to verify that the power ramp rates did not cause a stability problem. For the HFIR startup tests, the loop and thermosyphon were prepared in a manner similar to that used for the step-increase tests, 
including the loop heatup to $49^{\circ} \mathrm{C}$ using the FRSs at low power. Prior to starting the test, the FRS power would be set back to $0 \mathrm{~kW}$. The multistep ramp and hold recipe was programmed in the RSLogix software to match the power ramp rates of the normal HFIR startup, although hold periods were shorter than the period for normal HFIR startup for convenience. The program included (1) the multistep sequence to full power (which is nominally $80 \mathrm{~kW}$ for the thermosyphon), (2) a hold at full power, and (3) a controlled ramp down to zero power. The test is initiated by placing the ramp/soak control in auto mode. Along with the normal HFIR startup, a test was also conducted with the power steps at twice the normal HFIR power ramp rates.

\subsubsection{LOOP Transient Tests}

The LOOP transient tests were performed by attempting to match the water flow rate and FRS power profiles to a previously analyzed HFIR LOOP transient. The power profile could be matched fairly easily using a ramp/soak profile in the PLC that controls the output of the power supply. However, ramping down the pump speed using the variable speed drive did not provide the desired flow profile. The deceleration rate was not fast enough. The closest approximation was achieved by fully opening a manual $\mathrm{V}$-notch control valve on the bypass line-HCV-3 - and increasing the pump speed to get the desired initial flow rate of $1.2 \mathrm{~L} / \mathrm{s}$ (see Figure 4-17). To initiate the transient, the HCV-2 control valve on the return line from the thermosyphon assembly was quickly closed to a specified position to match the minimum flow rate at the end of the simulation. As measured by FT-1, the change in flow below a set limit value was used to automatically initiate the ramp/soak profile on the power supply. The method worked fairly well in synchronizing the flow and power profiles. The flow measurement was obtained from an electromagnetic-type flow meter, but the response time was not fast enough to accurately capture the flow rate decrease. The differential pressure transmitter (DPT-1) had a much faster response time and can be used to some extent to characterize the actual flow decrease. Separate flow vs. differential pressure measurements were made to characterize this relationship (Sect. 4.5). To improve this type of test in the future, it is recommended that a faster response flow meter be installed. Results of the LOOP transient tests are described later in the report.

\subsection{EXPERIMENTAL DATA}

Data were collected in log files using the Allen Bradley RSView32 software that is part of the Controllogix system. A file was collected at $1 \mathrm{~s}$ intervals for most of the tests. In addition, a second log file was collected at $100 \mathrm{~ms}$ intervals (in practice at $\sim 110 \mathrm{~ms}$ ) for the transient tests and for other cases in which higher time resolution was warranted. Data logged includes all of the instruments listed in Table 4-2, as well as some operational parameters such as pump speed and pump speed set point, power supply current and voltage set points, and the temperature control valve position set point. The primary data collected are described in more detail in this section. The test names shown in the first column of Table 5-1 are the same as the data file name with the word fast added, indicating the $100 \mathrm{~ms}$ data files that are available.

Power input into the FRSs is calculated from voltage and current measurements. Individual current measurements-IT-FRS1, IT-FRS2 and IT-FRS3 - were made for each FRS. A voltage measurement, VT-FRS, was made across the power clamps for FRS-1 and was used as the voltage for all three FRSs in the power calculation since they are connected in parallel to the power supply output bus. This voltage measurement is closer to the FRSs than the power supply output voltage of VT-1 that is measured across the output bus, and it is the preferred measurement for the power calculation. A total current from the power supply, IT-1, is also available for comparison. Total power is calculated from the sum of individual FRS current multiplied by voltage measurements (e.g., IT-FRS $1 \times$ VT-FRS). This is the preferred calculation. Total power can also be calculated from the power supply total current and power supply output voltage $(\mathrm{IT}-1 \times \mathrm{VT}-1)$, but this will include power losses from the bus to the power clamps. 
Fluid thermocouples are located inside of the thermosyphon vessel with the axial locations shown in Figure 5-1. The lower two thermocouples, TE-45 and TE-46, penetrate the flow separator wall at $90^{\circ}$ and extend into the region between the FRSs. TE-44 is located axially just above the end of the FRSs and also penetrates the flow separator and extends at $90^{\circ}$ into the fluid. The three other fluid thermocouples are part of a twisted wire bundle that extends through the condenser region and through the Conax fitting at the top of the condenser. The thermocouples are bent at $90^{\circ}$ and extend into the condenser space at intervals along the axial length.

Pressure in the thermosyphon is measured by two transmitters, PT-6 and PT-7, and a differential pressure transmitter, DPT-2, located on the $6.35 \mathrm{~mm}$ OD sensing lines that extend from the bottom of the vessel. By installing on the bottom, the sensing lines are cooled by loop flow and remain liquid filled. Pressure transmitters were not connected to the top of the vessel to avoid the transmitter cooling issue and the significant additional gas/vapor space volume that would have been effectively included in the condenser volume. PT-7 and the high side of the differential pressure transmitter DPT-2 are connected to the sensing line that extends to the annulus between the thermosyphon vessel wall and flow separator at the bottom of the evaporator region. PT- 6 and the low side of DPT-2 are connected to the sensing line that extends to the inside of the flow separator at the bottom of the evaporator region. With this configuration, DPT-2 is measuring the differential pressure across the flow orifices in the lower evaporator region. This measurement, along with the fluid thermocouples in the lower evaporator region, provided an excellent indication of the start of flow circulation in the thermosyphon vessel.

The six sheath thermocouples on each FRS provide heater wall temperature data over the axial heated length. Sheath thermocouples TE-11-TE-16 are located in FRS-1, TE-21-TE-26 are located in FRS-2, and TE-31-TE-36 are located in FRS-3. These temperatures are used in the analysis to determine local wall conditions and to provide high temperature limits for protecting the FRSs.

As noted earlier, the loop provides the simulated HFIR boundary conditions to the thermosyphon. Flow to the annulus between the outer vessel and the thermosyphon vessel is measured by FT-1. Inlet pressure (PT-2), inlet temperature (TT-1), outlet temperature (TT-2), and a differential pressure across the inlet and outlet lines (DPT)-1, all provide the remaining information needed to determine the cooling water properties on the outside wall of the thermosyphon vessel.

The amount of gas charged in each test was calculated from the initial condenser free volume, pressure, and temperature. The values for these data are given Table 5-1. 
Table 5-1. Summary of test data.

\begin{tabular}{|c|c|c|c|c|c|c|c|}
\hline \multicolumn{2}{|l|}{ TSTL Test Index } & \multicolumn{6}{|l|}{ Thermosypon } \\
\hline Test Name $\quad$ (file name)) & Loop Flow Rate (I/s) & $\begin{array}{l}\text { Water Charge } \\
\text { (g) }\end{array}$ & \begin{tabular}{|c|} 
Initial Gas \\
Space Pressure \\
(kPa)
\end{tabular} & $\begin{array}{c}\text { Initial Gas } \\
\text { Temp (degC) }\end{array}$ & $\begin{array}{c}\text { Gas Charge } \\
\text { (g) }\end{array}$ & Gas Type & Test Type \\
\hline TS-140818-1 & 1.2 & 1113 & 5.8 & 21 & & n/a & Step increase to $12 \mathrm{~kW}$ (nominal 5V steps) CHF Vacuum \\
\hline TS-140818-2 & 1.2 & 1113 & 5.8 & 21 & & n/a & Step increase to $10 \mathrm{~kW}$ (nominal 5V steps) CHF Vacuum \\
\hline TS-140819-1 & 1.2 & 1639.4 & 5.8 & 20 & & $n / a$ & Step increase to $10 \mathrm{~kW}$ (nominal 5V steps) CHF Vaccum \\
\hline TS-140820-1 & 1.2 & 1639.4 & 85.7 & 19 & 0.61 & $\mathrm{He}$ & Step increase to $80 \mathrm{~kW}$ (nominal 5V steps) \\
\hline TS-140821-1 & 1.2 & 1113.8 & 98.8 & 19 & 0.79 & $\mathrm{He}$ & Step increase to $80 \mathrm{~kW}$ (nominal 5V steps) \\
\hline TS-140821-2 & 1.2 & 1113.8 & 295.3 & 25 & 2.32 & $\mathrm{He}$ & Step increase to $80 \mathrm{~kW}$ (nominal $5 \mathrm{~V}$ steps) \\
\hline TS-140821-3 & 1.2 & 1113.8 & 642.8 & 22 & 5.10 & $\mathrm{He}$ & Step increase to $80 \mathrm{~kW}$ (nominal 5V steps) \\
\hline TS-140822-1 & 1.2 & 1113.8 & 918.6 & 19 & 7.37 & $\mathrm{He}$ & Step increase to $80 \mathrm{~kW}$ (nominal $5 \mathrm{~V}$ steps) \\
\hline TS-140822-2 & 1.2 & 1113.8 & 1125 & 21 & 8.96 & $\mathrm{He}$ & Step increase to $80 \mathrm{~kW}$ (nominal $5 \mathrm{~V}$ steps) \\
\hline TS-140822-3 & 1.2 & 1113.8 & 1342 & 19 & 10.8 & $\mathrm{He}$ & Step increase to $80 \mathrm{~kW}$ (nominal 5V steps) \\
\hline TS-140828-1 & 1.2 & 1113.8 & 1644 & 19 & 13.2 & $\mathrm{He}$ & Step increase to $80 \mathrm{~kW}$ (nominal 5V steps) \\
\hline TS-140828-2 & 1.2 & 1113.8 & 2162 & 21 & 17.2 & $\mathrm{He}$ & Step increase to $80 \mathrm{~kW}$ (nominal 5V steps) \\
\hline TS-140829-1 & 1.2 & 1113.8 & 2848 & 18 & 22.9 & $\mathrm{He}$ & Step increase to $80 \mathrm{~kW}$ (nominal 5V steps) \\
\hline TS-140902-1 & 1.2 & 1113.8 & 2851 & 19 & 22.9 & $\mathrm{He}$ & HFIR Startup Sequence (aborted due to PID control issue on PS) \\
\hline TS-140902-2 & 1.2 & 1113.8 & 2851 & 19 & 22.9 & $\mathrm{He}$ & Step increase to $80 \mathrm{~kW}$ \\
\hline TS-140902-3 & 1.2 & 1113.8 & 2851 & 19 & 22.9 & $\mathrm{He}$ & HFIR Startup Sequence \\
\hline TS-140904-1 & 1.2 & 1113.8 & 1482 & 19 & 11.9 & $\mathrm{He}$ & HFIR Startup Sequence (terminated early due to FRS failure) \\
\hline TS-140910-1 & 1.2 & 1117.2 & 107.7 & 19 & 8.62 & Ar & Step increase to $80 \mathrm{~kW}$ \\
\hline TS-140911-1 & 1.2 & 1117.2 & 1643 & 20.5 & 131 & Ar & Step increase to $80 \mathrm{~kW}$ \\
\hline TS-140911-2 & 1.2 & 1117.2 & 2071 & 22 & 164 & Ar & Step increase to $80 \mathrm{~kW}$ \\
\hline TS-140911-3 & 1.2 & 1117.2 & 2071 & 22 & 164 & Ar & HFIR Startup Sequence \\
\hline TS-140912-1 & variable & 1117.2 & 784.8 & 20 & 62.6 & Ar & Flow vs PDT- 1 data at $\sim 29$ degC \\
\hline TS-140912-2 & 1.2 & 1117.2 & 784.8 & 20 & 62.6 & Ar & Step increase to $80 \mathrm{~kW}$, varied loop flow 0.8 to $1.1 \mathrm{l} / \mathrm{s}$ at $80 \mathrm{~kW}$ \\
\hline TS-140912-3 flow correlatior & variable & 1117.2 & 784.8 & 20 & 62.6 & Ar & Flow vs PDT- 1 data at $\sim 49 \mathrm{deg} C$ \\
\hline TS-140912-4 & 1.2 & 1117.2 & 784.8 & 20 & 62.6 & Ar & HFIR Startup Sequence \\
\hline TS-140916-1 & 1.1 initial & 1117.2 & 2054 & 22 & 163 & Ar & Heat up to LOOP transient -aborted due to power supply trip on TE- 24 \\
\hline TS-140917-1 & 1.05 & 1117.2 & 2054 & 22 & 163 & $\operatorname{Ar}$ & Step increase to $80 \mathrm{~kW}$ (aborted due to power supply trip at $46 \mathrm{~kW}$ ) \\
\hline TS-140917-2 & 1.05 & 1117.2 & 2054 & 22 & 163 & $\operatorname{Ar}$ & Step increase to $80 \mathrm{~kW}$ (to LOOP initial conditions) \\
\hline TS-140917-2 fast & & & & & & & $100 \mathrm{~ms}$ data including FRS3 current increase at 10:23:29 \\
\hline TS-140919-1 & 1.05 & 1114.2 & 2856 & 18 & 23.0 & $\mathrm{He}$ & Step increase (trip at $7.9 \mathrm{~kW}$ due to TE- $24 \mathrm{HH}$ limit) \\
\hline TS-140919-2 fast & 1.05 & 1114.2 & 2856 & 18 & 23.0 & $\mathrm{He}$ & No Power (TE-24 signal indicating bad t/c) \\
\hline TS-140919-3 & $1.2-1.05$ & 1114.2 & 2856 & 18 & 23.0 & $\mathrm{He}$ & Step increase to $81 \mathrm{~kW}$ (with smaller increment power down) \\
\hline TS-140919-LOOP & 1.05 initial & 1114.2 & 2856 & 18 & 23.0 & $\mathrm{He}$ & Initial check of LOOP transient test sequence (100 ms data) \\
\hline TS-140919-80 kW transient & 1.05 initial & 1114.2 & 2856 & 18 & 23.0 & $\mathrm{He}$ & Jump to $80 \mathrm{~kW}$ from 0 Power (inadvertent) - shut off after $\sim 5 \mathrm{~s}$ \\
\hline TS-140923-1 & $1.2(1.1-1.3$ at $81 \mathrm{~kW})$ & 1114.2 & 2857 & 19 & 22.9 & $\mathrm{He}$ & Step Increase to $81 \mathrm{~kW}$ (flow variation $1.1-1.3 \mathrm{l} / \mathrm{s}$ at $81 \mathrm{~kW}$ ) \\
\hline TS-140923-2 & 1.2 & 1114.2 & 2857 & 19 & 22.9 & $\mathrm{He}$ & HFIR Startup Sequence \\
\hline TS-140923-2 fast & & & & & & & $100 \mathrm{~ms}$ data file \\
\hline TS-140924-1 & 1.2 & 1114.2 & 2857 & 19 & 22.9 & $\mathrm{He}$ & HFIR Startup Sequence \\
\hline TS-140925-1 & 1.2 & 1114.2 & 2857 & 19 & 22.9 & $\mathrm{He}$ & HFIR Startup Sequence (Ramp/Soak: Voltage set point w/o PID) \\
\hline TS-140925-1 fast & & & & & & & 100 ms data file \\
\hline TS-140925-2 & 1.2 & 1114.2 & 2857 & 19 & 22.9 & $\mathrm{He}$ & HFIR Startup Sequence with $2 \times$ ramp rate \\
\hline TS-140925-2 fast & & & & & & & $100 \mathrm{~ms}$ data file \\
\hline TS-140925-3 & 1.2 & 1114.2 & 1465 & 22 & 11.6 & $\mathrm{He}$ & HFIR Startup Sequence (Ramp/Soak: Voltage set point w/o PID) \\
\hline TS-140925-3 fast & & & & & & & $100 \mathrm{~ms}$ data file \\
\hline TS-140925-4 & 1.2 & 1114.2 & 106.4 & 21 & 0.85 & $\mathrm{He}$ & HFIR Startup Sequence (Ramp/Soak: Voltage set point w/o PID) \\
\hline TS-140925-4 fast & & & & & & & $100 \mathrm{~ms}$ data file \\
\hline TS-140926-1 & 1.2 & 1114.2 & 97.9 & 21 & 0.78 & $\mathrm{He}$ & Step Increase to $81 \mathrm{~kW}$ (with $1 \mathrm{~V} / \mathrm{s}$ ramp rate limit) Vacuum \\
\hline TS-140926-1 fast & & & & & & & $100 \mathrm{~ms}$ data file \\
\hline $\begin{array}{l}\text { TS-140926-2 } \\
\text { TS-140926-2 fast }\end{array}$ & 1.2 & 1114.2 & 84.4 & 21 & 0.67 & $\mathrm{He}$ & $\begin{array}{l}\text { Step Increase to } 81 \mathrm{~kW} \text { (with } 0.5 \mathrm{~V} / \mathrm{s} \text { ramp rate limit) Vacuum } \\
100 \mathrm{~ms} \text { data file }\end{array}$ \\
\hline TS-140926-3 & 1.2 & 1114.2 & 67.5 & 22 & 0.54 & $\mathrm{He}$ & Step Increase to $81 \mathrm{~kW}$ (with $0.5 \mathrm{~V} / \mathrm{s}$ ramp rate limit) Vacuum \\
\hline TS-140926-3 fast & & & & & & & $100 \mathrm{~ms}$ data file \\
\hline TS-140926-4 & 1.2 & 1114.2 & 50.5 & 21.5 & 0.40 & $\mathrm{He}$ & Step Increase to $81 \mathrm{~kW}$ (with $0.5 \mathrm{~V} / \mathrm{s}$ ramp rate limit) Vacuum \\
\hline TS-140926-4 fast & & & & & & & 100 ms data file \\
\hline TS-140929-1 & 1.2 & 1114.2 & 33.6 & 19 & 0.27 & $\mathrm{He}$ & Step Increase to $81 \mathrm{~kW}$ (with $0.5 \mathrm{~V} / \mathrm{s}$ ramp rate limit) Vacuum \\
\hline TS-140929-1 fast & & & & & & & $100 \mathrm{~ms}$ data file \\
\hline TS-140929-2 & 1.2 & 1114.2 & 16.7 & 21 & 0.13 & $\mathrm{He}$ & Step Increase to $81 \mathrm{~kW}$ (with $0.5 \mathrm{~V} / \mathrm{s}$ ramp rate limit) Vacuum \\
\hline TS-140929-2 fast & & & & & & & $100 \mathrm{~ms}$ data file \\
\hline TS-140929-3 & 1.2 & 1114.2 & 5.8 & 21 & 0.05 & $\mathrm{He}$ & Step Increase to $81 \mathrm{~kW}$ (with $0.5 \mathrm{~V} / \mathrm{s}$ ramp rate limit) CHF Vacuum \\
\hline TS-140929-3a fast & & & & & & & $100 \mathrm{~ms}$ data file Possible CHF - Trip on TE- $12 \mathrm{HH}$ Limit at $350 \mathrm{deg} \mathrm{C}$ \\
\hline TS-140929-3b fast & & & & & & & $100 \mathrm{~ms}$ data file CHF - Trip on TE-31 HH Limit at $350 \mathrm{degC}$ \\
\hline TS-140929-4 & 1.05 initial & 1114.2 & 2846 & 19 & 22.8 & $\mathrm{He}$ & LOOP Transient (power-up and transient) \\
\hline TS-140929-4 LOOP & & & & & & & $100 \mathrm{~ms}$ data ( LOOP transient portion) \\
\hline TS-140930-1 & 1.05 initial & 1114.2 & 2846 & 19 & 22.8 & $\mathrm{He}$ & LOOP Transient (power-up and transient) \\
\hline TS-140930-1 LOOP & & & & & & & 100 ms data ( LOOP transient portion) \\
\hline TS-140930-2 & 1.2 & 1114.2 & 2846 & 19 & 22.8 & $\mathrm{He}$ & Step increase to $92.7 \mathrm{~kW}$ ( $160 \mathrm{~V}$ - power supply rating) \\
\hline TS-140930-2 fast & & & & & & & 100 ms data file \\
\hline TS-140930-3 & 1.2 & 1114.2 & 2037 & 20 & 163 & Ar & Step increase to $84 \mathrm{~kW}$ \\
\hline TS-140930-3 fast & & & & & & & $100 \mathrm{~ms}$ data file \\
\hline
\end{tabular}




\section{EXPERIMENTAL PROGRAM DATA ANALYSIS}

This section describes the most relevant data, analysis of the data and interpretation of the results. Note that in the figures of this section and in figures 7-13 to 7-48 of Section 7, the initial gas pressure reported is not adjusted for the liquid head as performed in Table 5-1. In order to match the pressures listed in Table 5-1, subtract $12.9 \mathrm{kPa}$ from the value given on the figure.

\subsection{RECIRCULATION FLOW RATE}

The flow rate in the thermosyphon is not measured directly. However, there is an orifice at the bottom of the assembly in which the outer recirculation flow returns to the center heated region. A detail of this region of the flow separator is shown in Figure 6-1. Outside the flow separator is a $50.8 \mathrm{~mm}$ (2 in) schedule 80 piping with an ID of $49.2 \mathrm{~mm}$ (1.94 in), and three heater rods with an OD of $9.5 \mathrm{~mm}(0.374$ in) are located inside the flow separator.

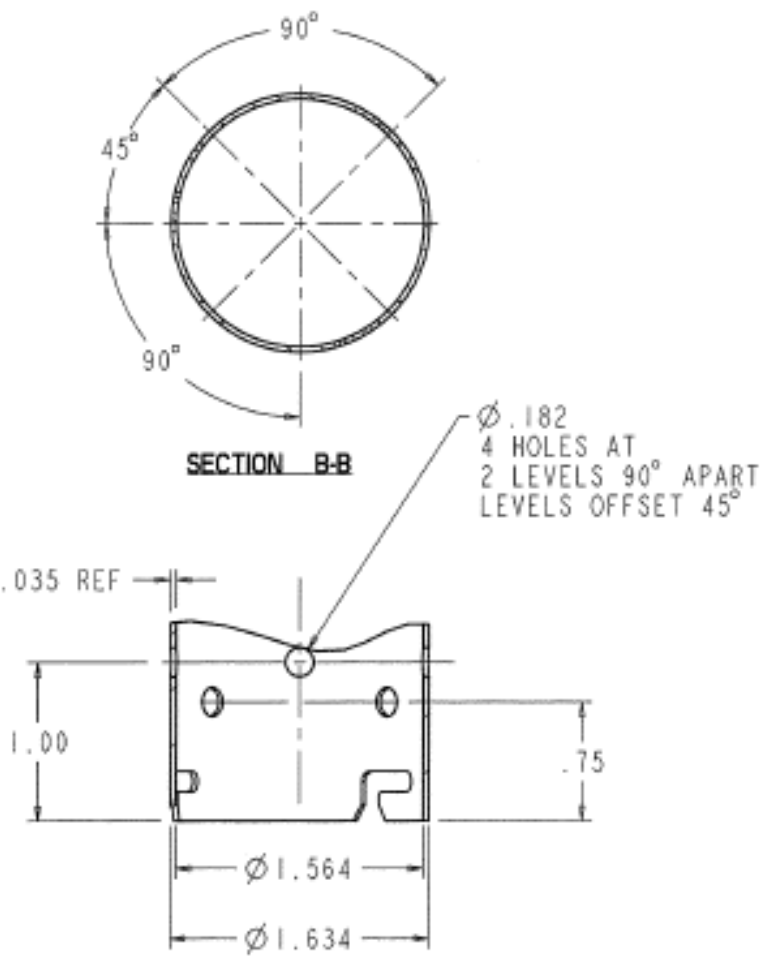

Figure 6-1. Flow separator detail showing lower flow orifice (in inches).

Figure 6-2 shows the pressure drop across the orifice for several test cases. The downcomer and evaporator are both hydraulically connected to the gas blanket so that all three regions share the same pressure boundary condition. For a given power, as the initial gas blanket pressure increases, the volume of bubbles generated and the void fraction in the evaporator decrease. For a given initial gas blanket pressure, as the power increases, the volume of bubbles generated and the void fraction in the evaporator increase.

In general, the differential pressure between the evaporator and downcomer is dominated by the differences in static head. Thus, the differential pressure decreases with decreasing void fraction in the evaporator (i.e., increasing system pressure, or decreasing power). For high void fractions, (i.e., low system pressure and high powers) the frictional and acceleration losses become larger contributors to the 
pressure drop across the evaporator. Thus, the pressure differential between the evaporator and downcomer slowly decreases as the power increases (observed in the 0.01 MPa trend shown in Figure 6-2). Other factors such as subcooling in the downcomer, possible vapor carryover into the downcomer, and flow regime transitions complicate the description of the system response.

Mass flow rates through the orifice are not measured directly. The OFTF described in Sect. 4.5 measured orifice flow rates versus orifice pressure drops.

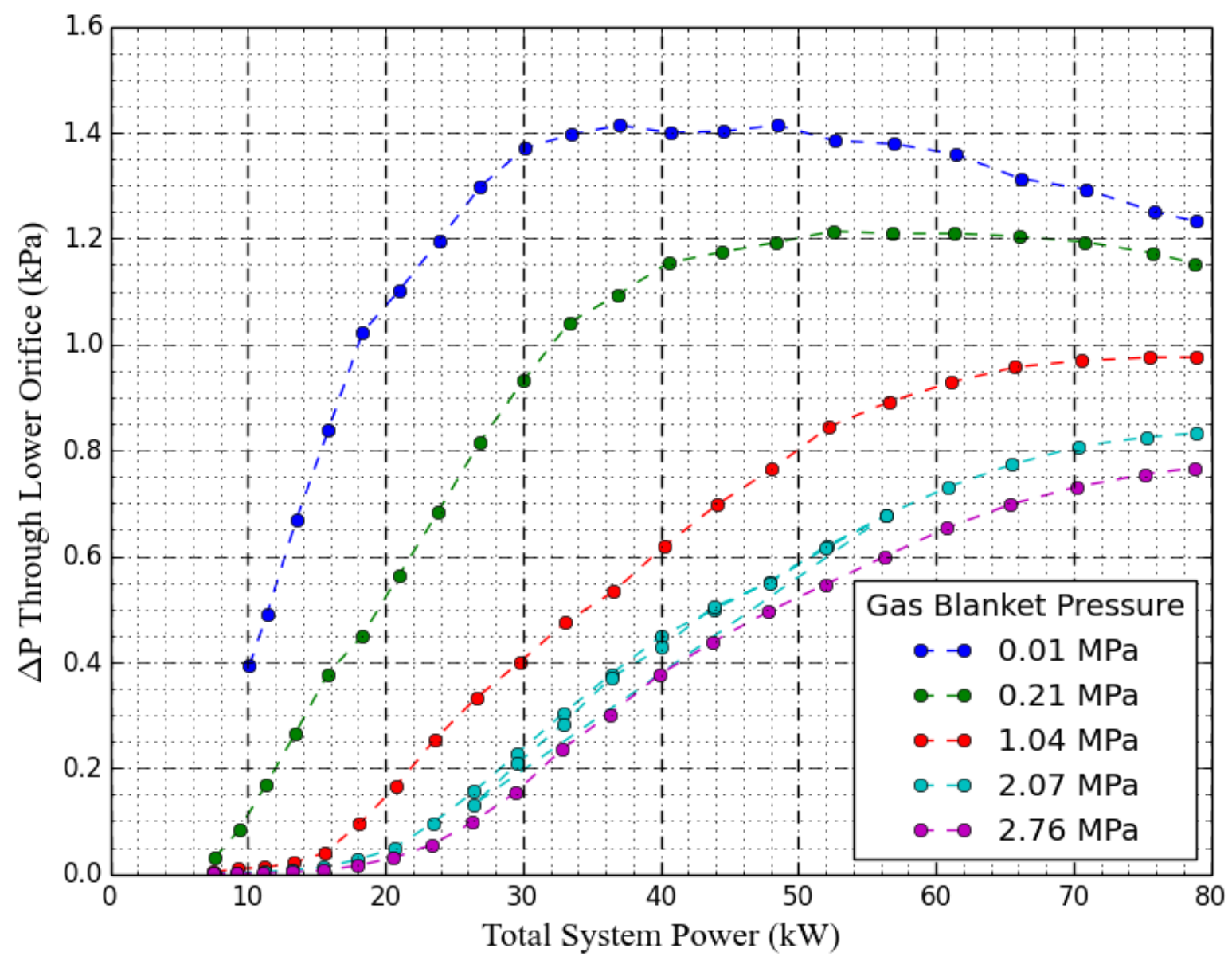

Figure 6-2. Pressure drop through the lower orifice for several tests.

\subsection{LOW PRESSURE OPERATION}

One of the first experiments at the TSTL was conducted with no inert backfill gas so that the initial system pressure was the water saturation pressure at the initial coolant temperature. At this low pressure, the bubbles generated on the FRSs were quite large, which led to a CHF condition early in the test. The data traces for the top thermocouple in each of the three FRSs are shown in Figure 6-3. Thermocouple TE-31 clearly shows a CHF event at about $9.6 \mathrm{~kW}$ total power. The test was repeated two more times with similar results in which the CHF occurred at total powers between 9.6-11.6 kW. The conditions at the CHF point are summarized in Table 6-1. 
After the initial tests were conducted under steam-only conditions, a series of tests was conducted at decreasing vacuum conditions adding helium up to $1 \mathrm{~atm}$, and the results are shown in Figure 6-4. Except for the lowest pressure condition tested ( $\sim \mathrm{kPa}$, or 28.2 in $\mathrm{Hg}$ vacuum), every test successfully reached $80 \mathrm{~kW}$ system power without resulting in $\mathrm{CHF}$ (at initial pressures of or above $16.7 \mathrm{kPa}$ ).

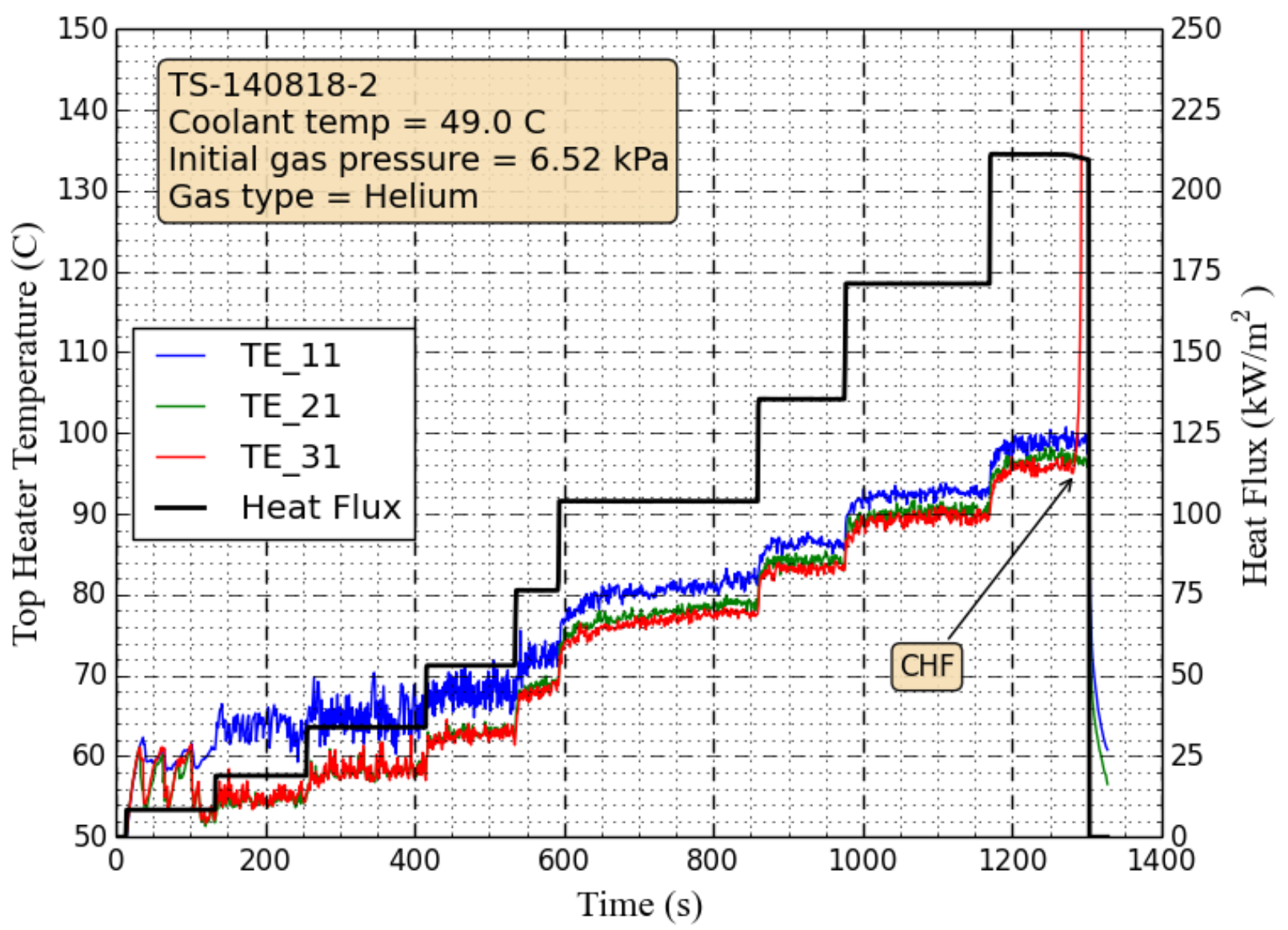

Figure 6-3. Temperature trace for the top three heater thermocouples in test TS-140818-2 showing CHF at a heat flux of $211 \mathrm{~kW} / \mathrm{m}^{2}$.

Table 6-1. Summary of conditions at CHF occurrence

\begin{tabular}{lccc}
\hline \multicolumn{1}{c}{ Parameter* } & TS-140818-1 & TS-140818-2 & TS-140819-1 \\
\hline Total system power $(\mathrm{kW})$ & $11.60 \pm 0.02$ & $9.60 \pm 0.01$ & $9.59 \pm 0.01$ \\
Heat flux $\left(\mathrm{kW} / \mathrm{m}^{2}\right)$ & $254.7 \pm 1.0$ & $211.0 \pm 0.8$ & $210.7 \pm 0.6$ \\
Condenser pressure $(\mathrm{kPa}, \mathrm{abs})$ & $42.2 \pm 0.7$ & $40.0 \pm 0.8$ & $37.9 \pm 0.7$ \\
Condenser temperature $\left({ }^{\circ} \mathrm{C}\right)$ & $77.1 \pm 0.4$ & $75.8 \pm 0.5$ & $74.5 \pm 0.4$ \\
Evaporator inlet subcooling $\left({ }^{\circ} \mathrm{C}\right)$ & $8.9 \pm 0.3$ & $8.8 \pm 0.4$ & $8.5 \pm 0.5$ \\
Estimated mass flow $(\mathrm{kg} / \mathrm{s})$ & $0.566 \pm 0.015$ & $0.542 \pm 0.014$ & $0.592 \pm 0.019$ \\
\hline
\end{tabular}

*All uncertainties are $2 \sigma$ 


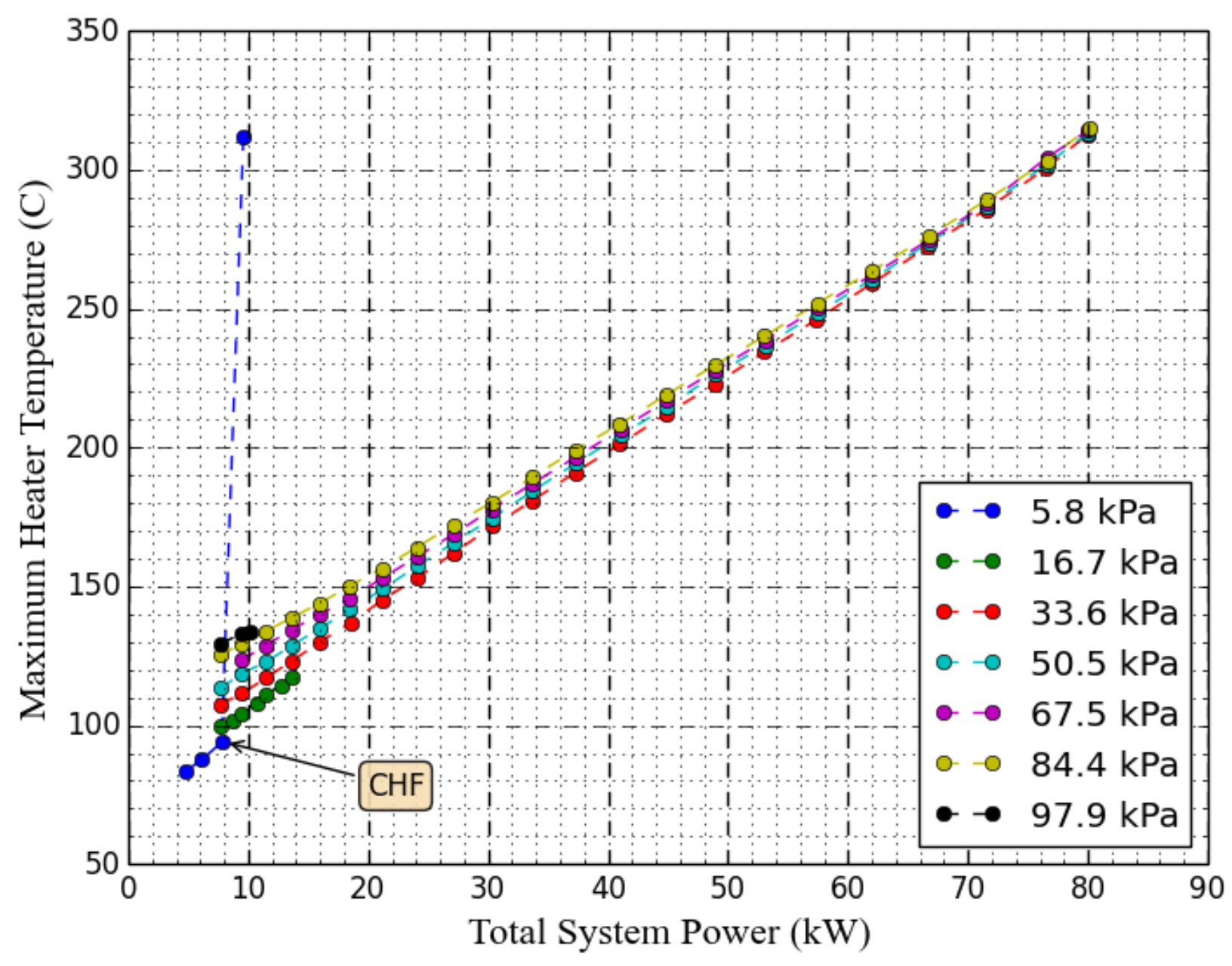

Figure 6-4. Maximum heater temperature for a series of tests at different condenser pressures.

\subsection{GAS PRESSURE EFFECT}

The tests performed in the TSTL confirm that the thermosyphon working temperature and pressure can be controlled by initially pressurizing the condenser with helium. Other investigators [5] reported that rather than mixing with the steam coming from the evaporator, the helium gas forms a bubble that stays at the top of the condenser. As the thermosyphon pressure rises, the helium bubble gets smaller, thereby increasing the available surface area for condensation.

Figure 6-5, which shows the three condenser thermocouple traces and the top evaporator trace as the power is increased, clearly shows how the helium and steam stay separated. At low powers $(<17 \mathrm{~kW} / \mathrm{m})$, all of the thermocouples are showing $50^{\circ} \mathrm{C}$, which is the primary coolant temperature, despite the fact that the steam temperature (TE-44) is significantly higher. Once the condenser pressure shrinks the helium gas bubble sufficiently $(\approx 12 \mathrm{~kW})$, TE-43 shows a sudden temperature increase in the working steam temperature. The same occurs for TE-42 at a much higher power/pressure level ( $\approx 24 \mathrm{~kW})$. The helium bubble is eventually small enough to expose TE-41 to steam at about $70 \mathrm{~kW}$, but it never reaches equilibrium. 

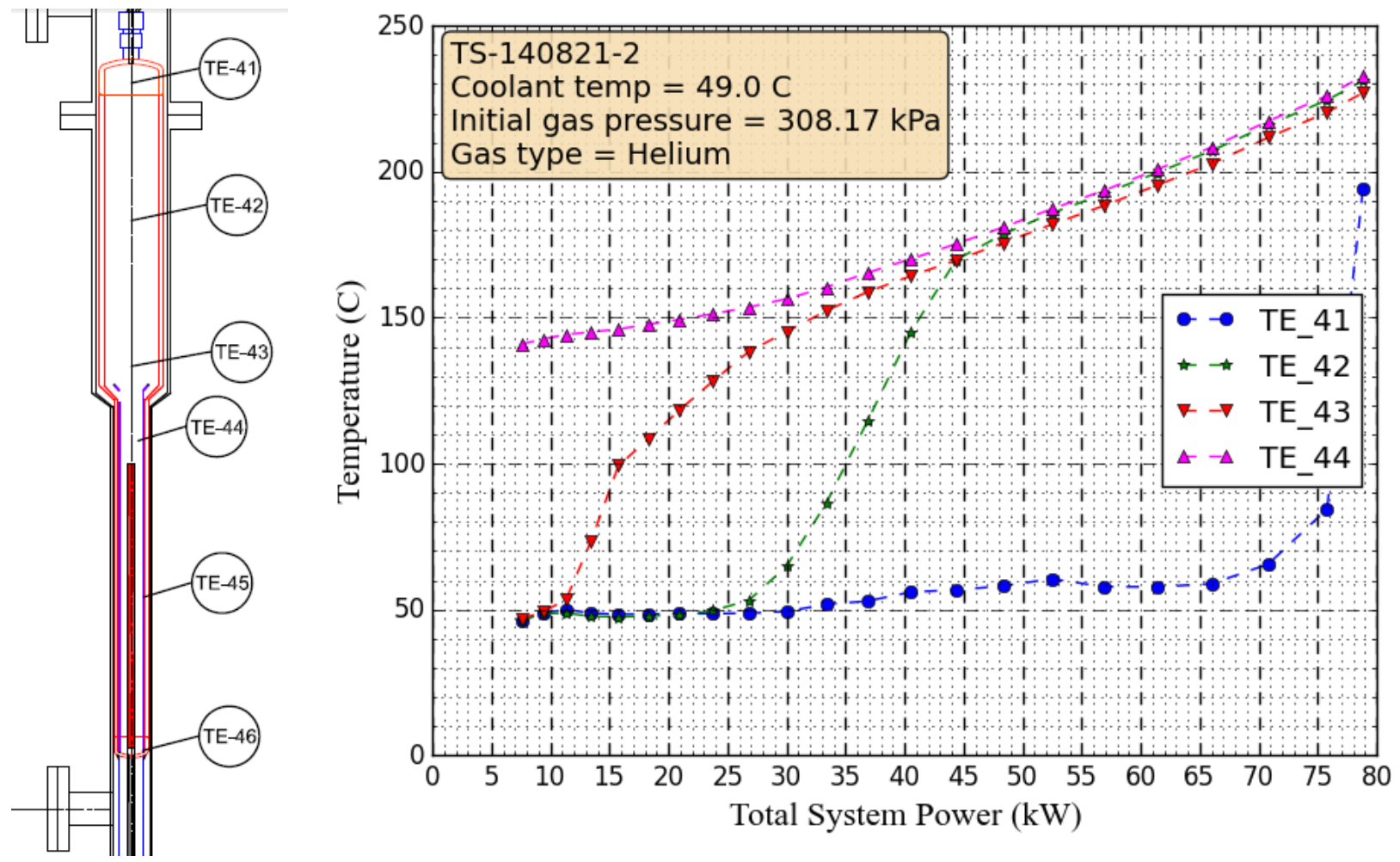

Figure 6-5. Condenser thermocouple traces showing clear separation of the steam and helium gases.

As shown in Figure 6-6 and Figure 6-7, the working condenser pressure and temperature can be controlled by varying the initial gas pressure. Between an initial gas fill pressure of $10 \mathrm{kPa}-2.8 \mathrm{MPa}$, the working condenser pressure and temperature at $80 \mathrm{~kW}$ total power ranged from about $2.4 \mathrm{MPa}-7.7 \mathrm{MPa}$ and $220-290{ }^{\circ} \mathrm{C}$, respectively. The maximum temperatures reached are the saturation temperatures for each pressure.

Figure 6-8 shows the water temperature range in the evaporator region for low and high pressure initial conditions. The higher pressure case shows a significantly larger temperature span from the bottom of the evaporator to the top because the smaller effective condensation area and resulting higher pressure and saturation temperatures results in more heat removal through the downcomer so that the recirculation flow is more subcooled. The same is true for cases with argon fill gas. The conclusion from this observation is that it is better to design a smaller condenser to operate with a lower noncondensable gas pressure than to rely on high gas pressures and a larger condenser to achieve high temperatures.

Although the TSTL thermosyphon is closed during operation, gas pressure can be varied during operation to exact more control over the thermosyphon operating condition. This can be accomplished by adding a gas feed and effluent line at the top of the thermosyphon and monitoring condenser temperatures. If the operating temperature at full power is lower than expected, the experimenter could raise the gas pressure in situ, thereby reducing the effective condenser area and raising the operating temperature.

Another possible option is to add an electric heater to the thermosyphon condenser. A gas blanket heater could raise the system pressure, albeit with a smaller possible operational range than directly adding gas pressure. An electric heater could be used to provide an initial pressurization sufficient to overcome the early CHF described earlier, although this was not tested in this set of experiments. 


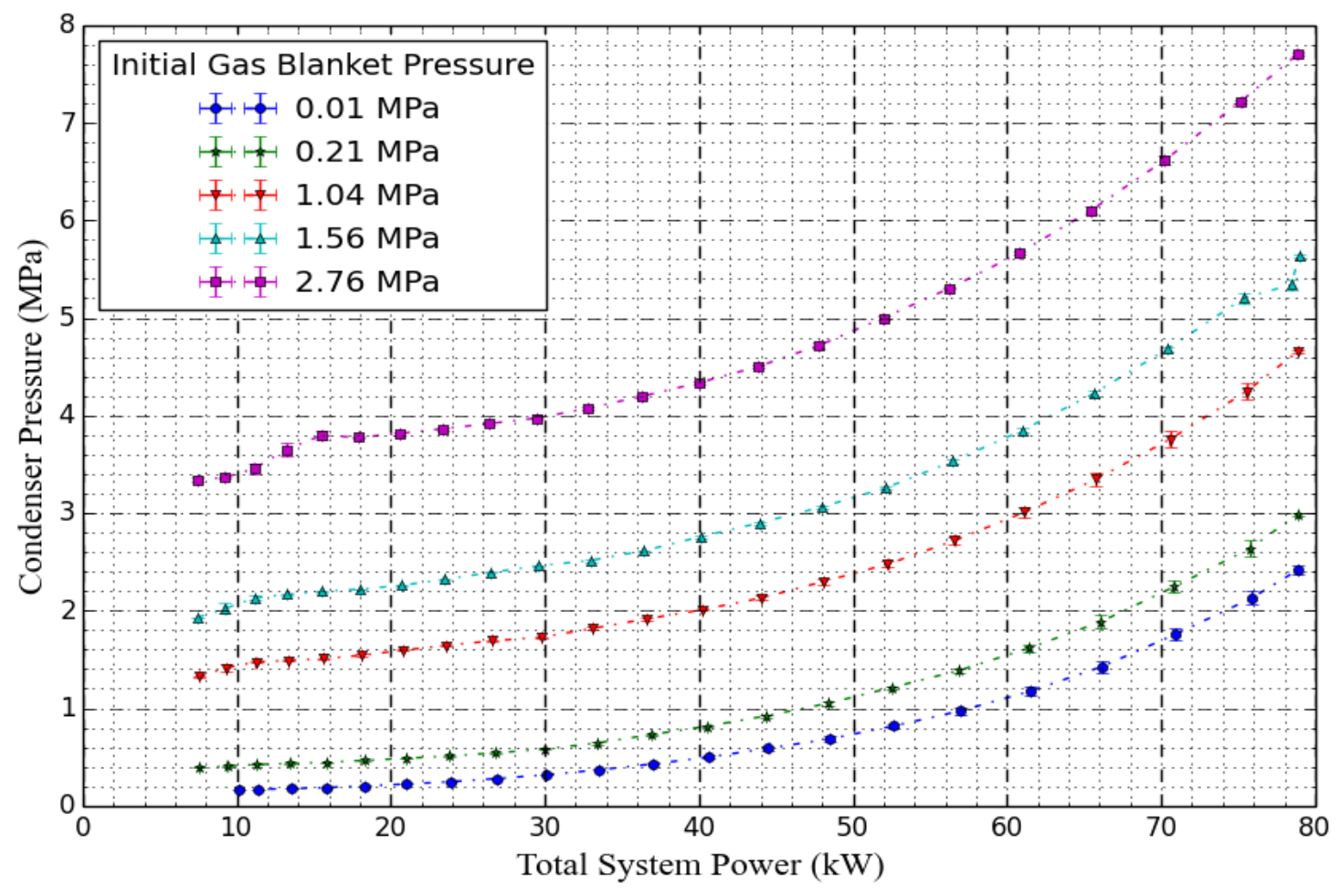

Figure 6-6. Condenser pressure for various starting helium gas blanket pressures.

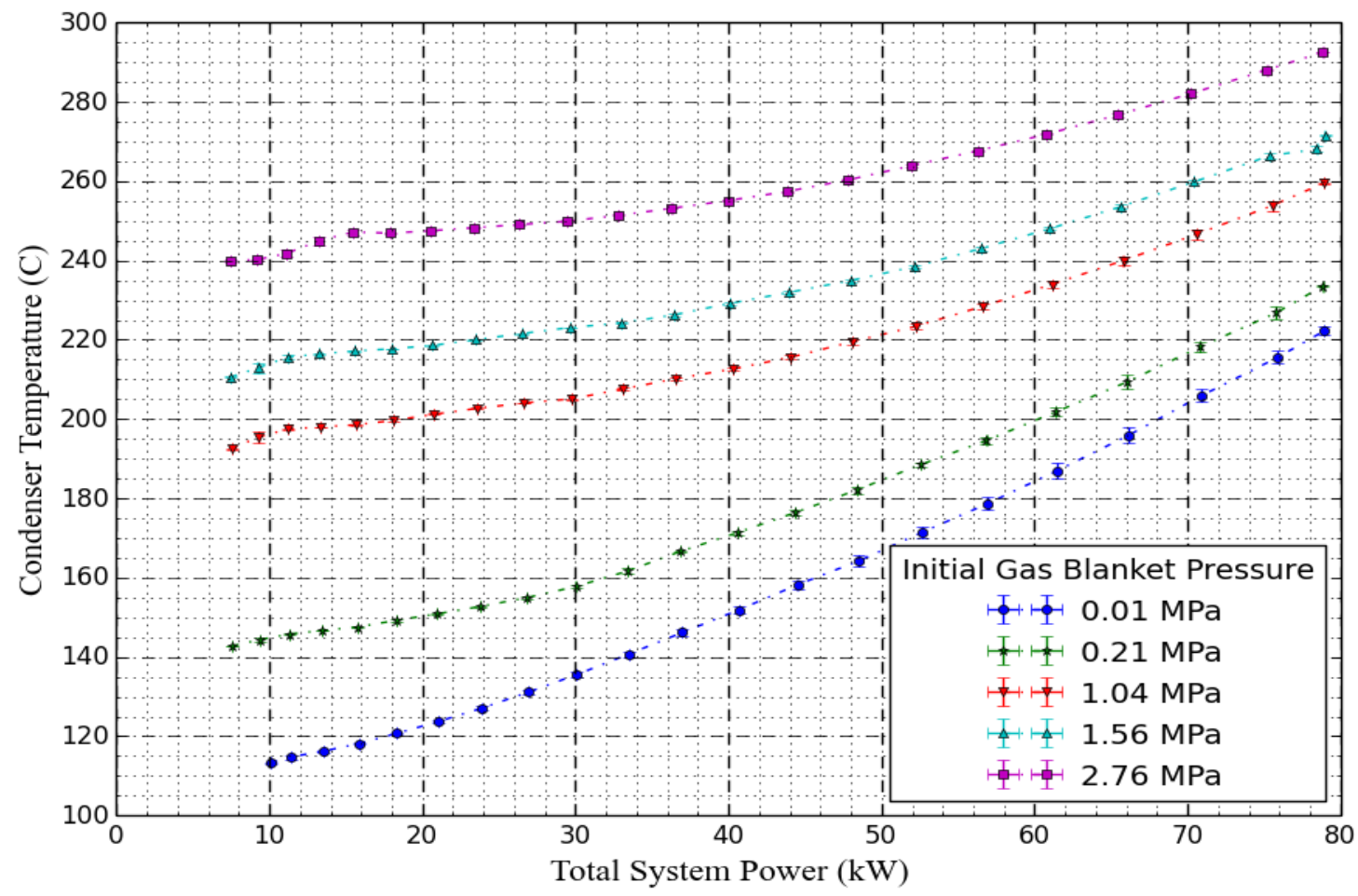

Figure 6-7. Condenser saturation temperature for various starting helium gas blanket pressures. 


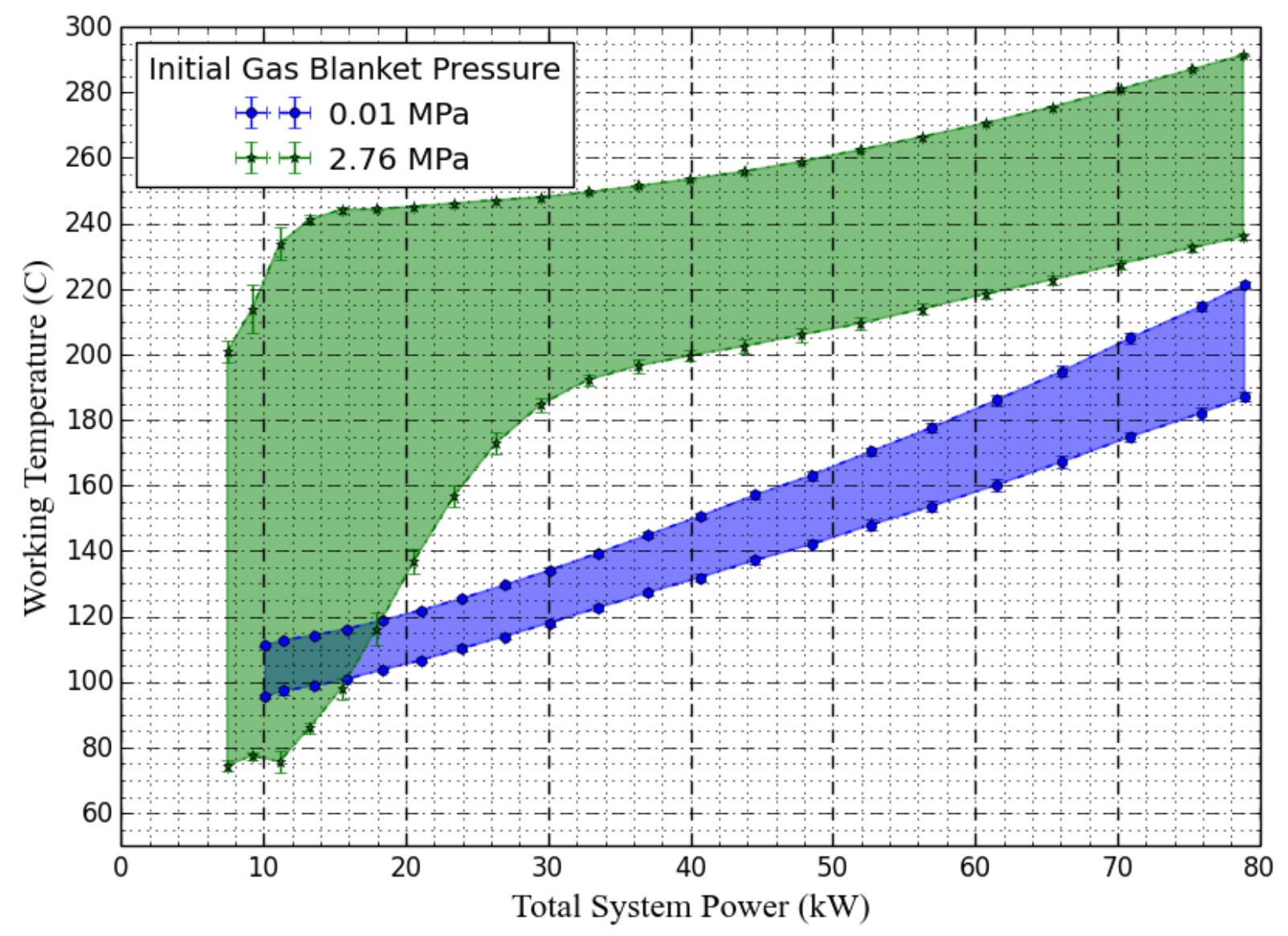

Figure 6-8. Evaporator working temperature range for two gas blanket pressures (0.01 MPa and 2.76 MPa).

\subsection{HYSTERESIS}

Figure 6-9, which shows the maximum heater temperature as a function of both ascending and descending power, demonstrates that the thermosyphon has little or no hysteresis. Other similar cases showed similar results. There does not appear to be any history dependence on the steady-state state-space. Similarly, Figure 6-10 shows the condenser operating pressure for rising and falling power for two tests performed on different days under the same conditions. Again, there is no evidence for history dependence on the experimental results. 


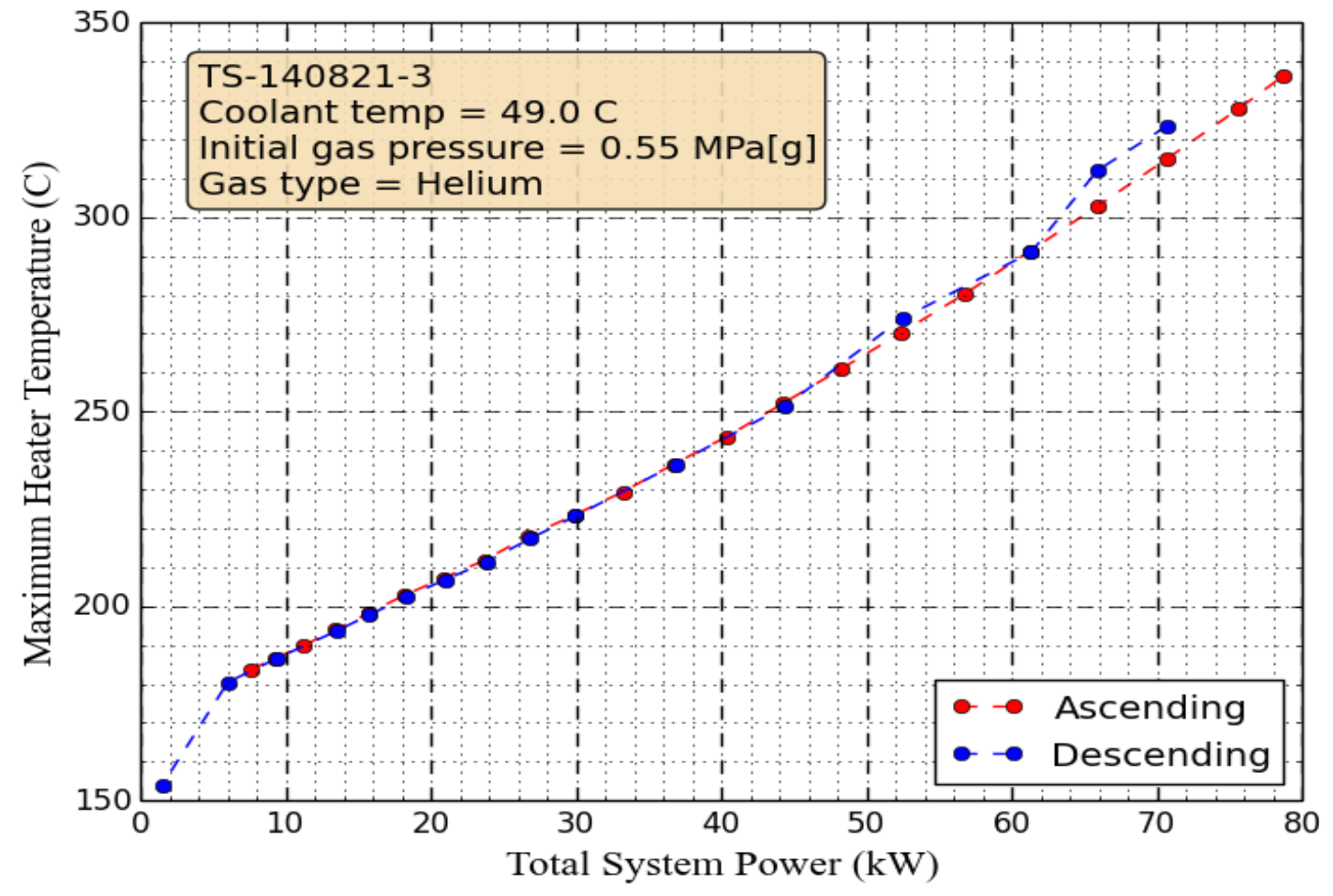

Figure 6-9. Maximum heater temperature for TS-140821-3 showing little or no hysteresis.

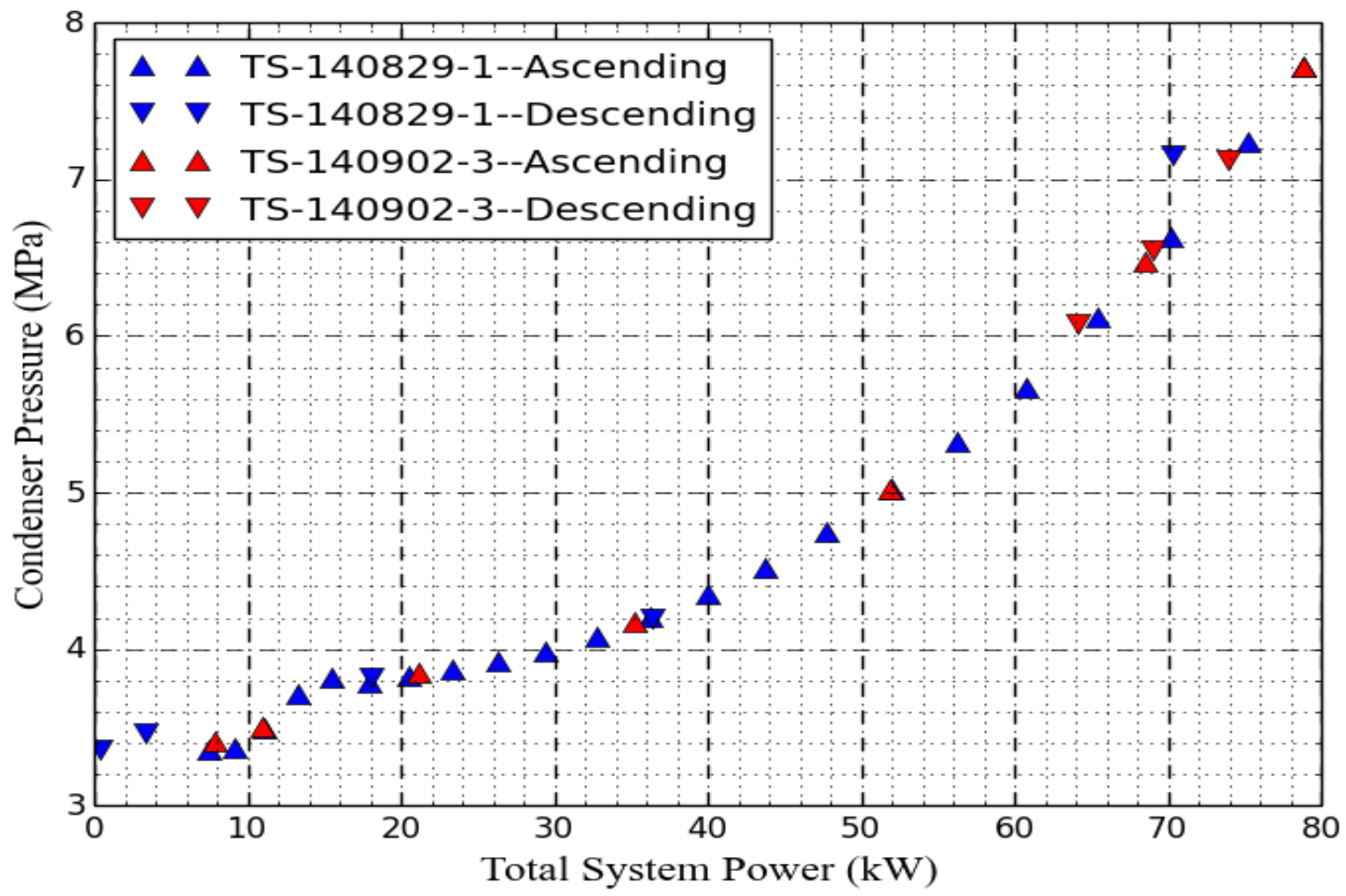

Figure 6-10. Condenser pressure for rising and falling power on multiple test days showing little or no hysteresis. 


\subsection{HELIUM AND ARGON PLENUM GAS}

As discussed in Sect. 6.3, an initial helium gas fill forms a bubble that stays at the top and does not generally mix with the up-flowing steam. Another set of experiments was conducted using argon with a very different outcome, as shown in Figure 6-11. While the helium fill gas experiment shows a clear line of separation, the argon fill gas experiment shows mixing all the way to the top of the condenser. Measured condenser gas temperatures in the argon case follow the steam saturation temperature at the steam partial pressure.

Final operating conditions, as represented by the evaporator steam temperature, are somewhat different between the helium- and argon-filled cases. At $80 \mathrm{~kW}$ system power, the helium case has a steam temperature of $\sim 265^{\circ} \mathrm{C}$, whereas the argon case has a steam temperature of $\sim 285^{\circ} \mathrm{C}$. A physical explanation for this difference is not obvious. One possibility is that the lighter helium molecules are pushed preferentially upward, resulting in collisions with the heavier steam molecules, while the argon molecules are actually larger and heavier than the steam, so they stay mixed. The argon/steam mixture would have a significantly reduced condensation rate.

\subsection{HFIR STARTUP SEQUENCE}

A typical HFIR startup power sequence is shown in Figure 6-12. A typical HFIR power increase occurs over 20-30 seconds, but for this particular case, each step increase in power occurs over a 10-second period. The delay times between power increases correspond to typical startup sequences at HFIR. The results show that the thermosyphon has no problem accommodating HFIR startup sequences.

In general, steady state in the thermosyphon is reached in $\sim 1$ min. Figure 6-13 shows thermocouple traces after a $17 \mathrm{~kW}$ increase in power. The power increase occurs over the first 10 seconds, and all thermocouples ( 3 in the evaporator and 1 in the condenser) reach a new steady state temperature in less than 70 seconds. Other tests at lower gas pressures give similar results. 

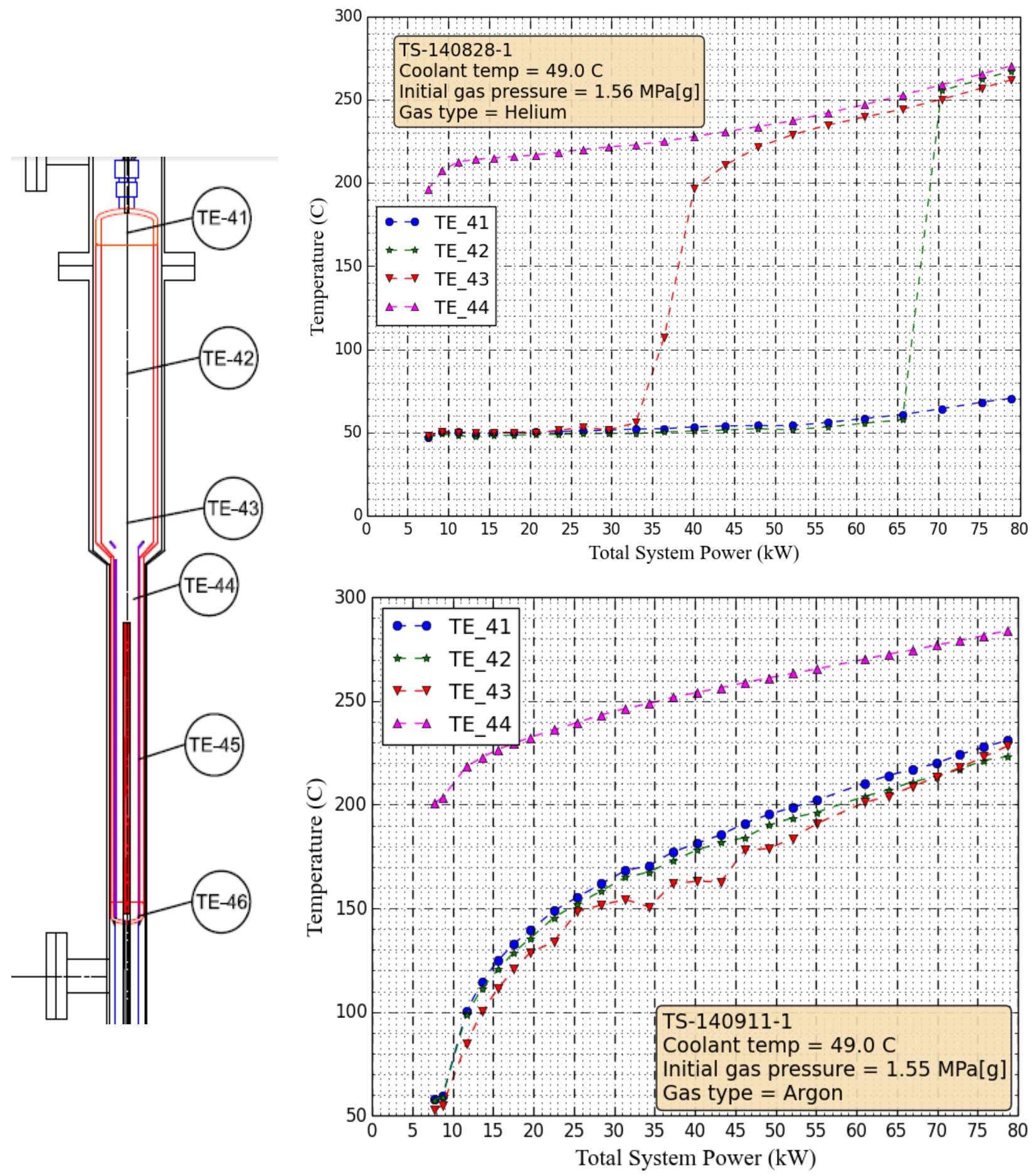

Figure 6-11. Condenser temperature profile using helium and argon gas. 


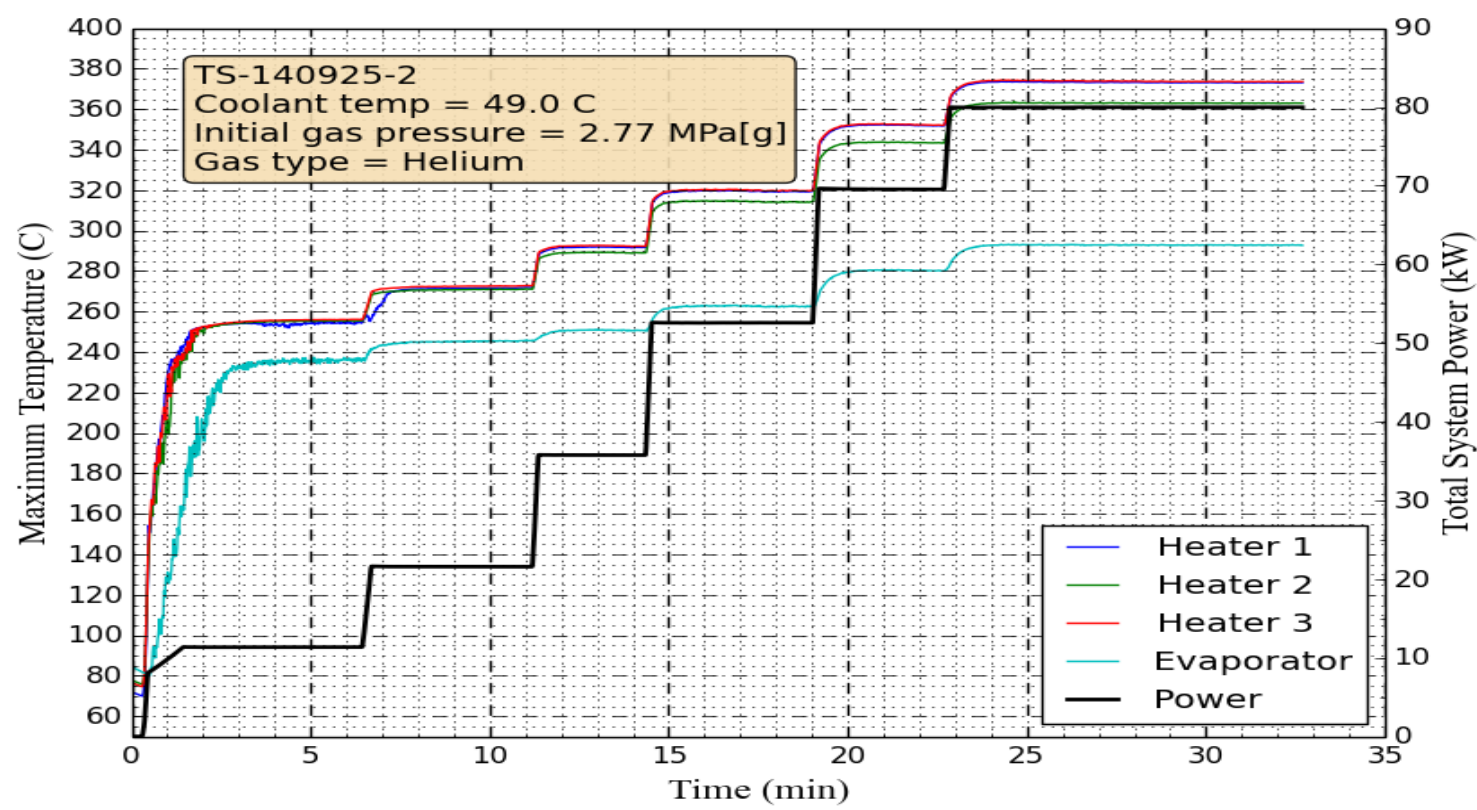

Figure 6-12. HFIR startup sequence.

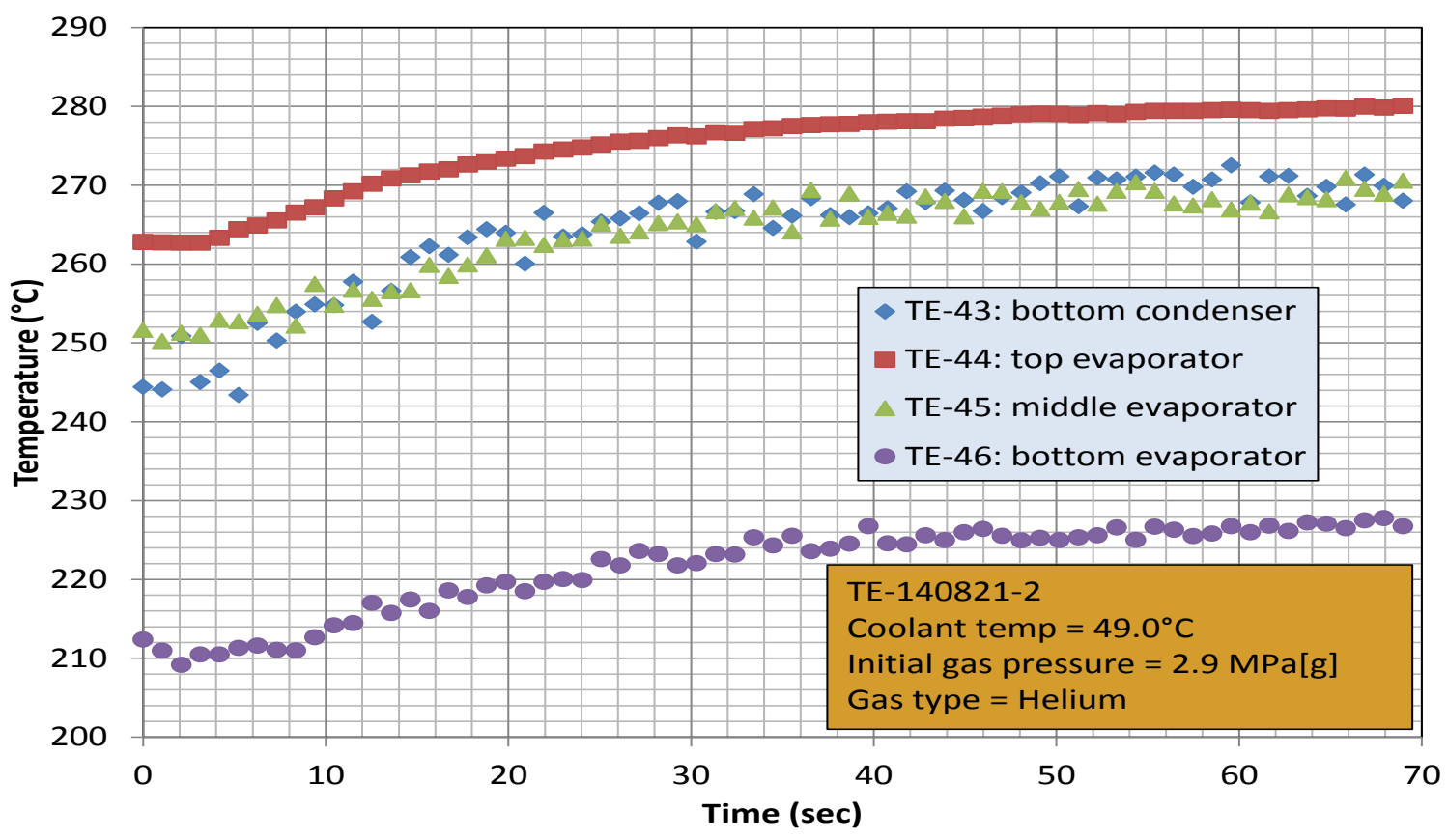

Figure 6-13. Thermocouple time trace after a $17 \mathrm{~kW}$ power increase.

\subsection{LOSS OF OFFSITE POWER SIMULATION}

As described in Sect. 5.1.3, a LOOP transient was simulated by quick-closing HCV-3 to a preset stop that was calibrated to provide an amount of flow to the thermosyphon equivalent to a simulated LOOP. All transient parameters are based on the analysis documented in report C-HFIR-2009-003, Rev. 0 [6]. The power trip was keyed to the primary coolant mass flow rate, so there was a specific delay between the two, as shown in Figure 6-14. Figure 6-15 shows that internal temperatures monotonically decrease 
during the transient. Most importantly, Figure 6-16 shows that the subcooling in the primary coolant stays highly subcooled $\left(>90^{\circ} \mathrm{C}\right)$ during the critical first 10 minutes after the trip. In report C-HFIR-2009-003 [6], the maximum Nusselt number-which is the criterion used to determine whether onset of significant void has been reached in low flow conditions-occurs within the first 50 seconds after the trip. This test shows that the thermosyphon performs well in the standard transient tests that HFIR requires all experiments to withstand to qualify for irradiation time in the reactor.

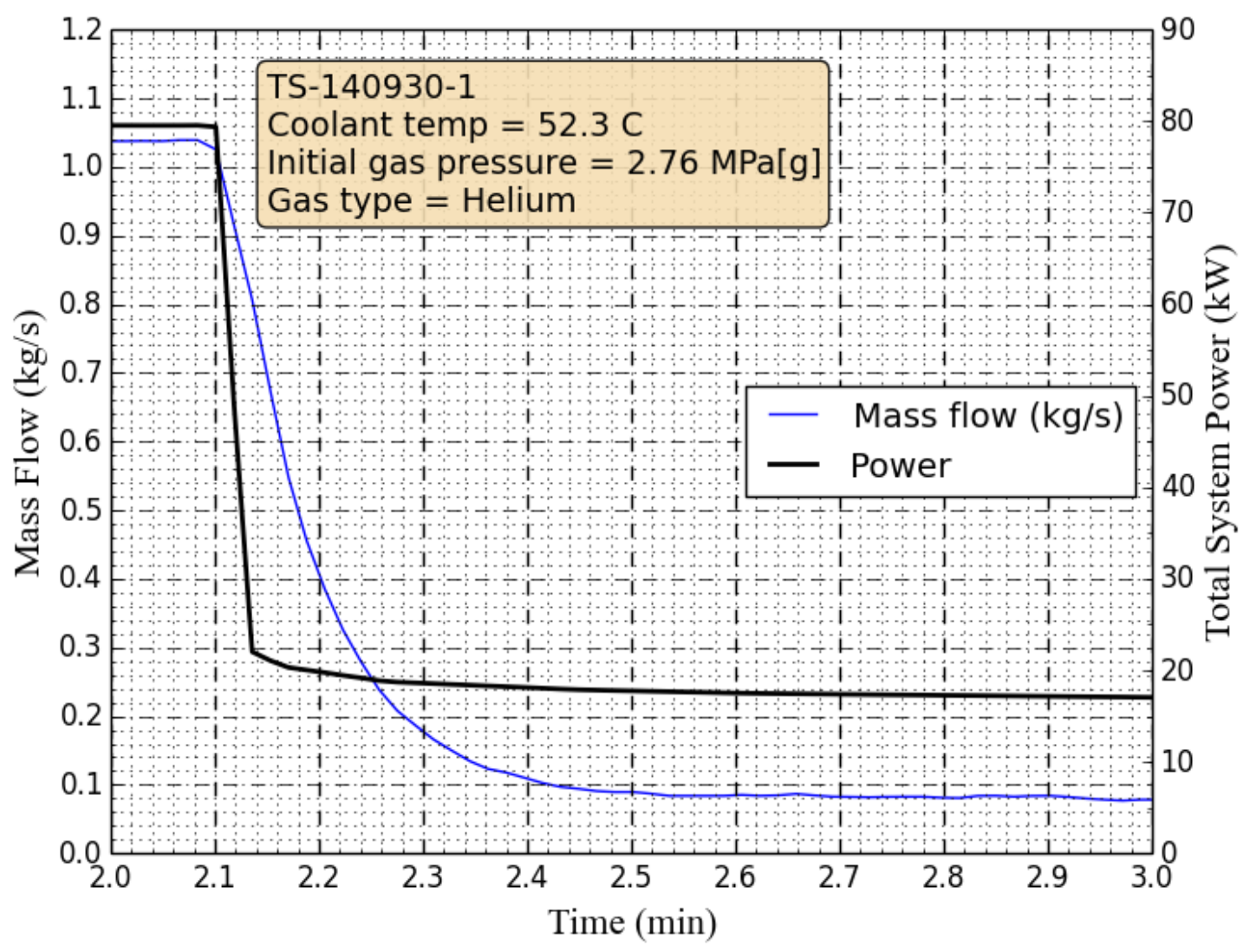

Figure 6-14. Mass flow and power profile during a LOOP simulation. 


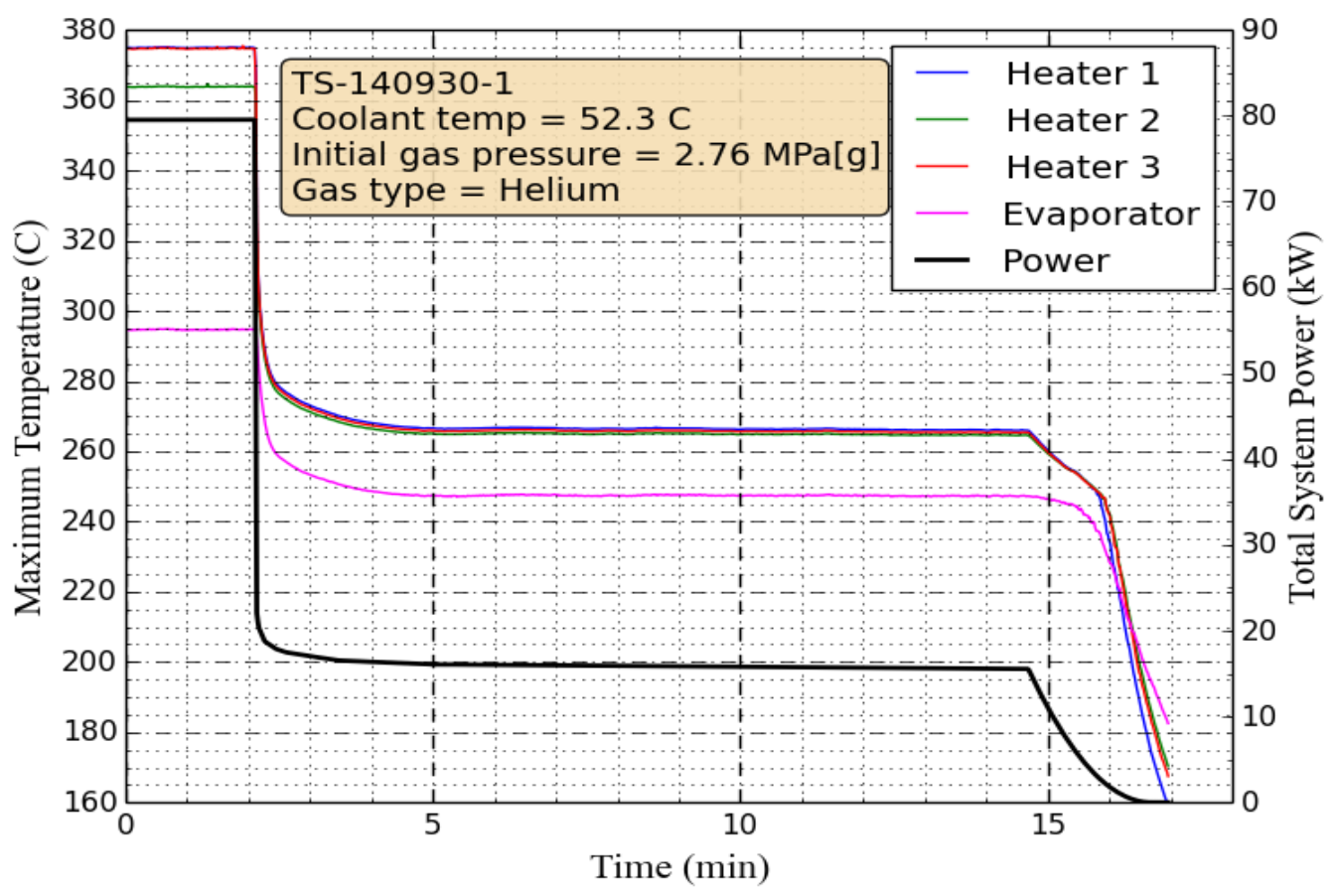

Figure 6-15. Internal temperatures during a LOOP simulation.

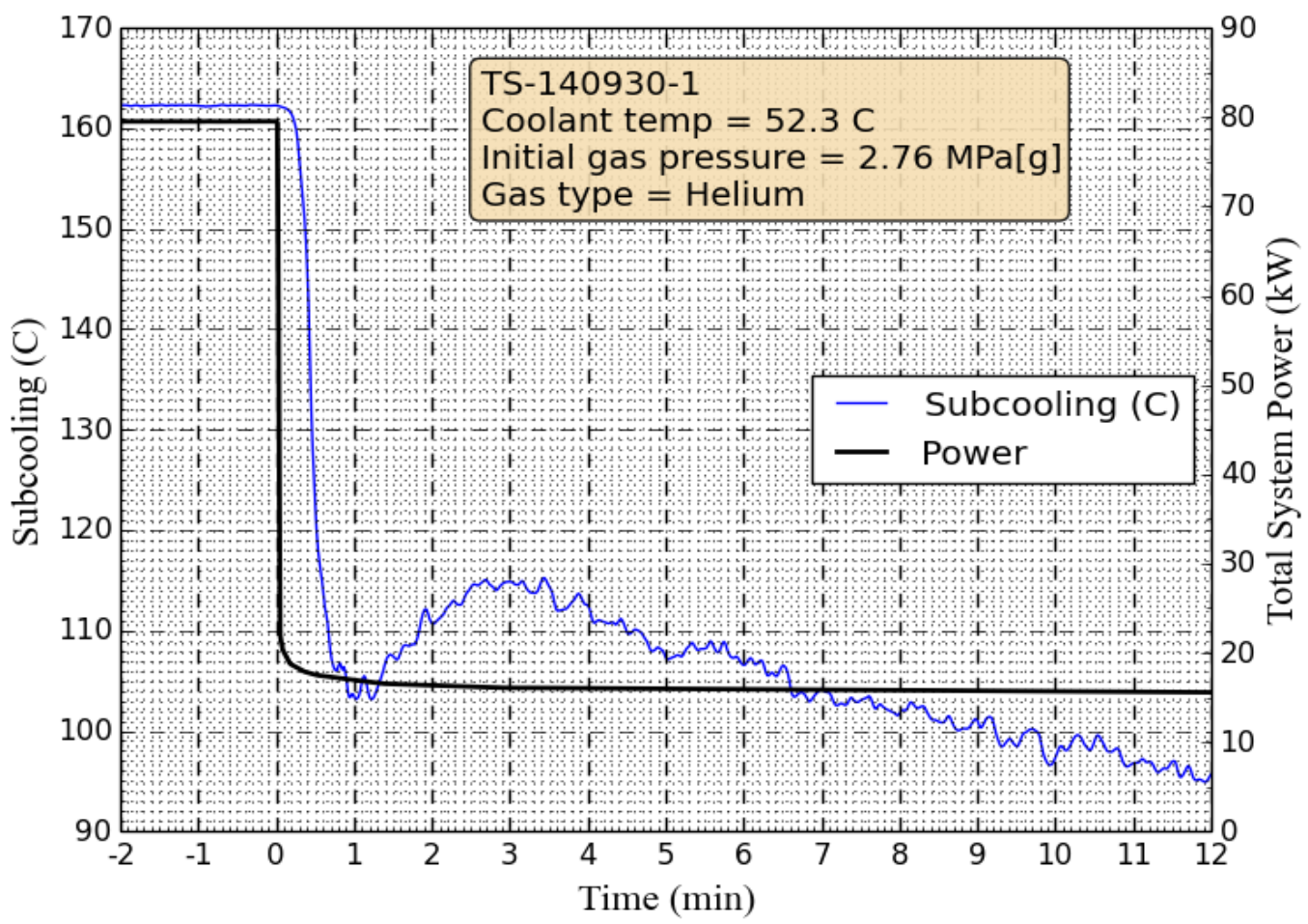

Figure 6-16. Subcooling in the primary coolant during a LOOP simulation. 


\section{COMPARISON OF EXPERIMENTAL DATA WITH COMPUTER CODE RESULTS}

\subsection{COMPUTER MODELS}

Two computer codes, RELAP5-3D [7] Version 4.2.1 and TRACE [8] Version 5.890, were selected to aid in the design of the TSTL, to perform pretest calculations, and to simulate the experimental data (post-test calculations). Computer models were prepared for both codes. Both models are completely identical, having the same geometry, boundary conditions, and nodalization. Figure 7-1 shows the nodalization employed with the TRACE code; the same nodalization has been employed with the RELAP5-3D code, as shown in Fig. 7-2.

The models include the primary system (left of Figure 7-1 and Figure 7-2), modeled as an open loop that simulates the primary coolant flowing at a constant mass flow rate of $1.18 \mathrm{~kg} / \mathrm{s}$, at an inlet pressure of $2.98 \mathrm{MPa}$, and at an inlet temperature of $322 \mathrm{~K}\left(49^{\circ} \mathrm{C}\right)$. The secondary system models the test section (TS) with the condenser at the top and the boiler/evaporator and the downcomer at the bottom. The condenser is modeled with a 3-D volume in RELAP5-3D and with a "Vessel" volume in TRACE, which is also a 3-D component. The condenser is modeled as a vertical cylinder with two radial nodes (with radii $0 \mathrm{~cm}, 2.95 \mathrm{~cm}$, and $4.24 \mathrm{~cm})$ and with 34 axial nodes equally spaced $(2.54 \mathrm{~cm}$ each). The total height of the condenser is $0.864 \mathrm{~m}$. The boiler/evaporator and the downcomer are modeled as 1-D pipes with 28 axial nodes each, the node height varying between 1.57 and $2.54 \mathrm{~cm}$. The top node is $1.57 \mathrm{~cm}$ high, the bottom node is $2.03 \mathrm{~cm}$ high, and the remaining nodes are $2.54 \mathrm{~cm}$ high. The total height of the downcomer or the boiler is $0.696 \mathrm{~m}$. The open flow area of the boiler is $10.27 \mathrm{~cm}^{2}$ with a hydraulic diameter of $1.92 \mathrm{~cm}$. The open flow area of the downcomer is $5.28 \mathrm{~cm}^{2}$ with a hydraulic diameter of $0.743 \mathrm{~cm}$. The primary coolant pipe (CV30) has a total of 62 axial nodes, which is the same number as the total axial nodes of the condenser (34) and downcomer (28) combined. The flow area of this pipe is $10.74 \mathrm{~cm}^{2}$ for the top 34 nodes facing the condenser and $6.39 \mathrm{~cm}^{2}$ for the bottom 28 nodes facing the downcomer.

There are three heat structures modeling the three heaters with 23 axial nodes and 14 radial nodes each. The outside radius of the heaters is $0.475 \mathrm{~cm}$. The axial nodes are $2.54 \mathrm{~cm}$ each except for the bottom node, which is $2.03 \mathrm{~cm}$ high. As in the actual heaters, the top node and the two bottom nodes of these structures do not have power; only the 20 central nodes are heated. One structure models the wall separating the boiler/evaporator from the downcomer with 28 axial nodes (same number of axial nodes of the boiler/evaporator or the downcomer and with the same axial heights) and radii of $1.98 \mathrm{~cm}$ and 2.07 $\mathrm{cm}$. The wall separating the primary coolant system and the condenser is modeled with a vertical heat structure with 34 axial nodes, the same as the condenser. Another vertical structure with one axial node $(1.57 \mathrm{~cm}$ high) models the transition between the condenser and the downcomer. Finally, one vertical structure with 27 axial nodes models the wall separating the primary coolant system from the downcomer. The droplet/steam separator above the boiler was not modeled because its effects are not expected to be significant on the overall results.

Nonequilibrium thermodynamics with the wall friction activated is the option chosen for the calculations by both codes. They are the default options. The heat transfer coefficients are calculated internally by each code for boiling, condensing, or single-phase liquid forced or natural convection, depending on the region under consideration. Default options are also used for the heat transfer coefficients.

Computer models were prepared to simulate the OFTF using both RELAP5-3D and TRACE. The OFTF is an isothermal facility intended to measure flows and $\triangle \mathrm{Ps}$ through the orifices connecting the bottom of the downcomer with the bottom of the boiler (Section 4.5). The OFTF computer model is a simplified model of the full TSTL model. Only the downcomer and the boiler are modeled. The dummy heaters 
inside the boiler of the OFTF are also in the facility to keep the same geometry as the actual TSTL: they are not heated.

Figure 7-3 shows the TRACE model of the OFTF. The central pipe (CV111) is the boiler/evaporator with a flow area of $10.27 \mathrm{~cm}^{2}$ and a hydraulic diameter of $1.92 \mathrm{~cm}$. The downcomer is CV112, with an area of $5.28 \mathrm{~cm}^{2}$ and a hydraulic diameter of $0.743 \mathrm{~cm}$. The eight orifices at the bottom connecting the downcomer and the boiler are modeled with flow path FL115 as a side (horizontal) flow with the abrupt area change option, an area of $1.342 \mathrm{~cm}^{2}$ (the combined area of 8 orifices), and a hydraulic diameter of $4.62 \mathrm{~mm}$ (the diameter of one orifice). This is the same modeling as in the TSTL computer models of Figure 7-1 and Figure 7-2. There are 32 axial nodes, $2.54 \mathrm{~cm}$ high each, that are employed for both CV111 and CV112. The water flowing into the OFTF is at $\sim 104 \mathrm{kPa}(\sim 1 \mathrm{~atm})$ and at $\sim 293 \mathrm{~K}(+/-1 \mathrm{~K})$. The form factor k of flow path FL115 was varied until good agreement of the calculated values was obtained with the experimental data. Figure 7-4 shows the experimental data compared with calculations by both codes for values of $\mathrm{k}$ of 0.18 and 0.2 . Mass flow rates $(\mathrm{kg} / \mathrm{s})$ vs orifice $\Delta \mathrm{P}(\mathrm{Pa})$ are shown. The mass flow rates $(\mathrm{kg} / \mathrm{s})$ were calculated from the experimental volumetric flow rates using the density of water at $293 \mathrm{~K}\left(20^{\circ} \mathrm{C}\right)$ of $998 \mathrm{~kg} / \mathrm{m}^{3}$. A form loss factor of $\mathrm{k}=0.18$ for flow path FL115 yielded the best agreement for both codes. The same factor of $\mathrm{k}=0.18$ has also been implemented into the orifice flow path of the complete TSTL models of Figure 7-1 and Figure 7-2.

The actual test conditions in the TS of the TSTL at the full power of $80 \mathrm{~kW}$ are at significantly higher pressure and temperature than the conditions employed in the OFTF. Therefore, additional runs were performed with the TRACE code to evaluate the effects of higher pressures and temperatures. Runs completed for higher system pressures did not show any effect. The mass flow rates and the orifice $\Delta \mathrm{P}$ are not affected by the overall system pressure, as the thermal hydraulic properties of water are weak functions of pressure. On the other hand, the water temperature has an effect on the results, as shown in Fig. 7-5, with calculations for two different temperatures $\left(293 \mathrm{~K}\right.$ or $20^{\circ} \mathrm{C}$ and $500 \mathrm{~K}$ or $\left.227^{\circ} \mathrm{C}\right)$. For the same orifice $\Delta \mathrm{P}$, the calculated water mass flow rates for the high temperature $(500 \mathrm{~K})$ are larger by $\sim 9 \%$ than the mass flow rates calculated for the low temperature $(293 \mathrm{~K})$. This is due to the effect of temperature in the water properties, mainly in the viscosity that is reduced as the temperature increases. 


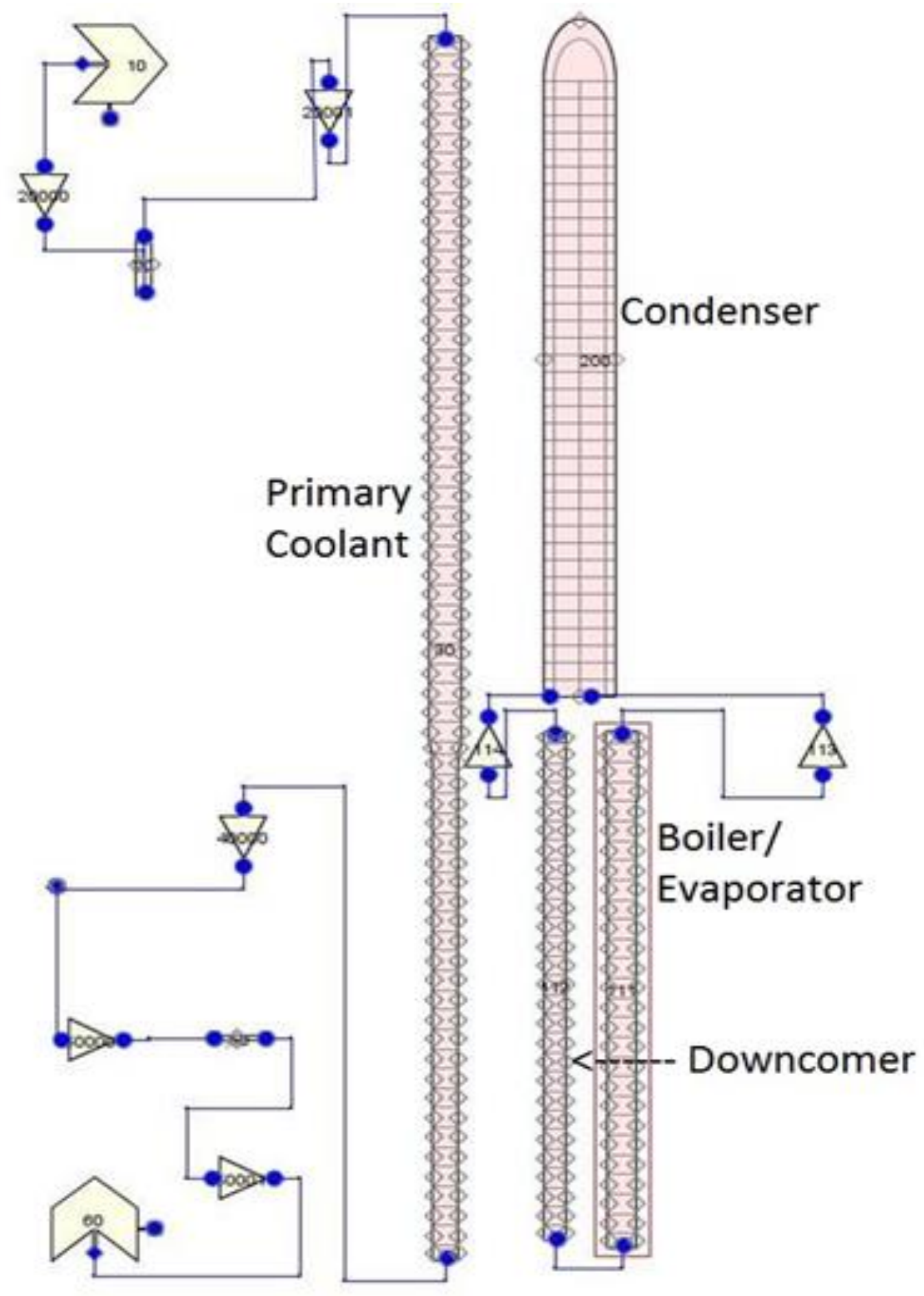

Figure 7-1. TRACE model of the TSTL. 


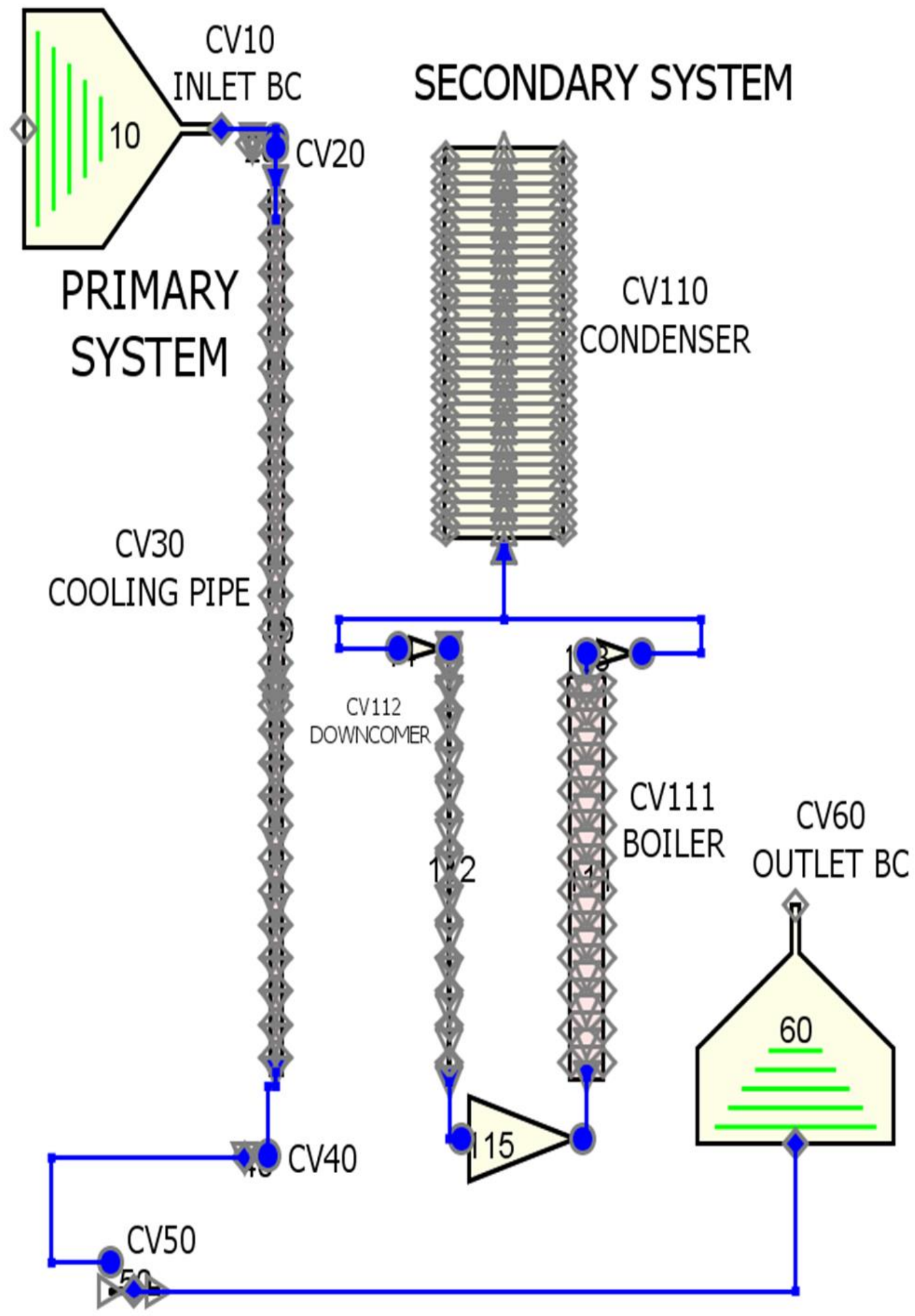

Figure 7-2. RELAP5-3D model of the TSTL. 


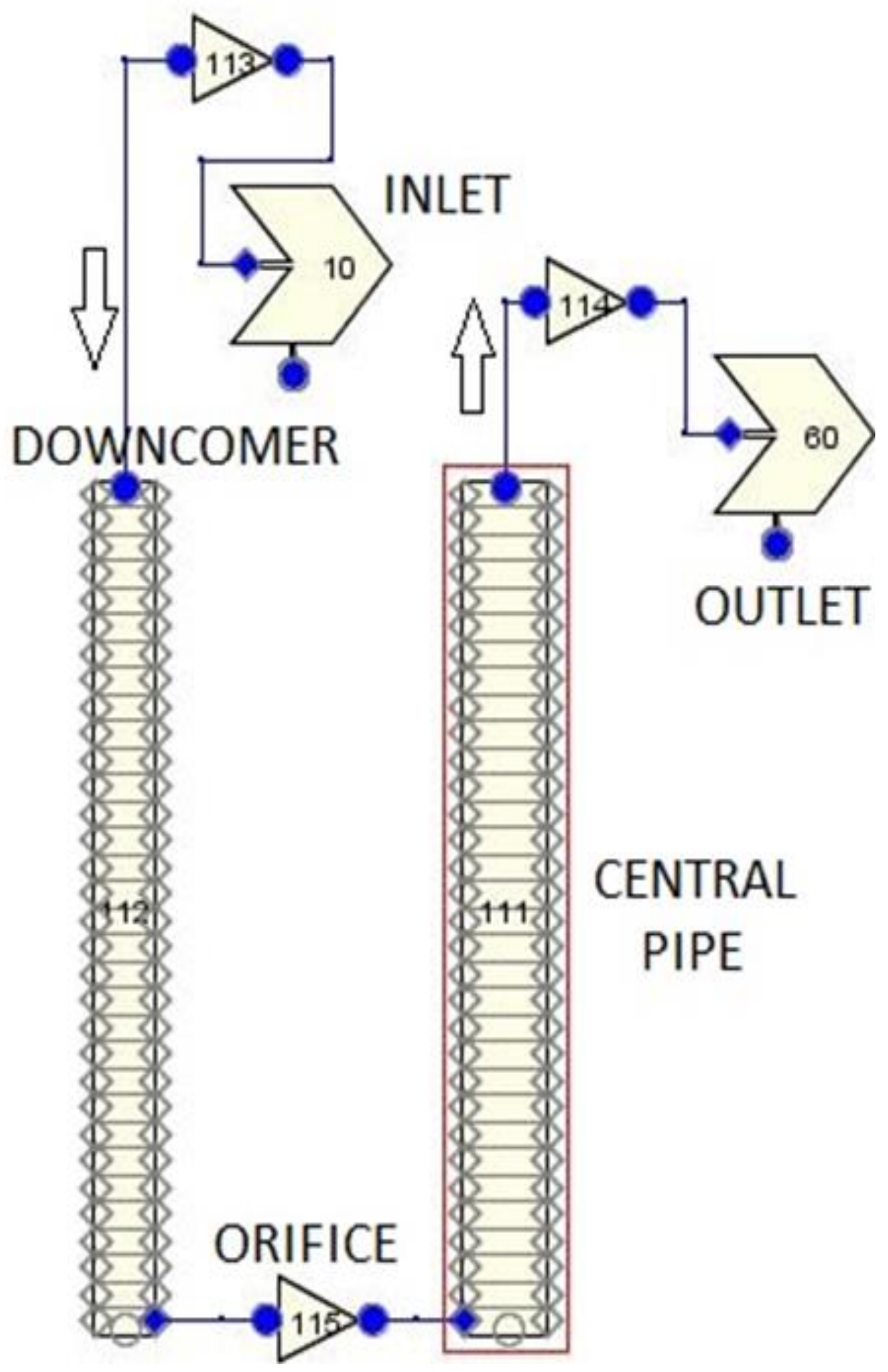

Figure 7-3. TRACE model of the OFTF. 


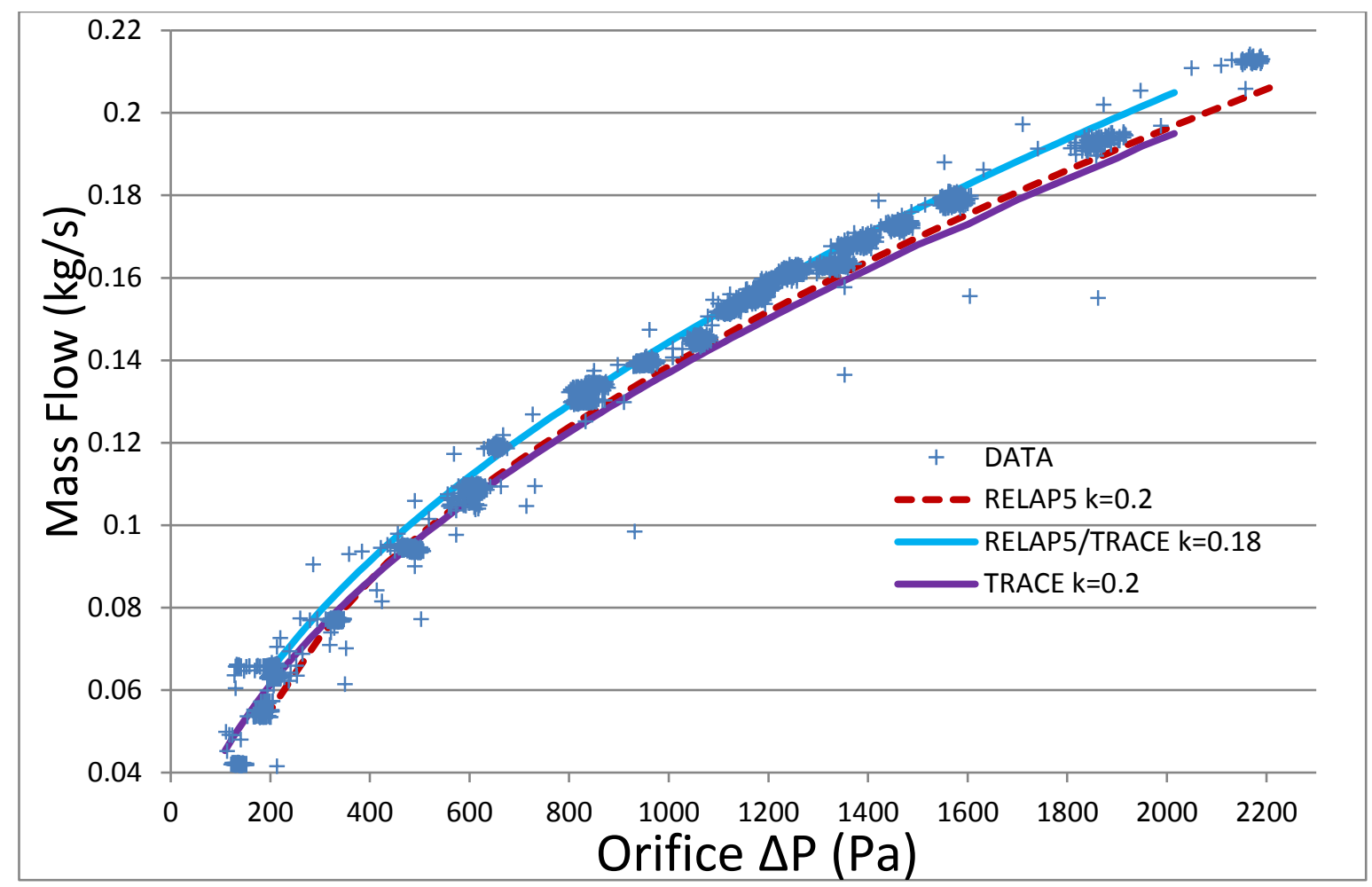

Figure 7-4. Comparison of OFTF data with calculations by the codes RELAP5-3D and TRACE.

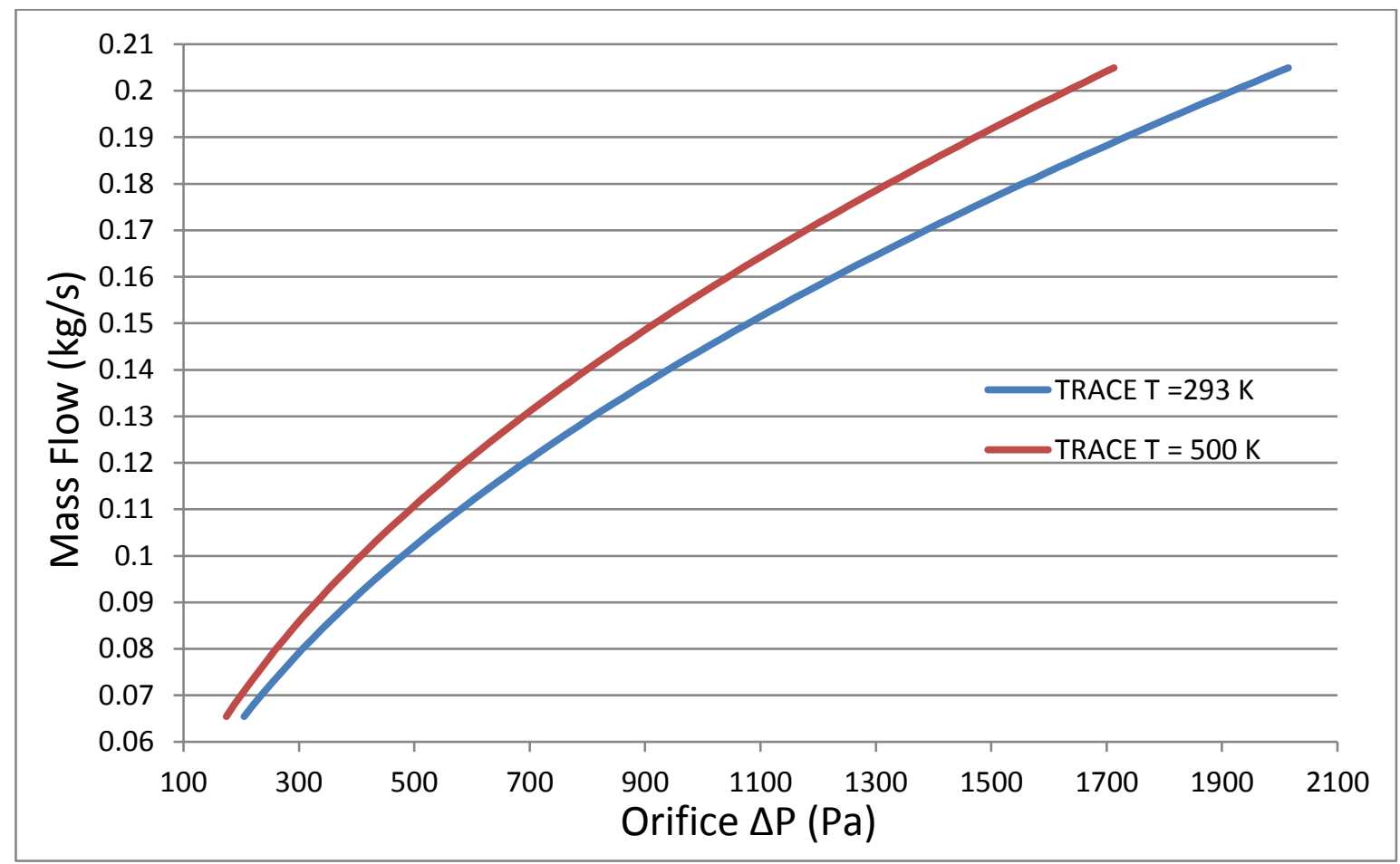

Figure 7-5. Effect of the water temperature in the OFTF calculated mass flow rates. 


\subsection{PRE-TEST PREDICTIONS}

The RELAP5-3D model was developed first [9], and the TSTL was designed based on the results of this early model. Subsequently, the TRACE model was developed, and different results were obtained [10]. Pressures and temperatures calculated with the TRACE code were significantly lower than the values calculated with the RELAP5-3D code. Figure 7-6 shows the calculated pressures for the TSTL using the two codes, employing only water in the system (without noncondensable gases). RELAP5-3D calculated a final pressure (for the total power of $80 \mathrm{~kW}$ ) of $3.75 \mathrm{MPa}$, while TRACE calculated a final pressure of $1.84 \mathrm{MPa}$. The total power of $80 \mathrm{~kW}$ (for the three heaters) was applied in 6 consecutive steps, with 10\%, 30\%, 50\%, 70\%, 90\% and finally $100 \%$ power $(80 \mathrm{~kW})$ applied at $1,000 \mathrm{~s}$ (Fig. 7-6). This is a power scheme typical for a HFIR startup sequence (per Sect. 6.6). From 1,000 s until 2,000 s (end of the calculation), the total power of $80 \mathrm{~kW}$ was kept constant.

Figure 7-7 shows calculated temperatures of the boiler inlet water as liquid and of steam leaving the top of the boiler as vapor, and Figure 7-8 shows calculated heater surface temperature (for node 2, the top node of the heated section). RELAP5-3D also calculated higher temperatures than TRACE, as with the pressures. At the total power of $80 \mathrm{~kW}$, RELAP5-3D calculated a heater surface temperature of $548 \mathrm{~K}\left(275^{\circ} \mathrm{C}\right)$, while TRACE calculated a heater surface temperature of $496 \mathrm{~K}\left(223^{\circ} \mathrm{C}\right)$, a difference of $52 \mathrm{~K}$. Similar differences were calculated for the fluid (liquid water and steam) temperatures calculated by both codes (Fig. 7-7).

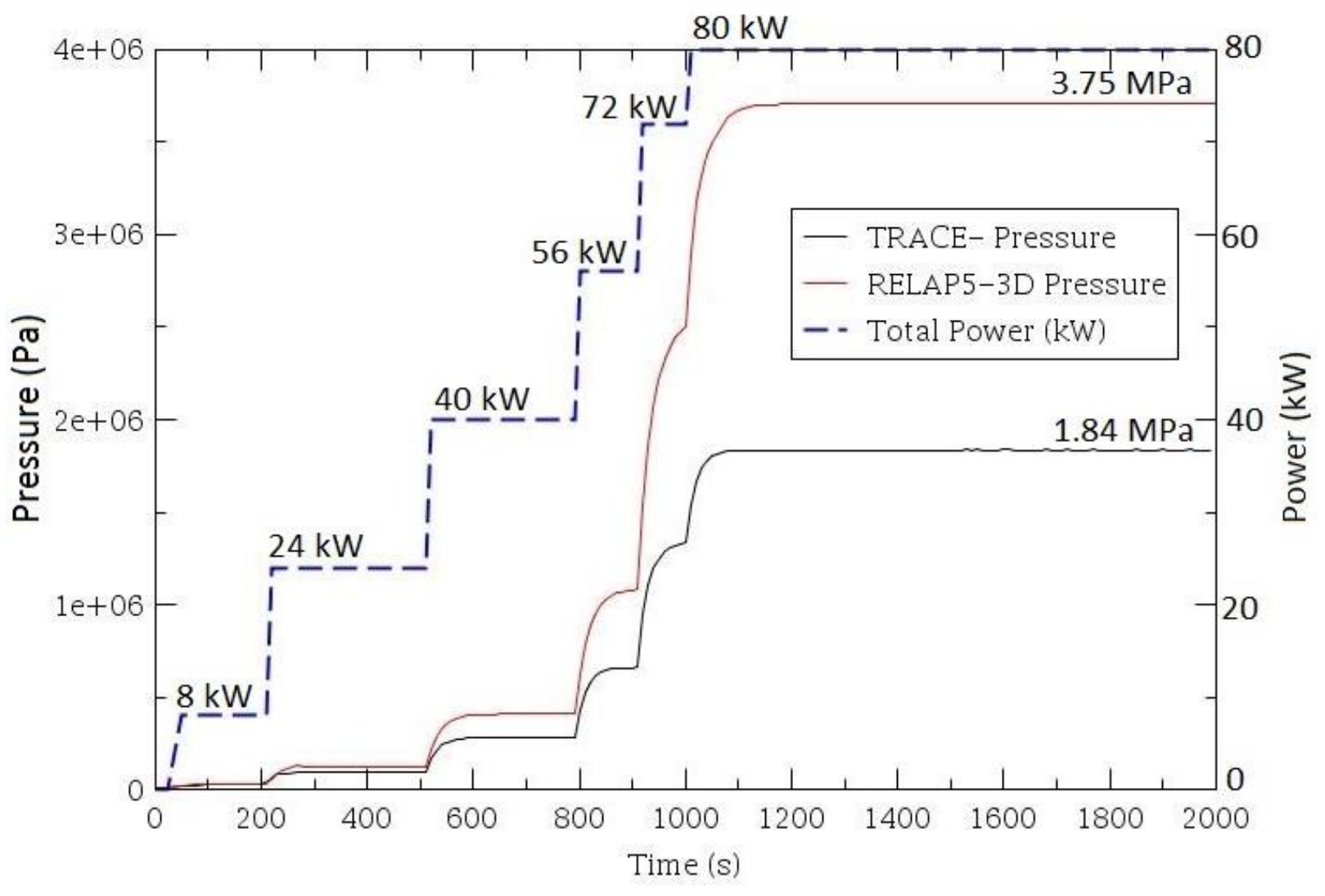

Figure 7-6. TSTL calculated pressures by RELAP5-3D and TRACE with only steam. 


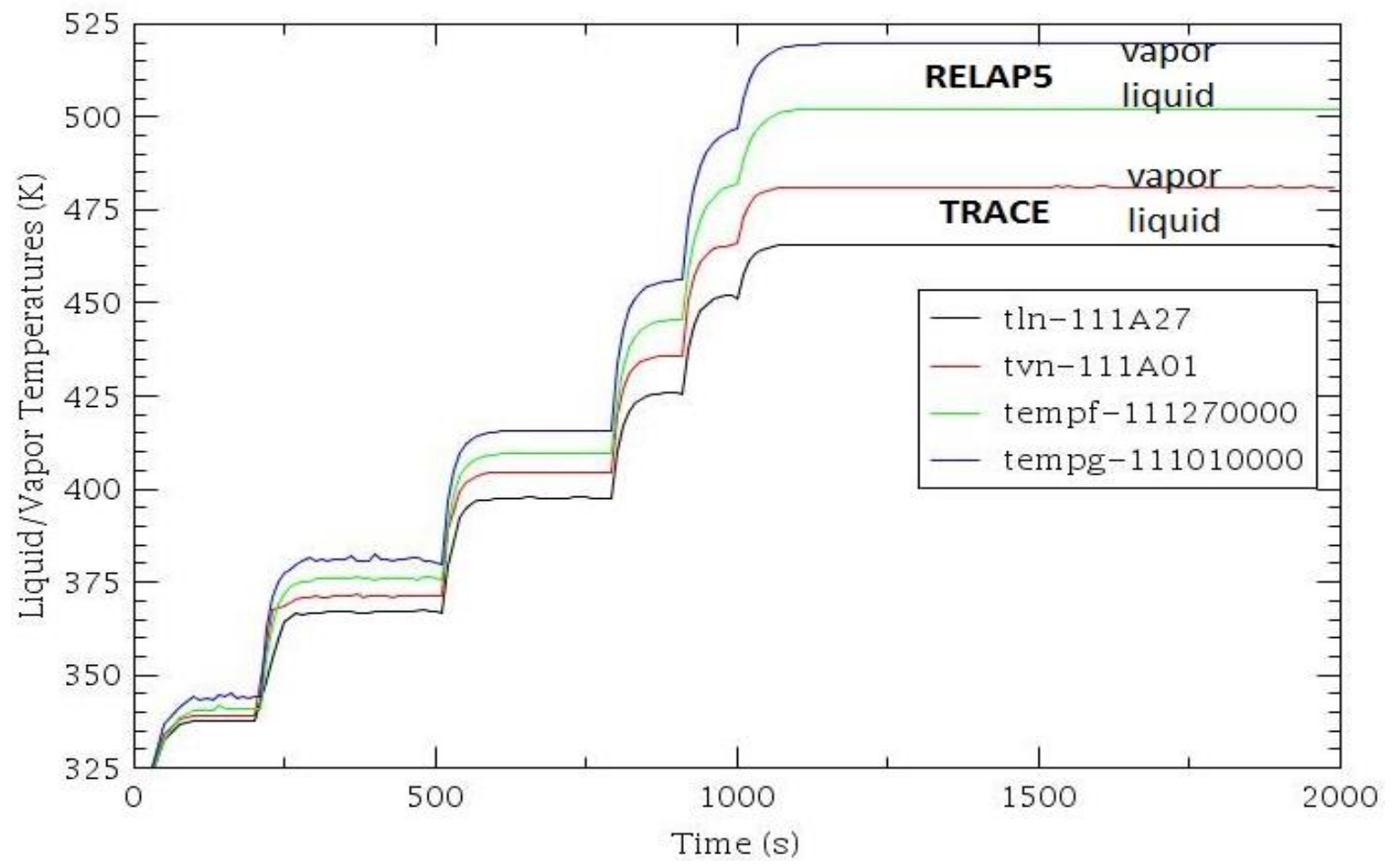

Figure 7-7. Vapor and liquid temperatures calculated by TRACE and RELAP5.

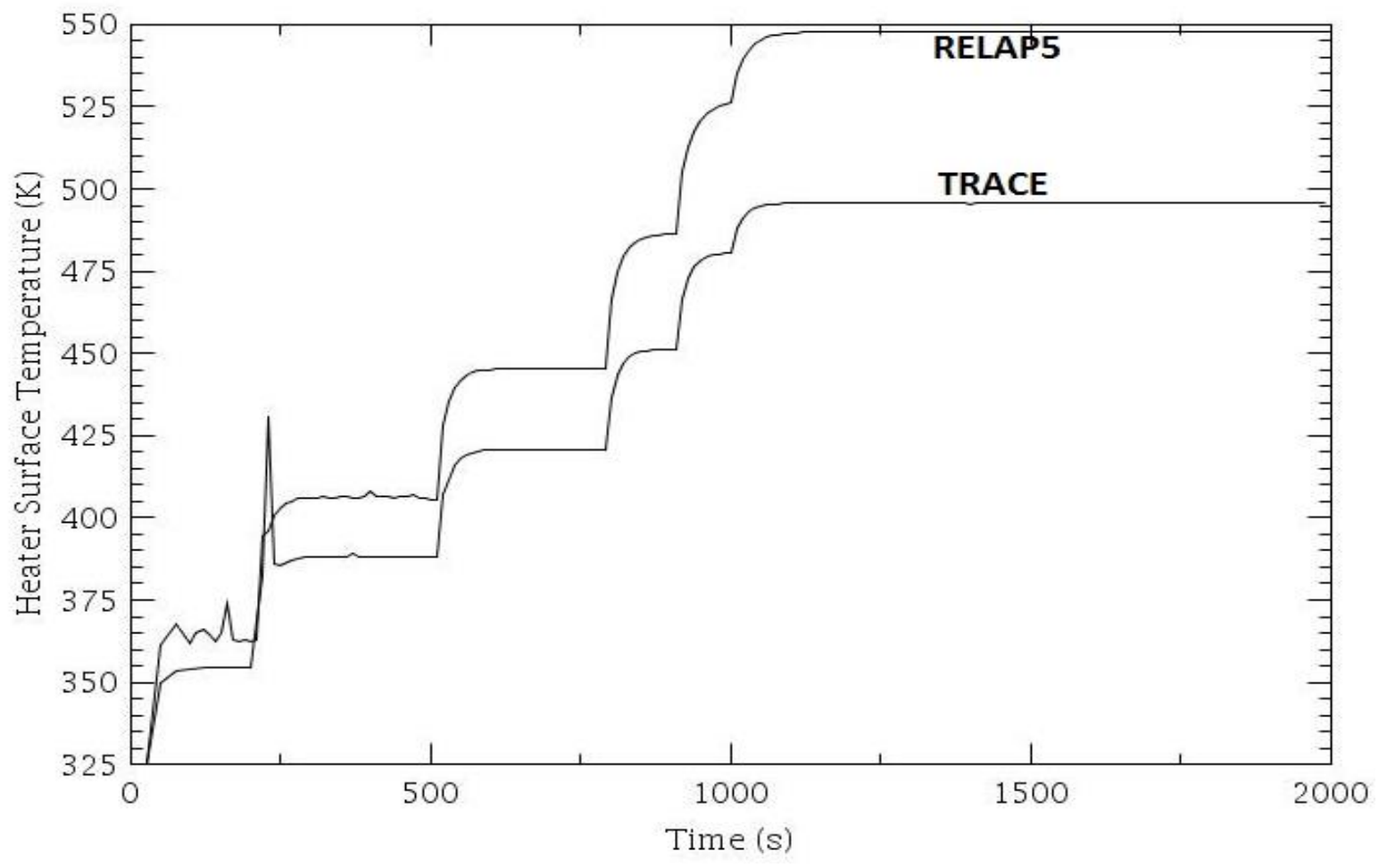

Figure 7-8. Heater surface temperatures calculated by TRACE and RELAP5. 
Other calculations were completed to estimate the temperature difference $(\Delta \mathrm{T})$ between the heater thermocouples (TCs) and the surface of the heaters. This $\Delta \mathrm{T}$ is through the outside sheath of the heaters, which have a thickness of $0.55 \mathrm{~mm}$. At the full power of $26.67 \mathrm{~kW}$ per heater, this $\Delta \mathrm{T}$ is $84 \mathrm{~K}$, as shown in Figure 7-9, with radial temperatures calculated by the TRACE code inside a heater. Therefore, a TC temperature of $592 \mathrm{~K}\left(319^{\circ} \mathrm{C}\right)$ corresponds to a surface temperature of $508 \mathrm{~K}\left(235^{\circ} \mathrm{C}\right)$ and to a maximum temperature of $720 \mathrm{~K}\left(447^{\circ} \mathrm{C}\right)$ at the center of the heater. The nickel core and the $\mathrm{BN}$ filling located inside the heating filament are at the same temperature because it is assumed that no heat is generated inside these two components. The calculated temperature of the cooling water was $492 \mathrm{~K}\left(219^{\circ} \mathrm{C}\right)$, with a calculated temperature drop of $16 \mathrm{~K}$ across the coolant. Again, these temperatures were calculated at the full power of the heater $(26.67 \mathrm{~kW})$. To a first order, the difference between the measured thermocouple temperature and the surface temperature will be proportional to the power as:

$$
\Delta \mathrm{T}_{\mathrm{TC} \rightarrow \text { wall }}=84^{\circ} \mathrm{K} \cdot \frac{\text { Pow }}{80 \mathrm{~kW}}=84^{\circ} \mathrm{K} \cdot \frac{\text { pow }}{26.67 \mathrm{~kW}^{\prime}}
$$

where Pow is the total system power (power of the three heaters combined), and pow is the power of one heater $(1 / 3$ of the Pow value).

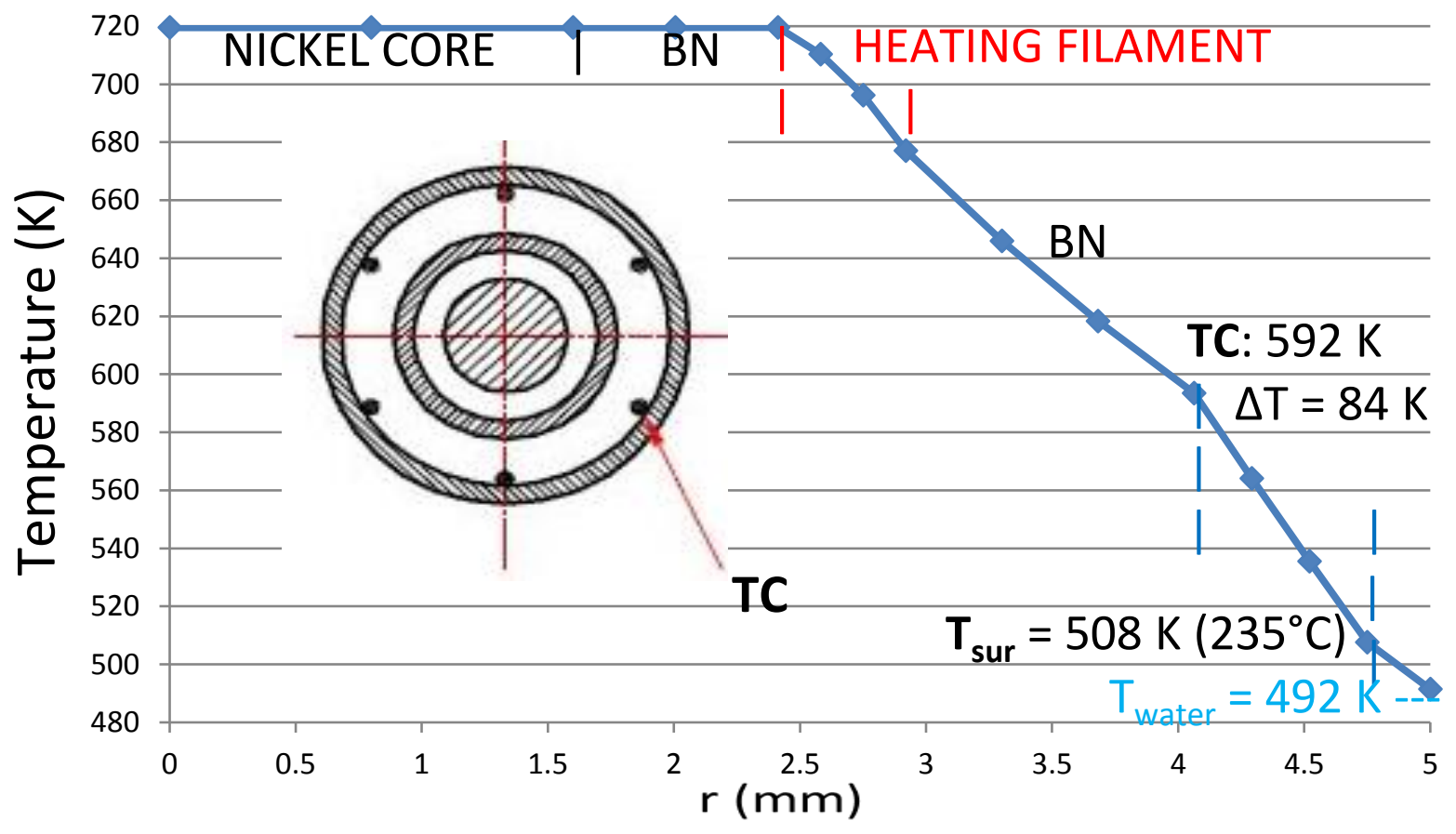

Figure 7-9. Radial temperatures calculated by TRACE inside a heater at full power (Test TS-140820-1).

\subsection{STEAM TESTS}

The first experimental tests performed with water/steam only (without noncondensable gases) were tests TS-140818-1, TS-140818-2, and TS-140819-1. These tests ended in heater temperature excursions or critical heat flux (CHF) at a total power of only $\sim 10 \mathrm{~kW}$ (or $\sim 3.3 \mathrm{~kW} /$ heater). The starting pressure for these tests at zero power is subatmospheric. The initial pressure in the TS is the saturation pressure of steam $(11.6 \mathrm{kPa})$ at the initial temperature of $322 \mathrm{~K}\left(49^{\circ} \mathrm{C}\right)$. Neither RELAP5-3D nor TRACE predicted this event. Both codes predicted that $80 \mathrm{~kW}$ of power could be applied to the heaters without reaching CHF. The CHF correlations of the codes are applicable to pressures above atmospheric and did not 
extrapolate correctly to these low pressures. The Groeneveld $[11,12]$ look-up table is used by both codes for CHF predictions (the 1995 look-up table by TRACE and the 1986 AECL-UO look-up table by RELAP5-3D).

Nine tests have been modeled with the TRACE code, which was selected for these calculations as described in Sect. 7.4. One calculation is for pure steam/water (already described), three tests with helium added, two tests with argon added, one HFIR startup test, one HFIR LOOP test, and one high power test. The list of the tests modeled by the TRACE code is given in

Table 7-1, which shows the experimental and the calculated values for each test. The following variables are given:

- Po: the initial test pressure in the condenser at zero power and at the initial temperature of $322 \mathrm{~K}$ $\left(49^{\circ} \mathrm{C}\right)$

- Pf: the final pressure in the condenser at the final power of $80 \mathrm{~kW}$ (or at $92.6 \mathrm{~kW}$ for the high power test, the last test in Table 7-1)

- $\quad \Delta \mathrm{P}$ : the measured pressure differential across the entrance orifices to the boiler/evaporator at the final power

- $\mathrm{T}_{\mathrm{v}}$ : the temperature of the vapor (steam) leaving the boiler/evaporator

- $\mathrm{T}_{1}$ : the temperature of the liquid water entering the bottom of the boiler/evaporator (which is the coldest water temperature in the system)

- $m_{\text {vap }}$ and $m_{\text {liq }}$ : TRACE calculated mass flow rates of steam (vapor) leaving and liquid water entering the boiler at the final power of the calculation

The Po values of Table 7-1 are at a higher temperature $\left(49^{\circ} \mathrm{C}\right)$ than the pressures reported in Table 5-1 which were measured at temperatures between $18^{\circ} \mathrm{C}$ and $25^{\circ} \mathrm{C}$. Both $\mathrm{T}_{\mathrm{v}}$ and $\mathrm{T}_{1}$ temperatures in Table 7-1 are at the final power of the test. TRACE input employed the same initial Po value at zero power as the experimental values and the same initial temperature of $322 \mathrm{~K}\left(49^{\circ} \mathrm{C}\right)$.

Additional TRACE runs were completed to estimate the maximum power that the TSTL can tolerate: these additional runs are not included in Table 7-1.

Table 7-1. Tests modeled with the TRACE Code

\begin{tabular}{|c|c|c|c|c|c|c|c|c|c|c|c|c|}
\hline \multirow{2}{*}{$\begin{array}{l}\text { Test } \\
\text { number } \\
\text { TS- }\end{array}$} & \multicolumn{6}{|c|}{ Experimental values } & \multicolumn{5}{|c|}{ TRACE calculated values } & \multirow[b]{2}{*}{ Notes } \\
\hline & $\begin{array}{l}\text { NC } \\
\text { gas }\end{array}$ & $\begin{array}{c}\text { Po } \\
\text { MPa }\end{array}$ & $\begin{array}{c}\mathbf{P f} \\
\mathrm{MPa}\end{array}$ & $\begin{array}{l}\mathbf{P P} \\
\mathbf{P a}\end{array}$ & $\begin{array}{c}\mathbf{T}_{\mathbf{v}} \\
(\mathbf{K})\end{array}$ & $\begin{array}{c}\mathbf{T}_{\mathbf{1}} \\
(\mathbf{K})\end{array}$ & $\begin{array}{c}\text { Pf } \\
\text { MPa }\end{array}$ & $\begin{array}{l}\mathbf{T}_{\mathbf{v}} \\
(\mathbf{K})\end{array}$ & $\begin{array}{c}\mathbf{T}_{\mathbf{1}} \\
(\mathbf{K})\end{array}$ & $\begin{array}{c}\mathrm{m}_{\mathrm{liq}} \\
(\mathrm{kg} / \mathrm{s})\end{array}$ & $\begin{array}{c}\mathbf{m}_{\text {vap }} \\
(\mathrm{kg} / \mathrm{s})\end{array}$ & \\
\hline $\begin{array}{l}140818-1,2 \\
140819-1\end{array}$ & -- & 0.012 & $\mathrm{CHF}$ & -- & -- & -- & 1.84 & 480 & 465 & 0.29 & 0.025 & Pure steam \\
\hline $140820-1$ & $\mathrm{He}$ & 0.101 & 2.3 & 1200 & 492 & 460 & 2.34 & 493 & 468 & 0.21 & 0.025 & Low $\mathrm{P}$ \\
\hline $140821-1$ & $\mathrm{He}$ & 0.112 & 2.46 & 1200 & 494 & 460 & 2.47 & 496 & 475 & 0.2 & 0.025 & Low $\mathrm{P}$ \\
\hline $140829-1$ & $\mathrm{He}$ & 3.0 & 7.66 & 750 & 565 & 510 & 7.66 & 565 & 528 & 0.16 & 0.022 & High P \\
\hline $140910-1$ & $\mathrm{Ar}$ & 0.121 & 2.67 & 1100 & 500 & 463 & 2.69 & 500 & 477 & 0.2 & 0.024 & Low $\mathrm{P}$ \\
\hline $140911-2$ & $\mathrm{Ar}$ & 2.406 & 7.98 & 600 & 567 & 503 & 8.0 & 567 & 527 & 0.16 & 0.02 & High P \\
\hline $140925-1$ & $\mathrm{He}$ & 3.24 & 7.897 & 775 & 567 & 511 & 7.9 & 567 & 529 & 0.15 & 0.023 & HFIR startup \\
\hline \multirow[t]{2}{*}{ 140930-1 } & $\mathrm{He}$ & 3.3 & 8.1 & 750 & 568 & 513 & 8.08 & 570 & 532 & 0.15 & 0.023 & LOOP \\
\hline & & & 4.0 & 55 & 520 & 465 & 4.0 & 522 & 473 & 0.039 & 0.0003 & Post-LOOP \\
\hline $140930-2$ & $\mathrm{He}$ & 3.2 & 9.9 & 780 & 583 & 525 & 9.8 & 584 & 545 & 0.15 & 0.032 & High power \\
\hline
\end{tabular}




\subsection{HELIUM TESTS}

\subsubsection{Test TS-140820-1}

The next series of tests added helium gas to the TS in order to increase the initial pressure to $\sim 1$ atmosphere $(101 \mathrm{kPa})$ at zero power and $322 \mathrm{~K}\left(49^{\circ} \mathrm{C}\right)$. Test TS-140820-1, with an initial pressure of $101 \mathrm{kPa}$, tolerated the full $80 \mathrm{~kW}$ power resulting in a final pressure of $2.3 \mathrm{MPa}$ at full power.

TRACE and RELAP5-3D runs duplicating the conditions of this helium test TS-140820-1 were also completed. Helium was added to an initial condenser pressure of $101 \mathrm{kPa}$ at zero power and $322 \mathrm{~K}$ $\left(49^{\circ} \mathrm{C}\right)$. The calculated condenser pressures for the total power of $80 \mathrm{~kW}$ were $2.34 \mathrm{MPa}$ by the TRACE code and 4.76 MPa by the RELAP5-3D code, as shown in Figure 7-10. TRACE calculated pressure agrees well with the experimental value of 2.3 MPa, while RELAP5-3D calculated pressure is very high too conservative and unrealistic. RELAP5-3D also calculated very high unrealistic temperatures. Based on these results, the RELAP5-3D code was not considered for additional calculations, and the TRACE code was selected for the calculations in this report. The reasons for the different results between the two codes are described in Sect. 7-11.

Figure 7-11 shows the experimental pressure and input power as a function of time for this test TS-140820-1, and Figure 7-12 shows the calculated pressure by the TRACE code. The time scales of Figure 7-11 and Figure 7-12 are different: the power of $80 \mathrm{~kW}$ was applied in the experiment in multiple steps over a time span of 9,000 s, while in the TRACE calculation, the power was applied in only 6 steps over 1,000 s, which is the same power scheme shown in Figure 7-6. According to the information presented in Sect. 6-4, the final condenser pressure is only a function of the final power, regardless of how the power is applied. To make the data/calculation comparisons more meaningful, both the data and calculated values are plotted against the system power. Figure 7-13 shows the condenser pressure for test TS-140820-1 with data and calculated values plotted against different powers. Figure 7-13 shows that the calculated pressures and the data agree not only at the final power of $80 \mathrm{~kW}$, but also at different powers.

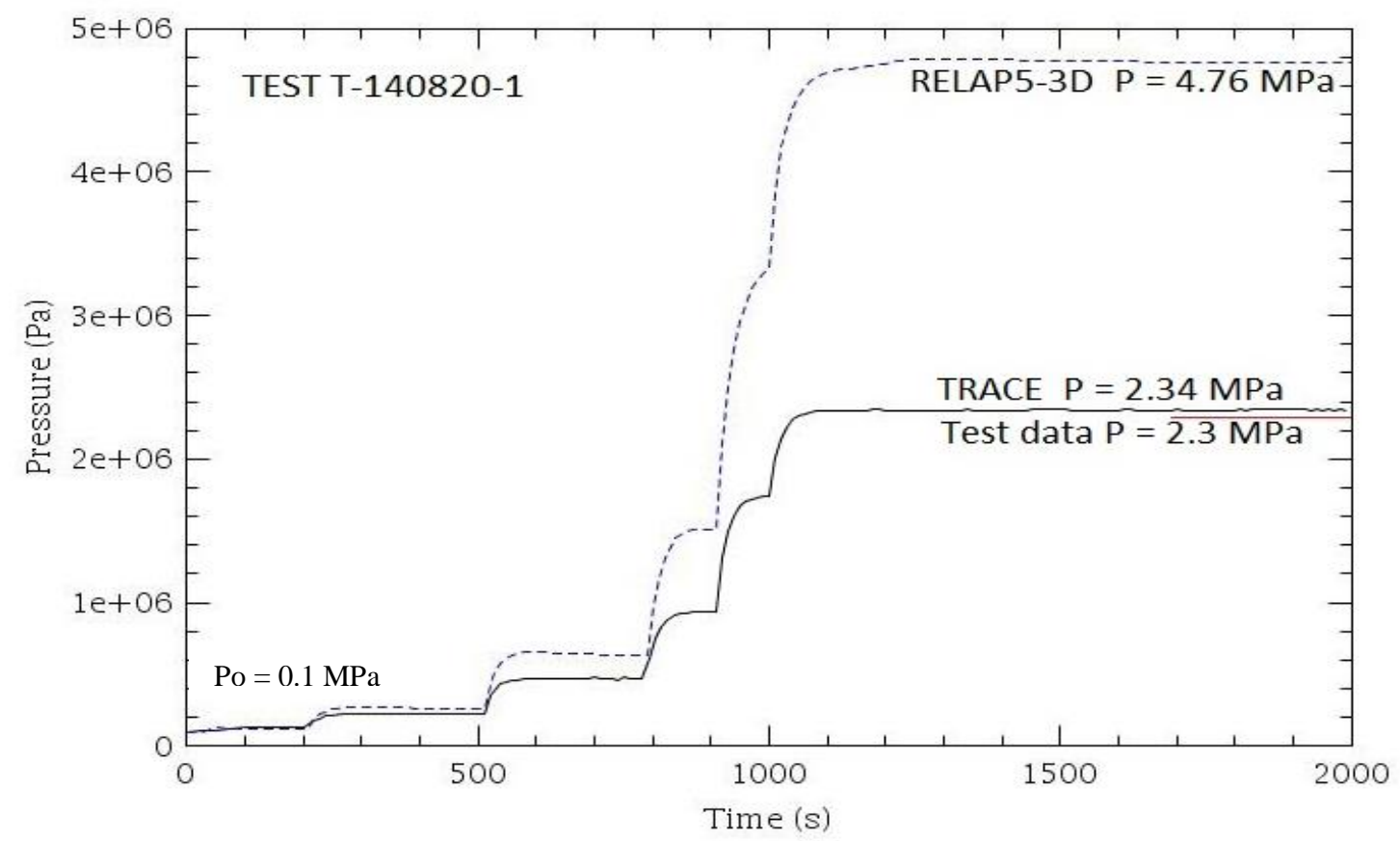

Figure 7-10. RELAP5-3D and TRACE calculated pressure for test TS-140820-1. 


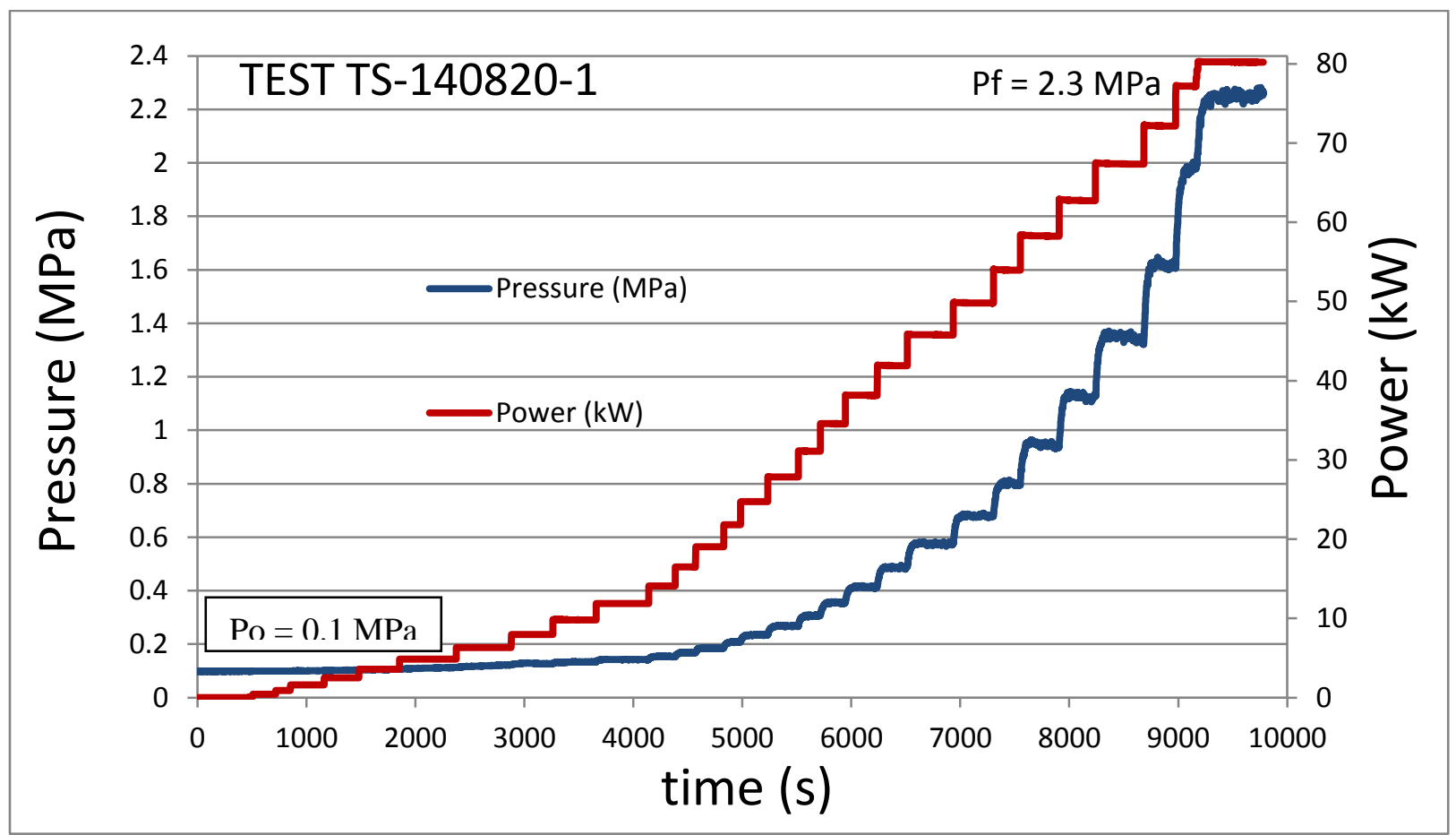

Figure 7-11. Pressure and power (kW) for helium test TS-140820-1.

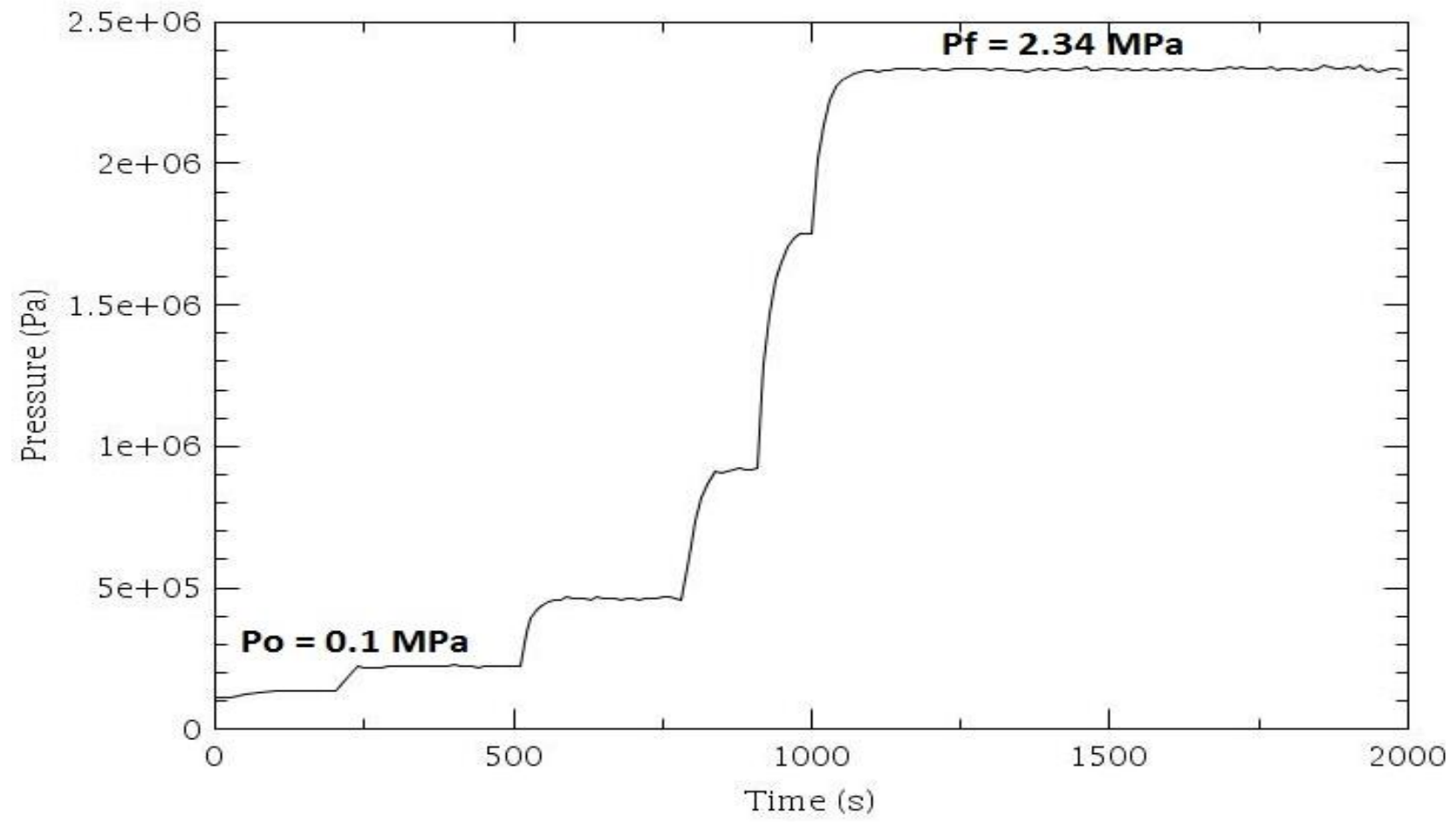

Figure 7-12. TRACE calculated pressure for Test TS 140820-1. 


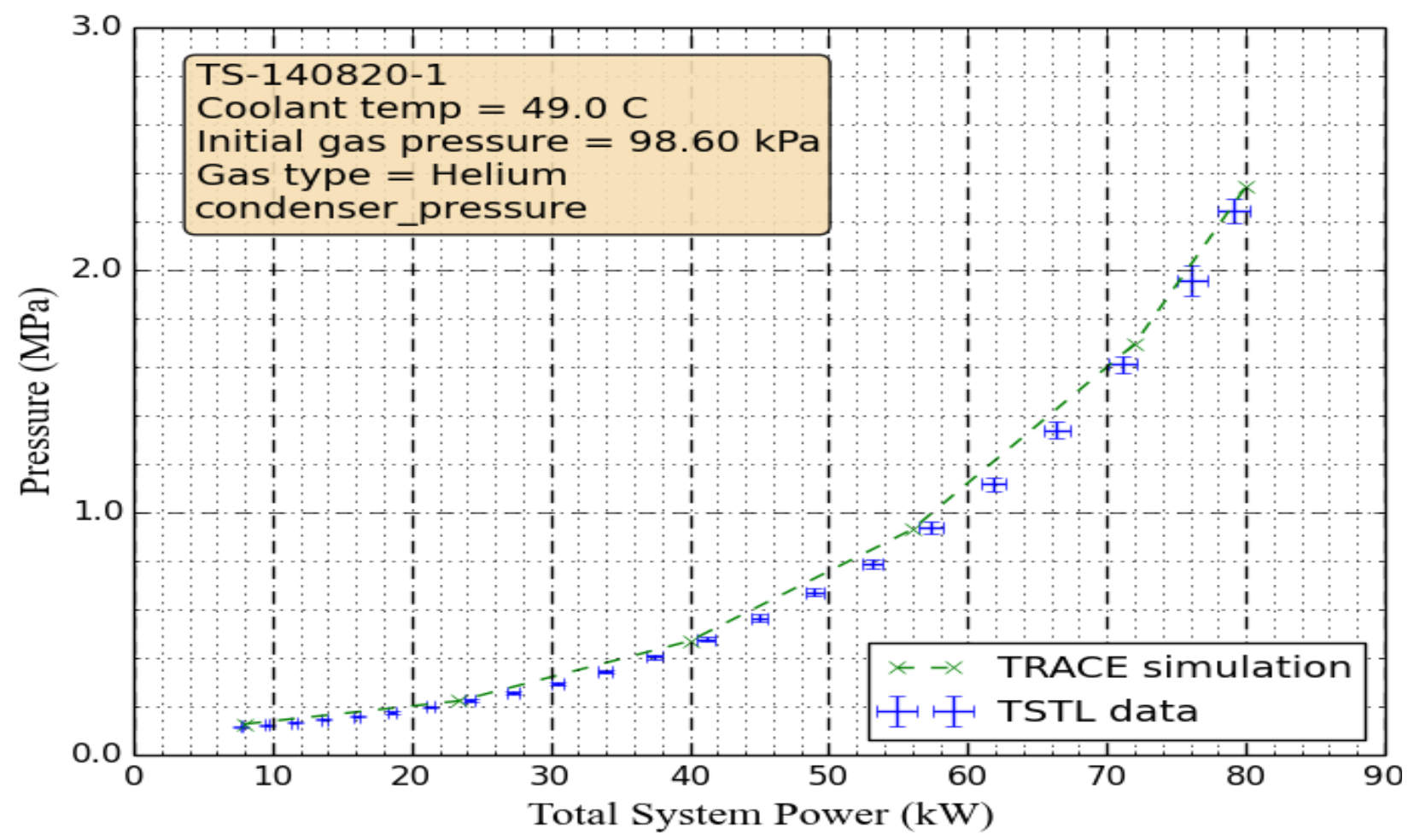

Figure 7-13. Measured data and TRACE-calculated condenser pressure.

Figures 7-14 through 7-16 show temperature comparisons for TE-41, TE-42 and TE-43, respectively, the three TCs located inside the condenser, as shown in Fig. 5-1. Figures 7-17 through 7-19 show temperature comparison for TE-44, TE-45 and TE-46, respectively, the three TCs located inside the boiler/evaporator (locations shown in Fig. 5-1). TE-44 is the TC located at the top of the boiler and measures the vapor temperature leaving the boiler (Fig. 7-17). TE-46 is located at the bottom of the boiler/evaporator and measures the temperature of the liquid water entering the boiler (Fig. 7-19). The calculated vapor temperature and the liquid water temperature entering the boiler at the final power are also shown in Table 7-1. The agreement with the data is very good for every variable except for the liquid water temperature entering the boiler: the TRACE calculated water temperature is higher than the experimental value except at very low powers. At the final power of $80 \mathrm{~kW}$, the difference is $8^{\circ} \mathrm{C}$, with the calculated value higher than the data.

These six TC positions correspond to condenser node 30 (TE-41), node 18 (TE-42) and node 8 (TE-43) and to boiler/evaporator node 1 (TE-44), node 14 (TE-45) and node 28 (TE-46) of the TRACE model shown in Fig. 7-1. Node 1 is the bottom node, and node 34 is the top node of the condenser. For the boiler, node 1 is the top node, and node 28 is the bottom node.

Figures 7-14 and 7-15 show temperature stratification in the condenser, with sudden temperature changes as the power is increased (at $40 \mathrm{~kW}$ in Fig. 7-14 and at $20 \mathrm{~kW}$ in Fig. 7-15). 


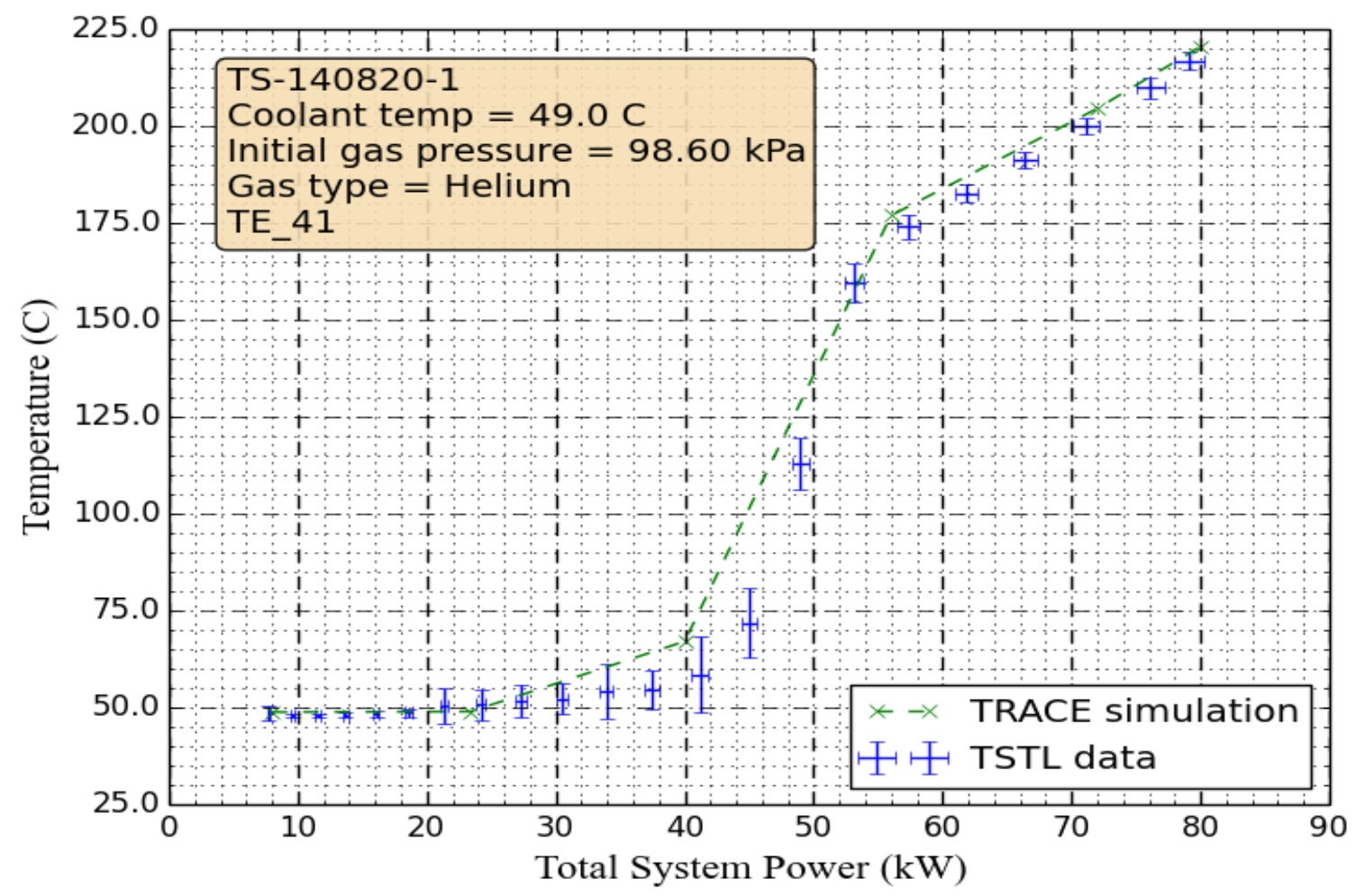

Figure 7-14. Measured and calculated temperatures for TE-41.

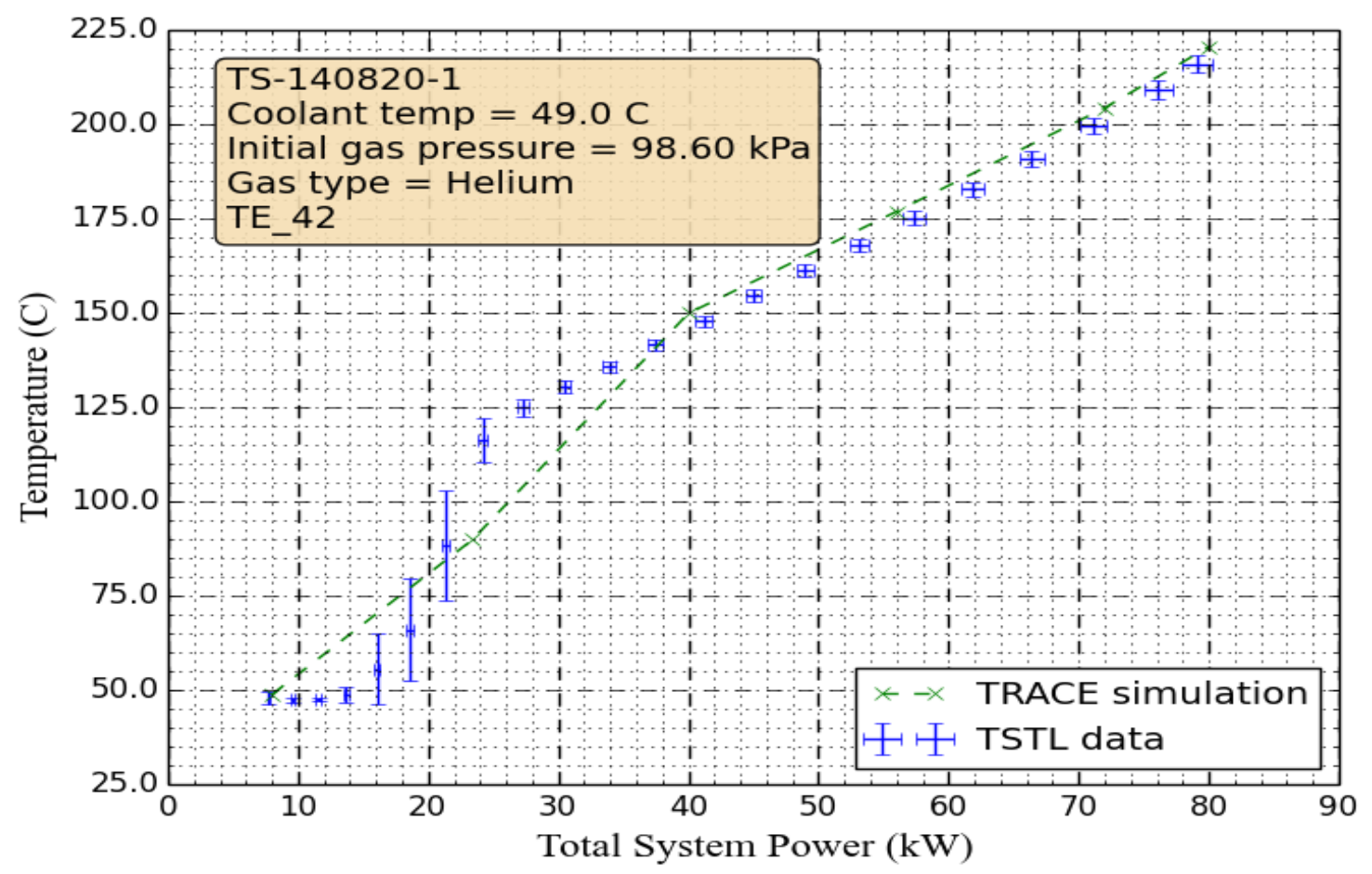

Figure 7-15. Measured and calculated temperatures for TE-42. 


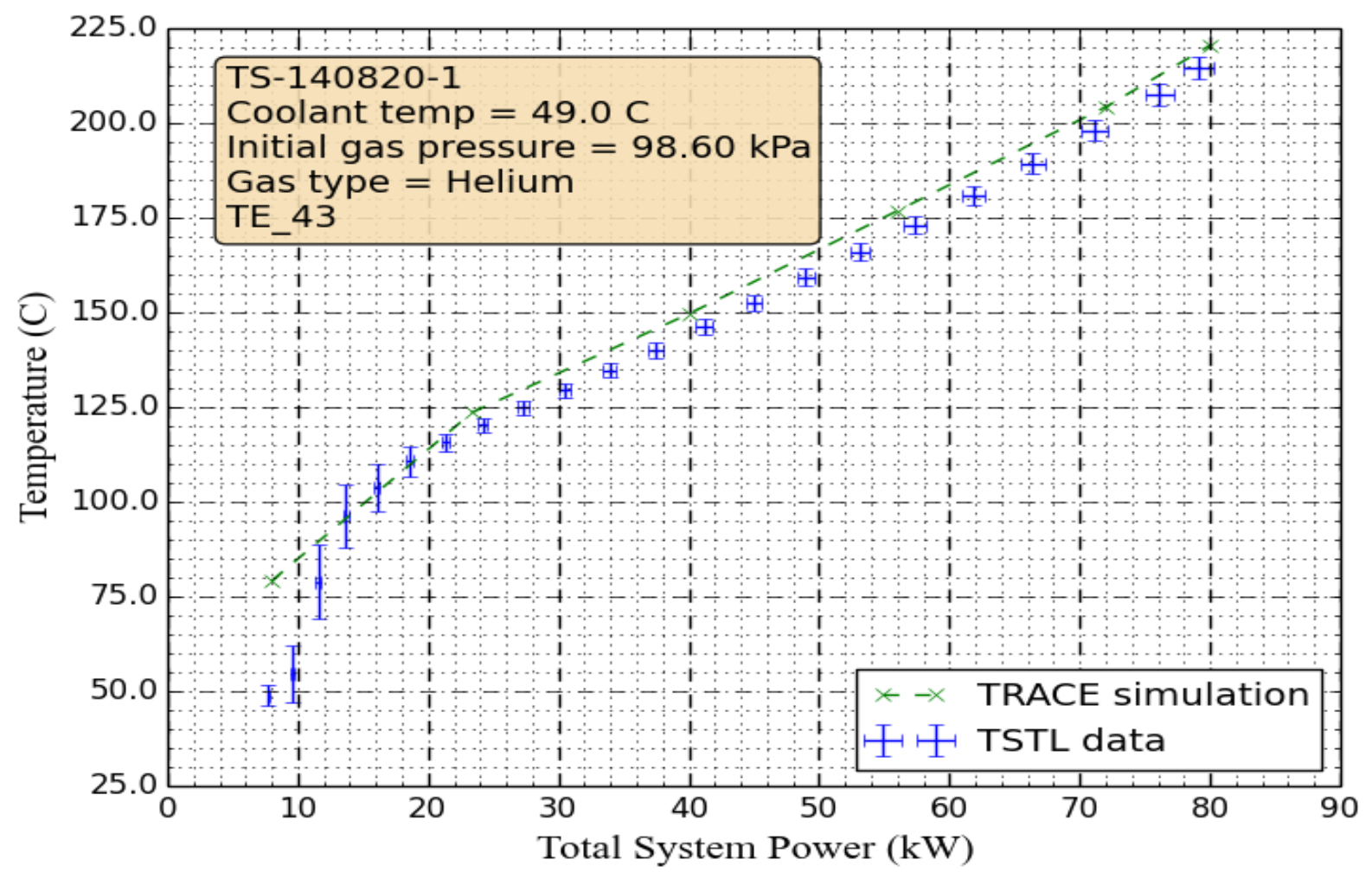

Figure 7-16. Measured and calculated temperatures for TE-43.

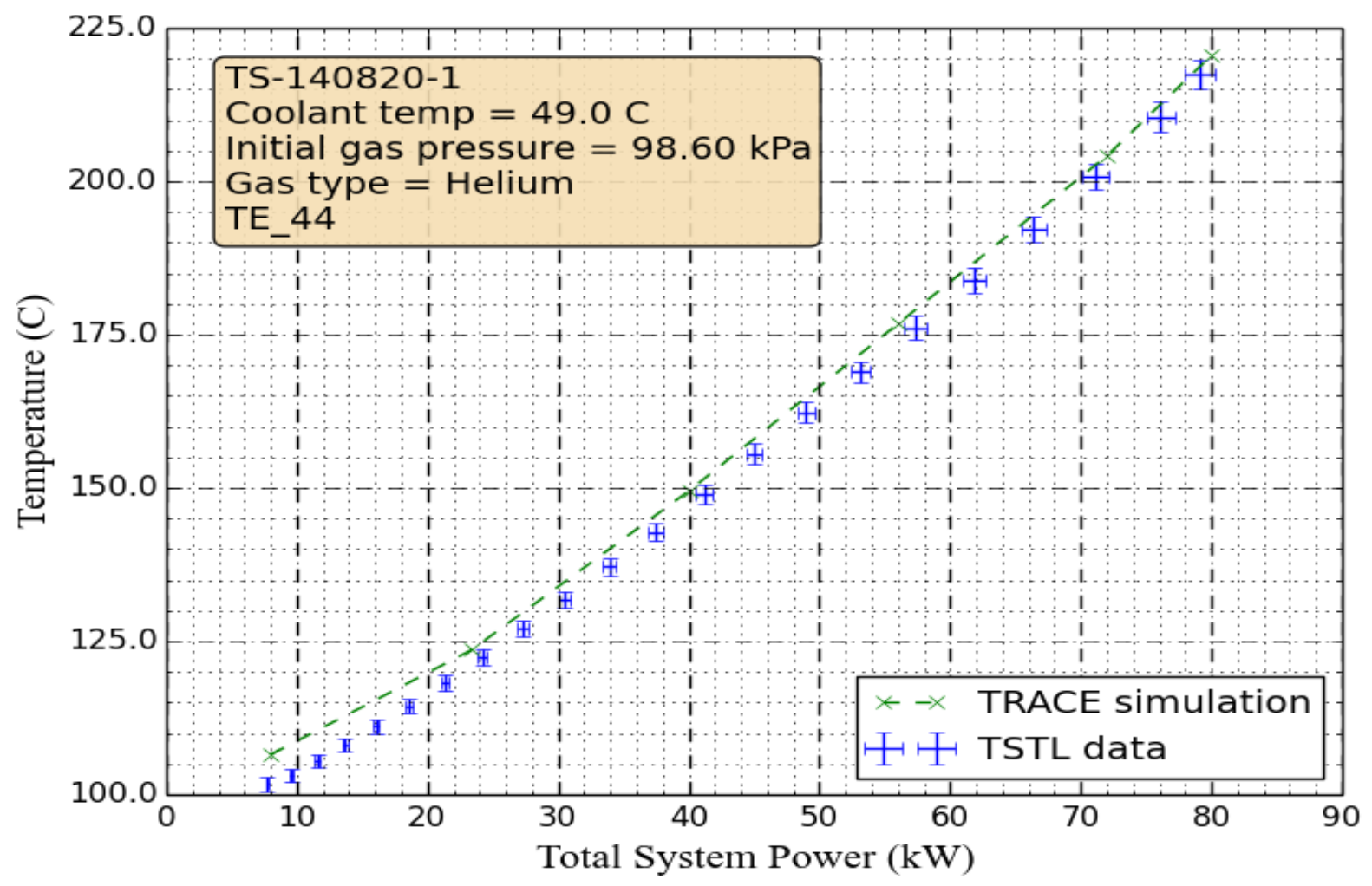

Figure 7-17. Measured and calculated temperatures for TE-44. 


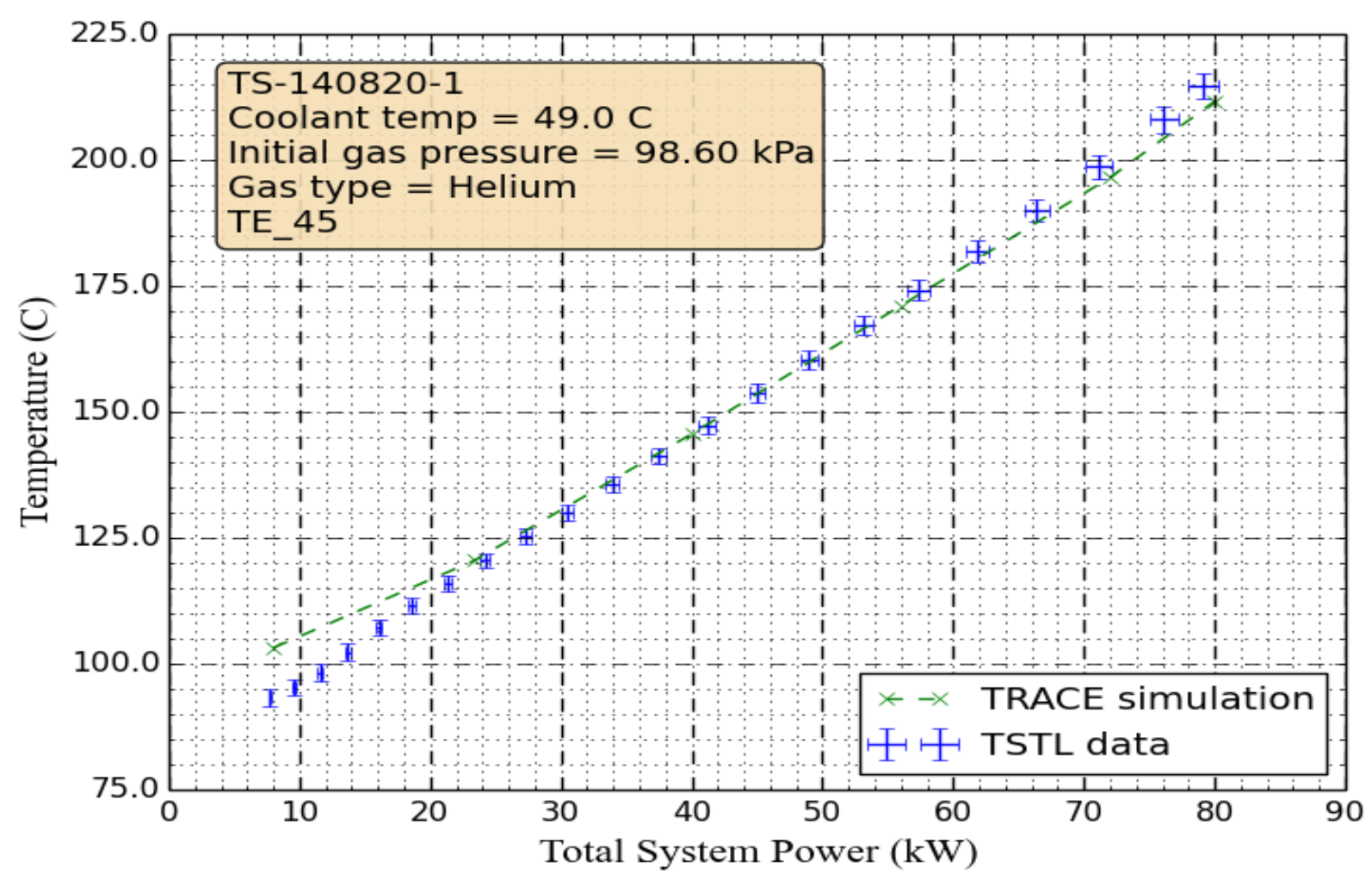

Figure 7-18. Measured and calculated temperatures for TE-45.

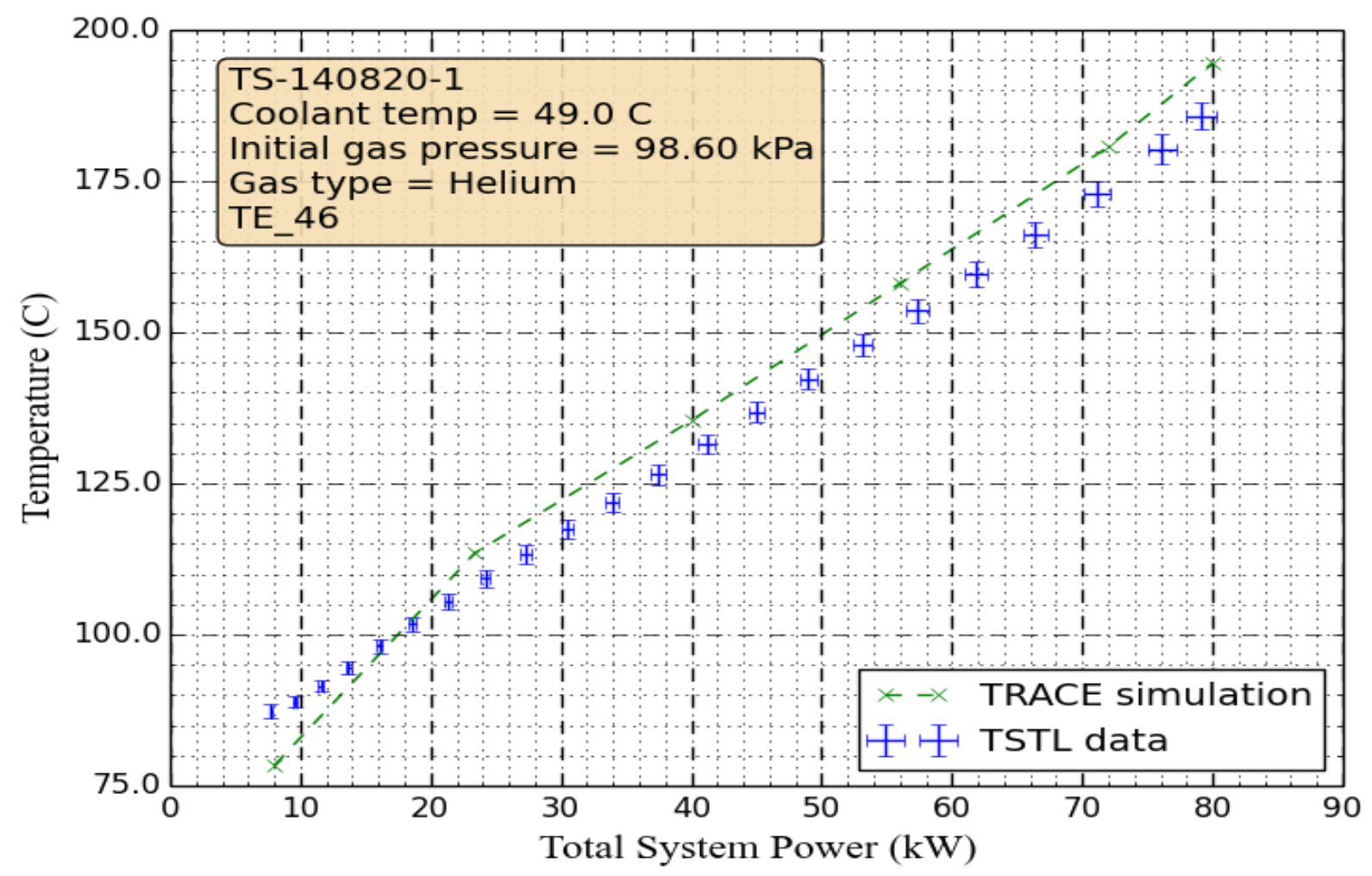

Figure 7-19. Measured and calculated temperatures for TE-46. 
The amount of helium in the TRACE model for this test is $0.7 \mathrm{~g}$; Table 5-1 shows a calculated mass of $0.61 \mathrm{~g}$ of helium for this test. The amount of helium cannot be entered directly into the TRACE code. TRACE input requires temperatures and pressures in the condenser nodes together with the type of NC gas present. A TRACE run calculates the amount of $\mathrm{NC}$ gas in the condenser volume and in the overall system as part of the output. This output is $0.7 \mathrm{~g}$ of helium.

\subsubsection{Test TS-140821-1}

This was another test with helium added to an initial pressure of $112 \mathrm{kPa}(1.6 \mathrm{psig})$ at zero power and $322 \mathrm{~K}\left(49^{\circ} \mathrm{C}\right)$. It resulted in a final pressure of $2.46 \mathrm{MPa}$ at the total final power of $80 \mathrm{~kW}$. The initial and final pressures are a little higher than in the previous test (TS-140820-1). The amount of helium calculated by the TRACE code for this test is $0.83 \mathrm{~g}$. Table 5-1 reports a calculated helium mass of 0.79 g. Figure 7-20 shows the measured and calculated pressures in the condenser as a function of power for this test. Both values agree well at all powers. Figures 7-21 through 7-26 show calculated and measured temperatures for TE-41, TE-42, TE-43, TE-44, TE-45 and TE-46 as a function of power.

This test was very similar to the previous test, TS-140820-1. The calculated pressures and temperatures agreed well with the data values at all powers except for the water temperature into the boiler. The calculated value $\left(475 \mathrm{~K}\right.$ or $\left.202^{\circ} \mathrm{C}\right)$ is $15 \mathrm{~K}$ higher than the measured value $\left(460 \mathrm{~K}\right.$ or $\left.187^{\circ} \mathrm{C}\right)$ at final power, as shown in Fig. 7-26.

Test TS-140821-1 showed notable temperature stratification in the condenser per Figs. 7-21, 7-22 and 7-23. This phenomenon was even more notable in the next test, TS-140829-1, in which there was a higher initial amount of helium (a high pressure helium test).

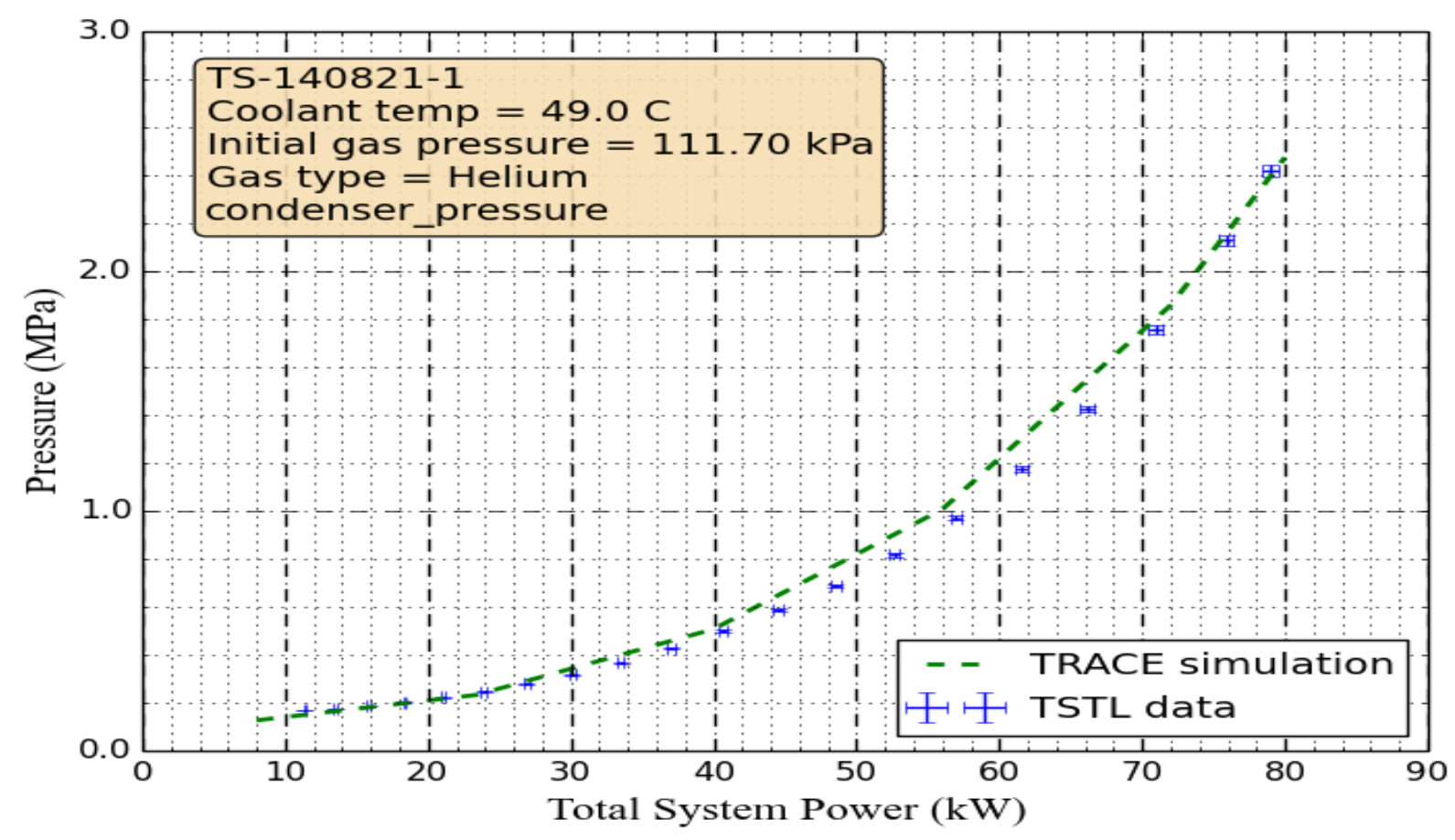

Figure 7-20. Measured and calculated pressure for Test TS-140821-1. 


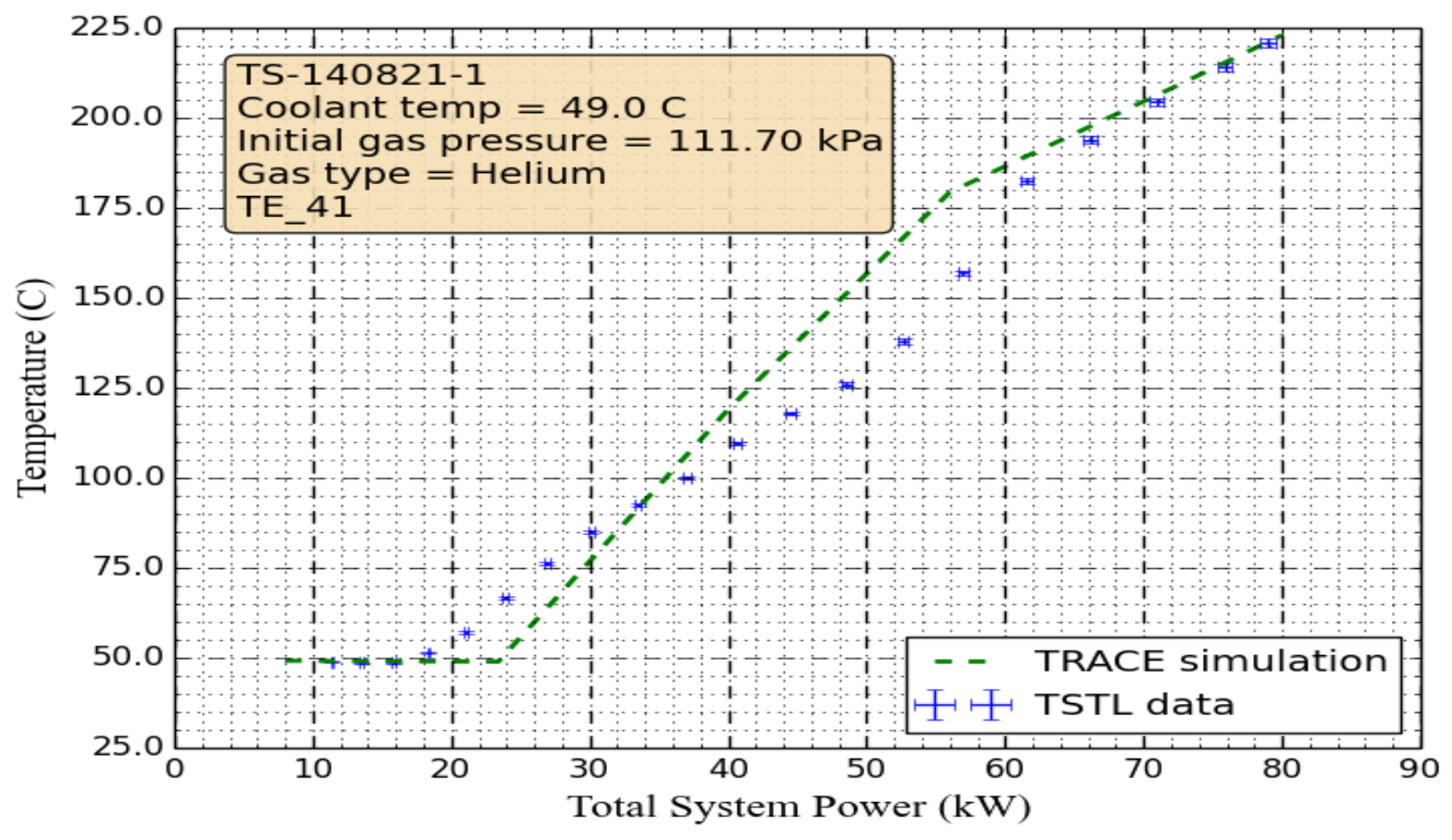

Figure 7-21. Measured and calculated temperatures for TE-41.

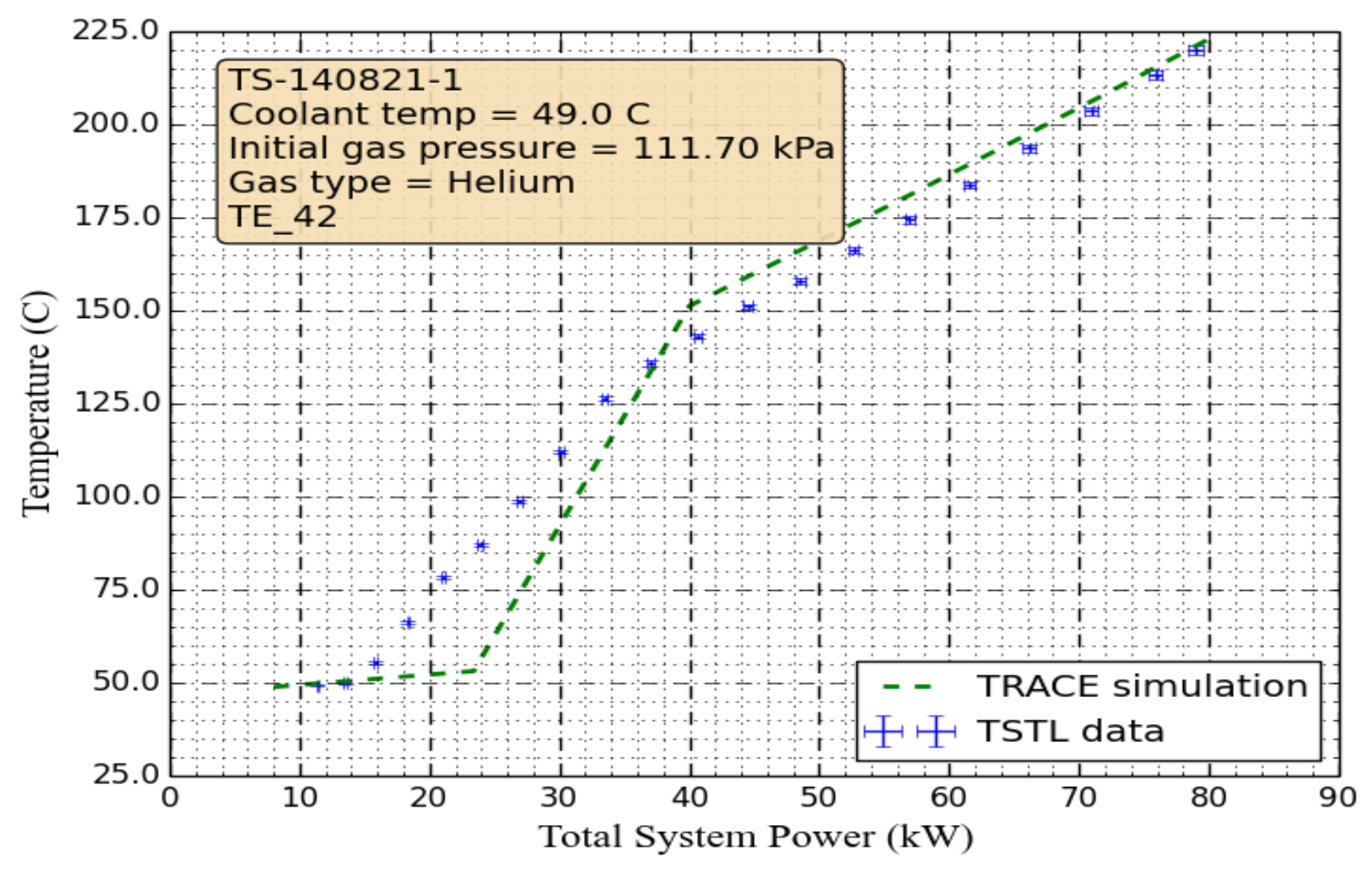

Figure 7-22. Measured and calculated temperatures for TE-42. 


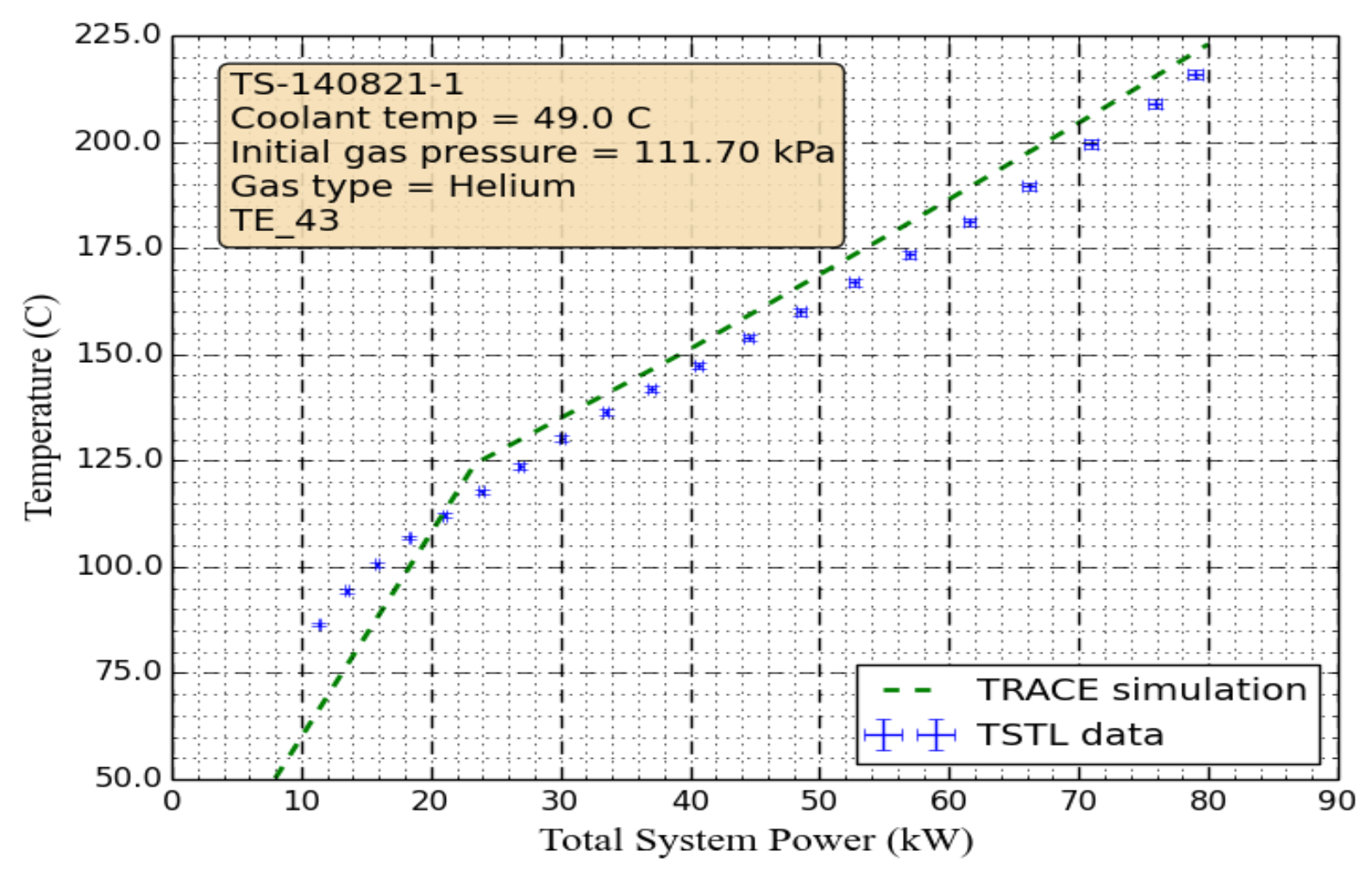

Figure 7-23. Measured and calculated values for TE-43.

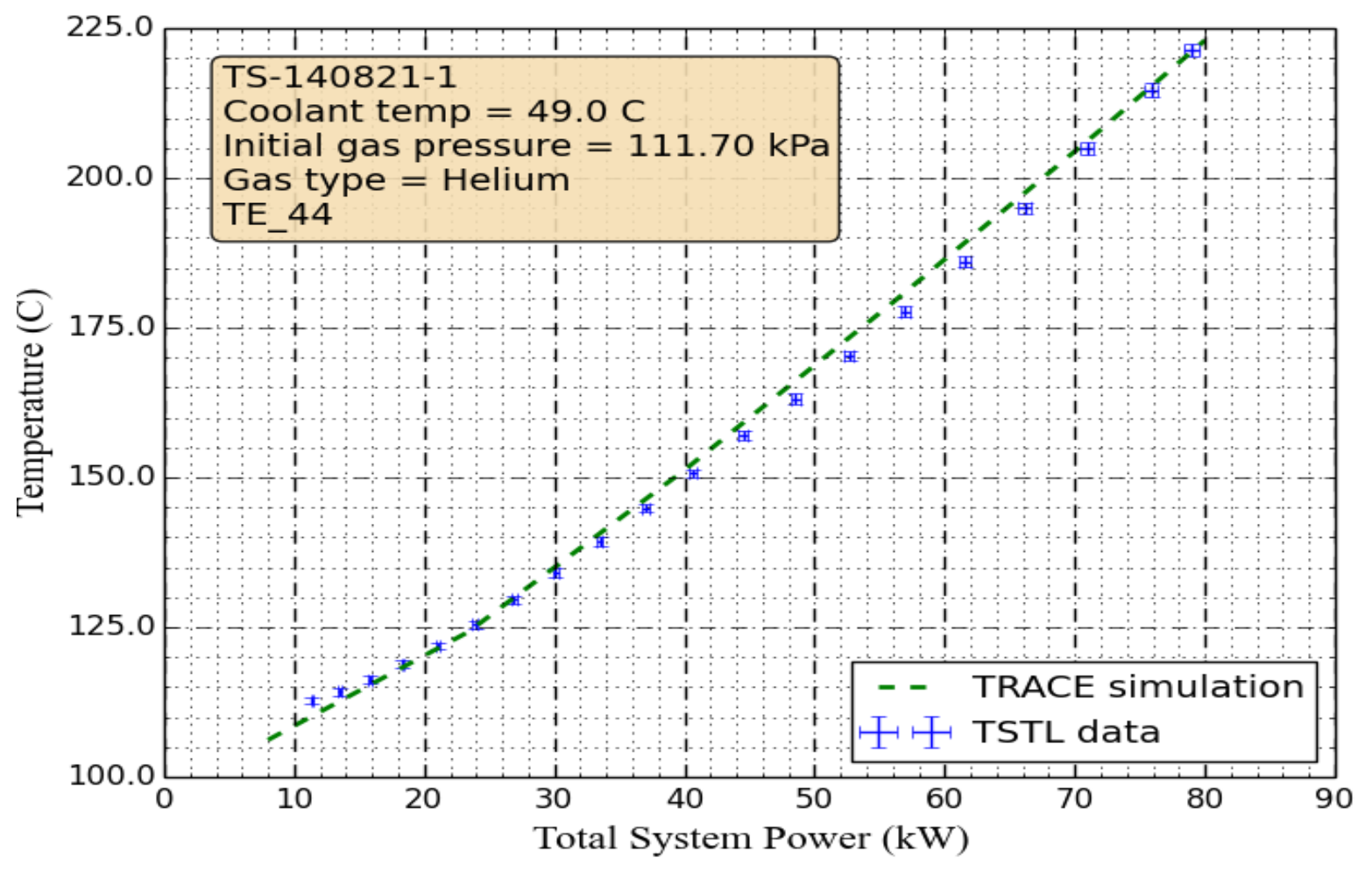

Figure 7-24. Measured and calculated values for TE-44. 


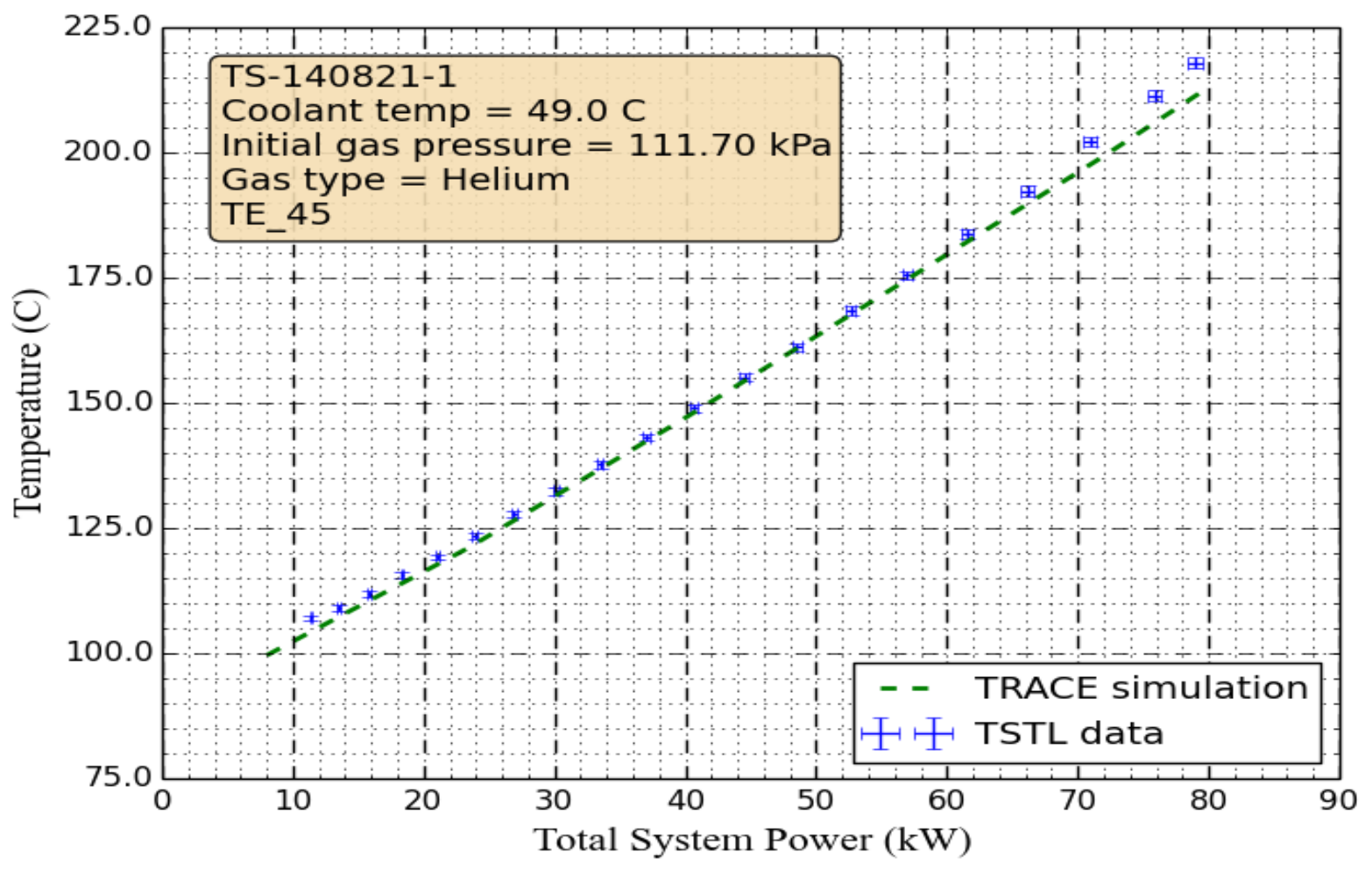

Figure 7-25. Measured and calculated values for TE-45.

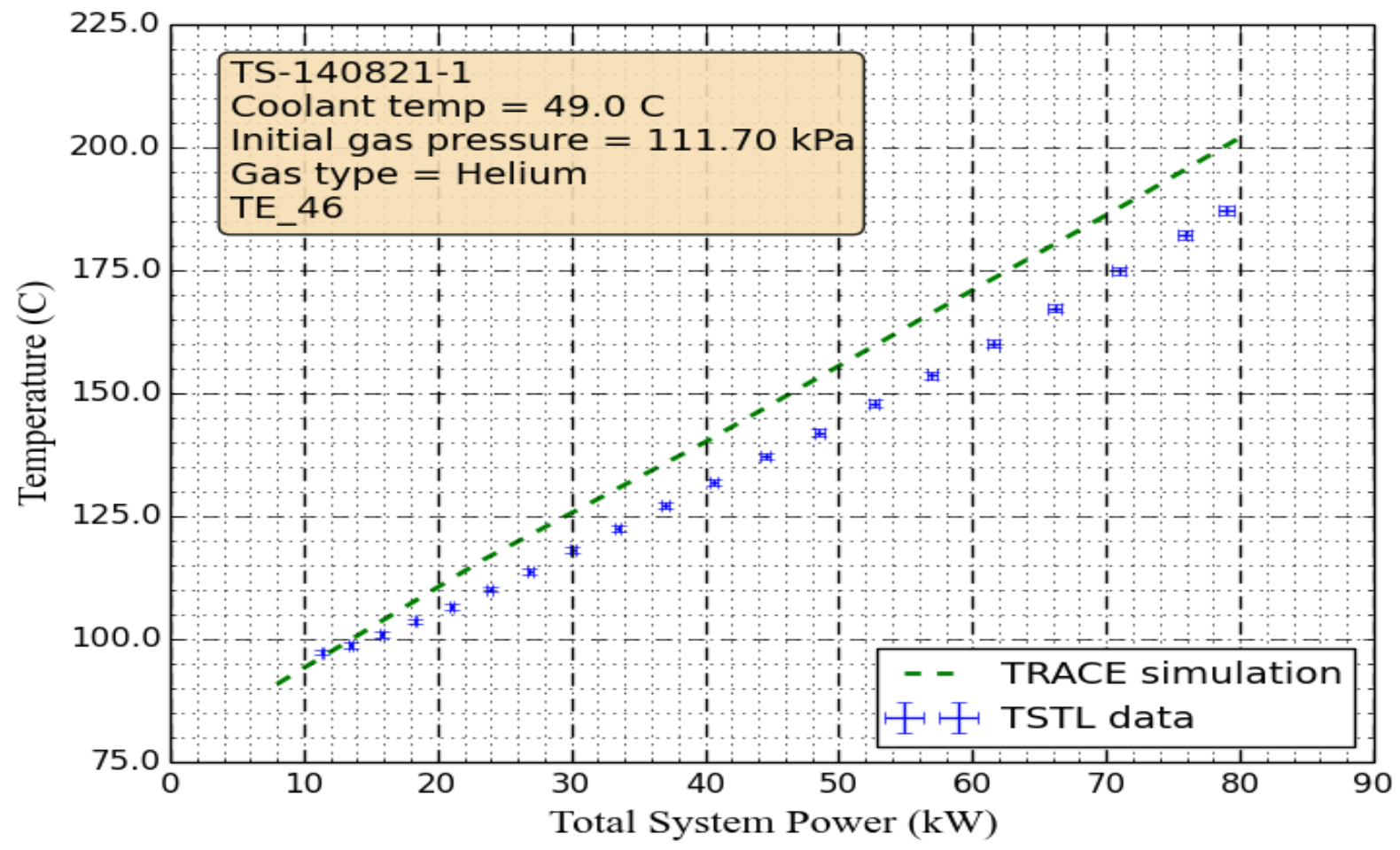

Figure 7-26. Measured and calculated values for TE-46. 


\subsubsection{Test TS-140829-1 (Helium High Pressure Test)}

In this test, the initial pressure at zero power and $322 \mathrm{~K}\left(49^{\circ} \mathrm{C}\right)$ was $\mathrm{Po}=3.0 \mathrm{MPa}(426 \mathrm{psig})$, which was achieved by injecting sufficient helium gas in the condenser. TRACE calculated that $21.2 \mathrm{~g}$ of helium were injected in this high pressure test. For comparison, the amount of helium charged in this experiment as calculated in Table 5-1 is $22.9 \mathrm{~g}$.

The final measured pressure at the total power of $80 \mathrm{~kW}$ was Pfinal $=7.66 \mathrm{MPa}$ (1110 psig). Figure 7-27 shows the measured and the calculated pressure, both of which agree well at powers over $50 \mathrm{~kW}$. At low powers, the calculated values are lower than the experimental values. Figures 7-28 through 7-33 compare the TRACE calculated temperatures and the measured temperatures for TE-41, TE-42, TE-43, TE-44, TE-45 and TE-46. The steam temperatures (TE-44) agree well with the data at all powers. At full power, the steam temperature is $565 \mathrm{~K}\left(292^{\circ} \mathrm{C}\right)$, which is in perfect agreement with the data. Other temperatures do not agree that well. The measured temperatures of TE- 41 and TE- 42 are about $10{ }^{\circ} \mathrm{C}$ lower than the calculated values. The measured temperature of the water into the boiler (TE-46) is $510 \mathrm{~K}\left(237^{\circ} \mathrm{C}\right)$, a value lower than the calculated value of $528 \mathrm{~K}\left(255^{\circ} \mathrm{C}\right)$ by $18 \mathrm{~K}$. Thus, the measured liquid subcooling $(55 \mathrm{~K})$ is larger by $18 \mathrm{~K}$ than the calculated value $(37 \mathrm{~K})$. Tests with large amounts of $\mathrm{NC}$ gases show larger subcoolings than tests with small amounts of NC gases. A possible reason is that the downcomer appears to be cooling the liquid water more than the TRACE code calculates. The TRACE code appears to under-calculate the subcooling of the water entering the boiler/evaporator.

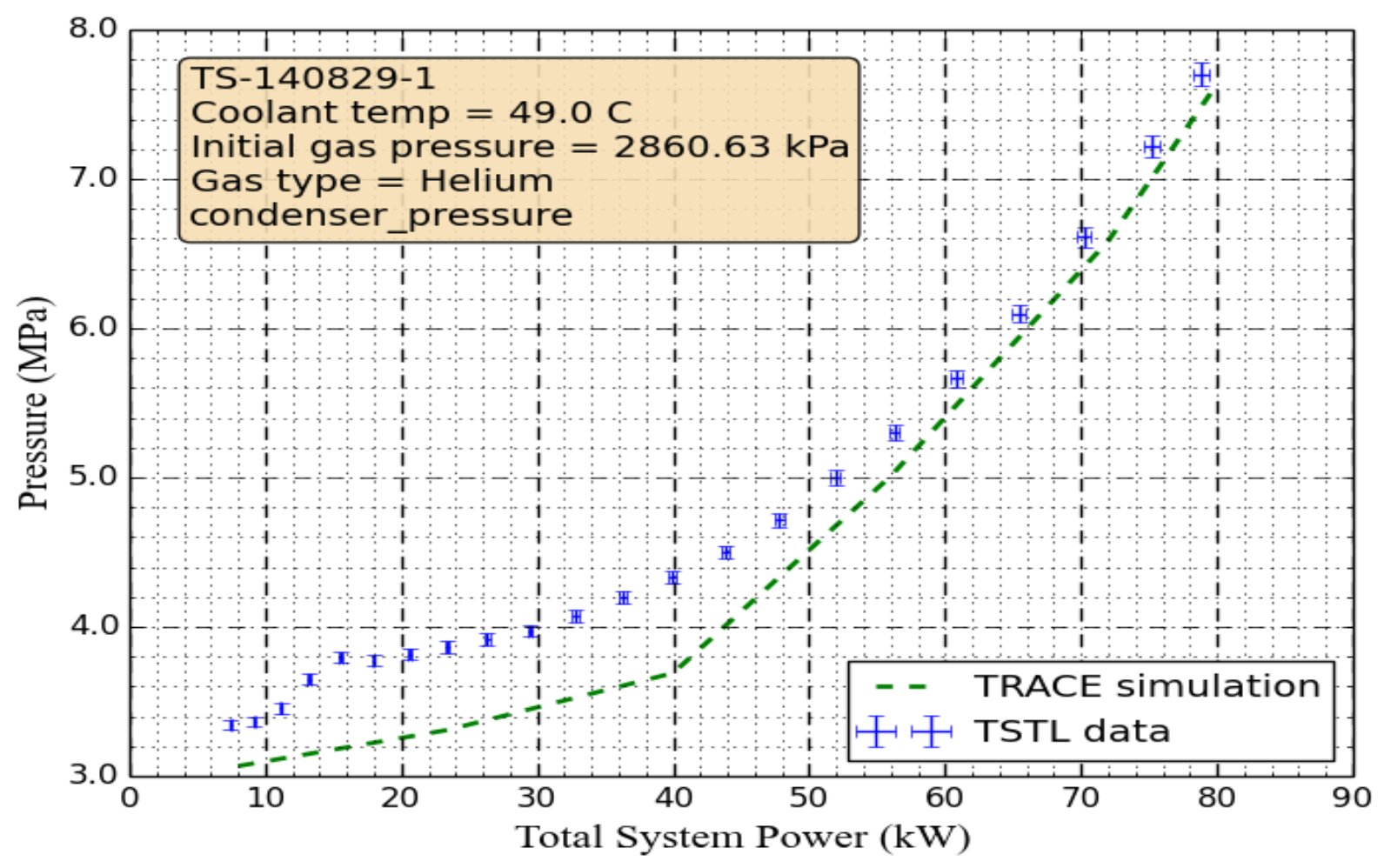

Figure 7-27. Measured and calculated condenser pressures. 


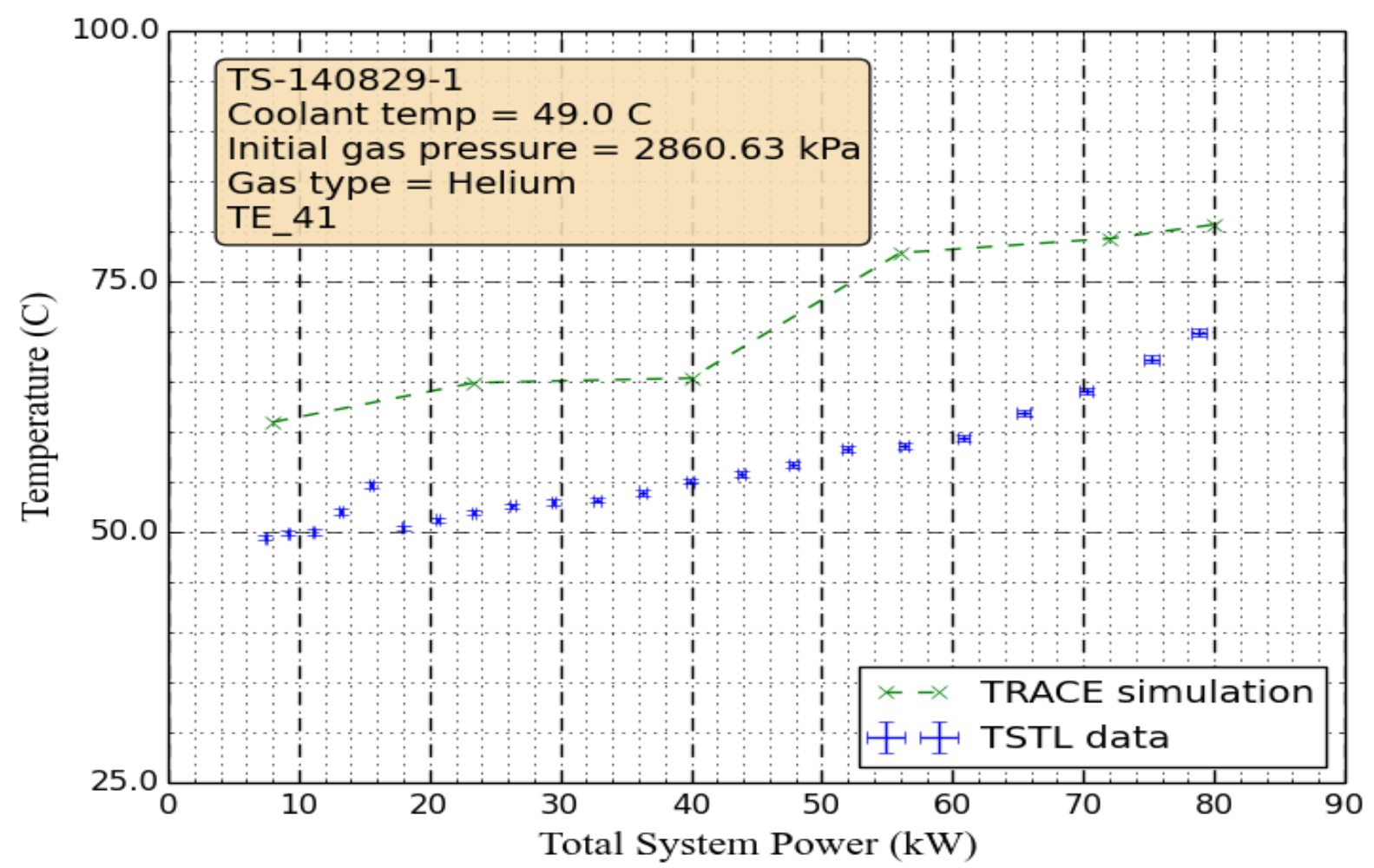

Figure 7-28. Measured and calculated temperatures for TE-41.

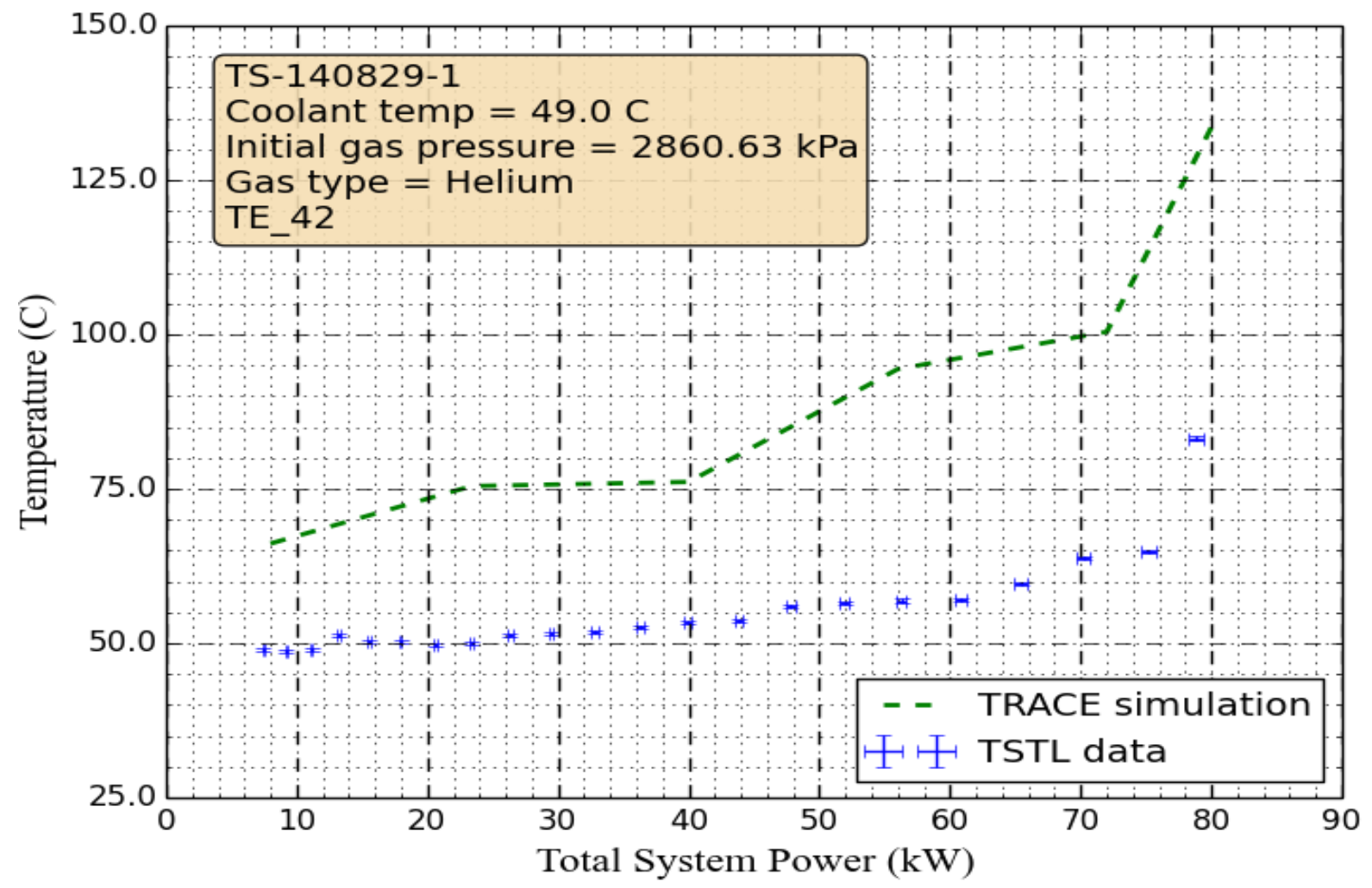

Figure 7-29. Measured and calculated temperatures for TE-42. 


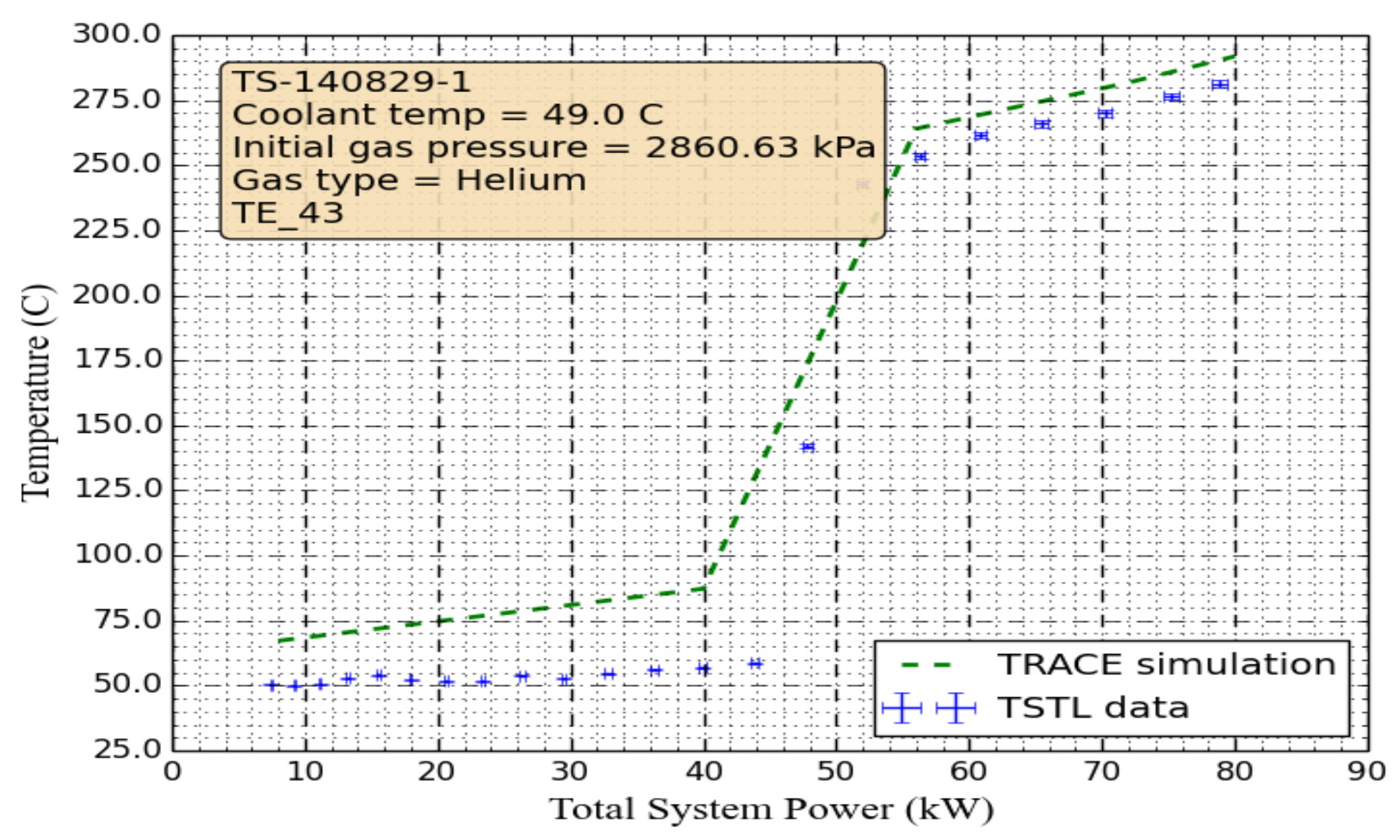

Figure 7-30. Measured and calculated temperatures for TE-43.

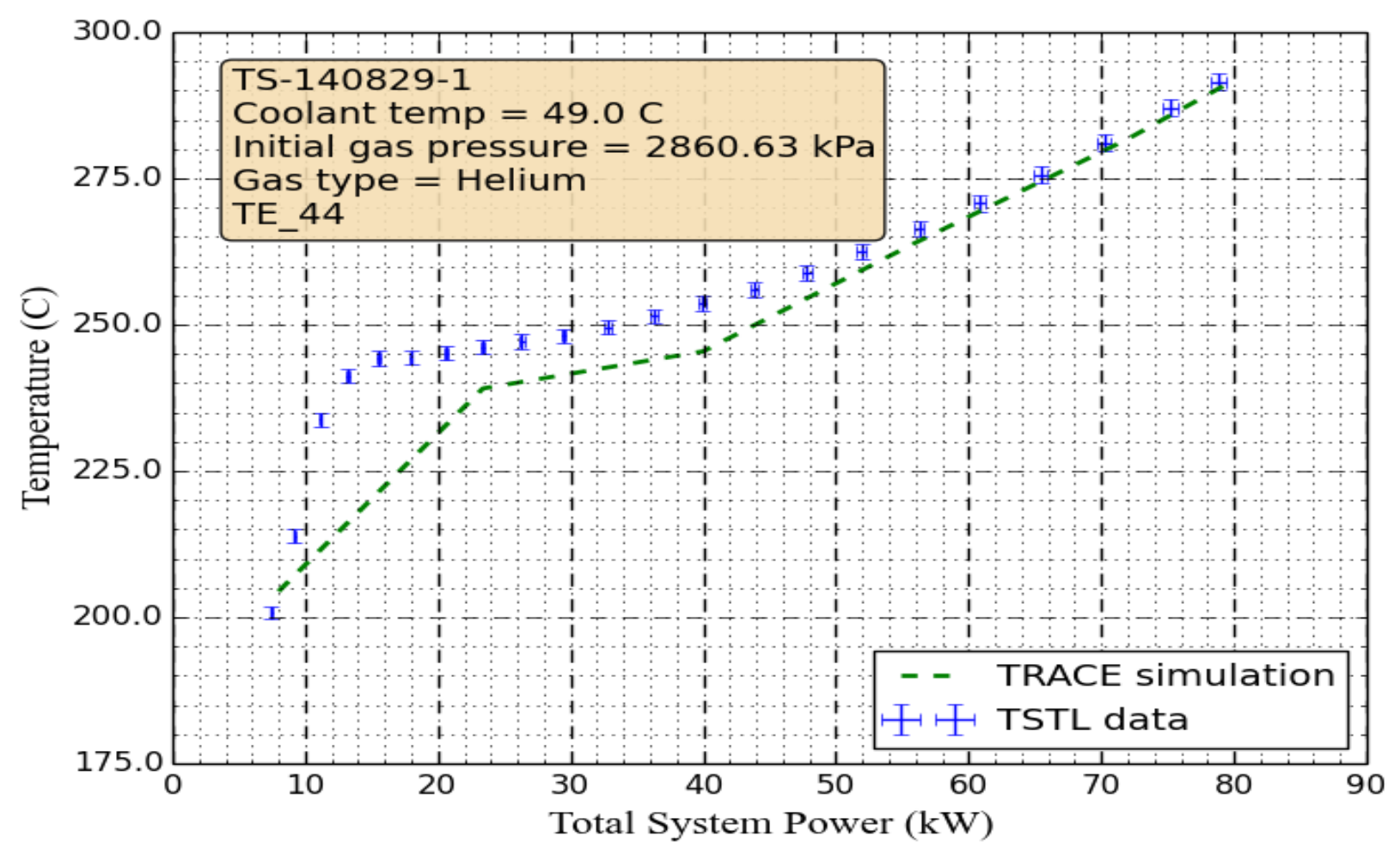

Figure 7-31. Measured and calculated temperatures for TE-44. 


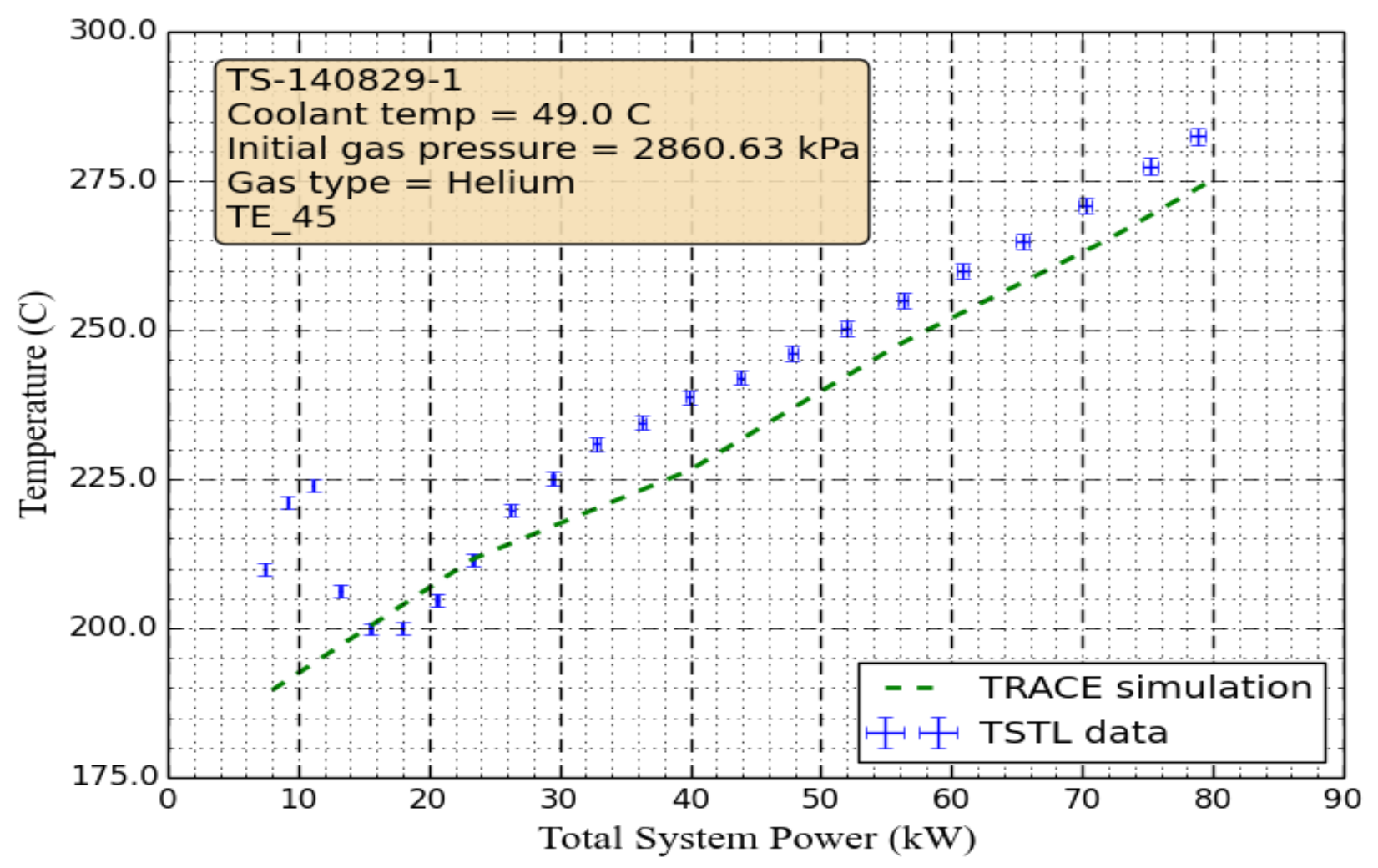

Figure 7-32. Measured and calculated temperatures for TE-45.

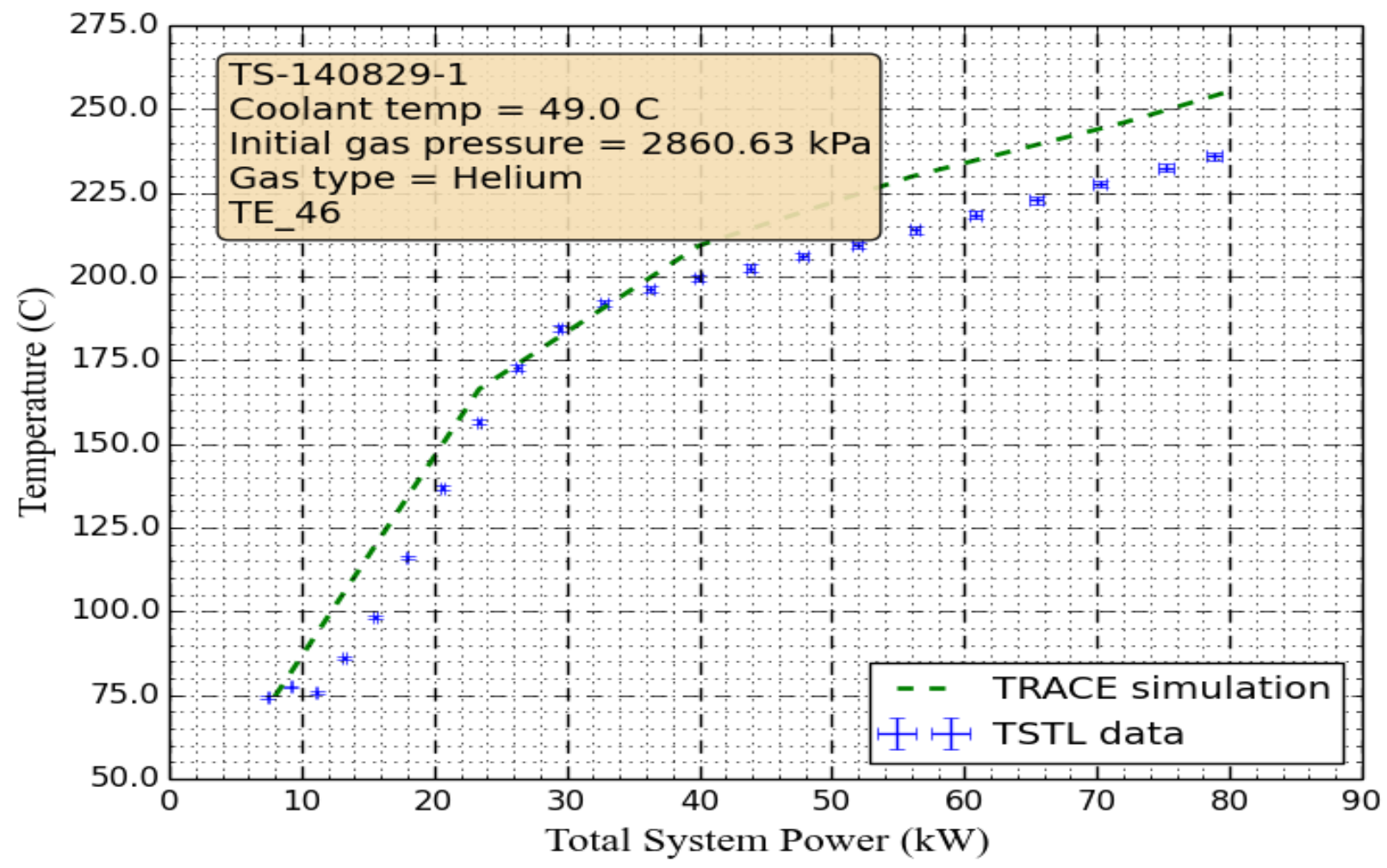

Figure 7-33. Measured and calculated temperatures for TE-46. 
Finally, Figure 7-34 compares calculated pressures from the previous TRACE runs with helium added plus the calculation with pure steam that could not be completed experimentally. This figure shows the effect of increasing amounts of helium on the system pressure. More helium added results in higher initial and final (at full power) pressures. Also, higher pressures correspond to higher temperatures for the liquid, vapor, and heaters, but more helium reduces the condensing capacity of the condenser and increases the subcooling of the water, as the downcomer may remove more heat than the condenser (as described in Sect. 7.10).

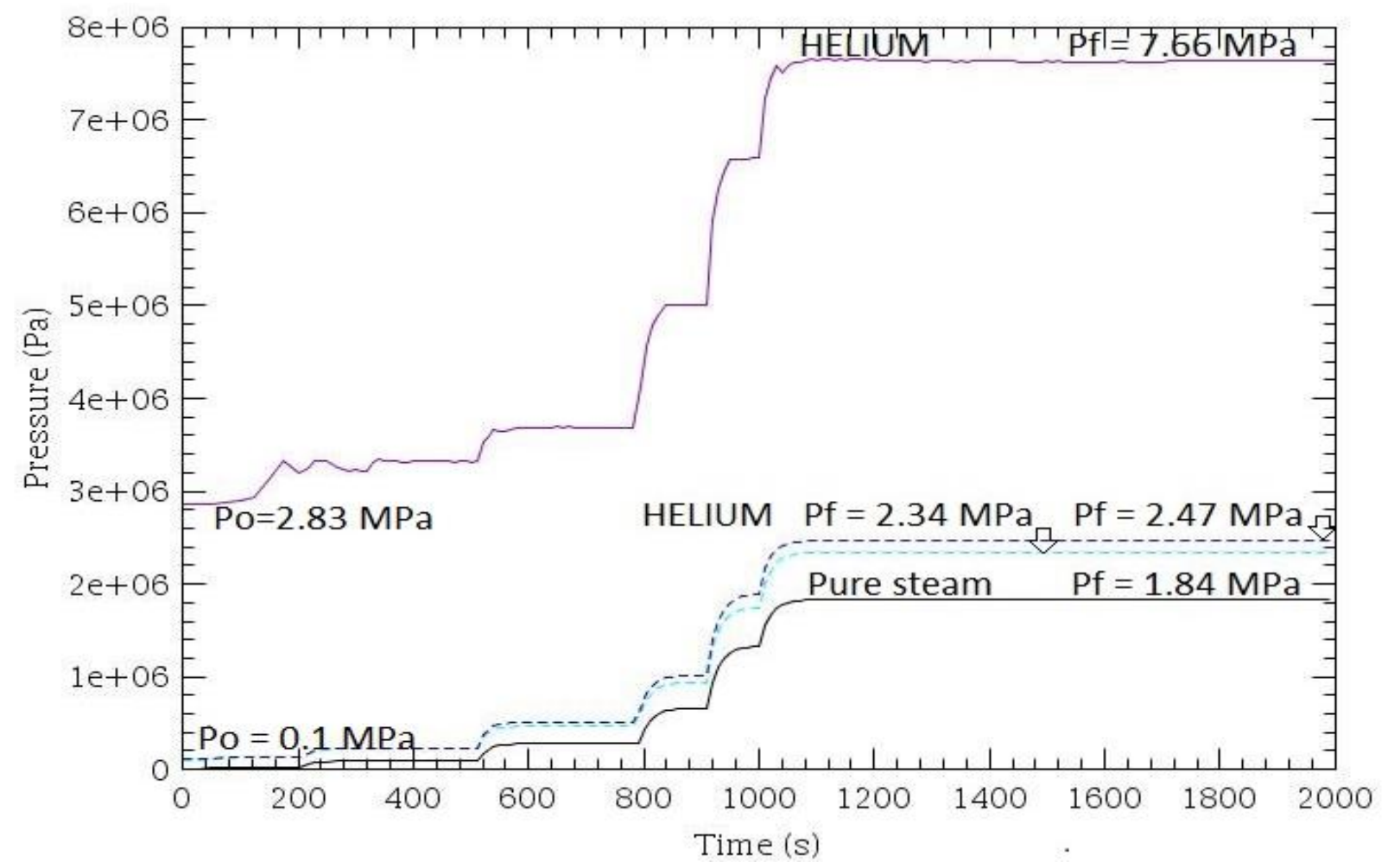

Figure 7-34. TRACE calculated pressures with increasing amounts of helium.

\subsection{ARGON TESTS}

Two argon tests were simulated with the TRACE code: one low pressure test, TS-140910-1, and one high pressure test, TS-140911-3.

\subsubsection{Low Pressure Test Argon TS-140910-1}

This test was started at a pressure of $0.121 \mathrm{MPa}$ at zero power and $322 \mathrm{~K}\left(49^{\circ} \mathrm{C}\right)$ and ended at a pressure of $2.67 \mathrm{MPa}(372 \mathrm{psig})$ at $80 \mathrm{~kW}$ of power. Figure 7-35 shows the measured and calculated pressure in the condenser, and Figs. 7-36 through 7-41 show calculated and measured temperatures for TE-41, TE-42, TE-43, TE-44, TE-45 and TE-46, which are the six temperatures measured in the condenser and in the boiler/evaporator. The agreement between the data and the calculated values is not as good as with previous helium tests. At full power, the measured temperatures of the water entering the boiler and the vapor leaving the boiler/evaporator were $463 \mathrm{~K}\left(190^{\circ} \mathrm{C}\right)$ and $500 \mathrm{~K}\left(227^{\circ} \mathrm{C}\right)$, respectively. The TRACEcalculated water and vapor temperatures are $477 \mathrm{~K}\left(204^{\circ} \mathrm{C}\right)$ and $500 \mathrm{~K}\left(227^{\circ} \mathrm{C}\right)$, respectively. As in the previous helium tests, the calculated vapor temperature agrees well with the measured value, but the calculated water temperature is $14 \mathrm{~K}$ above the measured value. 
According to the TRACE calculation, the amount of argon in the system for this test is $8.4 \mathrm{~g}$, which compares well to the experiment calculated charge of $8.6 \mathrm{~g}$ from Table 5.1.

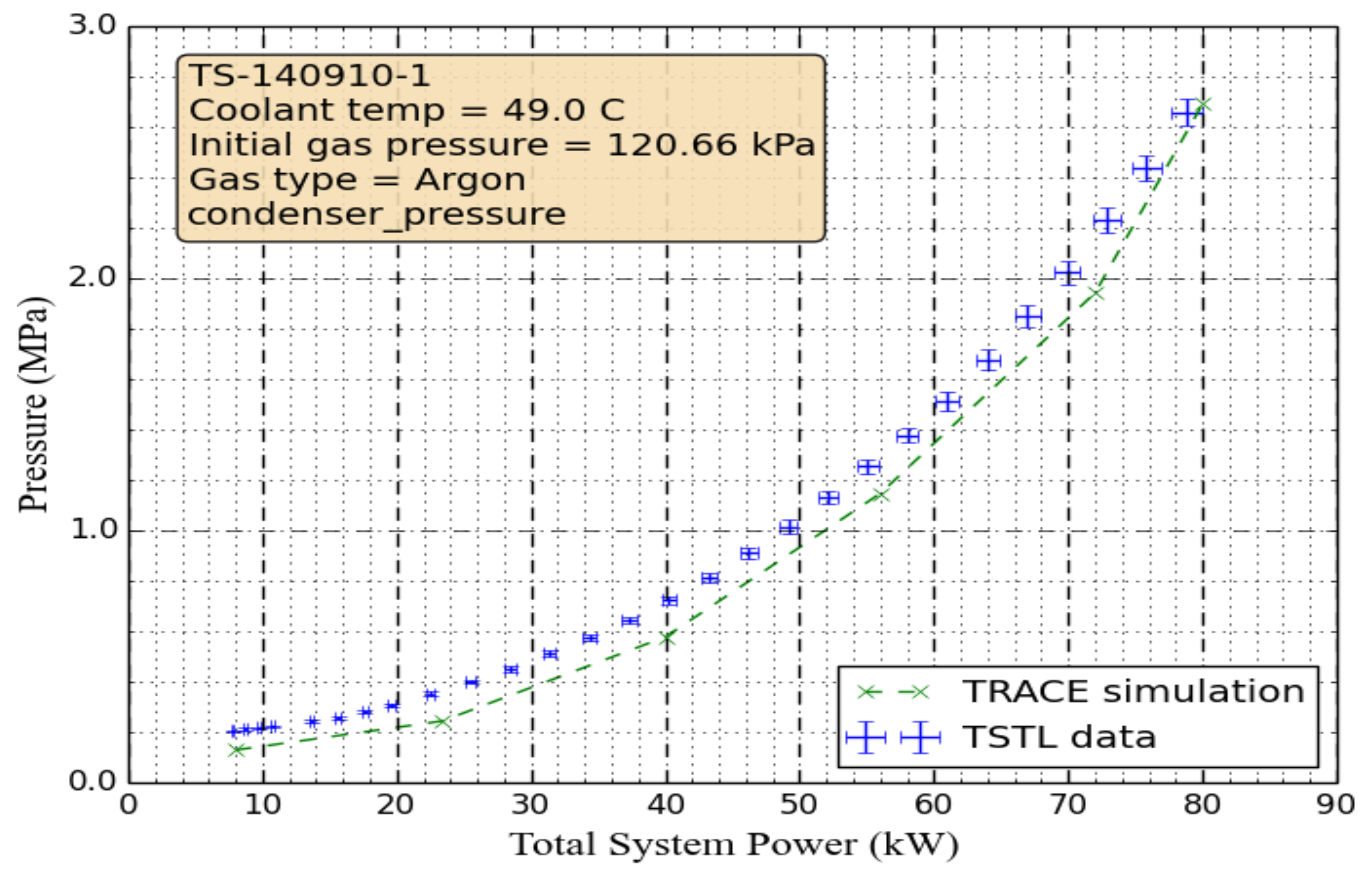

Figure 7-35. Measured and calculated pressure for argon test TS-140910-1.

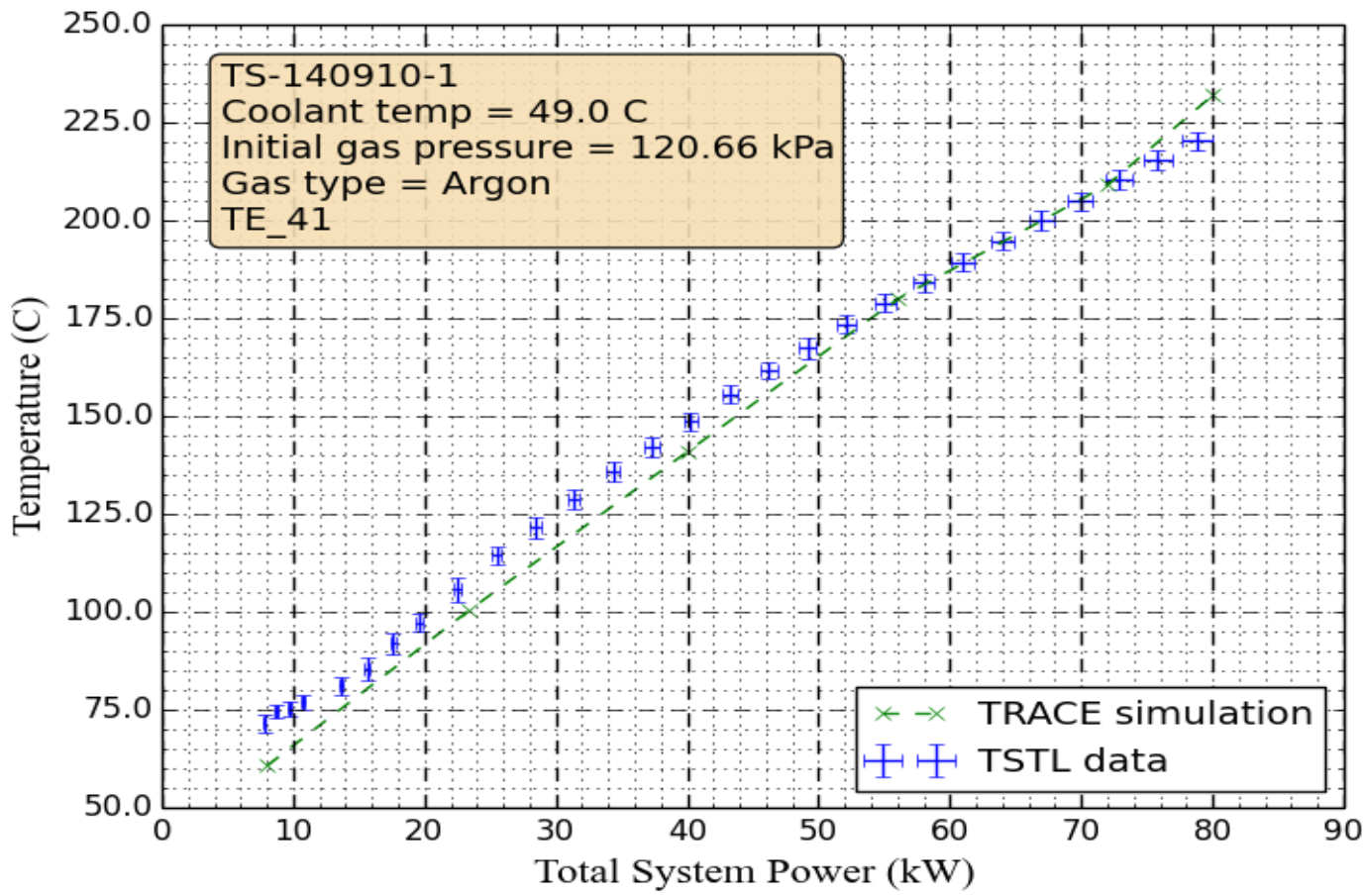

Figure 7-36. Measured and calculated temperatures for TE-41. 


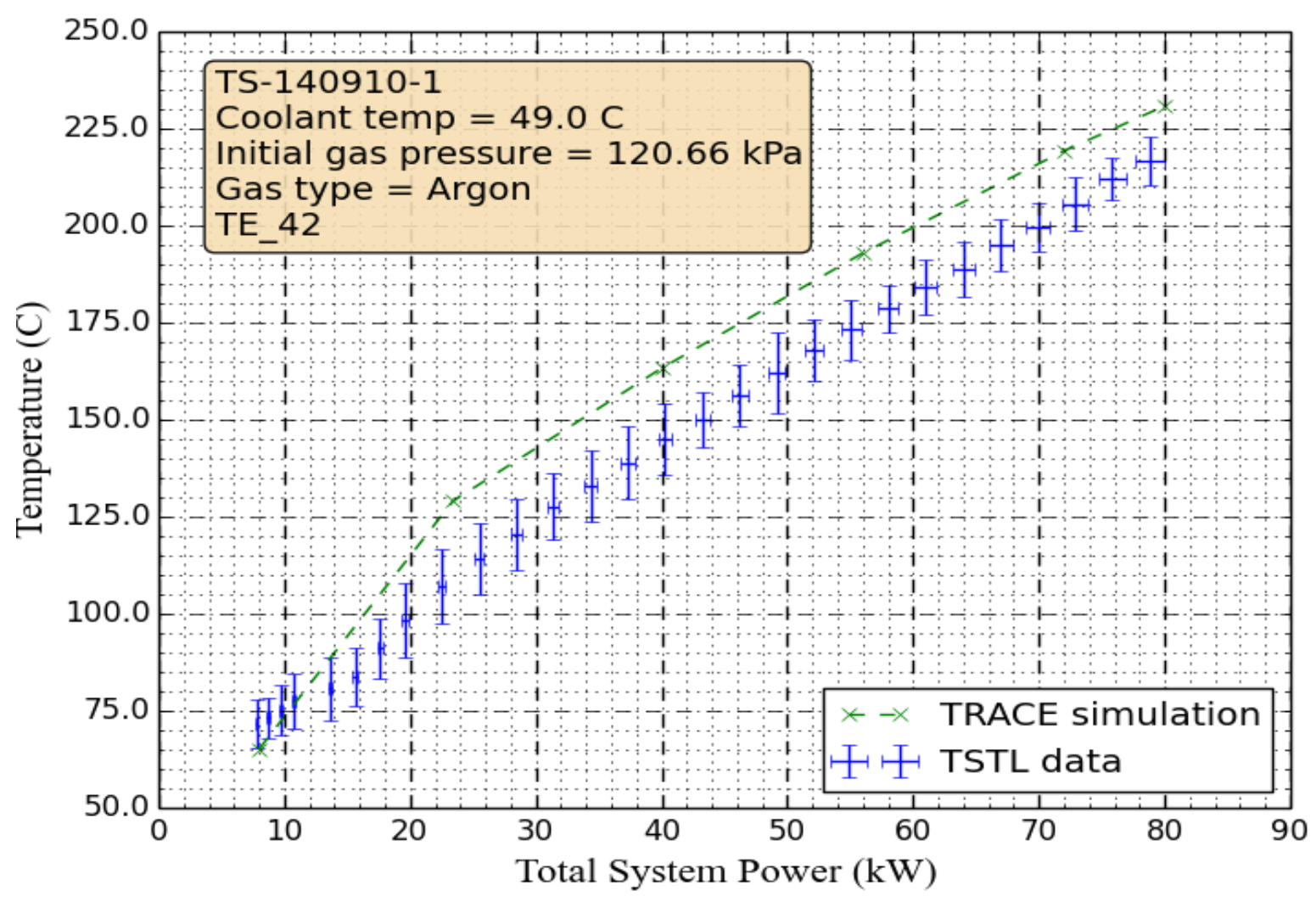

Figure 7-37. Measured and calculated temperatures for TE-42.

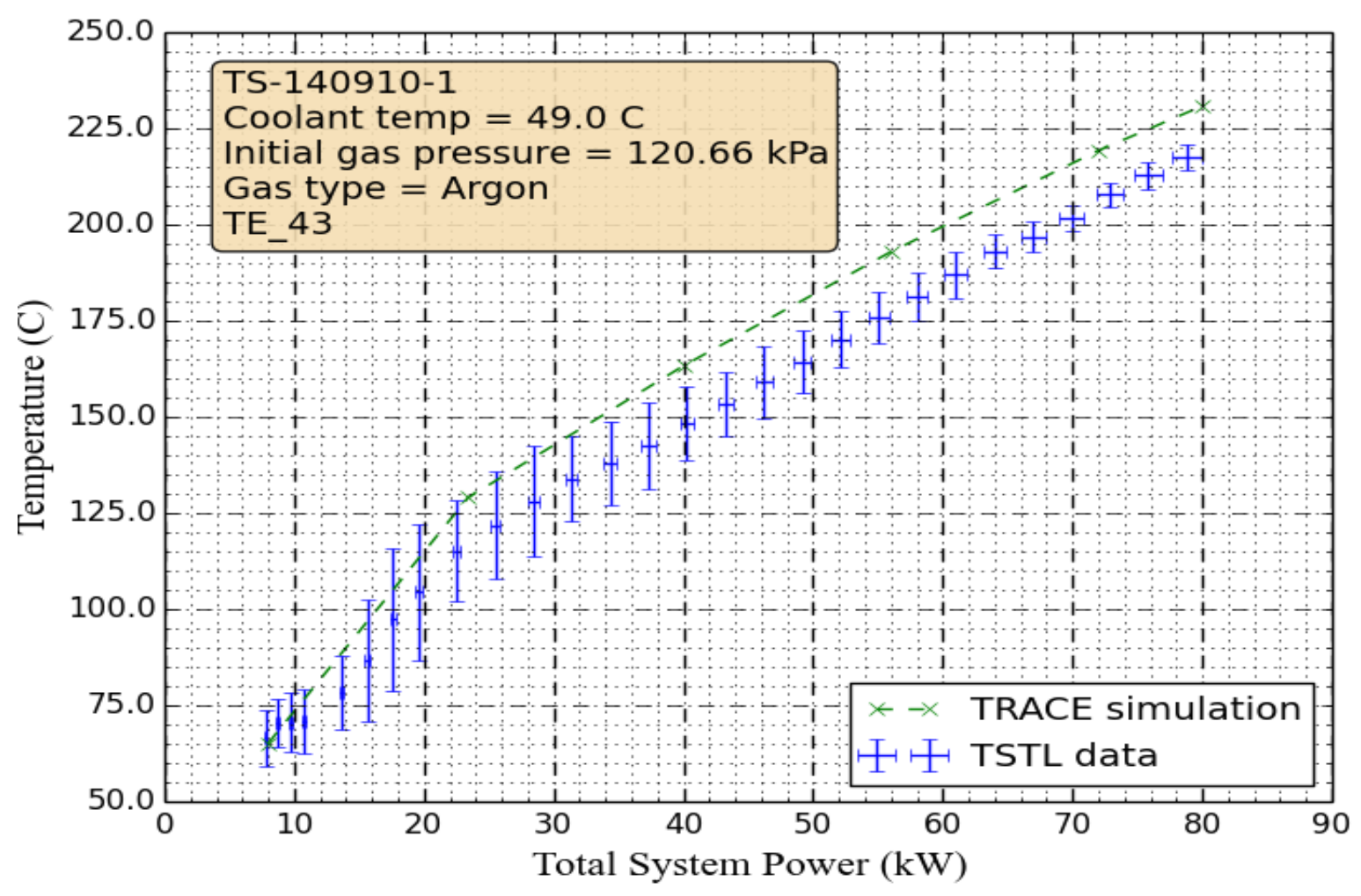

Figure 7-38. Measured and calculated temperatures for TE-43. 


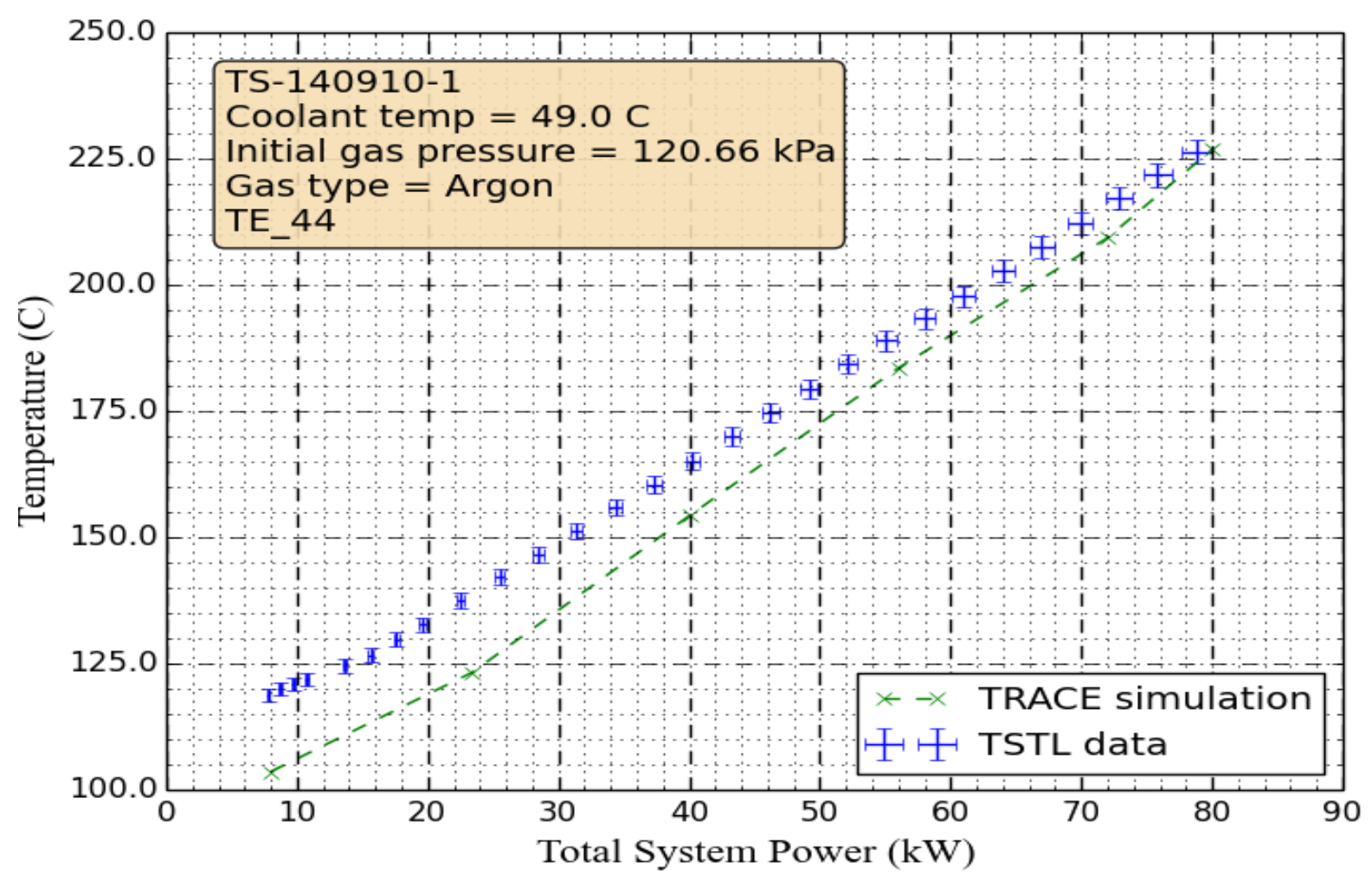

Figure 7-39. Measured and calculated temperatures for TE-44.

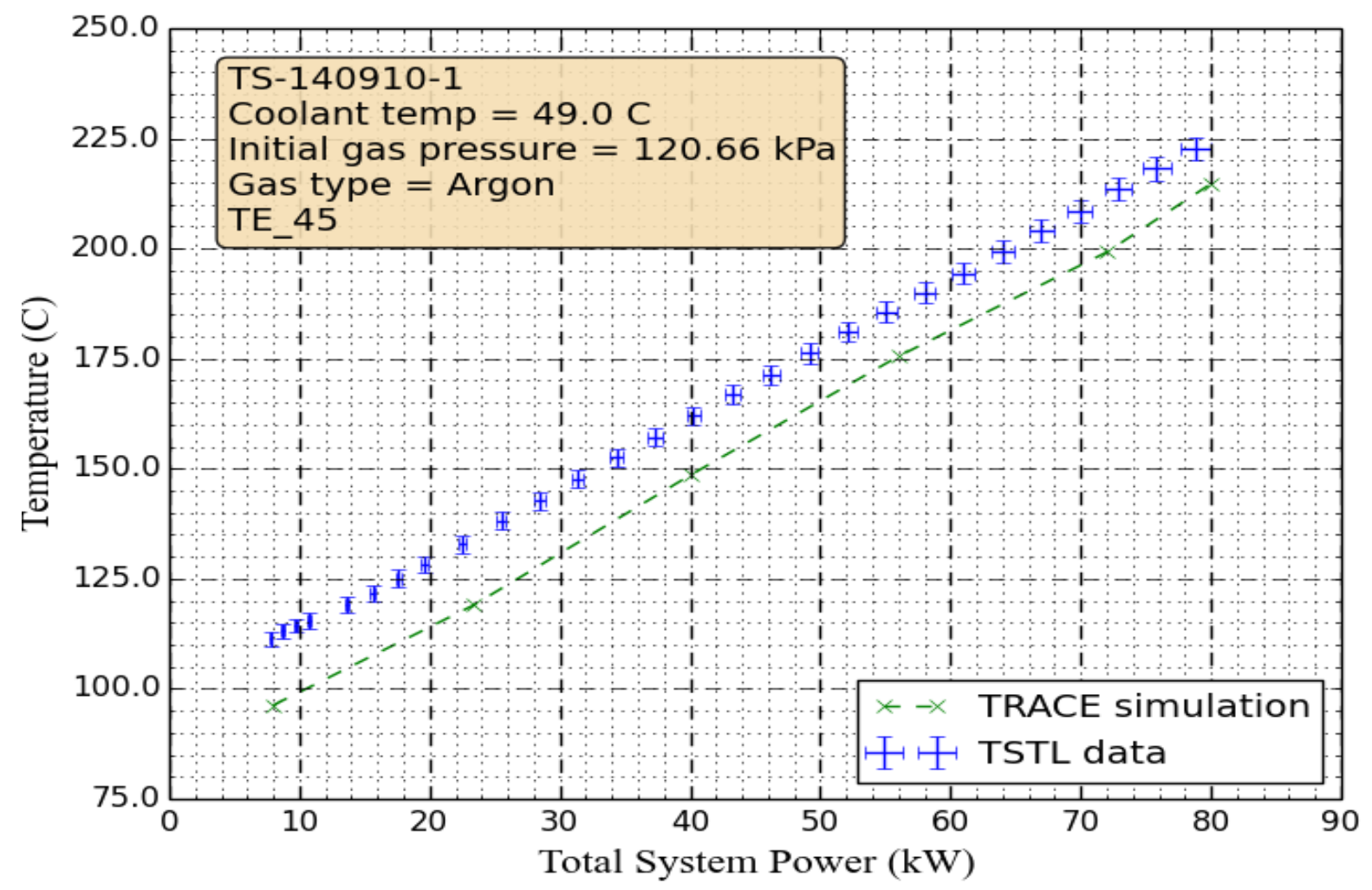

Figure 7-40. Measured and calculated temperatures for TE-45. 


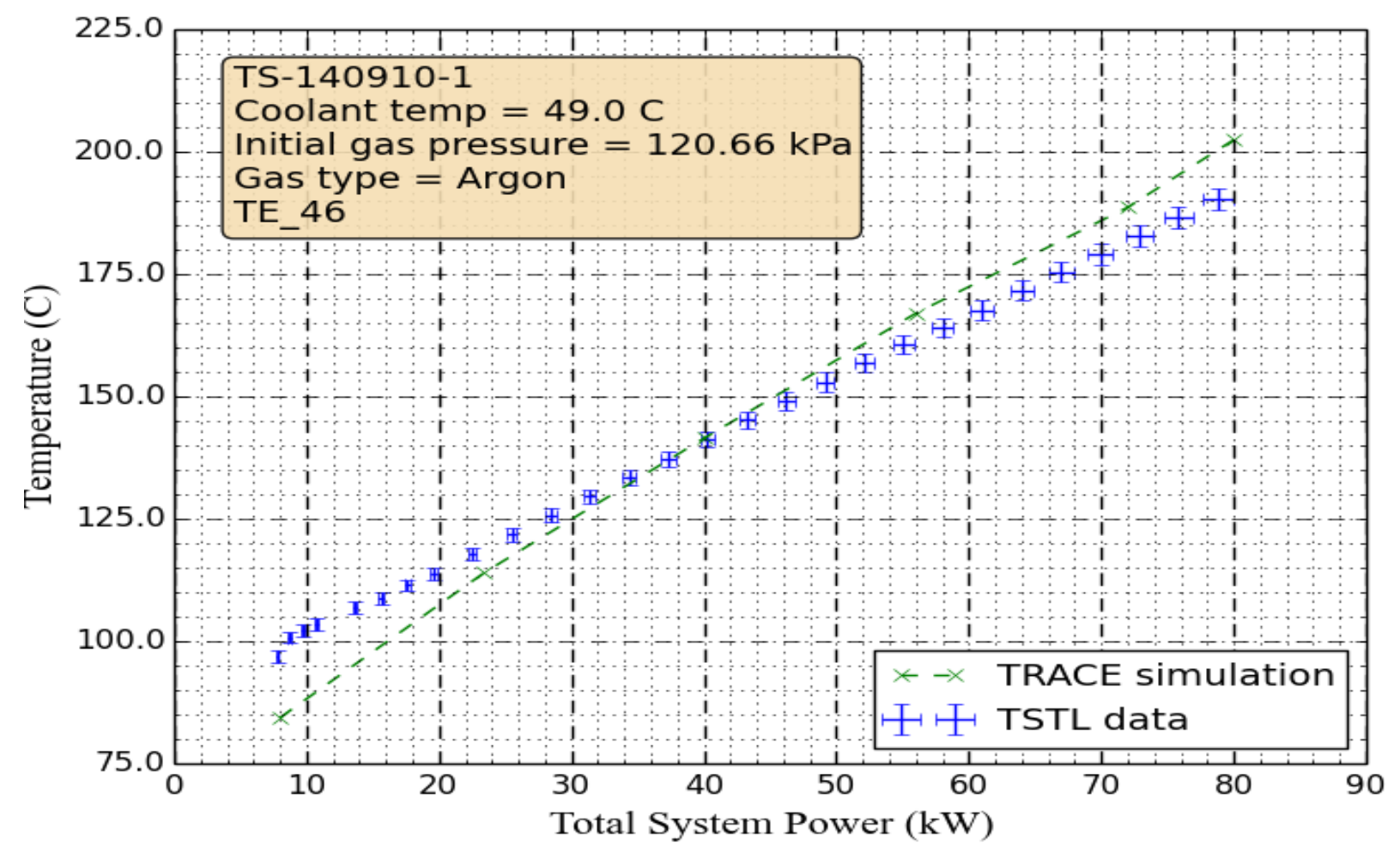

Figure 7-41. Measured and calculated temperatures for TE-46.

\subsubsection{High Pressure Argon Test TS-140911-3}

This test was started at an initial pressure of $2.406 \mathrm{MPa}(334.3 \mathrm{psig})$ at zero power and $322 \mathrm{~K}\left(49^{\circ} \mathrm{C}\right)$ and ended at a final pressure of $7.98 \mathrm{MPa}(1,149 \mathrm{psig})$ at the full power of $80 \mathrm{~kW}$. Comparison between the calculated and the measured condenser pressure at different powers is shown in Fig. 7-42. Figure 7-43 compares the TE-41 temperatures, Fig. 7-44 compares TE-42 temperatures, and Fig. 7-45 compares TE-43 temperatures. Figure 7-46 compares TE-44 temperatures, which is the temperature of the steam leaving the top of the boiler. Figure 7-47 compares TE-45 temperatures, and Figure 7-48 compares temperatures for TE-46, the temperature of the liquid water entering the bottom of the boiler.

At the full power of $80 \mathrm{~kW}$, the calculated final pressure is $8.0 \mathrm{MPa}$, the calculated boiler entrance orifice pressure differential is $600 \mathrm{~Pa}$, and the calculated vapor temperature is $567 \mathrm{~K}\left(294^{\circ} \mathrm{C}\right)$. All these calculated values are in good agreement with the experimental values (Table 7-1). While calculated values at lower powers do not agree that well with experimental data, both calculated and experimental values follow the same trend. The error of this test data is also larger than in other tests, with some of the data questionable (e.g., TE-45 for low powers in Fig. 7-47).

The calculated liquid temperature at full power is $527 \mathrm{~K}\left(254^{\circ} \mathrm{C}\right)$, which is higher than the experimental value of $503 \mathrm{~K}\left(230^{\circ} \mathrm{C}\right)$ by $24 \mathrm{~K}$.

The calculated mass flow rates of water and steam at full power are $0.16 \mathrm{~kg} / \mathrm{s}$ and $0.02 \mathrm{~kg} / \mathrm{s}$, respectively, as shown in Table 7-1. These values were not measured.

The TRACE code does not model the argon tests as well as the previous helium tests, which have better agreement at all powers. 
From the TRACE calculation, the total amount of argon in this test is $166 \mathrm{~g}$. The argon charge calculated in Table 5.1 is $164 \mathrm{~g}$, a very similar amount.

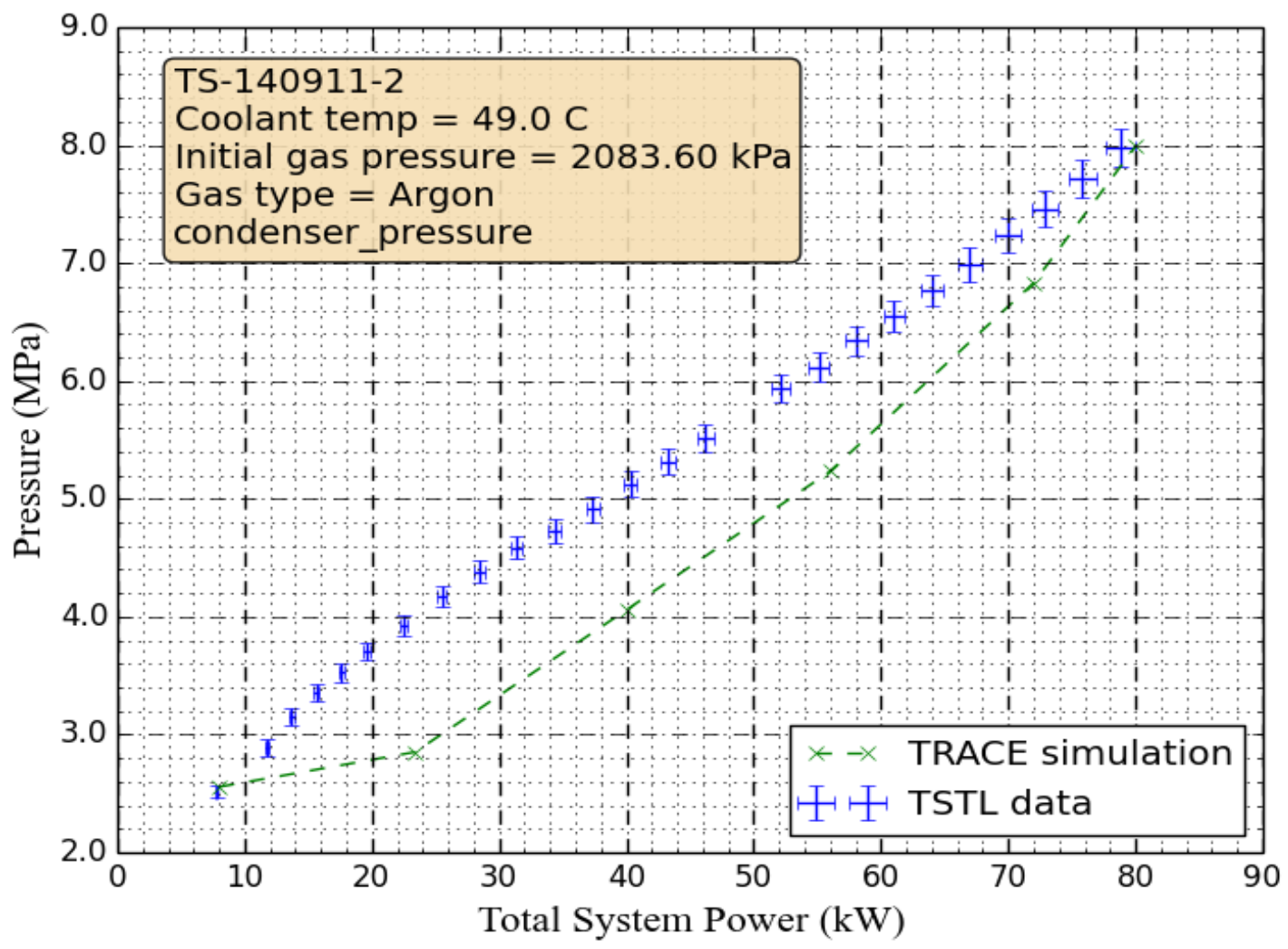

Figure 7-42. Measured and calculated pressures for test TS-140911-2.

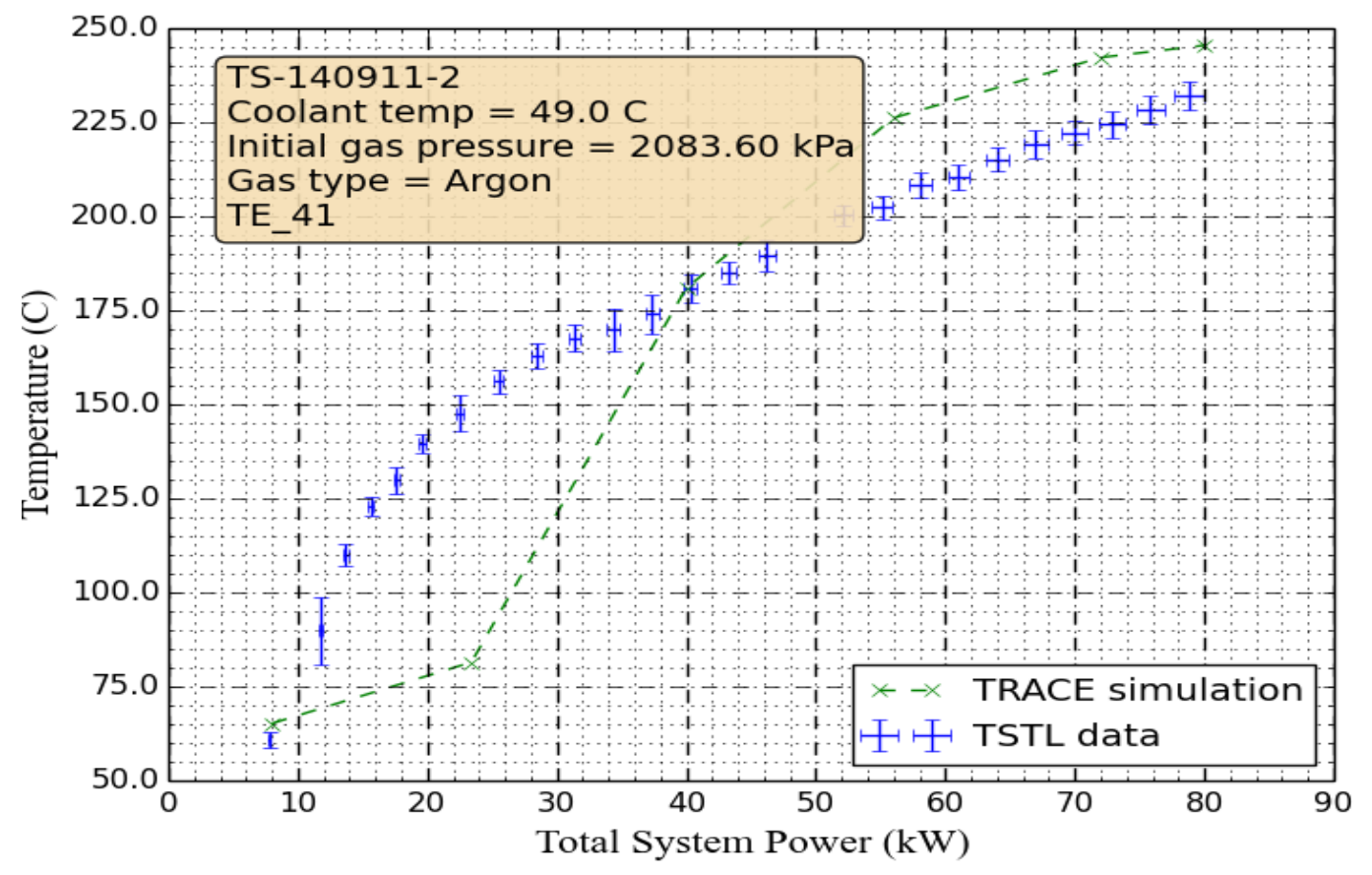

Figure 7-43. Measured and calculated temperatures for TE-41. 


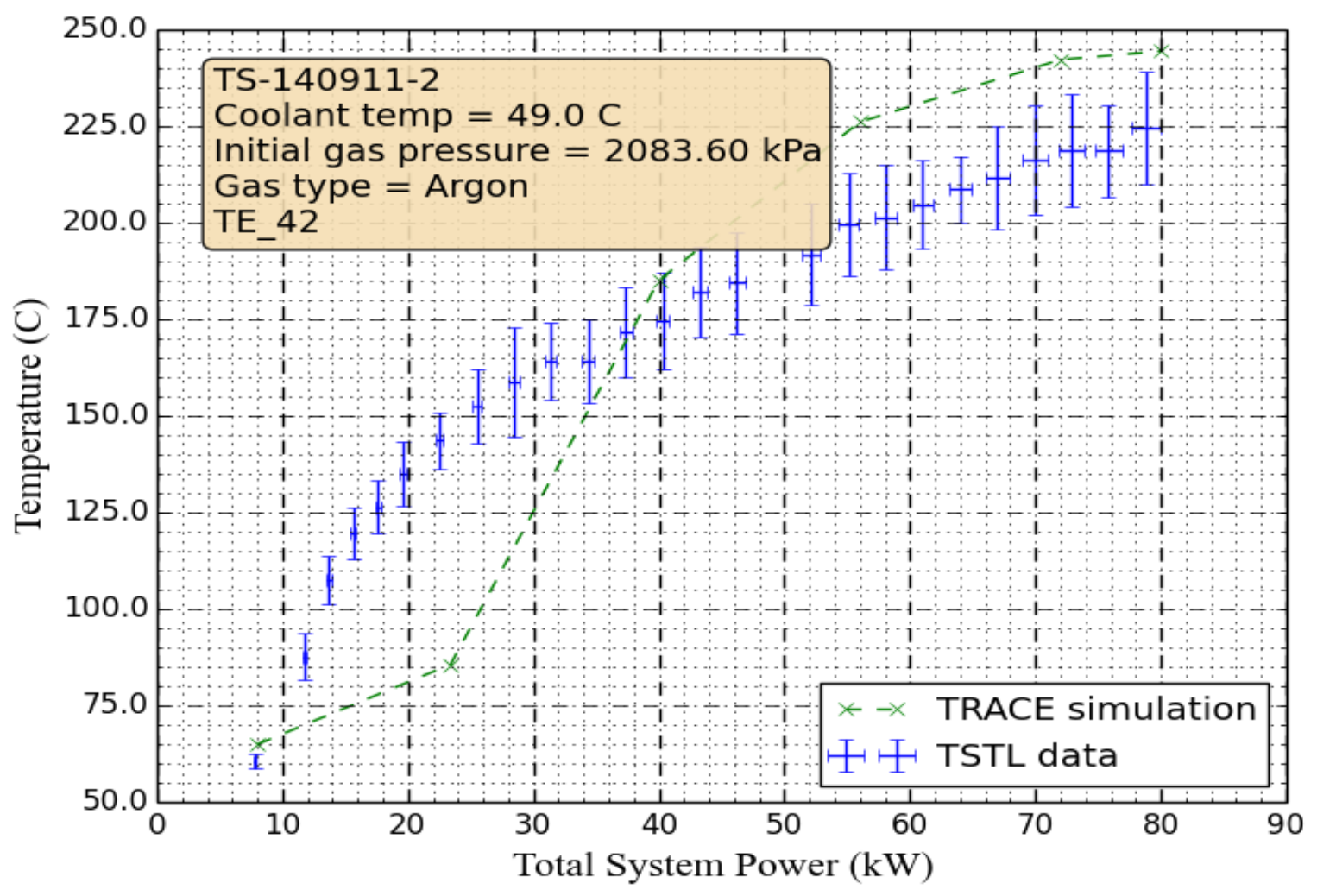

Figure 7-44. Measured and calculated temperatures for TE-42.

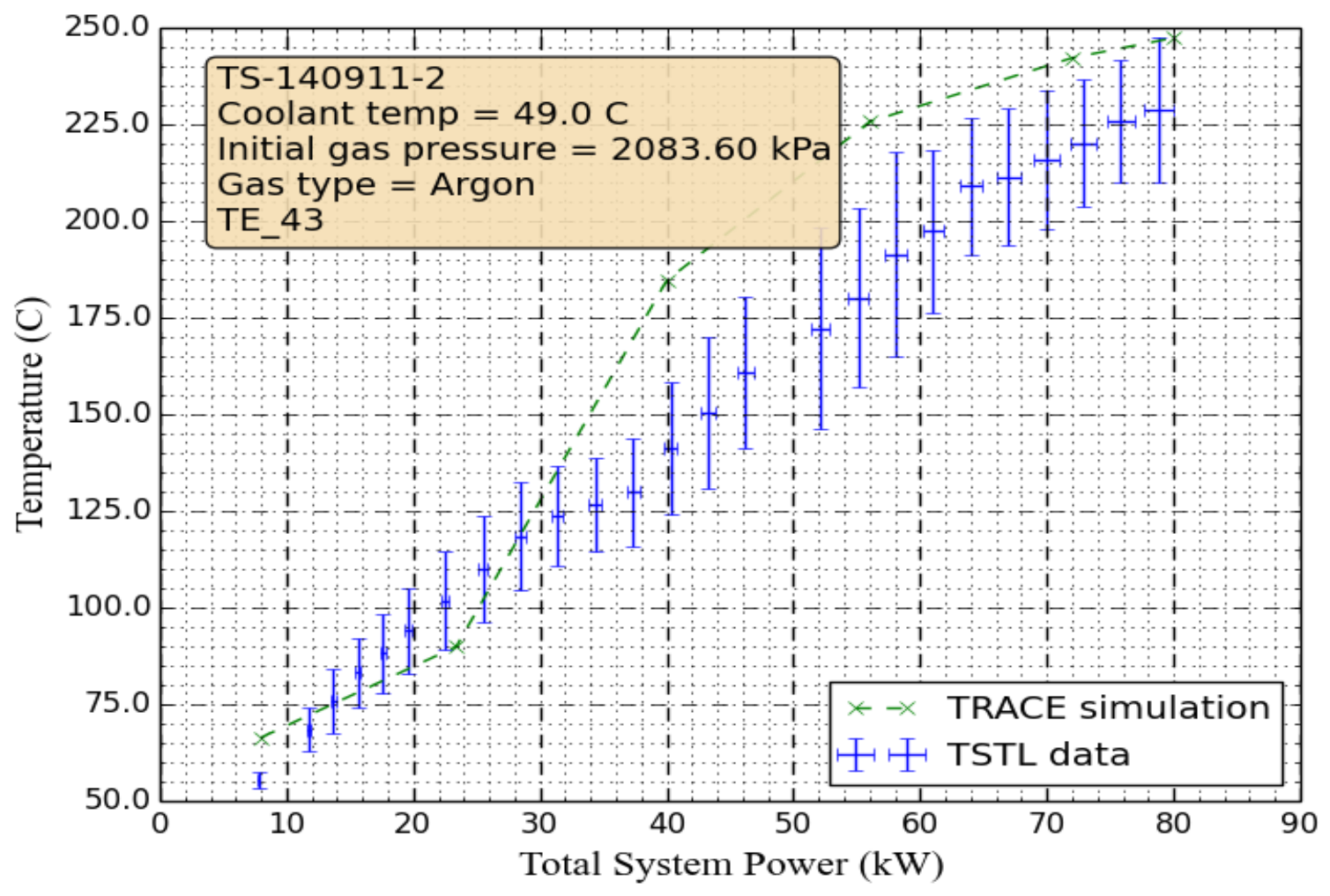

Figure 7-45. Measured and calculated temperatures for TE-43. 


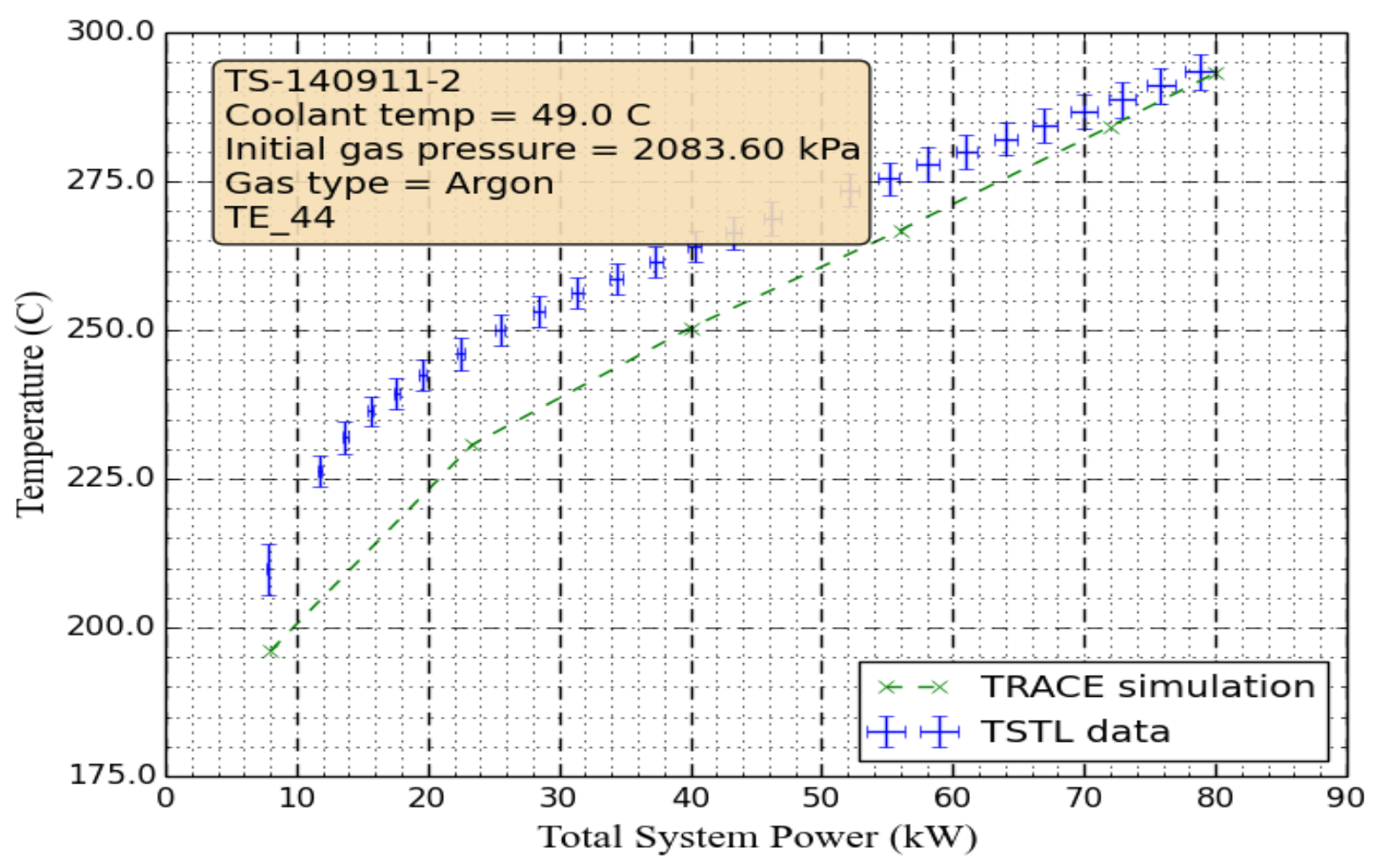

Figure 7-46. Measured and calculated temperatures for TE-44.

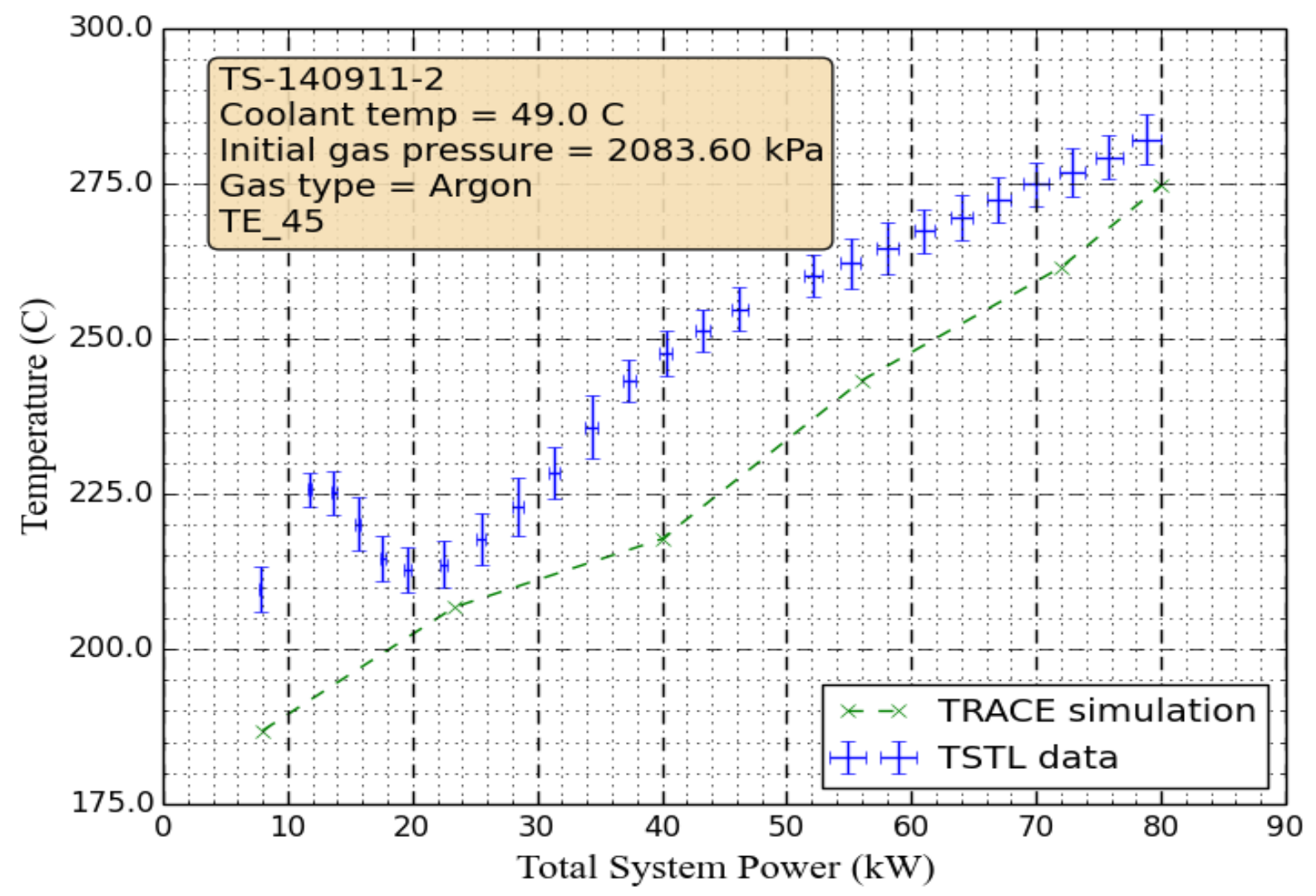

Figure 7-47. Measured and calculated temperatures for TE-4. 


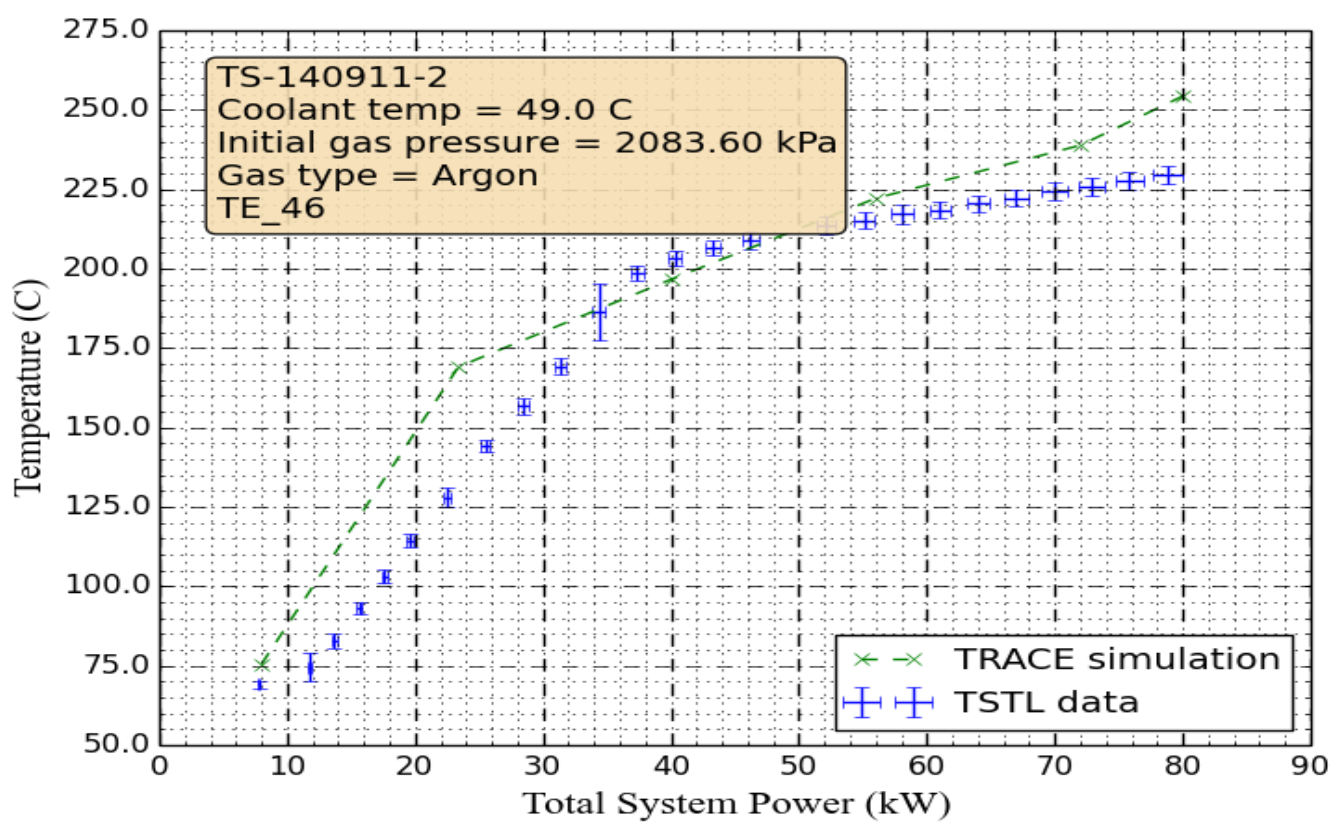

Figure 7-48. Measured and calculated temperatures for TE-4.

Finally, Figure 7-49 summarizes pressures previously calculated in TRACE for different tests with NC gases (either helium or argon) added. This figure is similar to previous Fig. 7-34 that presented data from calculations for tests with helium added. The more $\mathrm{NC}$ gas that is added, the higher the initial (at zero power) and the final (at full power) pressures will be. For the same initial pressure $(0.1 \mathrm{MPa})$ at zero power, adding argon results in a higher final pressure (3.2 MPa) at full power than adding helium $(2.45 \mathrm{MPa})$.

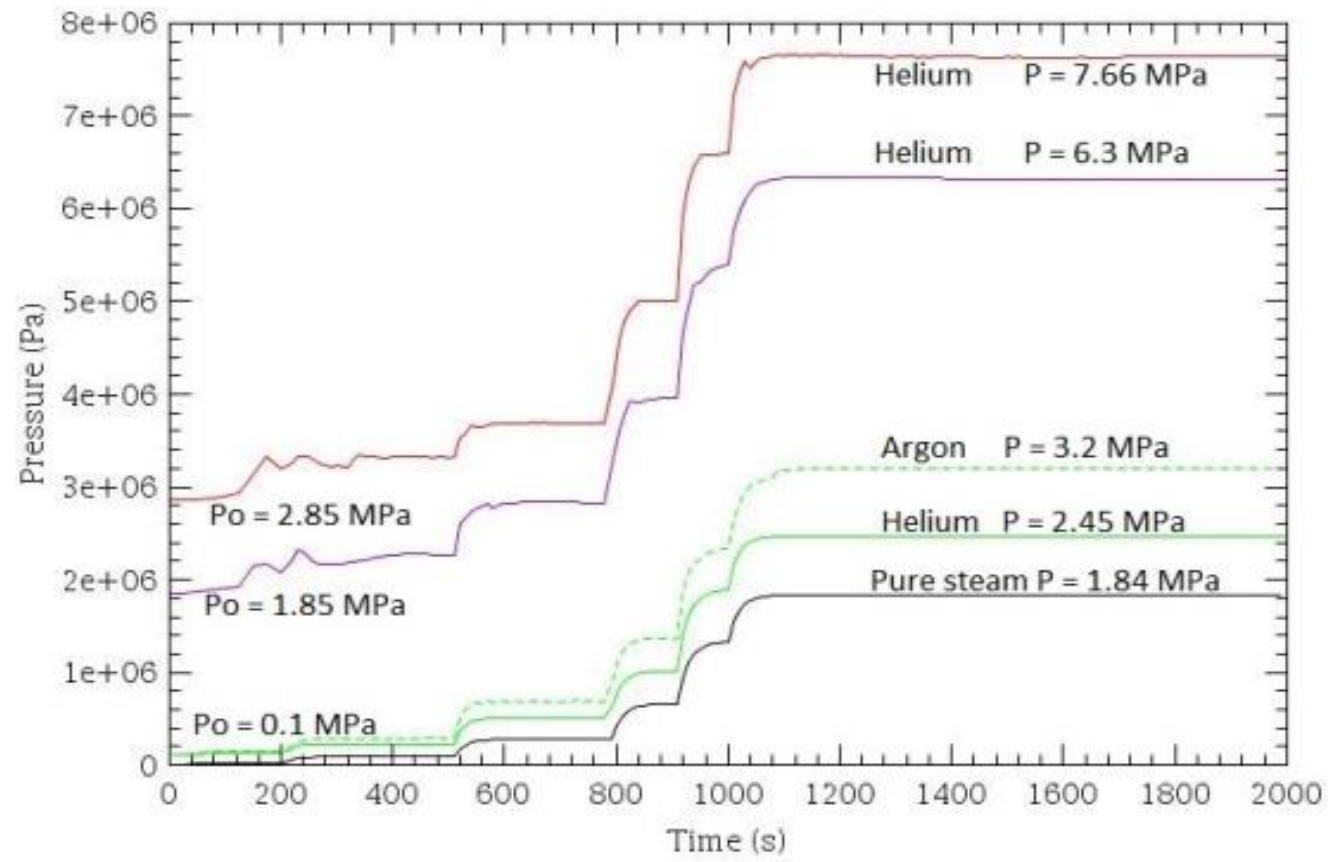

Figure 7-49. Calculated pressures for tests with different amounts of noncondensable gases. 


\subsection{HFIR STARTUP SEQUENCE}

Test TS-140925-1, which simulated a HFIR startup sequence, was modeled with the TRACE code. The total power was applied to the heaters in six steps over 1,450 s, as shown in Fig. 7-50. The final total power to the system (all three heaters) was $80 \mathrm{~kW}$, as in the previous tests. The initial pressure in the system was $2.86 \mathrm{MPa}(401 \mathrm{psig})$ at $292 \mathrm{~K}\left(19^{\circ} \mathrm{C}\right)$, and $3.24 \mathrm{MPa}(455 \mathrm{psig})$ at $322 \mathrm{~K}\left(49^{\circ} \mathrm{C}\right)$. Helium was the $\mathrm{NC}$ gas added to achieve this initial system pressure. The final pressure at full power was $7.897 \mathrm{MPa}$ $(1,131 \mathrm{psig})$. The inlet temperature of the primary system water varied in the experiment between $320 \mathrm{~K}$ $\left(47^{\circ} \mathrm{C}\right)$ and $326 \mathrm{~K}\left(53^{\circ} \mathrm{C}\right)$, as shown in Fig. 7-51. The TRACE calculation employed a constant inlet temperature of $322 \mathrm{~K}\left(49^{\circ} \mathrm{C}\right)$.

The input power as a function of time employed by the TRACE code was exactly the same as the experimental power, as shown in Fig. 7-52. The calculated results can be compared with the experimental values using the same time scale.

Experimental and calculated values of the temperature difference between the primary coolant outlet and inlet are shown in Fig. 7-53. The calculated values are slightly larger (by $\sim 0.5 \mathrm{~K}$ ) than the experimental values. Some of the many possible reasons for this discrepancy are:

a) lower power input to the system than the values indicated by the instruments (instrument error),

b) uncertainties in the measured temperatures (also an instrument error),

c) unaccounted power/heat losses from the system, and

d) uncertainties in the water properties used by the code TRACE.

Figure 7-54 compares the experimental and calculated pressures in the system. The agreement is very good, with some small discrepancies at low powers. Final calculated pressure is $7.9 \mathrm{MPa}$, the same as the experimental value. 


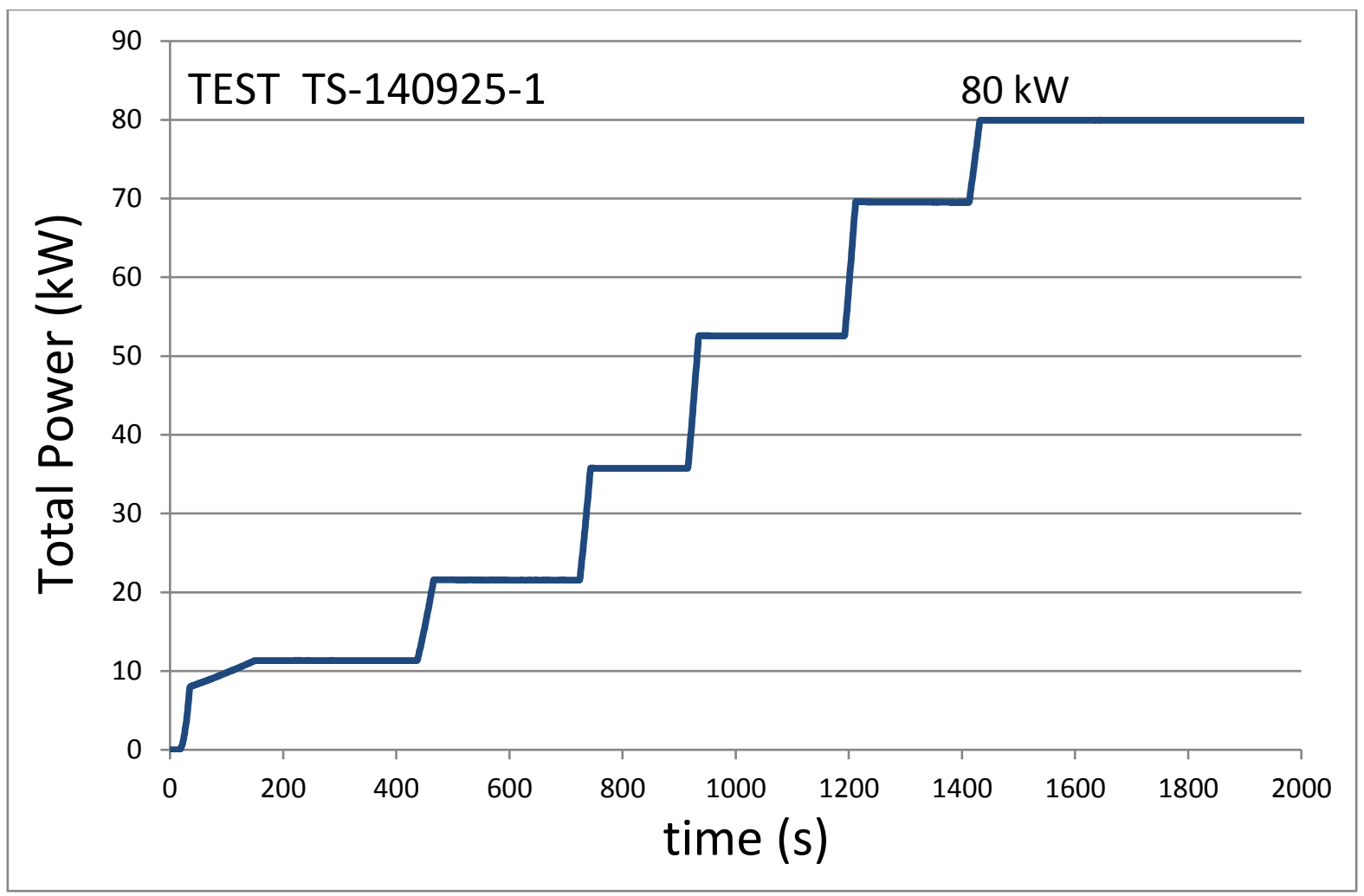

Figure 7-50. Power sequence for test TS-140925-1, HFIR startup sequence.

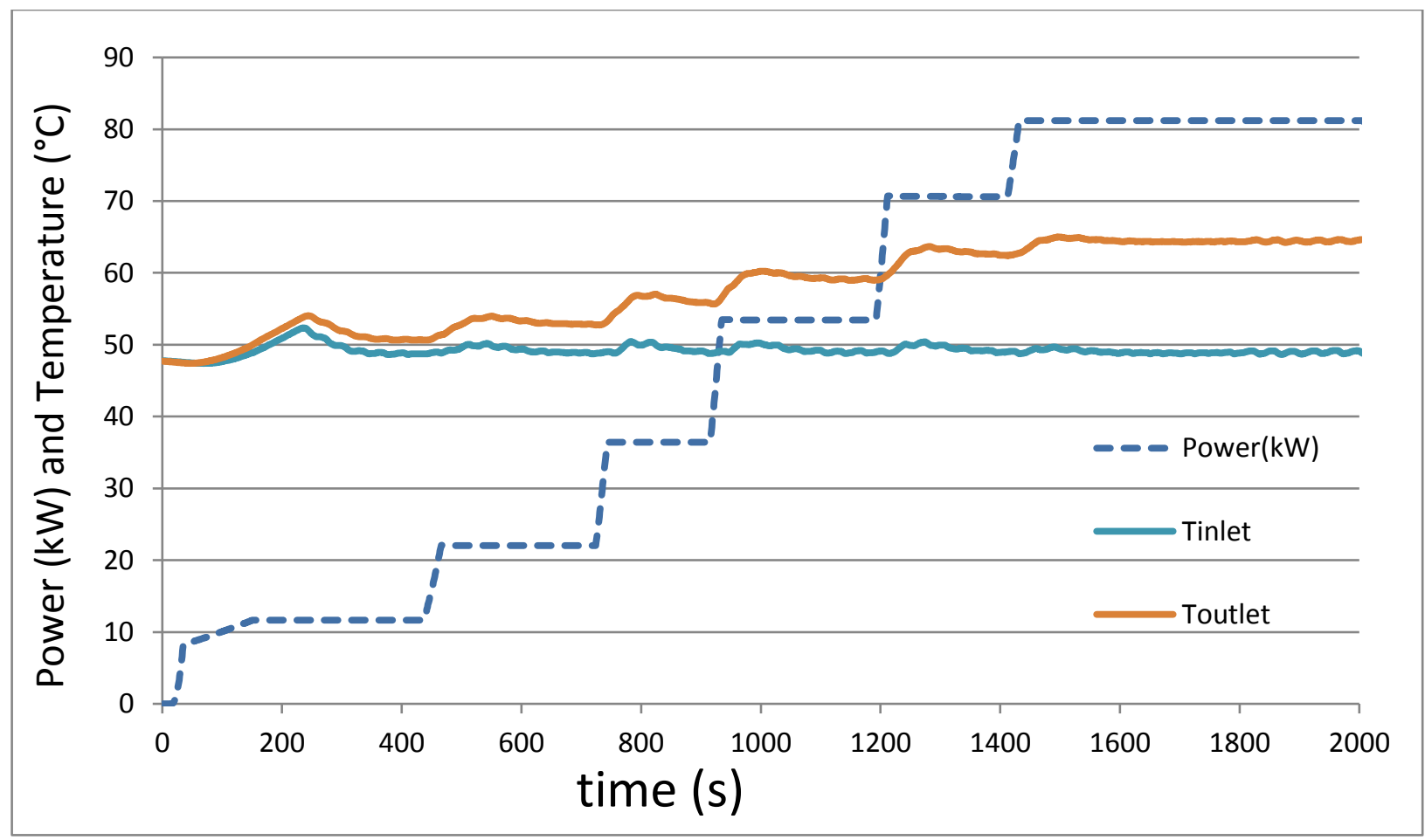

Figure 7-51. Primary inlet and outlet temperatures measured for test TS-140925-1. 


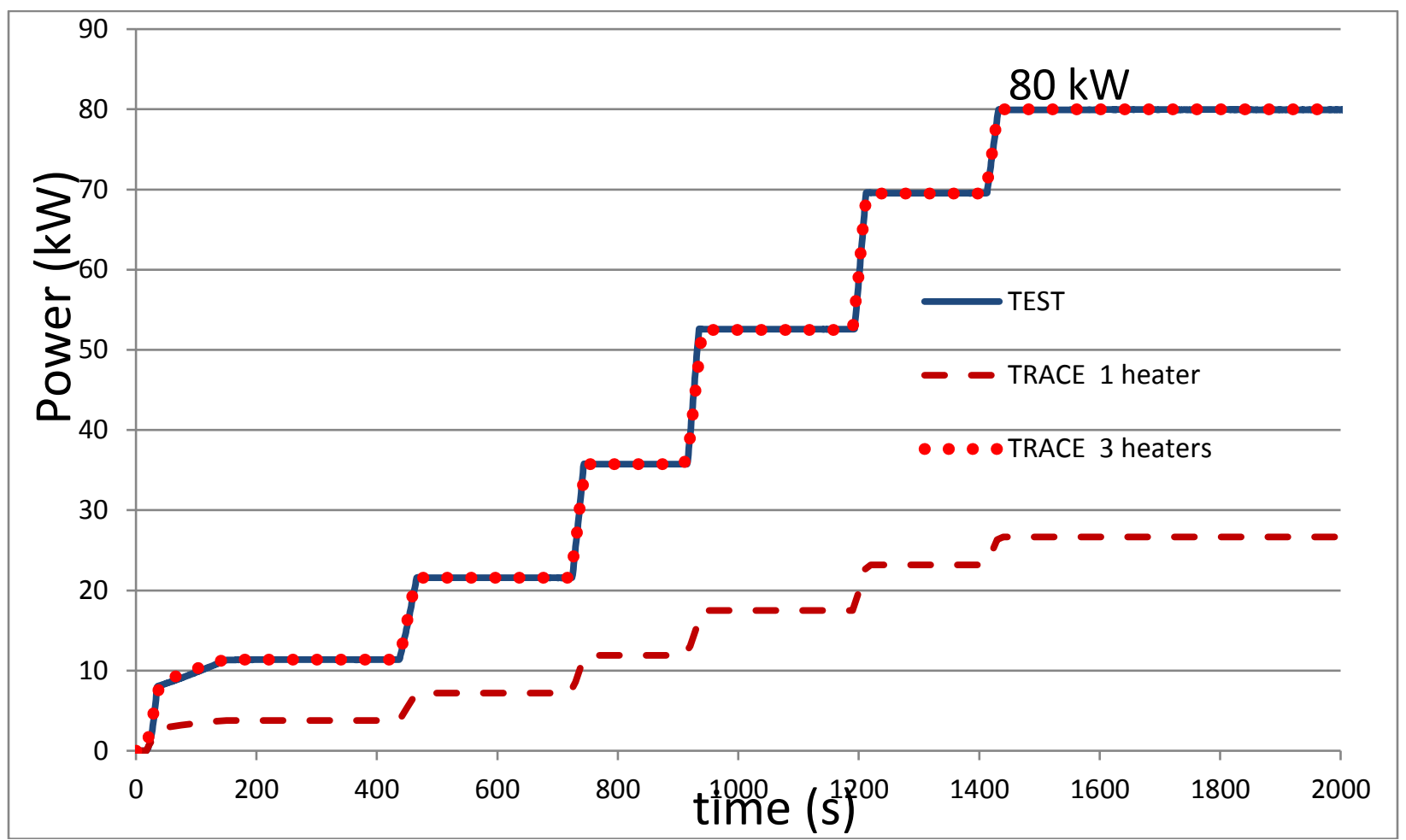

Figure 7-52. Comparison of experimental and TRACE input power to the heaters.

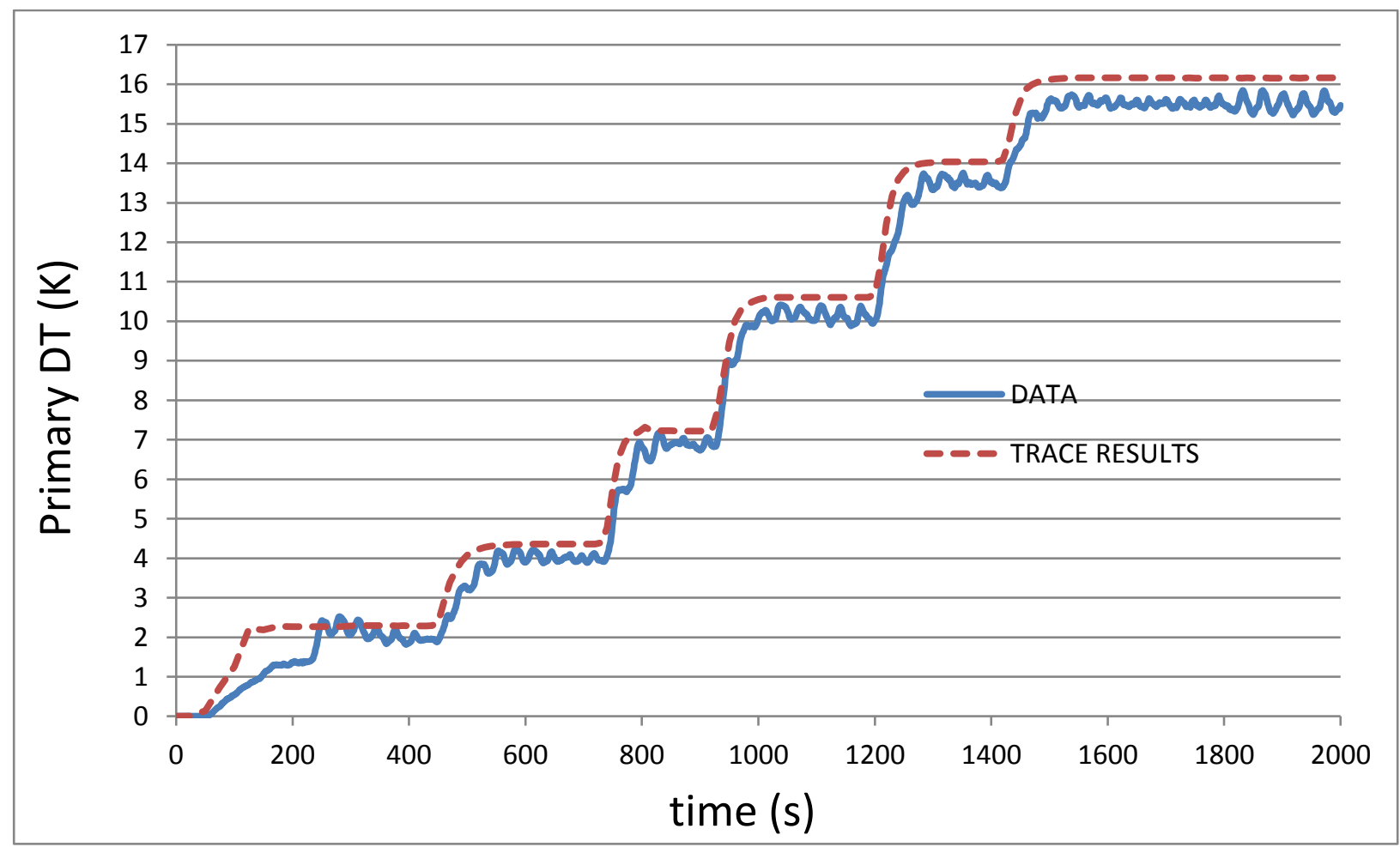

Figure 7-53. Experimental and TRACE-calculated primary outlet/inlet temperature difference. 


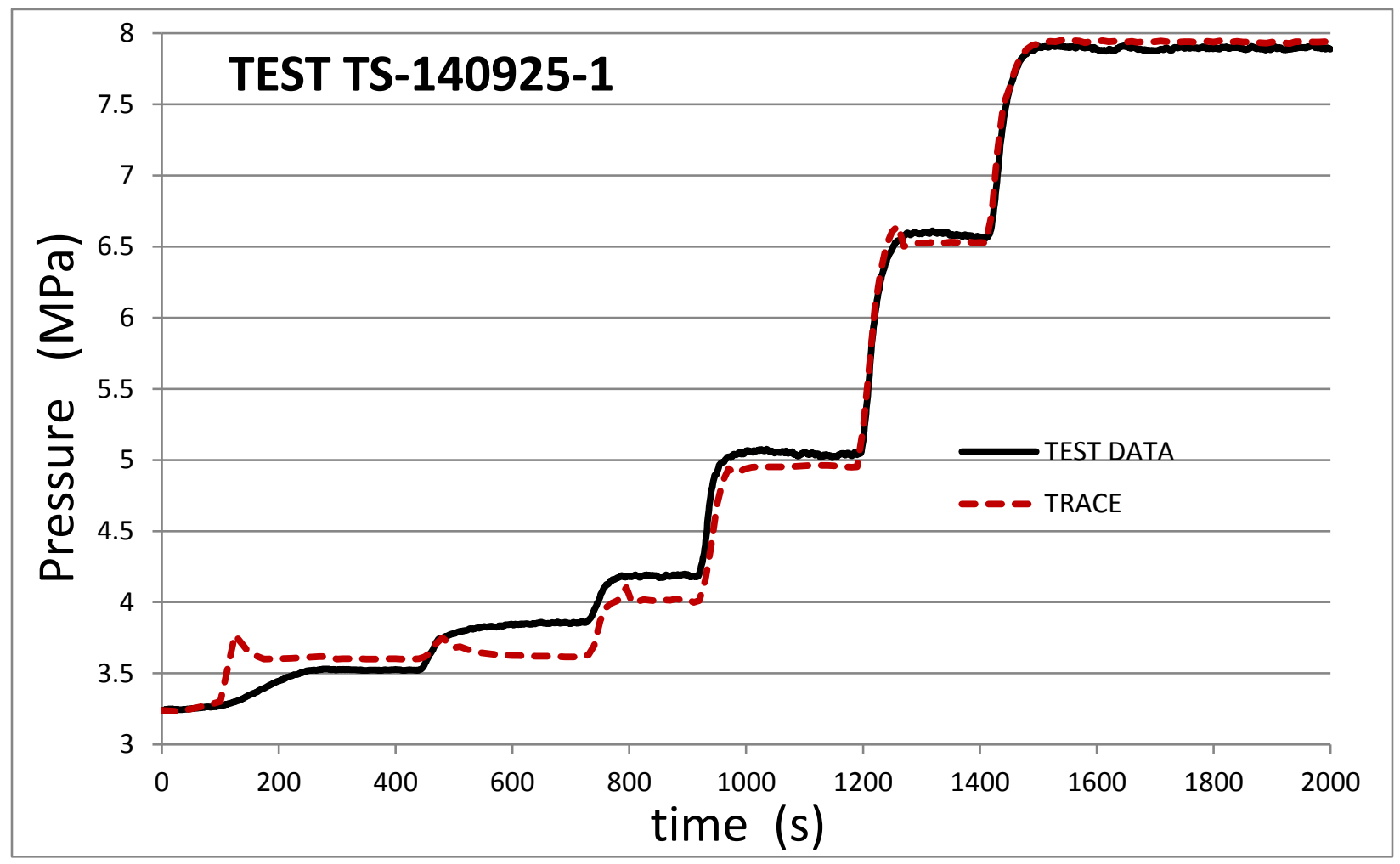

Figure 7-54. Experimental and TRACE-calculated pressures.

The measured and calculated pressure differentials across the boiler entrance orifices are compared in Fig. 7-55. Some disagreement occurred at low powers (between $22 \mathrm{~kW}$ and $36 \mathrm{~kW}$ ), with the calculated values larger than the measured values at those low powers. Good agreement is observed at the final power of $\sim 80 \mathrm{~kW}$, with a $\triangle \mathrm{P}$ of $775 \mathrm{~Pa}$.

Figure 7-56 compares the measured and calculated temperatures of the water at the inlet to the boiler/evaporator (bottom) and of the steam leaving the boiler/evaporator top. The calculated and measured temperatures of the steam are the same at $567 \mathrm{~K}\left(294^{\circ} \mathrm{C}\right)$. The liquid calculated temperature, $529 \mathrm{~K}\left(256^{\circ} \mathrm{C}\right)$, is higher than the experimental value of $511 \mathrm{~K}\left(238^{\circ} \mathrm{C}\right)$ by $18 \mathrm{~K}\left(18^{\circ} \mathrm{C}\right)$. This trend has been observed in previous tests: the calculated liquid temperature is higher and the calculated water subcooling is lower than the experimental values.

Figure 7-57 compares measured and calculated temperatures inside the condenser at the three different elevations where the three TCs are located (TE-41, TE-42 and TE-43), showing temperature stratification. TRACE can reproduce the observed temperature stratification in the condenser, with lower temperatures at the top and with sudden temperature changes when helium (colder) at one elevation is replaced by steam (hotter), as shown for TE-42 and TE-43. TE-41 corresponds to condenser node 30, TE-42 corresponds to condenser node 18, and TE-43 to condenser node 8 of the TRACE nodalization (Fig. 7-1). TE 41 remains inside helium at all times at a low temperature, TE-42 gets some steam (mixed with helium) at about 1,450 s, and TE-43 gets into the steam region at about $900 \mathrm{~s}$. 


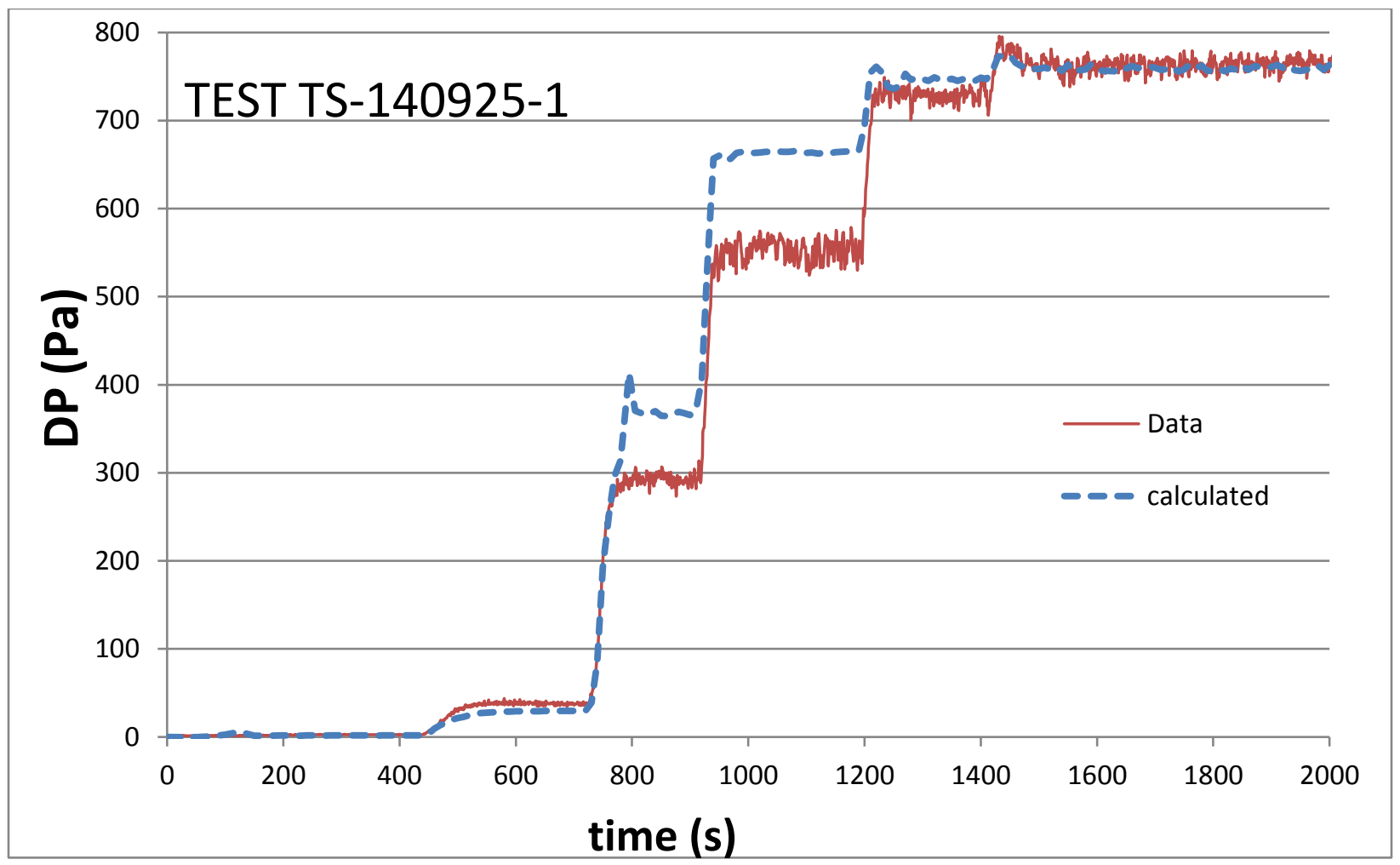

Figure 7-55. Experimental and calculated pressure differential across the entrance orifices.

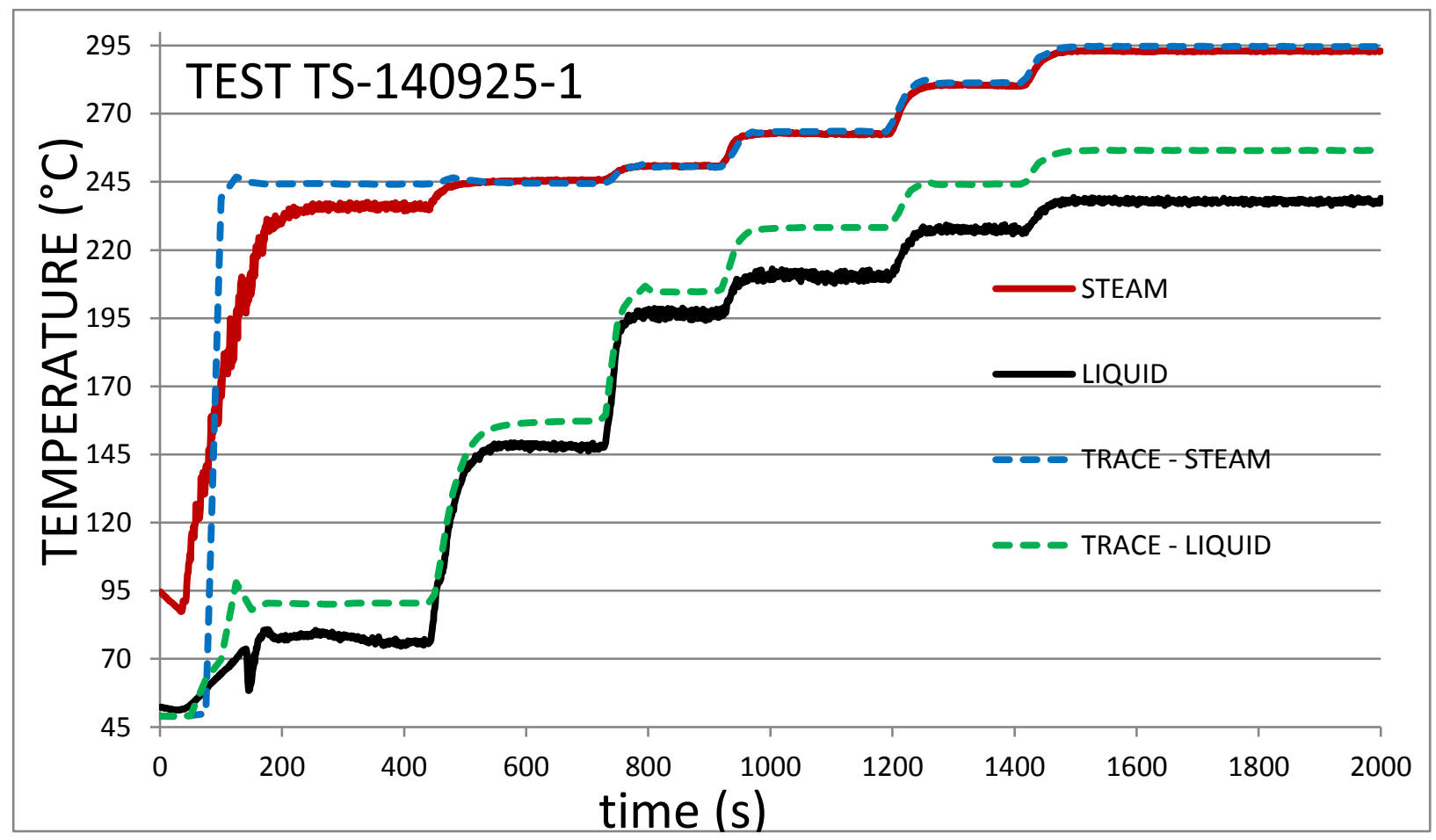

Figure 7-56. Experimental and calculated liquid and steam temperatures. 


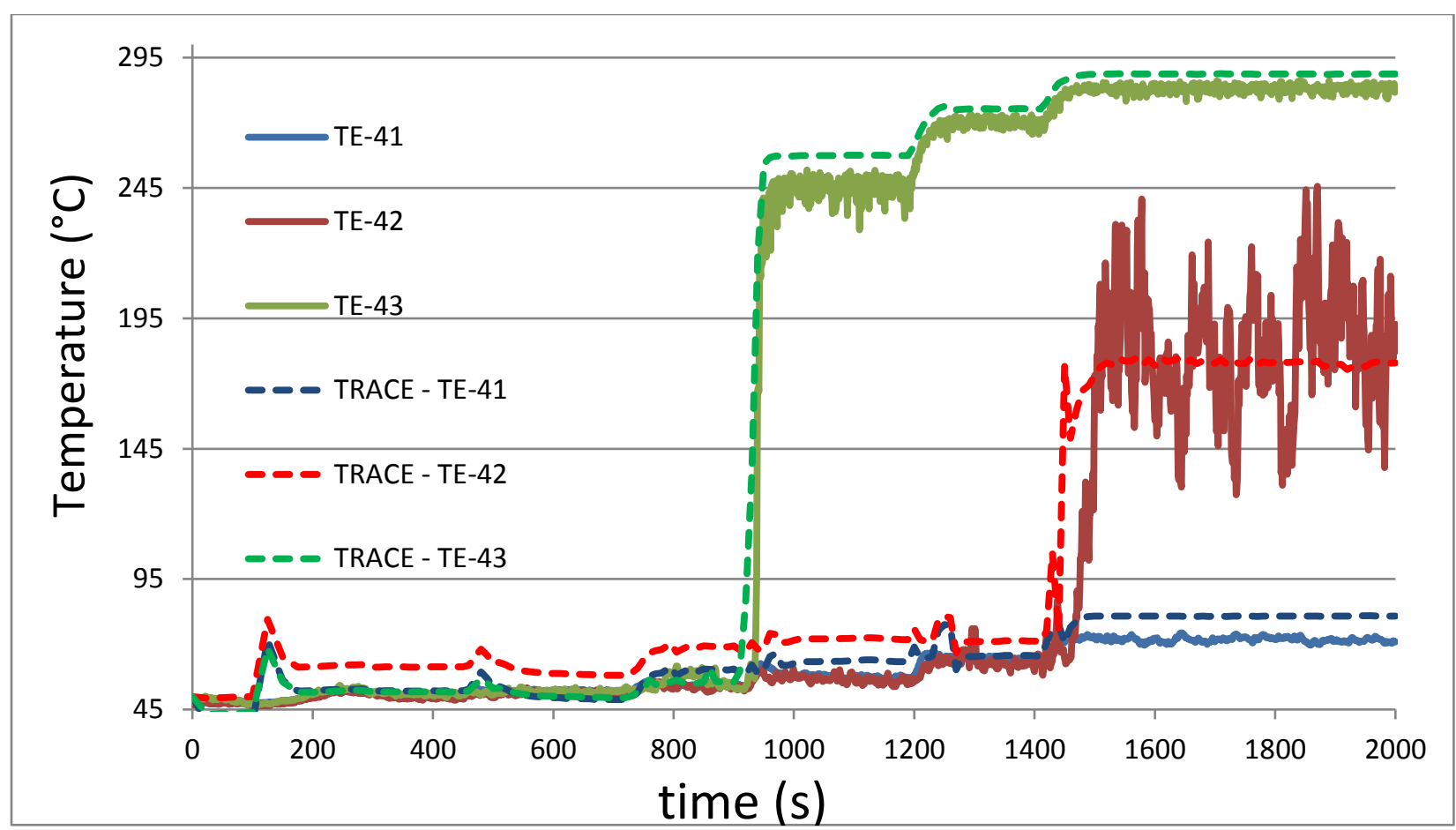

Figure 7-57. Experimental and calculated temperatures inside the condenser at three elevations.

Figure 7-58 shows TRACE-calculated mass of helium in nodes at different elevations of the condenser for ring 1 (the central ring). Node 1 is the bottom node, and node 34 is the top node of the condenser (Fig. 7-1). Initially, before power is applied to the heaters, the same amount of helium is in each axial node of the condenser (in the same ring) since all the nodes in the same ring have the same volume and all are filled with helium to the initial pressure of $2.86 \mathrm{MPa}$. As power is applied to the heaters, steam is generated at the bottom of the condenser, and the mass of helium in the bottom condenser nodes is depleted and goes to zero as it is replaced by steam (node 1 at $\sim 750 \mathrm{~s}$, nodes $2-6$ at $\sim 950 \mathrm{~s}$, nodes $8-10$ at $\sim 1200 \mathrm{~s}$, node 16 at $\sim 1450 \mathrm{~s}$ ). The mass of helium in the higher elevation nodes increases with time as helium from the bottom nodes is pushed to the top nodes. The total amount of helium in the system is constant, all the helium is located inside the condenser, and helium is being pushed to the high elevation nodes as steam is generated at the bottom. At the end of the calculation, helium is present in node 17 and above. Nodes 17 and 18 have some helium at the end of the calculation, Nodes 19-34 have mainly helium, and node 20 has the largest inventory. Node 16 has no helium after 1,450 s (only steam), as it occurred with all the nodes below at different times, while nodes 17 and 18 helium inventory increases with time, and suddenly at $\sim 1,450 \mathrm{~s}$, their helium inventory decreases but does not go to zero, an indication that the steam/helium boundary is in these two nodes. According to this TRACE calculation, there is a mixture of steam and helium in nodes 17 and 18 . While the bottom nodes contain only steam (nodes 1-16), the high elevation nodes (nodes 19-34) contain mainly helium with small amounts of steam. Even the top node 34 has some steam. At the end of this calculation (at $80 \mathrm{~kW}$ power), the total pressure in this node is $7.9 \mathrm{MPa}$ and the partial pressure of helium is $7.88 \mathrm{MPa}$. The difference is due to the steam contribution. 


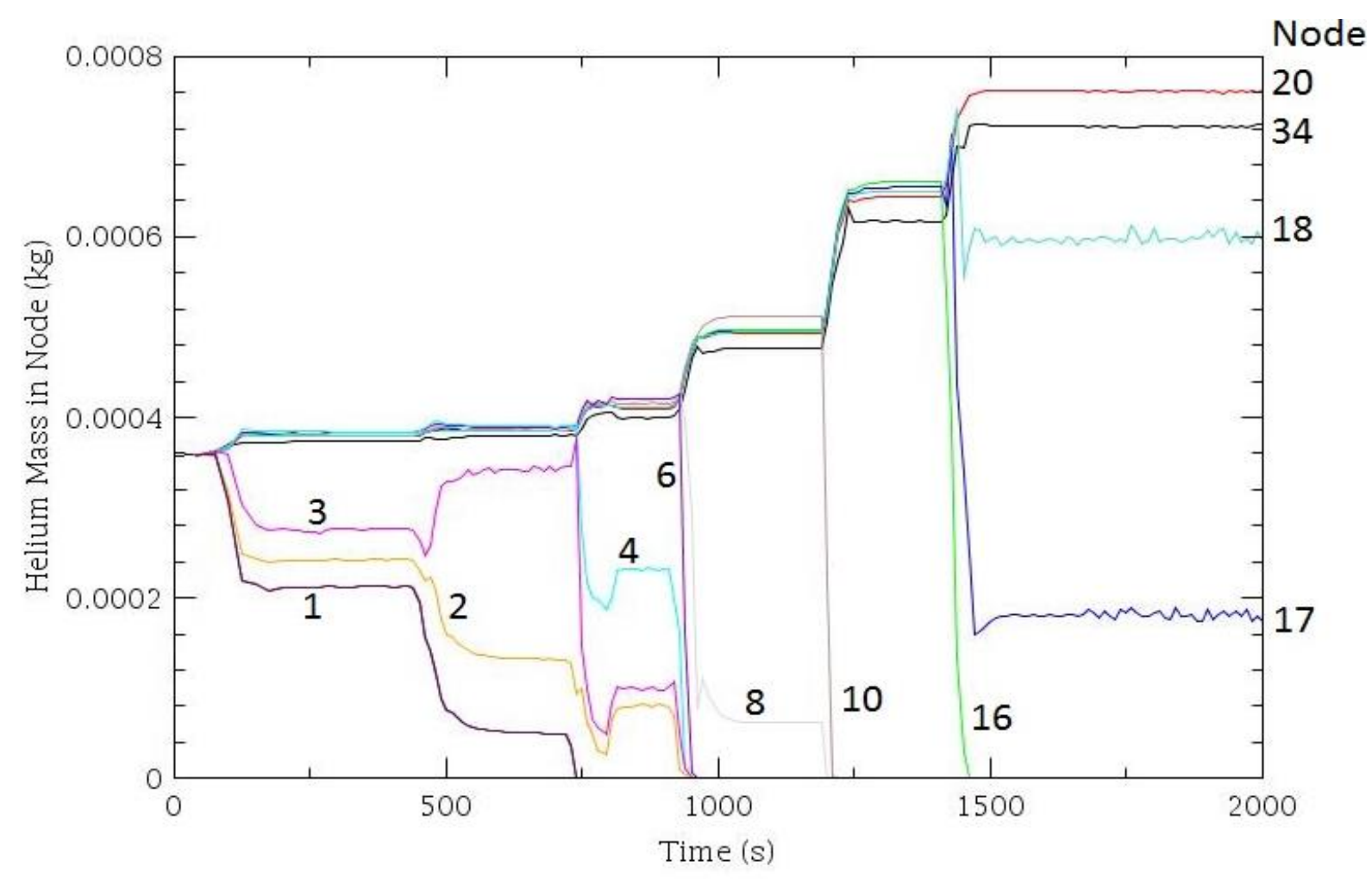

Figure 7-58. TRACE-calculated helium masses in different condenser nodes.

Figure 7-59 shows helium and steam distribution in the condenser at two times: initially at no power (left), and after power is applied (right). The TC shown (as X) is initially in the cold region inside the helium volume. As the power is increased, the helium is replaced by hot steam, and the TC temperature jumps to a high value, as shown in Fig. 7-57 for TE-42 and TE-43.

Other factors to consider in the steam/helium stratification are as follows:

a) At $100 \mathrm{kPa}$, the density of helium is $0.178 \mathrm{~g} / \mathrm{L}$, while the density of steam is $0.8 \mathrm{~g} / \mathrm{L}$; helium stays above steam.

b) Steam generation at the initial low powers is very small, so the steam velocity is small, and little mixing of steam and helium takes place at the interface.

c) Over time, some mixing of steam and helium takes place at the steam/helium interface.

This discussion described several factors causing temperature stratification in the condenser when helium is added. In summary, helium is lighter than steam and is located at the top. Newly generated steam fills the bottom portion of the condenser and pushes the helium volume up, with little mixing of steam and helium occurring at the helium/steam interface.

Temperature stratifications have not been observed in tests with argon added as the NC gas. Apparently, argon and steam can mix in the different elevations of the condenser. The densities of steam and argon are $0.8 \mathrm{~g} / \mathrm{L}$ and $1.78 \mathrm{~g} / \mathrm{L}$, respectively. Steam generated at the bottom can rise into the argon and mix with it, as its density is lower than argon's density. 

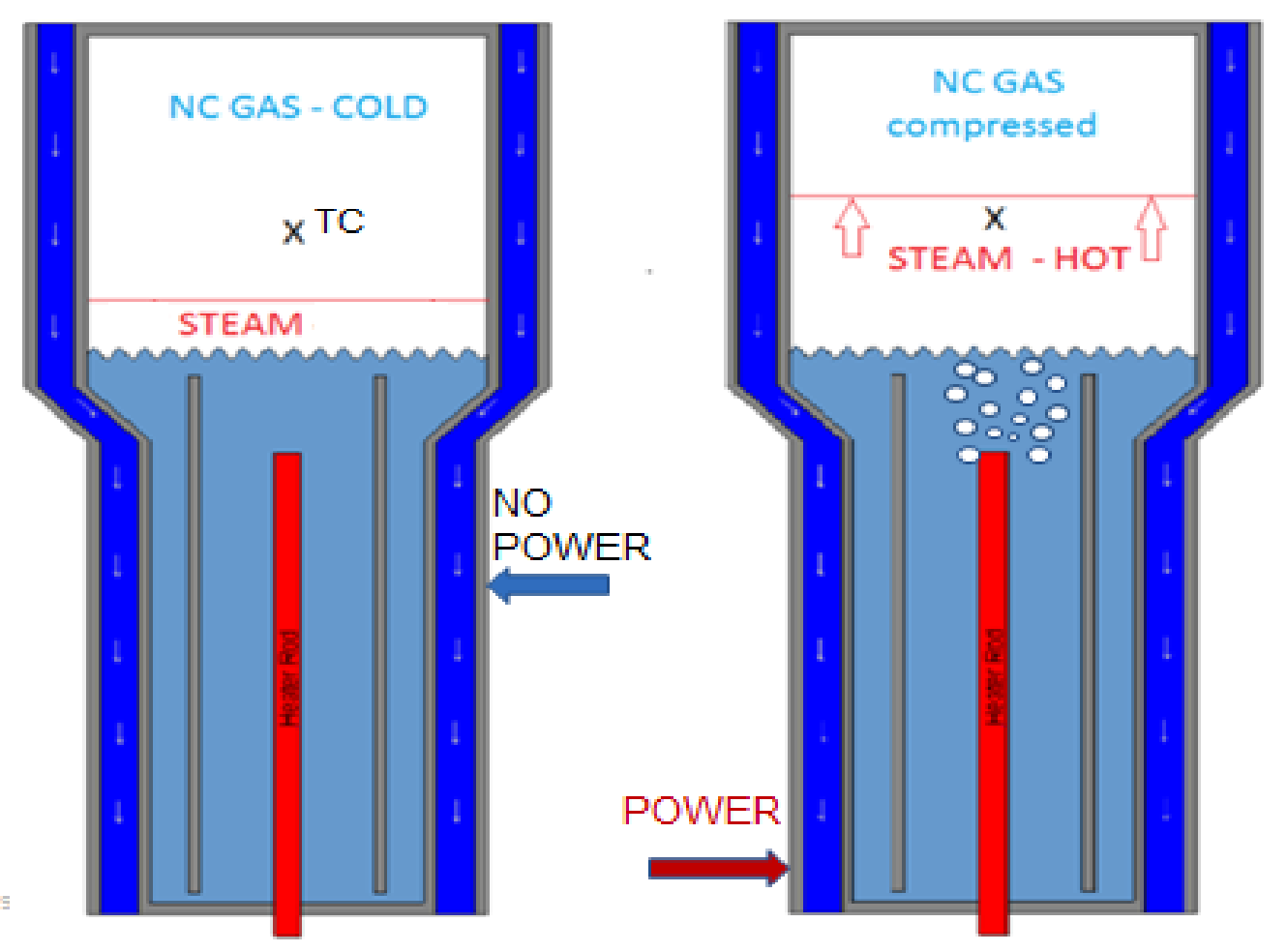

Figure 7-59. Steam and helium inside the condenser under no power and power conditions.

TRACE calculates that $23.5 \mathrm{~g}$ of helium are entered into the system in this test, which is very close to the value calculated in Table 5.1 of $22.9 \mathrm{~g}$. As previously noted, the helium mass is not a TRACE input. Rather, TRACE input consists of initial system temperatures and pressures in the system with helium as the NC gas. TRACE calculates the amount of NC gas in the system from the input values of NC gas pressures and temperatures in the different volumes.

Figure 7-60 compares measured TCs and TRACE-calculated temperatures for the three heaters (one measured temperature is shown for each heater, TE-14 for heater 1, TE-22 for heater 2, and TE-32 for heater 3). At a power of $80 \mathrm{~kW}$, there is a temperature difference of $84 \mathrm{~K}$ between the TC and the surface (Figure 7-9). At full power $(80 \mathrm{~kW})$, TRACE calculated a surface temperature of $575 \mathrm{~K}\left(302^{\circ} \mathrm{C}\right)$, which corresponds to an internal TC temperature of $659 \mathrm{~K}\left(386^{\circ} \mathrm{C}\right)$. Measured temperatures for the heater TCs vary in the range $650-661 \mathrm{~K}\left(377-388^{\circ} \mathrm{C}\right)$ at the full $80 \mathrm{~kW}$ power, which is in agreement with TRACEcalculated temperatures. At powers less than $80 \mathrm{~kW}$ (or $26.667 \mathrm{~kW} /$ heater), the temperature difference $(\Delta \mathrm{T})$ between the TC and the heater surface is proportional to the power of the heater (Sect. 7-2). At half power $(40 \mathrm{~kW})$, the $\Delta \mathrm{T}$ will be half, or $84 / 2=42 \mathrm{~K}$.

Finally, Figure 7-61 shows TRACE-calculated mass flow rates of water circulated into the bottom of the boiler/evaporator $(0.15 \mathrm{~kg} / \mathrm{s}$ at full power) through the entrance orifices, and steam $(0.023 \mathrm{~kg} / \mathrm{s}$ at full power) generated at the top of the boiler/evaporator. These values were not measured in the TSTL experiment, as only pressure drops were measured. Liquid mass flow rates and pressure drops were measured in the OFTF (Sect. 4.5), and they are in agreement with the value calculated here by the TRACE code. These values are also consistent with previously calculated values of liquid water and steam mass flow rates for similar tests with helium, such as test TS-140829-1, a high pressure test. 


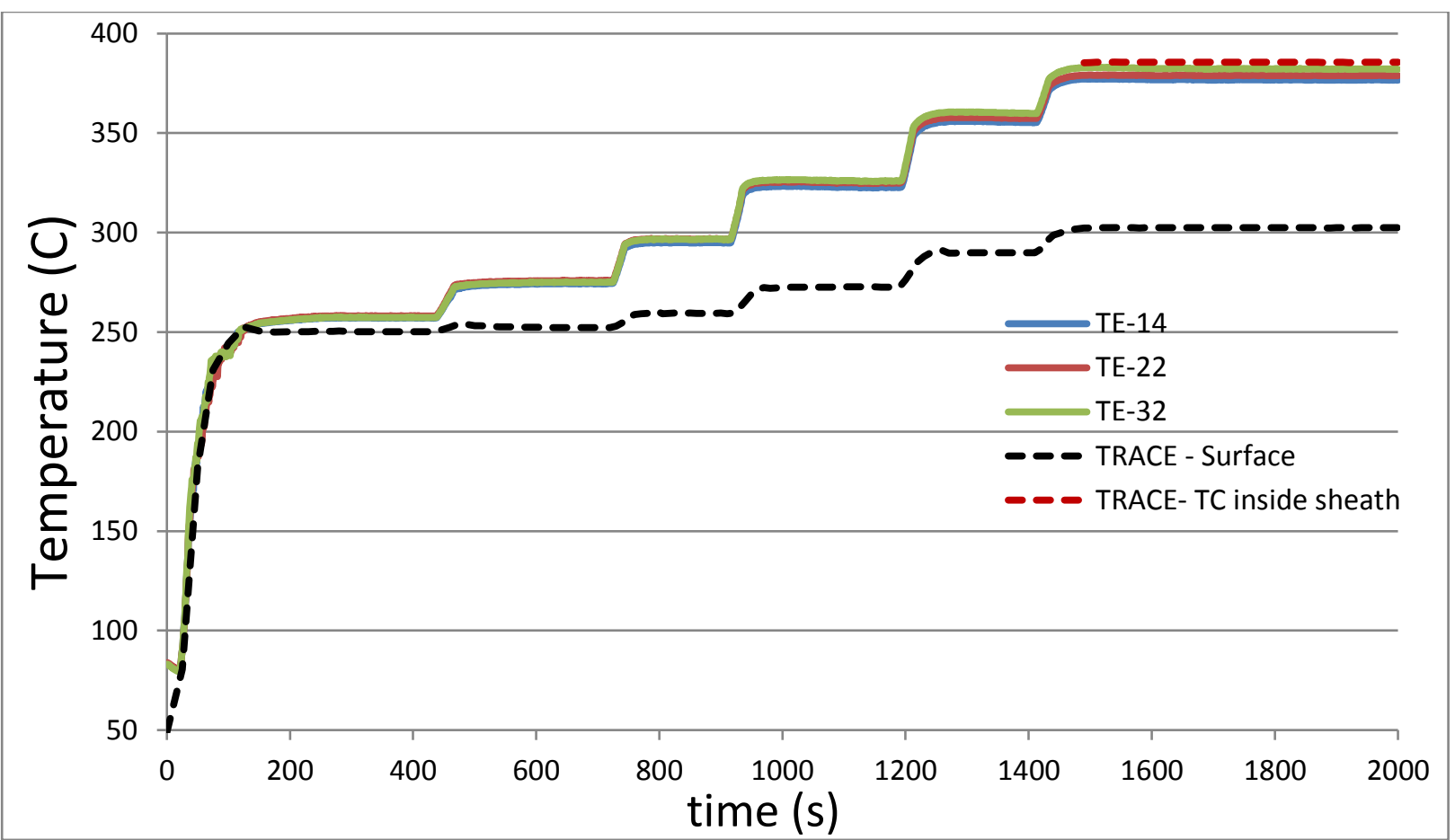

Figure 7-60. Experimental and TRACE-calculated temperatures for the three heaters.

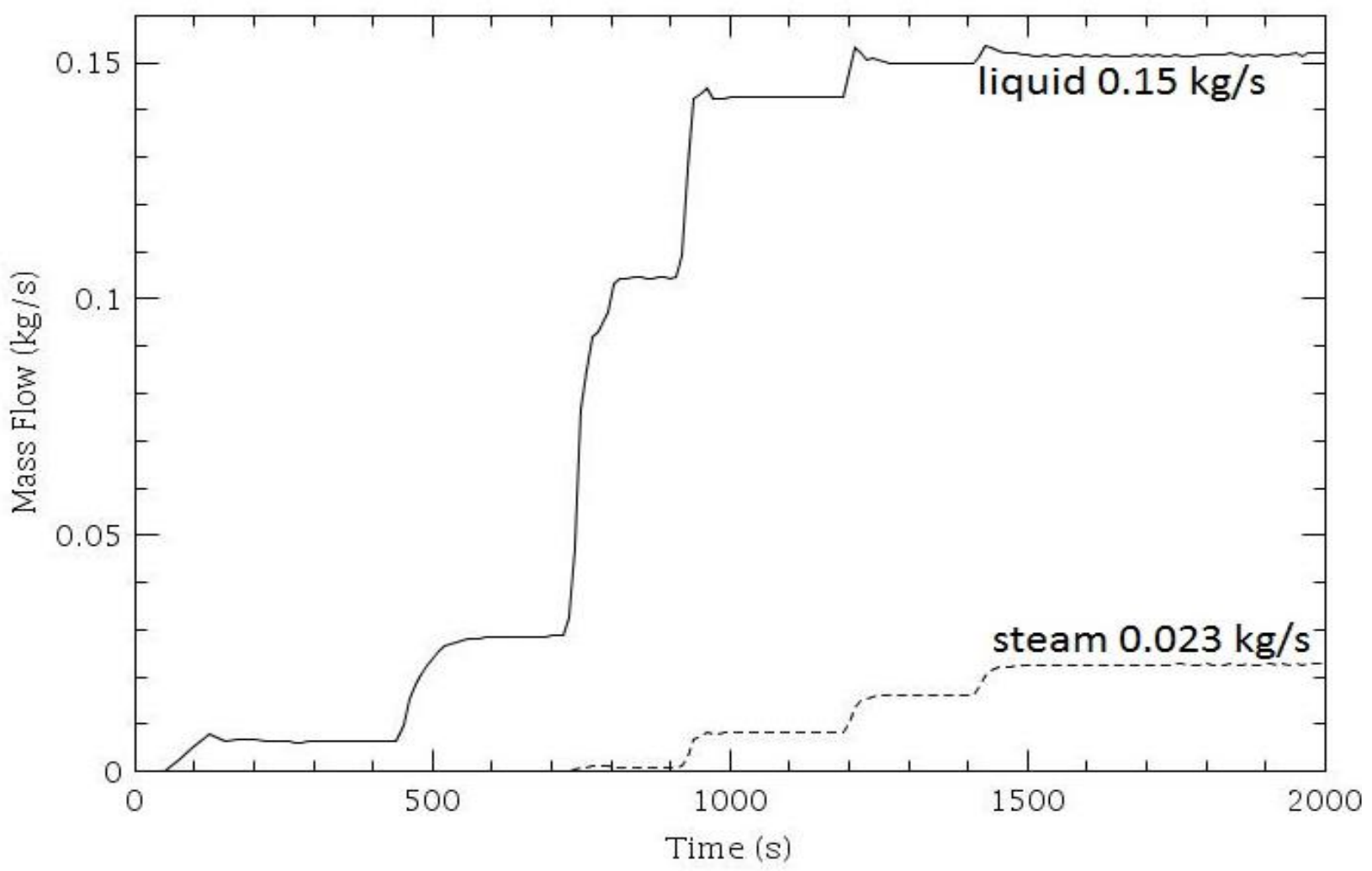

Figure 7-61. Calculated mass flow rates of liquid water and steam. 


\subsection{LOOP TEST}

\subsubsection{Test TS-140930-1}

This test simulated a LOOP transient in HFIR, and it was modeled with the TRACE code. In this test, the total power of $80 \mathrm{~kW}$ was entered in multiple steps over 2,200 s of time to get to the initial full power condition prior to initiation of the transient. In the TRACE run, the total power was approximated with six steps over a time of 1,450 s, kept constant until 2,000 s, and at this time the LOOP transient was started. When the LOOP was started, the power and primary coolant flow were both reduced. The power was reduced to $\sim 21 \%$ of the initial value, while the flow was reduced to only $\sim 8 \%$ the initial flow, which are typical LOOP values. In the experiment, the LOOP was started at 2,917 s. To compare experimental and calculated values, the experimental time of 2,917 s was shifted to 2,000 s. This correction makes experimental and calculated values comparable after the LOOP is started. The TRACE calculation was terminated at $2,500 \mathrm{~s}$.

Figure 7-62 compares the power employed in the experiment and the power input to the TRACE code. Values before 1,400 s are not relevant since the transient is started at 2,000 s. After 1,400 s, the full power of $80 \mathrm{~kW}$ is maintained for $600 \mathrm{~s}$, and the LOOP is started at 2,000 s with the total power of $80 \mathrm{~kW}$ being reduced to $16.4 \mathrm{~kW}$.

Figure 7-63 compares the primary loop flow measured in the experiment and the loop flow employed by the TRACE code (which is input to the code). Both flows are equal. The flow peak anomaly observed in the experiment at $\sim 2,240 \mathrm{~s}$ was not duplicated by the TRACE code. The initial primary coolant flow is $1.03 \mathrm{~kg} / \mathrm{s}(16.4 \mathrm{gpm})$, and the final flow is $0.08 \mathrm{~kg} / \mathrm{s}(1.3 \mathrm{gpm})$. The initial flow of $1.03 \mathrm{~kg} / \mathrm{s}$ is intentionally lower in this LOOP test than in previous tests with higher flow values of $1.18 \mathrm{~kg} / \mathrm{s}$.

Figure 7-64 shows measured temperatures of the primary coolant (inlet and outlet). In this figure, uncorrected times are used (LOOP started at 2,917 s) since there is no comparison to calculated values.

The inlet temperature in the experiment deviated from the desired value of $325.5 \mathrm{~K}\left(52.5^{\circ} \mathrm{C}\right)$. TRACE calculation employed a constant inlet temperature of $325.5 \mathrm{~K}\left(52.5^{\circ} \mathrm{C}\right)$ during the complete transient. It should be noted that the inlet temperature in the LOOP test is intentionally higher by $3.5 \mathrm{~K}$ than the temperature employed in other tests (which was $322 \mathrm{~K}$ or $49^{\circ} \mathrm{C}$ ).

Figure 7-65 compares the experimental and the calculated pressures in the test section (in the condenser). Both values agree before (8.08 MPa) and after the LOOP ( 4 MPa). 


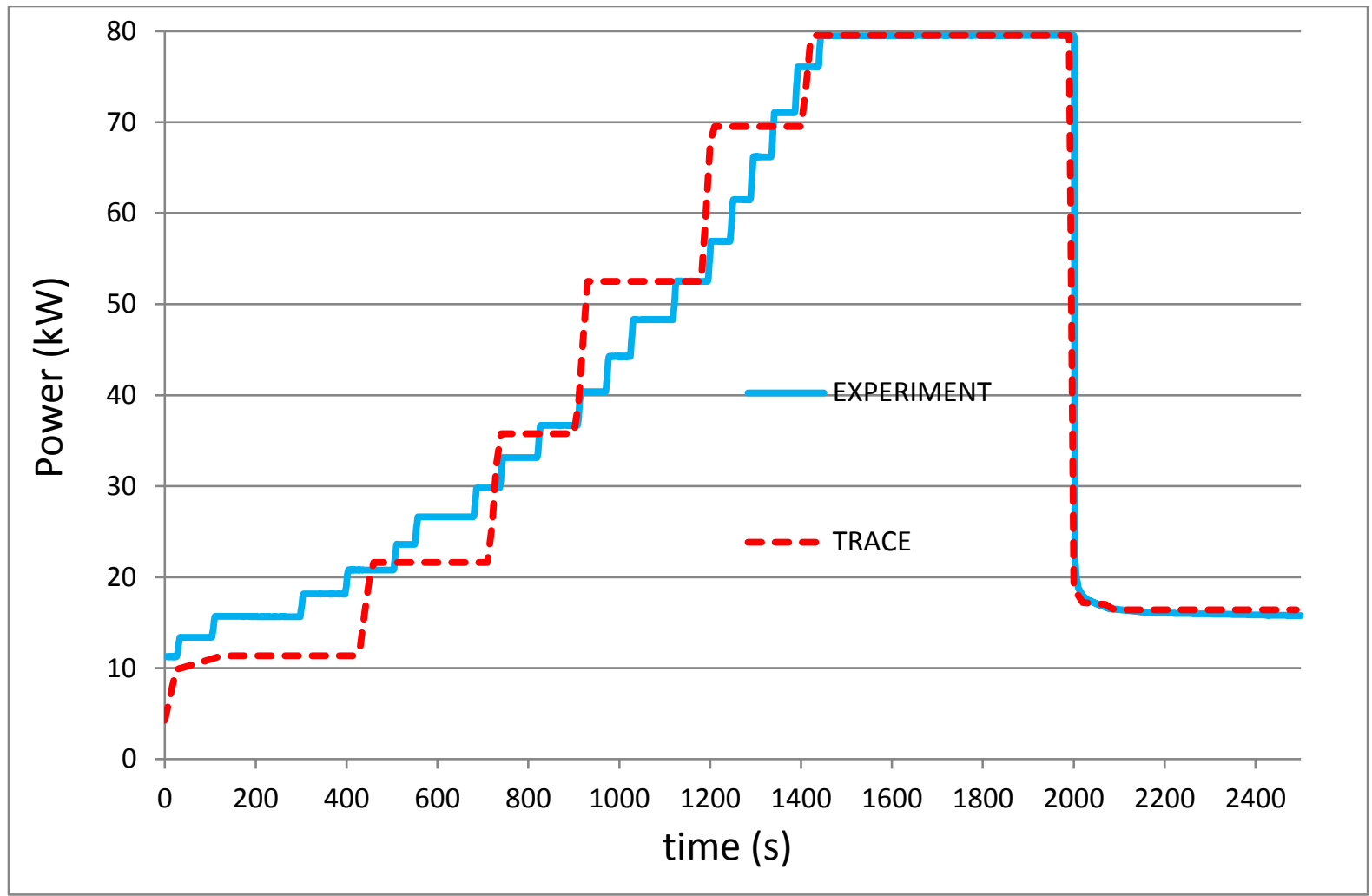

Figure 7-62. Experimental and TRACE input power for the LOOP test.

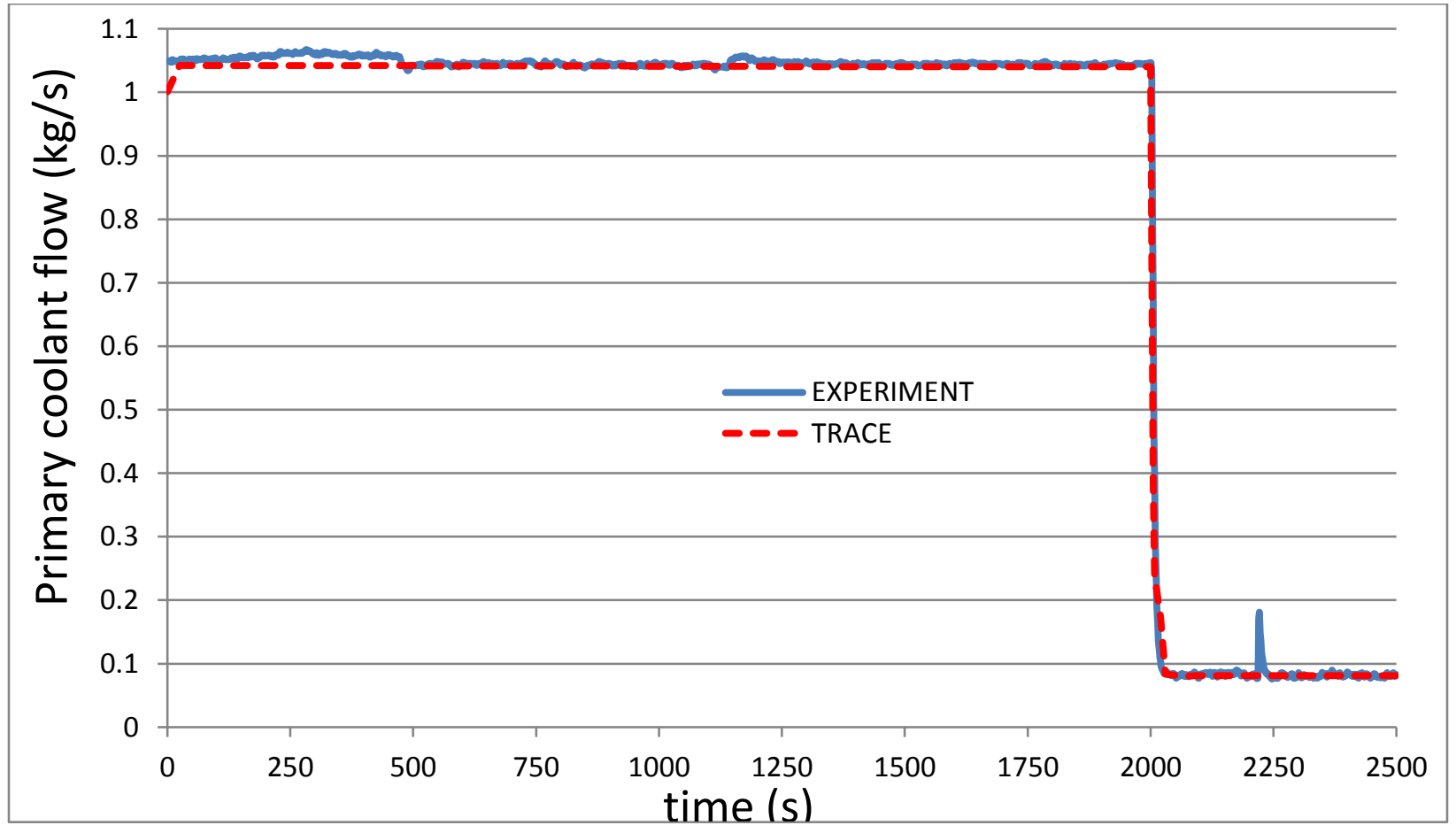

Figure 7-63. Experimental and TRACE input primary coolant flows. 


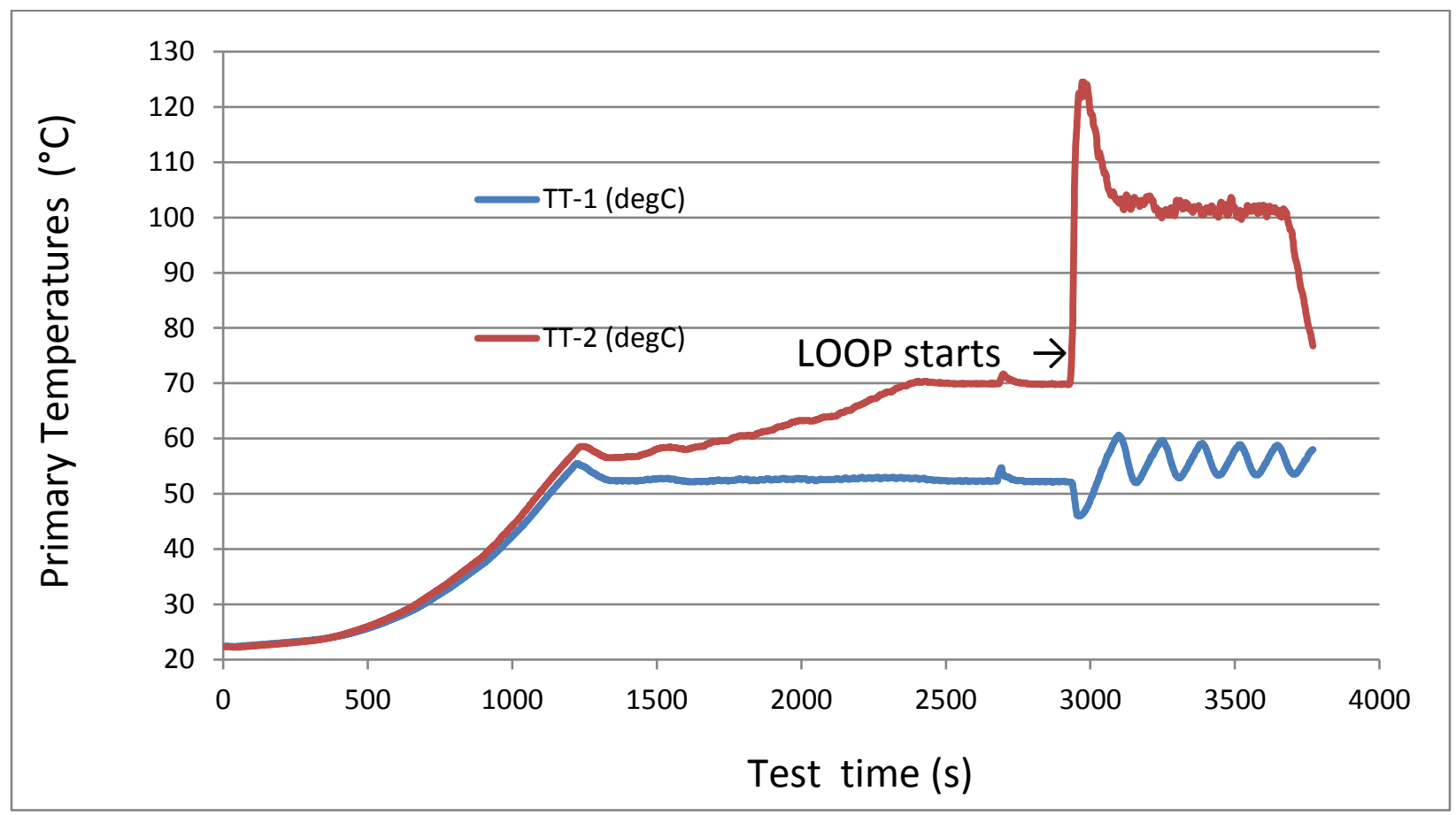

Figure 7-64. Experimental primary inlet and outlet temperatures (uncorrected test times).

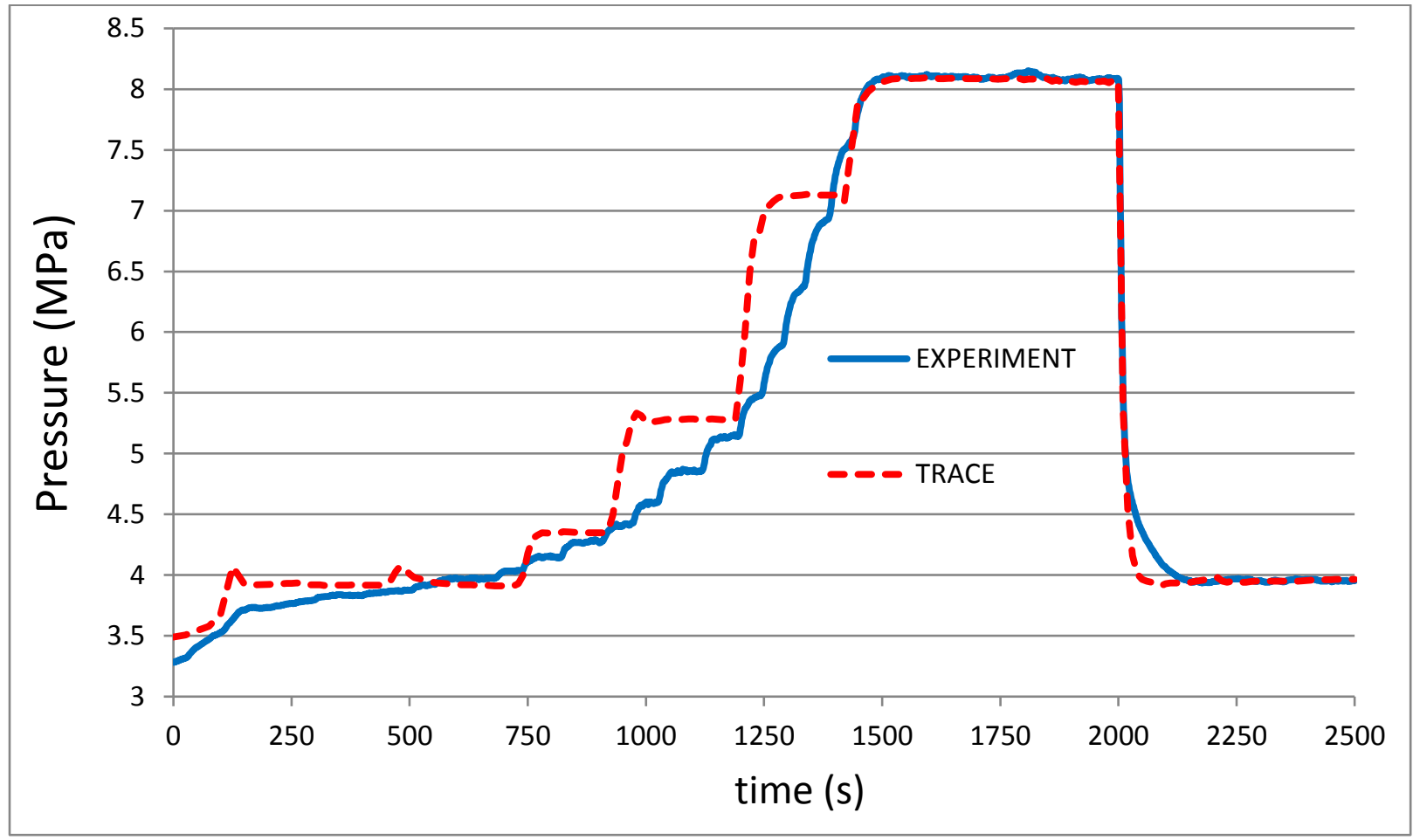

Figure 7-65. Measured and calculated pressures for the LOOP transient. 
Figure 7-66 compares measured and calculated TS temperatures. Measured temperature for the liquid water at the entrance to the boiler/evaporator is $513 \mathrm{~K}\left(240^{\circ} \mathrm{C}\right)$, and for steam leaving the boiler/evaporator it is $568 \mathrm{~K}\left(295^{\circ} \mathrm{C}\right)$ at full power. The calculated boiler inlet water temperature is $532 \mathrm{~K}$ $\left(259^{\circ} \mathrm{C}\right)$, which is over predicted by $19 \mathrm{~K}$. The calculated steam temperature is $570 \mathrm{~K}\left(297^{\circ} \mathrm{C}\right)$, which is over predicted by $2 \mathrm{~K}$.

At the end of the LOOP transient, TRACE calculated a steam temperature of $522 \mathrm{~K}\left(249^{\circ} \mathrm{C}\right)$; the experimental value is $520 \mathrm{~K}\left(247^{\circ} \mathrm{C}\right)$. The calculated liquid water temperature is now $473 \mathrm{~K}\left(200^{\circ} \mathrm{C}\right)$, which is also higher than the experimental value of $465 \mathrm{~K}\left(192^{\circ} \mathrm{C}\right)$.

Figure 7-67 compares the measured and calculated pressure differential across the entrance orifices. The $\triangle \mathrm{P}$ of $750 \mathrm{~Pa}$ before the LOOP initiation is modeled well by the TRACE code, but the value after the LOOP is started is under predicted by the TRACE code.

Finally, Figure 7-68 shows calculated mass flow rates of liquid $(0.15 \mathrm{~kg} / \mathrm{s})$ and steam $(0.023 \mathrm{~kg} / \mathrm{s})$ in the boiler/evaporator before the LOOP is started. At the end of the LOOP transient with reduced power, the mass flow rate of liquid is reduced to $0.039 \mathrm{~kg} / \mathrm{s}$, and there is only $0.0003 \mathrm{~kg} / \mathrm{s}$ of steam leaving the boiler/evaporator. Mass flow rates of water and steam were not measured in the experiment and cannot be compared to data.

TRACE calculated a mass of $23.6 \mathrm{~g}$ of helium in the system. The calculated value of Table 5-1 is $22.8 \mathrm{~g}$, a very similar amount.

This TRACE calculation proved that during this LOOP transient, no flow excursion occurred in the primary loop. The boundary conditions employed in the primary loop (inlet and outlet pressures as in the HFIR reactor) could result in a flow excursion which was not predicted. 


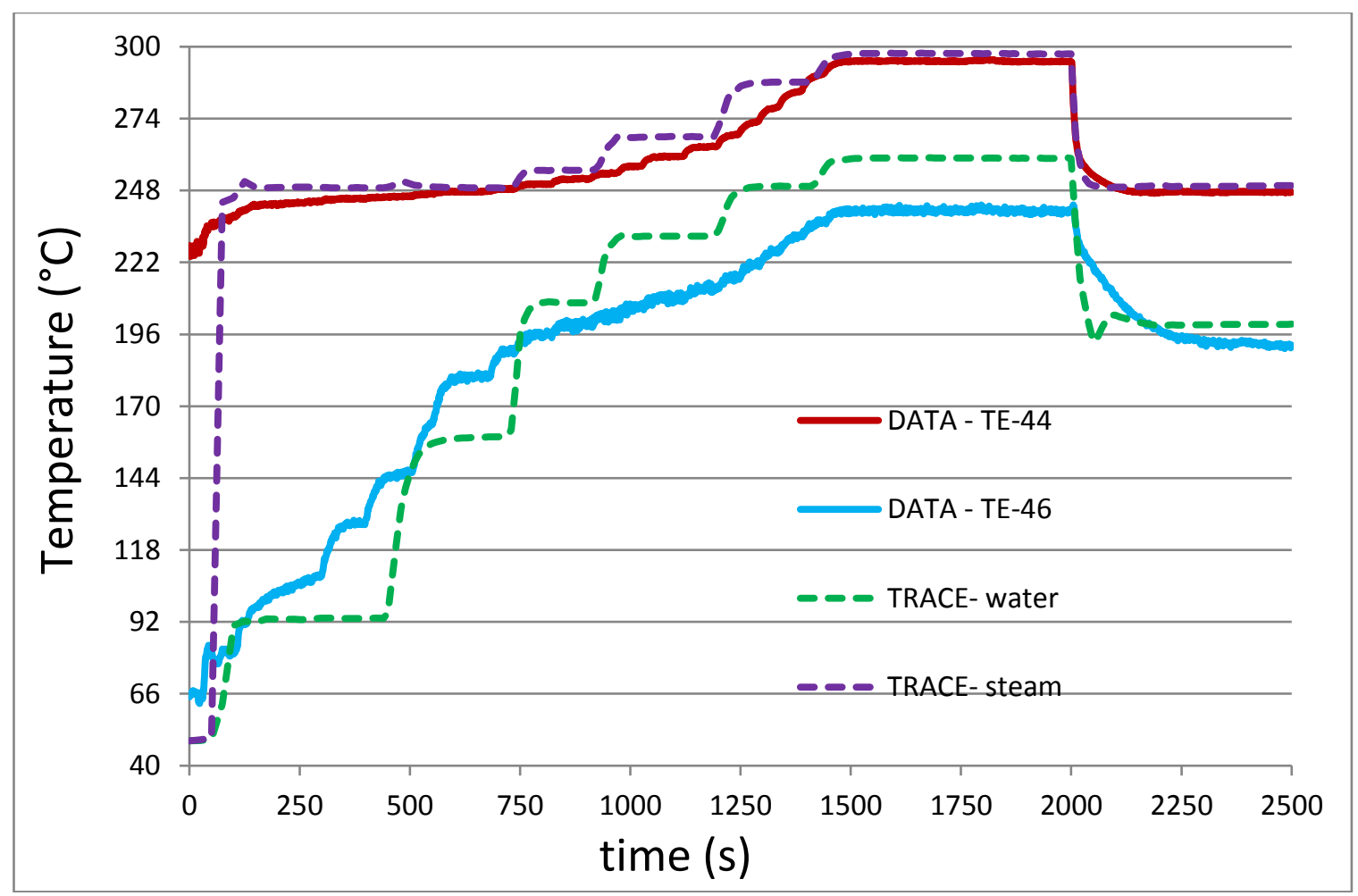

Figure 7-66. Measured and calculated steam and water/liquid temperatures

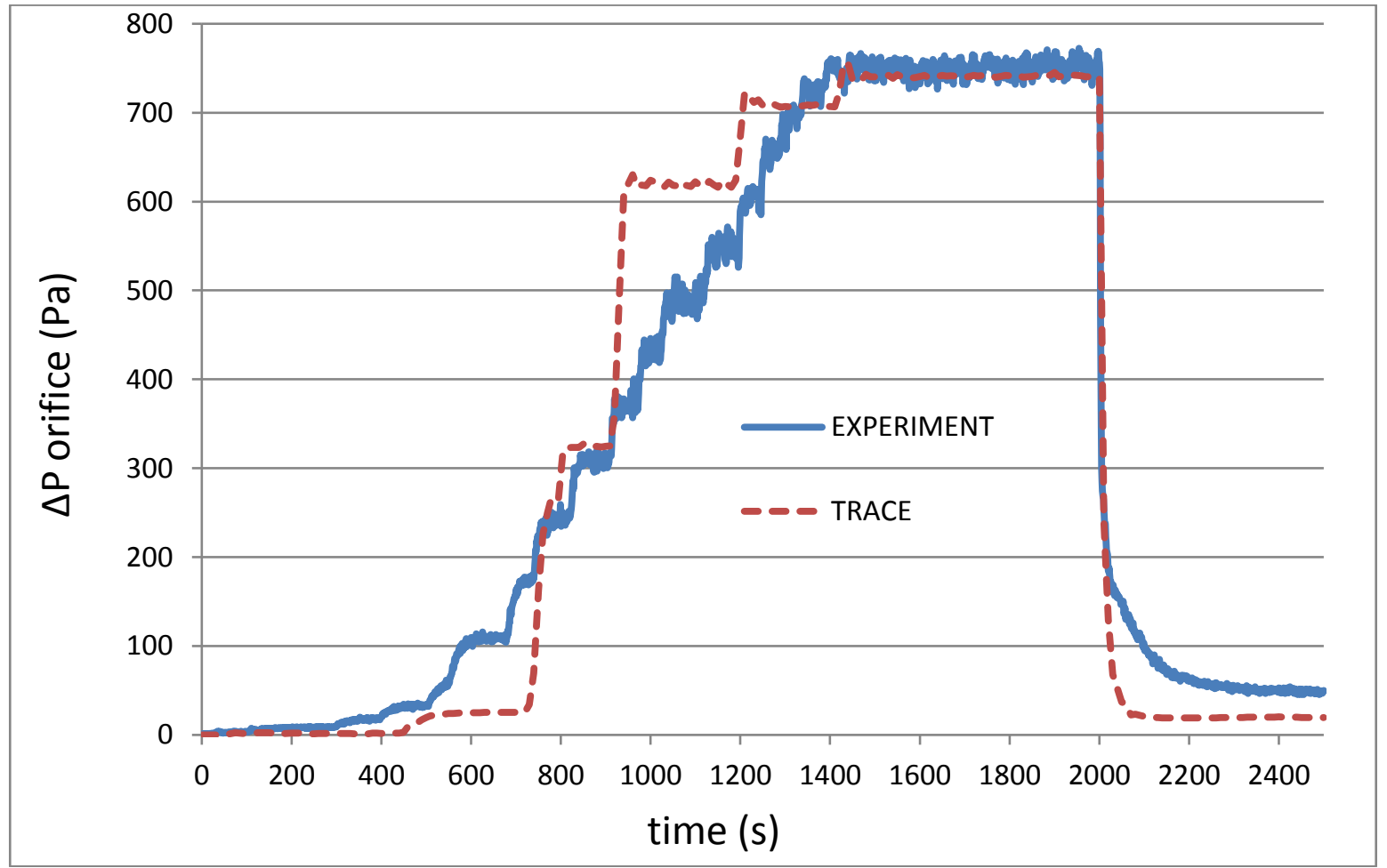

Figure 7-67. Measured and calculated pressure differential across the entrance orifice. 


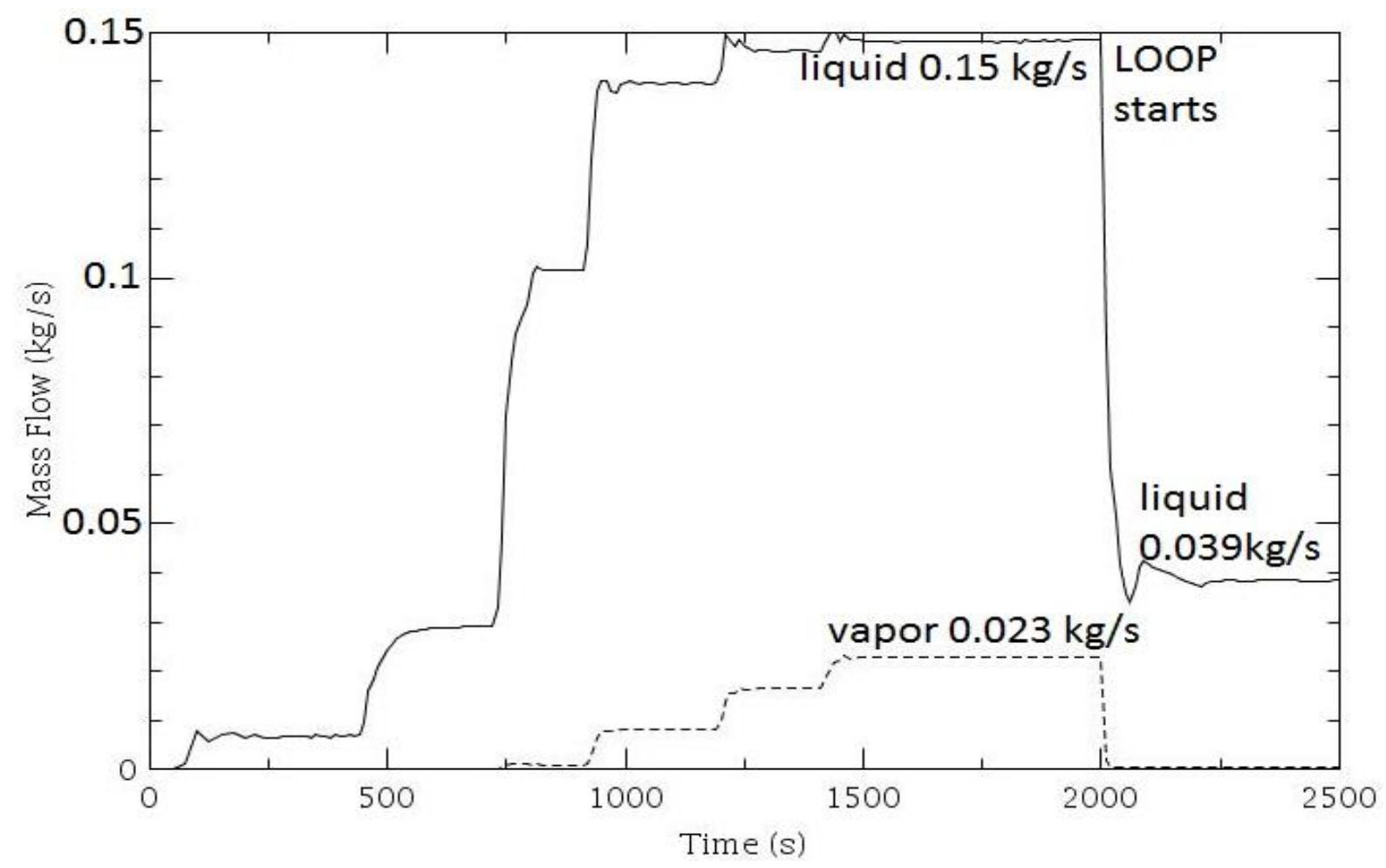

Figure 7-68. Calculated mass flow rates of water and steam in the boiler/evaporator - LOOP transient.

\subsection{HIGH POWER TEST}

Test TS-140930-2 is a high power test with a final power of $92.6 \mathrm{~kW}$, which is $\sim 1.16$ times the nominal $80 \mathrm{~kW}$ power. This test was also simulated with the TRACE code. The $130 \%$ power transient, which is required as a HFIR safety calculation, requires a high power of $80 \times 1.3=104 \mathrm{~kW}$, or $34.7 \mathrm{~kW} / \mathrm{heater}$, a power level that could not be achieved with the heaters/power supply matchup of the TSTL.

Figure 7-69 compares the experimental power levels with the TRACE power levels employed as input, showing that both powers' curves are similar. In the experiment, the power was increased in multiple steps, while the TRACE input used three power ramps approximating the experimental power transient: one from 0 to $9.3 \mathrm{~kW}$, the second one from 9.3 to $80 \mathrm{~kW}$, and the final one from 80 to $92.6 \mathrm{~kW}$. The 80 $\mathrm{kW}$ power level was reached at $940 \mathrm{~s}$ and maintained constant until $1020 \mathrm{~s}$. The $92.6 \mathrm{~kW}$ power level was reached at $1,300 \mathrm{~s}$ and kept constant for $300 \mathrm{~s}$.

Figure 7-70 compares the experimental and TRACE-calculated primary coolant temperatures. The experimental inlet temperature varied around the desired value of $322 \mathrm{~K}\left(49^{\circ} \mathrm{C}\right)$. TRACE used a constant inlet temperature of $322 \mathrm{~K}\left(49^{\circ} \mathrm{C}\right)$ during the complete transient.

Figure 7-71 compares the measured and TRACE-calculated primary coolant $\Delta \mathrm{T}$ (outlet-inlet). The calculated values appear to be slightly larger than the experimental values. The same discrepancy was discussed previously in Sect. 7.6. The initial $500 \mathrm{~s}$ of the transient data are not good to compare with the calculation because of these discrepancies. 
Figure 7-72 compares the measured and the TRACE-calculated pressure in the system. The initial pressure is $3.2 \mathrm{MPa}$. At the final power of $92.6 \mathrm{~kW}$, the measured value is $9.9 \mathrm{MPa}$, TRACE calculates $9.8 \mathrm{MPa}$. At the $80 \mathrm{~kW}$ power level, TRACE over calculates the measured pressure of $8 \mathrm{MPa}$. This may be due in part to not reaching steady state conditions after the power increases because the time intervals at constant power may not be sufficiently long.

Figure 7-73 compares the measured and the calculated liquid water temperature (entering the bottom of the boiler/evaporator) and steam/vapor temperature (leaving the top of the boiler/evaporator). Measured values are $583 \mathrm{~K}\left(310^{\circ} \mathrm{C}\right)$ for the steam/vapor and $525 \mathrm{~K}\left(252^{\circ} \mathrm{C}\right)$ for the liquid water. Calculated values are $584 \mathrm{~K}\left(311^{\circ} \mathrm{C}\right)$ for the steam/vapor, and $545 \mathrm{~K}\left(272^{\circ} \mathrm{C}\right)$ for the liquid water. The steam/vapor temperatures agree well, but the liquid temperatures disagree by $20 \mathrm{~K}$. As in previous calculations, the calculated value is higher than the experimental value.

Figure 7-74 compares the measured and the calculated pressure differential across the entrance orifice with a value of $780 \mathrm{~Pa}$ at the end of the transient. Both measured and calculated values agree well.

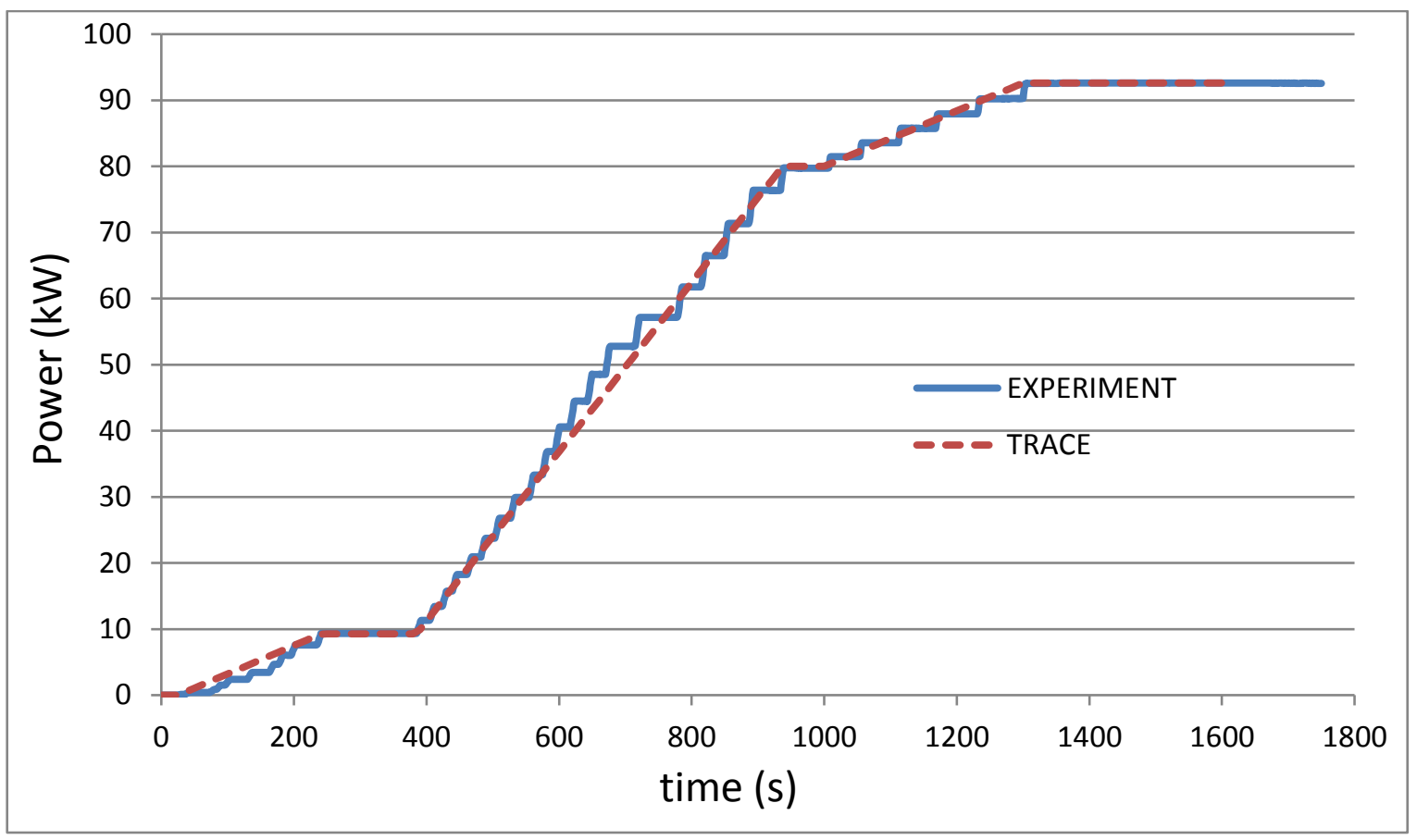

Figure 7-69. Power employed in the experiment and in the TRACE input. 


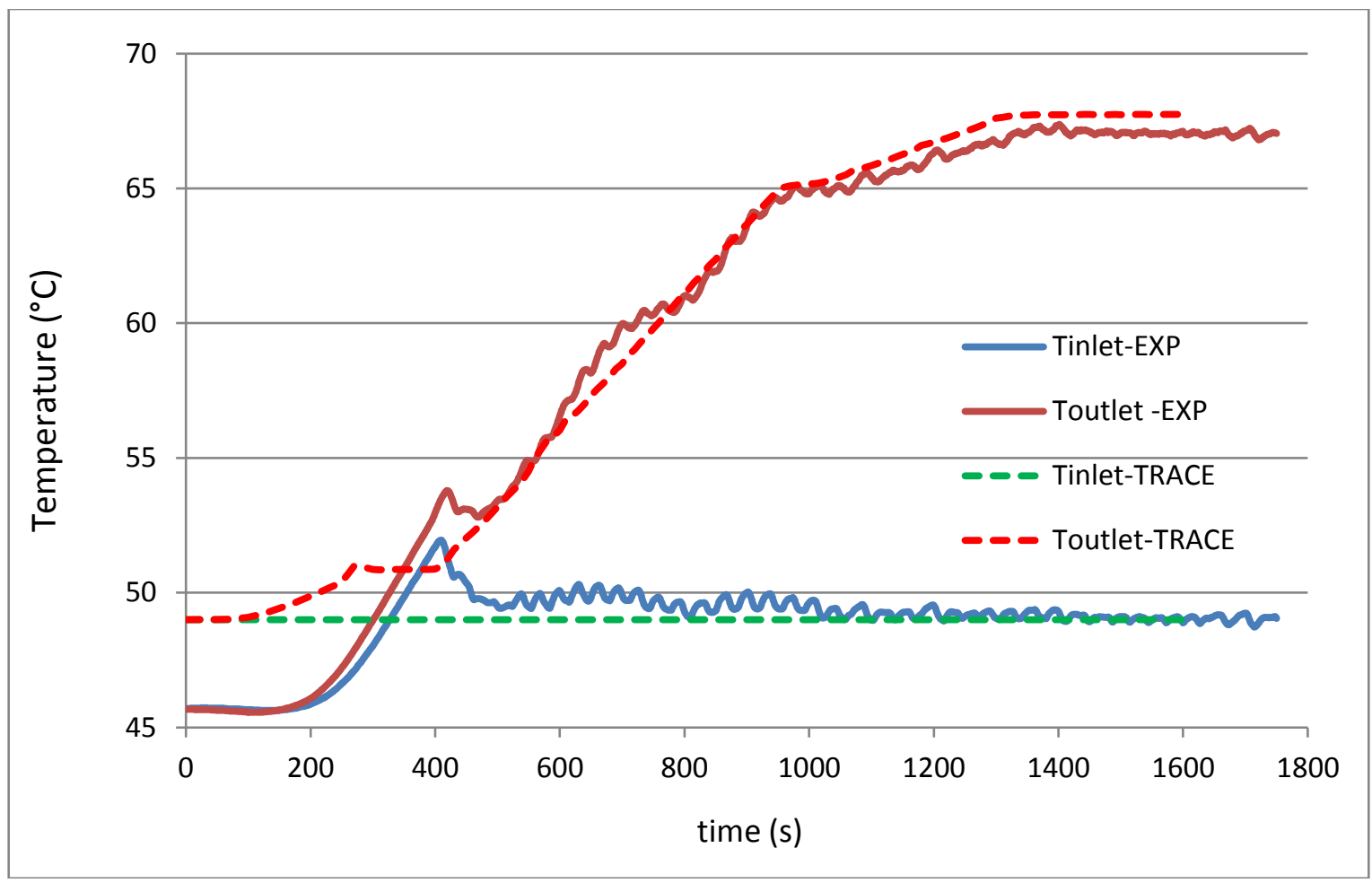

Figure 7-70. Primary inlet and outlet temperatures - experiment and TRACE simulation.

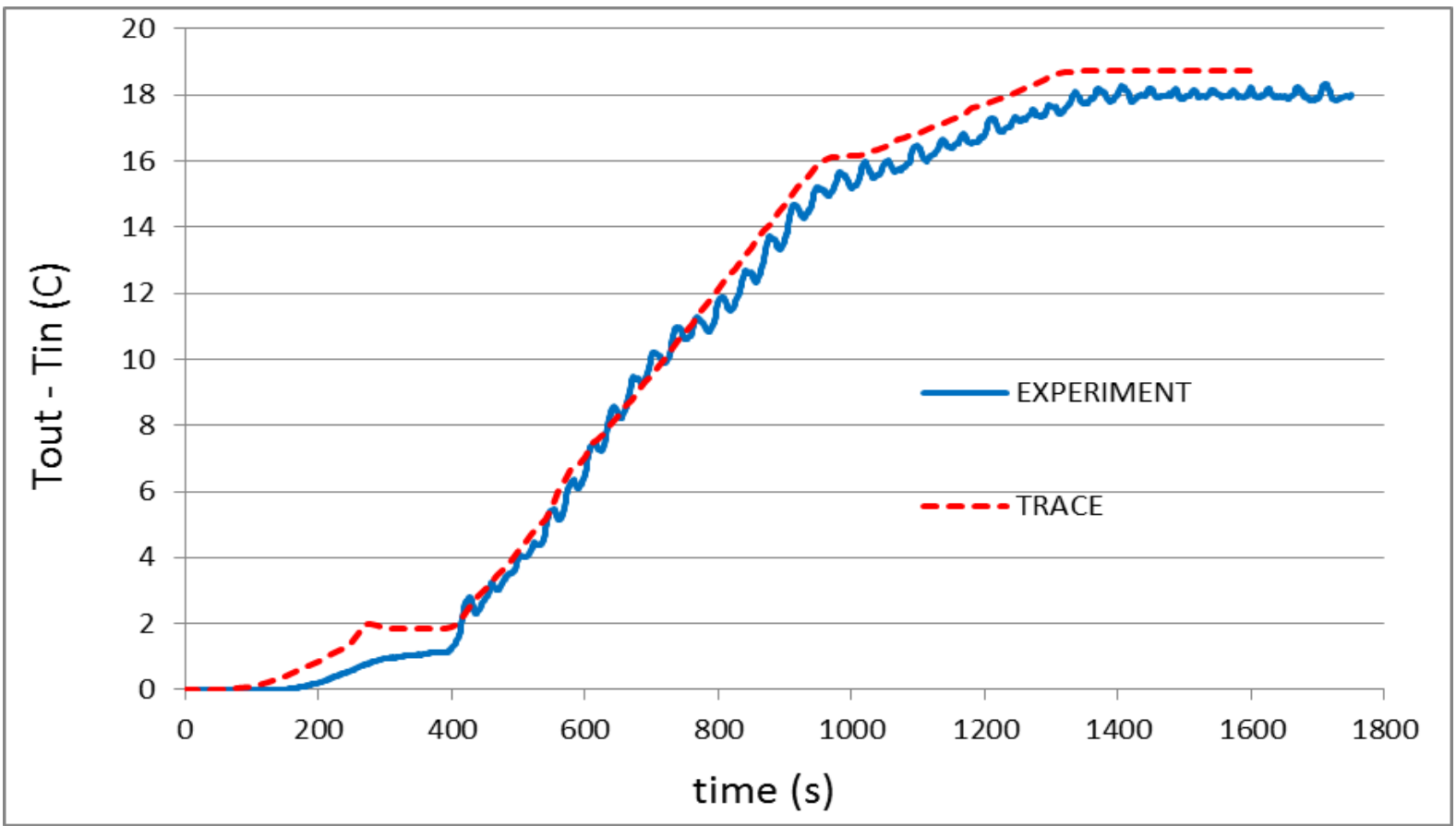

Figure 7-71. Primary coolant temperature difference - experiment and TRACE simulation. 


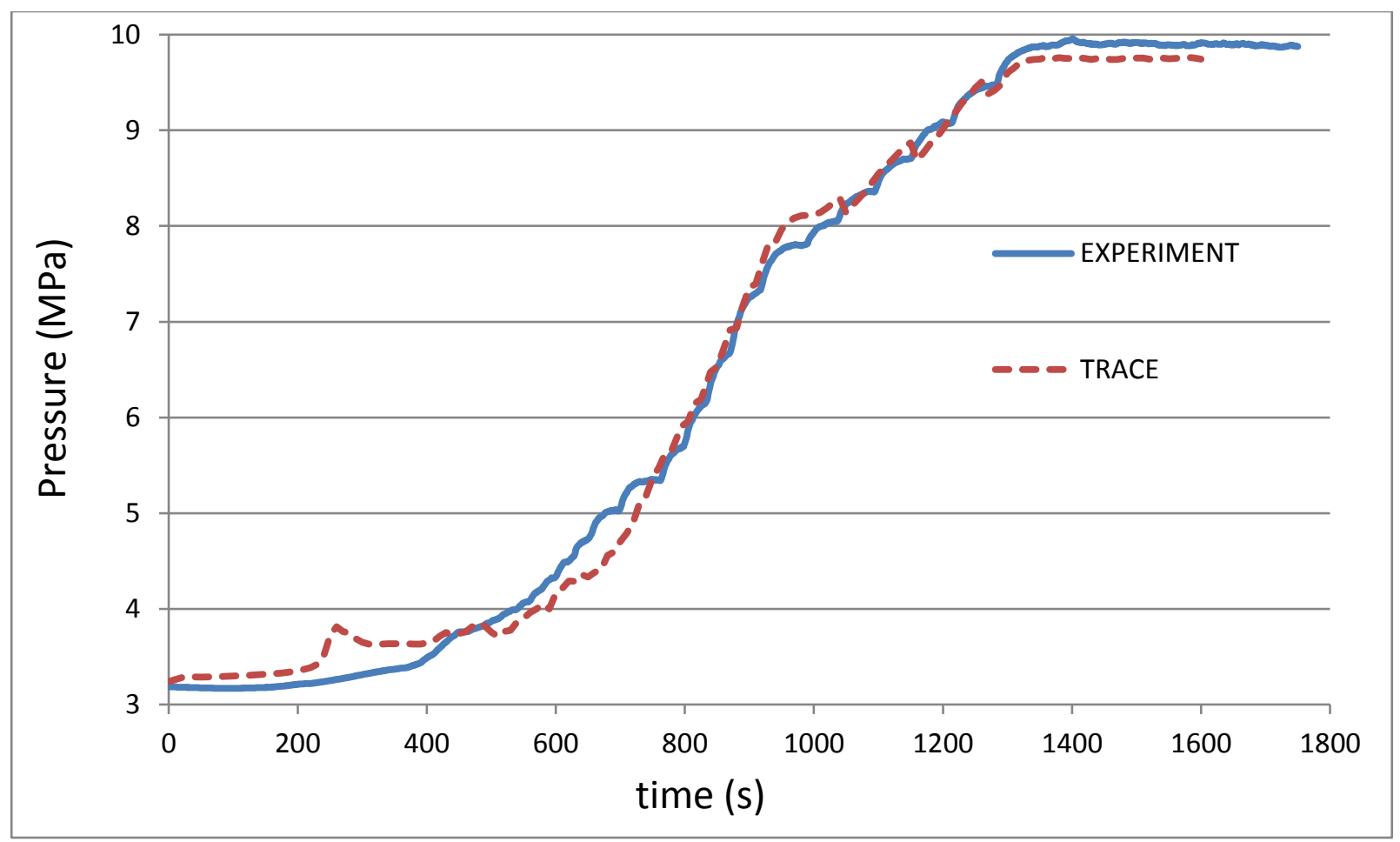

Figure 7-72. Measured and TRACE-calculated pressures for Test TS-140930-2.

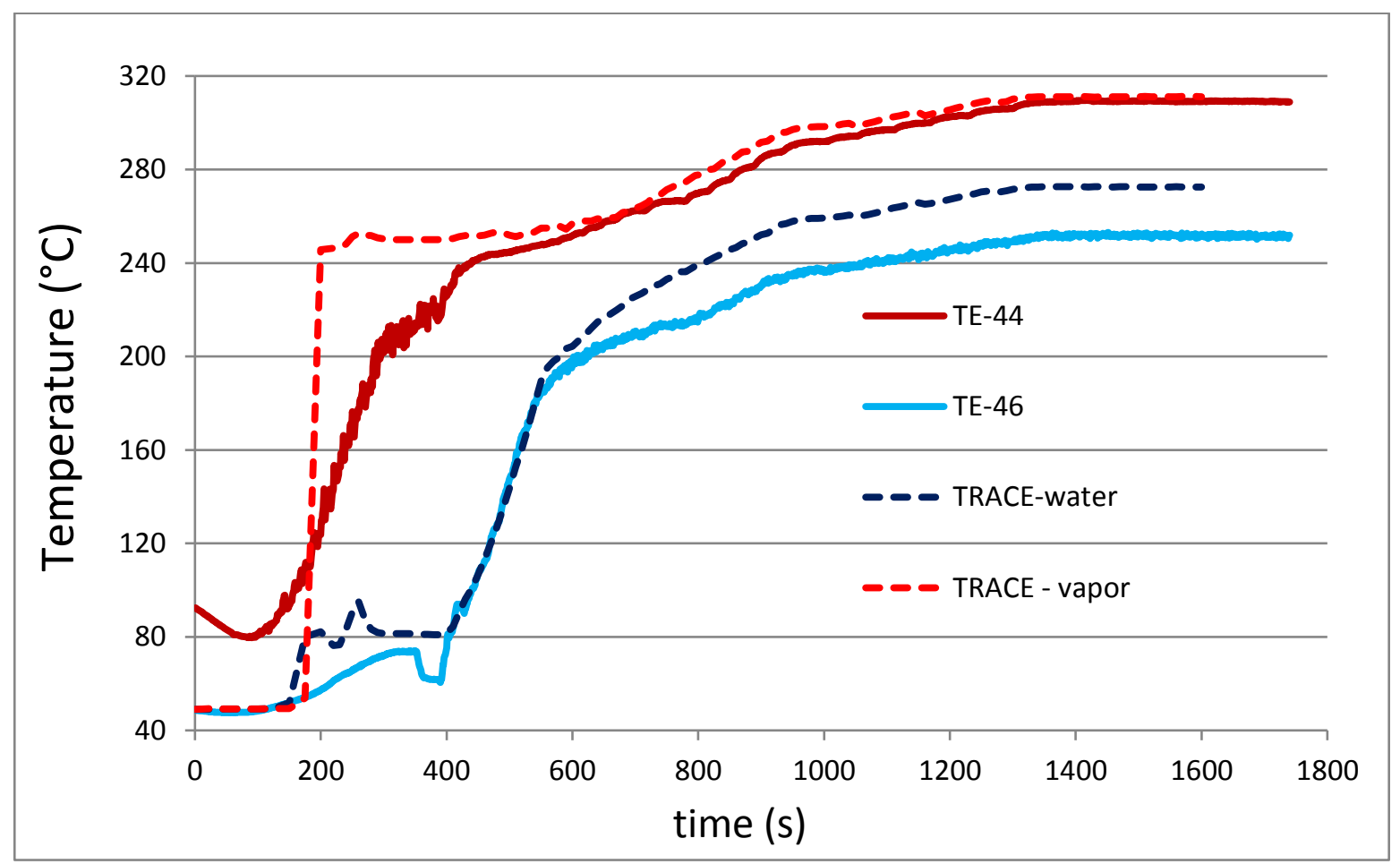

Figure 7-73. Measured and calculated liquid and vapor temperatures. 


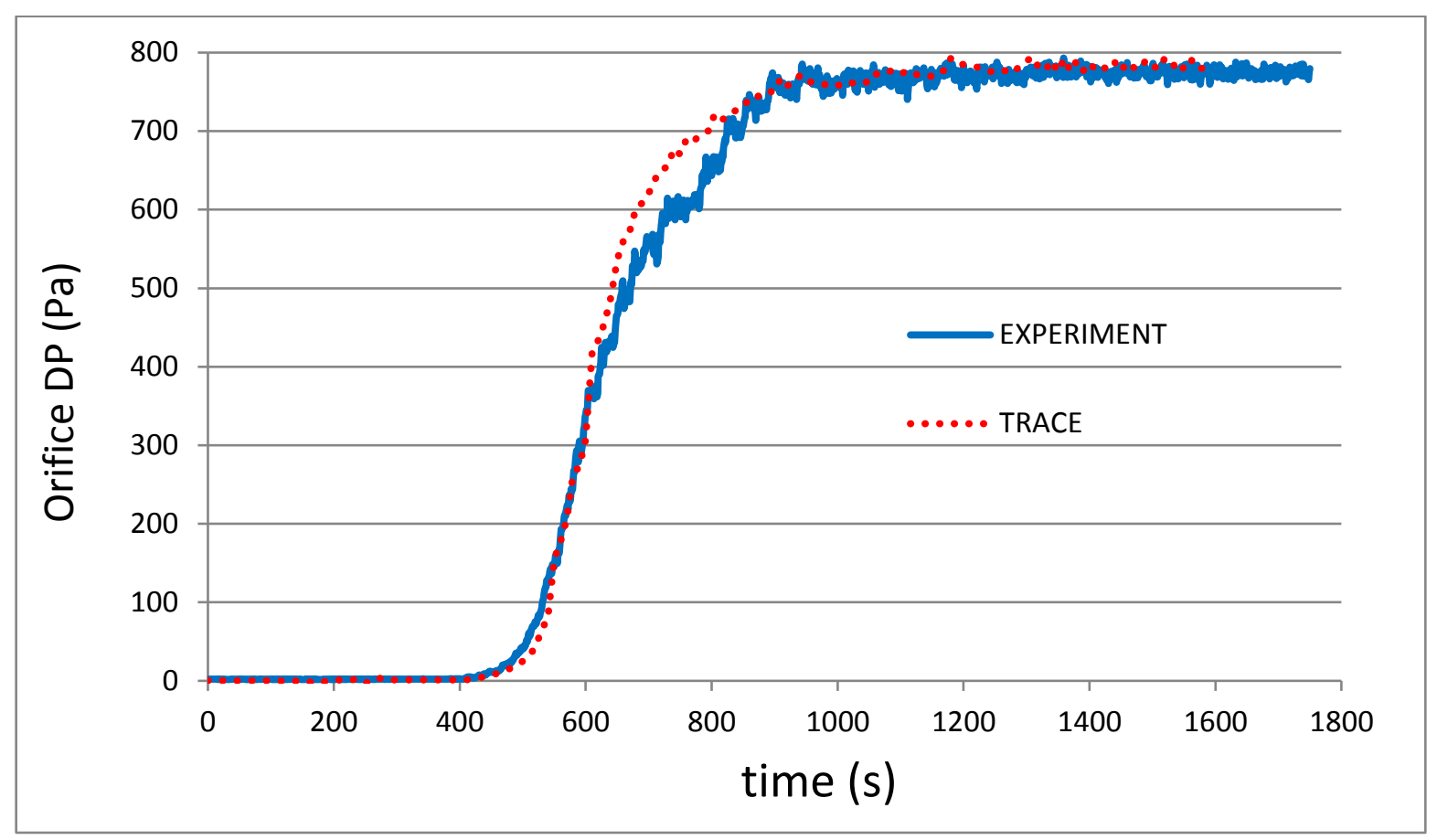

Figure 7-74. Pressure differential across the inlet orifices.

Figure 7-75 shows TRACE calculated mass flow rates of liquid and steam in the boiler/ evaporator. The amount of steam generated at the final power $(0.032 \mathrm{~kg} / \mathrm{s})$ is larger in this test than in previous tests $(0.02-0.025 \mathrm{~kg} / \mathrm{s})$ because this test has a higher power $(92.6 \mathrm{~kW})$ than previous tests $(80 \mathrm{~kW})$. The calculated mass flow rate of liquid water is comparable to other tests analyzed with high initial pressures, either with helium or argon as the NC gas.

TRACE calculated a mass of $23.75 \mathrm{~g}$ of helium in the system. The value calculated in Table 5-1 is $22.8 \mathrm{~g}$, a very similar amount. 


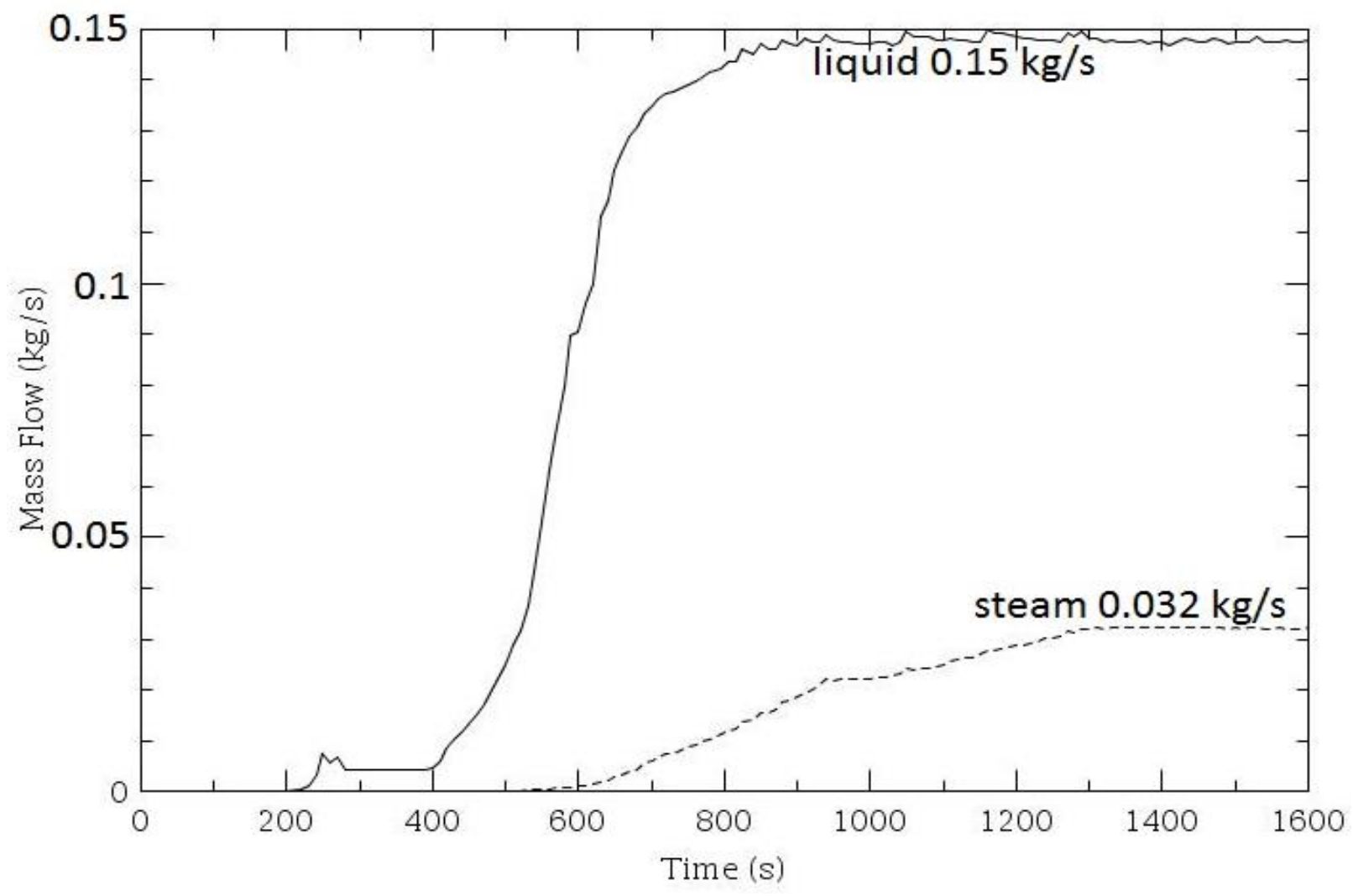

Figure 7-75. TRACE-calculated liquid ad vapor mass flow rates.

\subsection{MAXIMUM POWER CALCULATIONS}

Additional TRACE calculations were completed to estimate the maximum power level that can be tolerated by the TSTL before reaching CHF. Several TRACE calculations were performed as a continuation of the previous high power test calculation, test TS-140930-2 (Sect. 7.8), with the total power increased beyond the $92.6 \mathrm{~kW}$ value of the test. The same initial conditions of the previous test were employed: helium was added to an initial pressure at zero power of 3.2 MPa. Two different power ramps above the $80 \mathrm{~kW}$ power were employed: one at $0.06 \mathrm{~kW} / \mathrm{s}$ (or $24 \mathrm{~kW}$ increase in $400 \mathrm{~s}$ ), and the other at $0.04 \mathrm{~kW} / \mathrm{s}$ (or $24 \mathrm{~kW}$ increase in $600 \mathrm{~s}$ ). These runs were designed to reach a final power of $104 \mathrm{~kW}$, which is $130 \%$ of $80 \mathrm{~kW}$, or $24 \mathrm{~kW}$ over the $80 \mathrm{~kW}$ nominal power.

CHF was reached at a total power of $98.8 \mathrm{~kW}$ for the $400 \mathrm{~s}$ ramp and at $98.3 \mathrm{~kW}$ for the $600 \mathrm{~s}$ ramp: very similar values for both calculations. Figure 7-76 shows the power employed in these calculations. The previous calculation run for test TS-140930-2 is also shown in this figure. An additional calculation was completed with the power increased rapidly (in just $1 \mathrm{~s}$ ) from $80 \mathrm{~kW}$ to $104 \mathrm{~kW}$. The $80 \mathrm{~kW}$ power level was reached at $1,400 \mathrm{~s}$, maintained for $600 \mathrm{~s}$, and with the power ramp to $104 \mathrm{~kW}$ at 2,000 s (blue line of Fig. 7-76). This calculation was a continuation of the calculation performed for test TS-140925-1, the HFIR start-up sequence (Sect. 7.6). This calculation was started at an initial pressure of $3.24 \mathrm{MPa}$ with helium added to the system. The nominal power of $80 \mathrm{~kW}$ was applied in 6 steps as in Fig. 7-52. Again, the sudden power increase from $80 \mathrm{~kW}$ to $104 \mathrm{~kW}$ took place at 2,000 s. The total power of $104 \mathrm{~kW}$ was in principle tolerated, but CHF occurred $20 \mathrm{~s}$ after the $104 \mathrm{~kW}$ power level was applied. 
Figure 7-77 shows the calculated pressures in the system for the previous calculations. The pressure calculated for the high power test calculation (Sect. 7.8) is also included in this figure.

Figure 7-78 shows calculated surface temperatures for the top two nodes of one of the heaters (HS-1104)

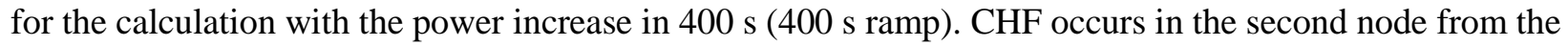
top since the top node is not heated (Sect. 7.1) and has a lower temperature. The temperature of this second node increases rapidly at $1,312 \mathrm{~s}$, an indication of CHF occurrence.

Figure 7-79 shows the surface temperature and the central (at the axis of the heater) temperature calculated for the second node of heater HS-1106 for the same TRACE run (with the $400 \mathrm{~s}$ power ramp). The inside temperature in the nickel core is higher than the surface temperature by more than $200 \mathrm{~K}$ after $900 \mathrm{~s}$. Both temperatures increase rapidly at the end of the calculation. The TRACE run was terminated because the calculated temperatures of the heaters were beyond the values of the input property tables.

According to these calculations, the maximum power that the TS can tolerate appears to be $\sim 98 \mathrm{~kW}$. Different power limits may be calculated if the initial conditions (NC gas mass) are different than the values employed here. The thermal properties of the heaters are also an important factor in these calculations - different materials or specimens will yield different results.

To be certain that the $98 \mathrm{~kW}$ power can be tolerated by the TSTL under steady state conditions, another run was completed at this maximum power of $98 \mathrm{~kW}$. This run was a continuation of the previous HFIR start-up sequence (Sect. 7.6) with the $80 \mathrm{~kW}$ power level reached at 1,400 s. The power increase from 80 $\mathrm{kW}$ to $98 \mathrm{~kW}$ occurred at 2,000 s using a power ramp of $400 \mathrm{~s}$.

The power increase level is $(98-80) \mathrm{kW} / 400 \mathrm{~s}=18 \mathrm{~kW} / 400 \mathrm{~s}=0.045 \mathrm{~kW} / \mathrm{s}$.

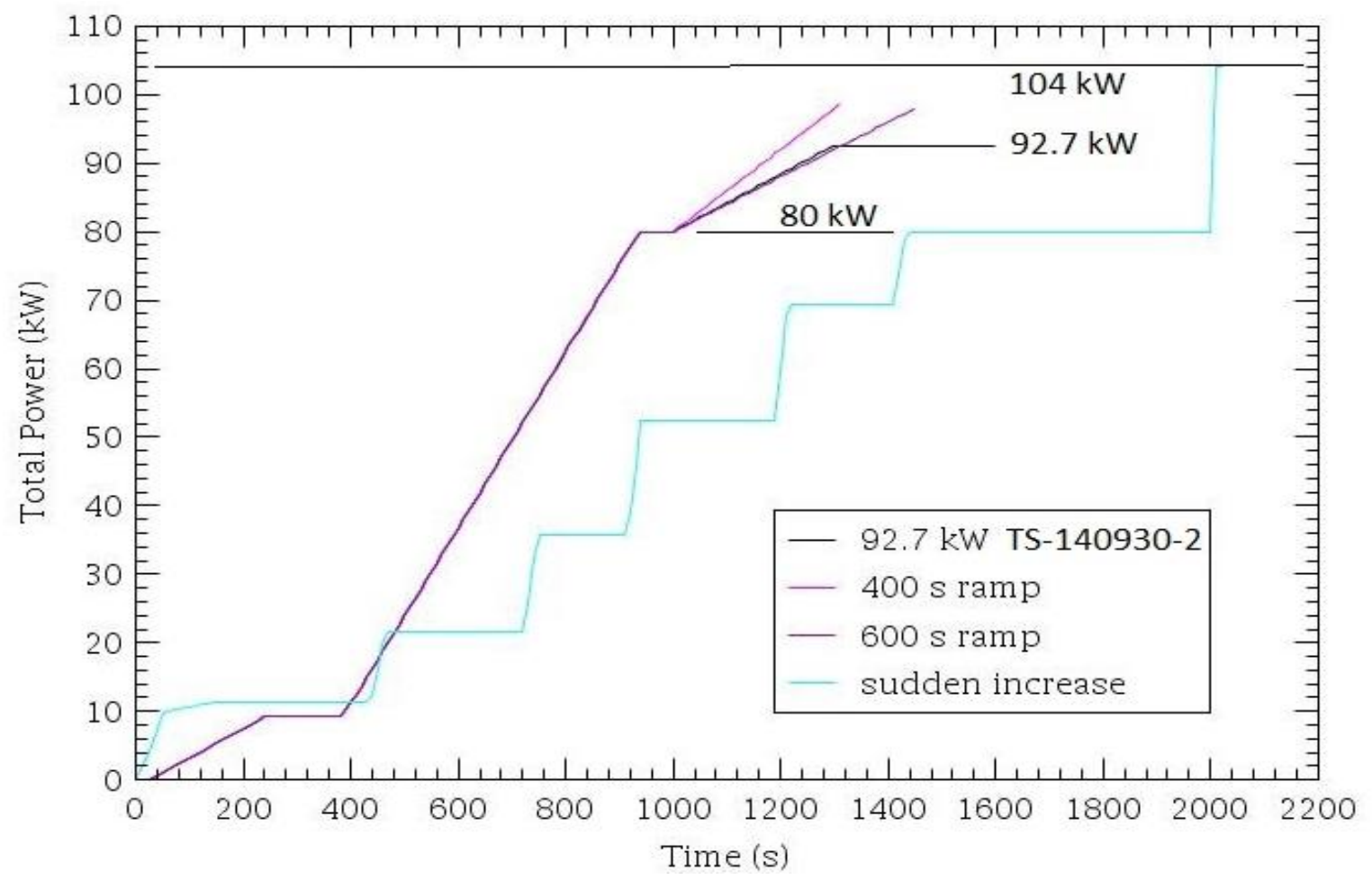

Figure 7-76. System power employed in maximum power calculations. 


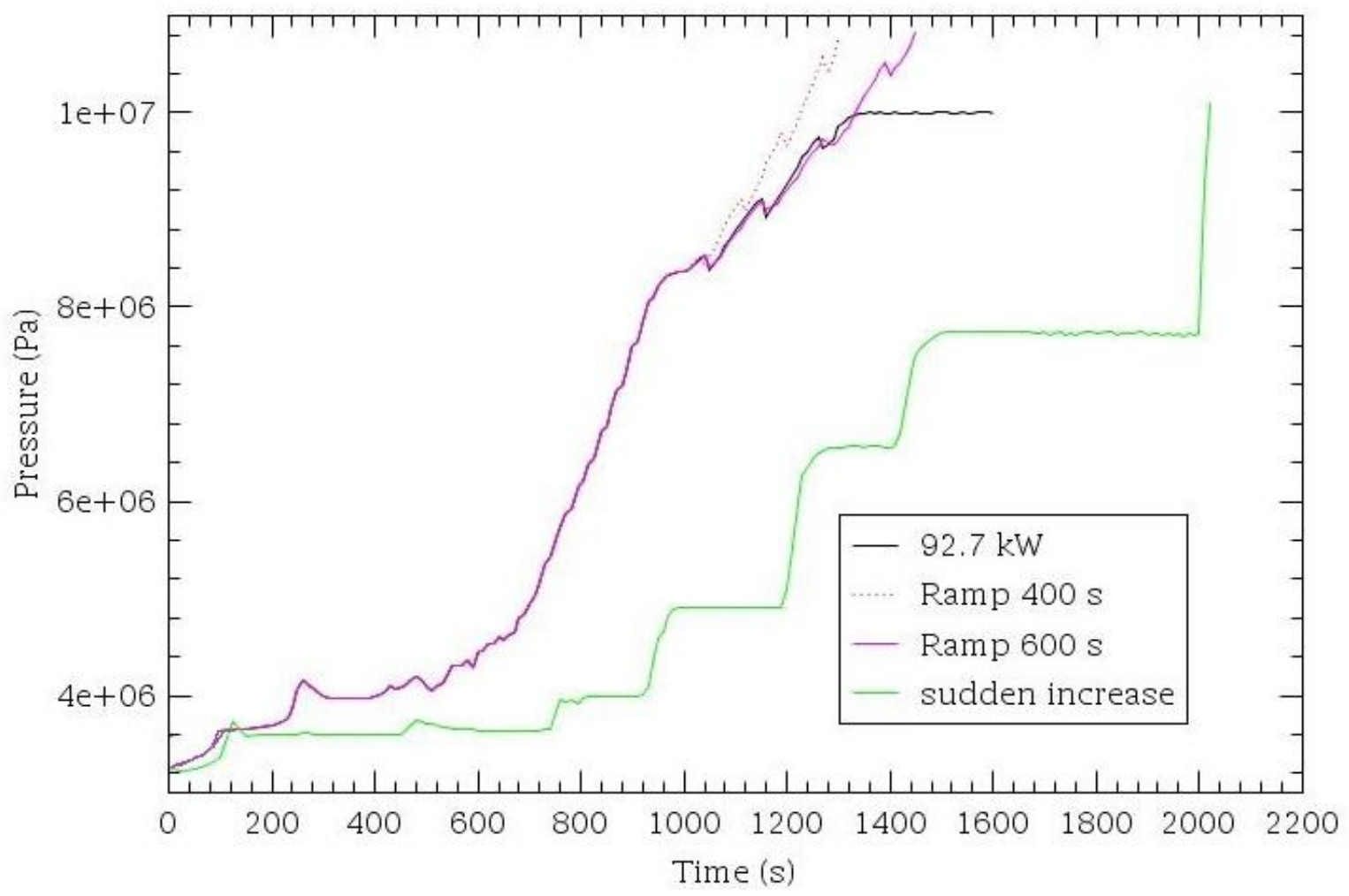

Figure 7-77. Calculated pressures for the maximum power calculations.

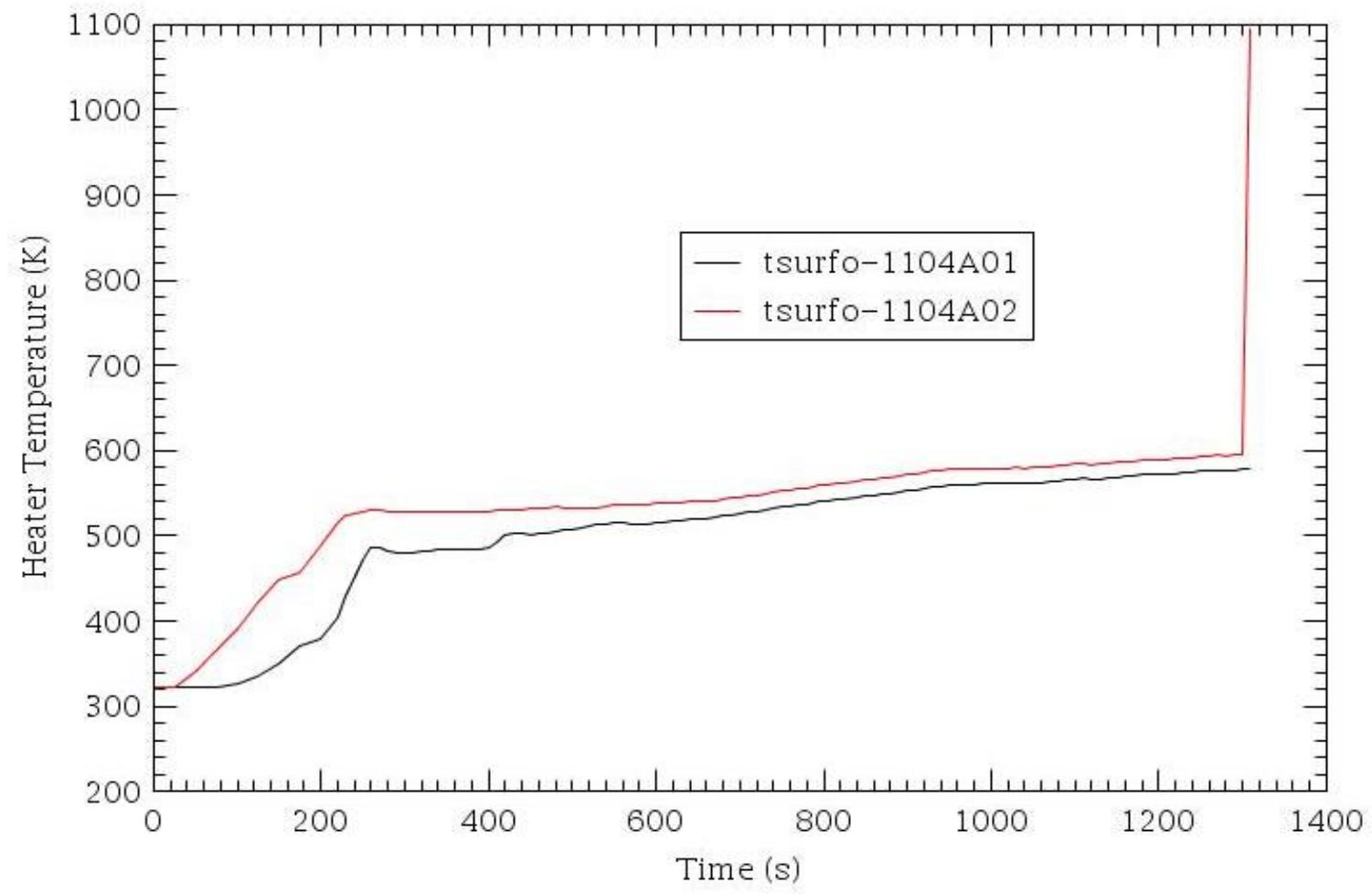

Figure 7-78. Calculated temperature for the surface of one heater (HS-1104). 


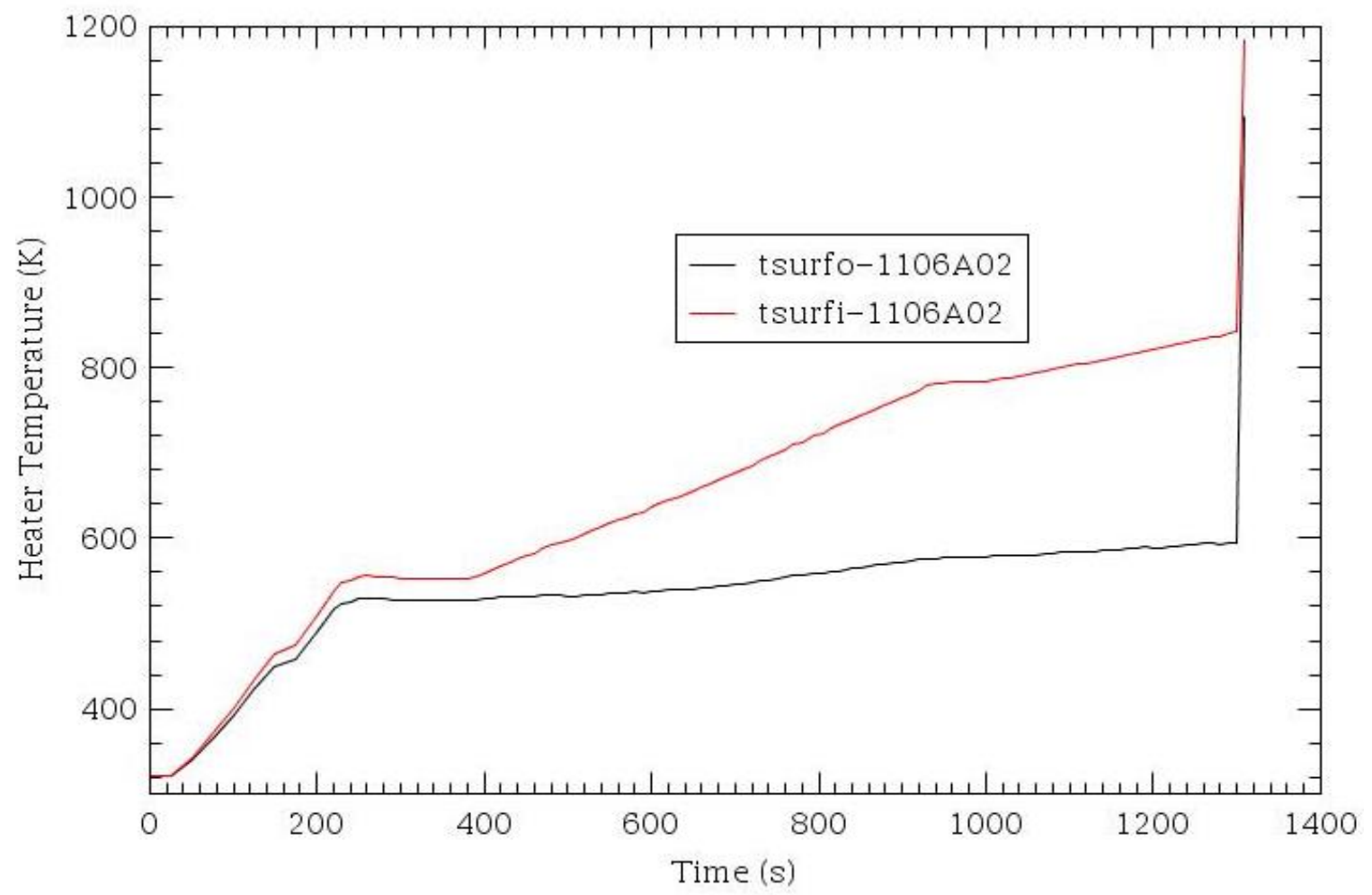

Figure 7-79. Calculated temperatures for heater HS-1106.

This run was completed successfully at the maximum power of $98 \mathrm{~kW}$, demonstrating that $98 \mathrm{~kW}$ can be tolerated by the TSTL. Figure 7-80 shows the power employed in this run. The $98 \mathrm{~kW}$ maximum power level was reached at 2,400 s, and the run was continued to 3,000 s at the $98 \mathrm{~kW}$ power level. Figure 7-81 shows the pressure calculated in the system for this run. Figure 7-82 shows the calculated surface temperature of the four top nodes of heater HS-1400. The top node is not heated and has a lower temperature (by more than $20 \mathrm{~K}$ ) than the other three heated nodes. The top three heated nodes show the same calculated temperatures. The other two heaters show the same behavior. CHF was not predicted to occur for any of the nodes of the three heaters in this run.

These calculations are very dependent on the thermal properties of the FRS and on the power profile (uniform heating) employed, and they cannot be applied directly to any other experiment in which different FRS or specimens are employed. A reevaluation for different specimens or different conditions will be needed for each specific case. 


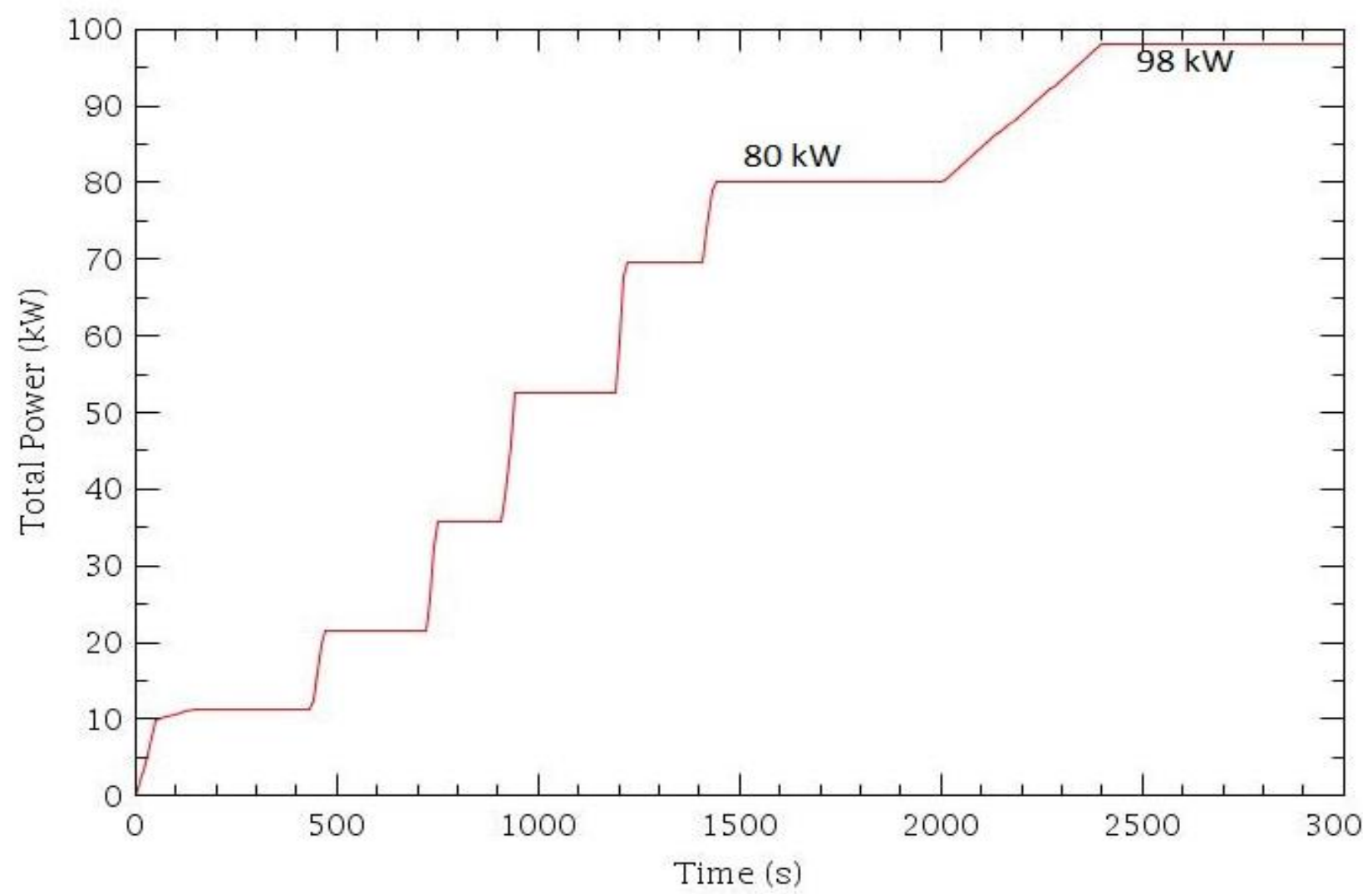

Figure 7-80. Power employed in the $98 \mathrm{~kW}$ maximum power run.

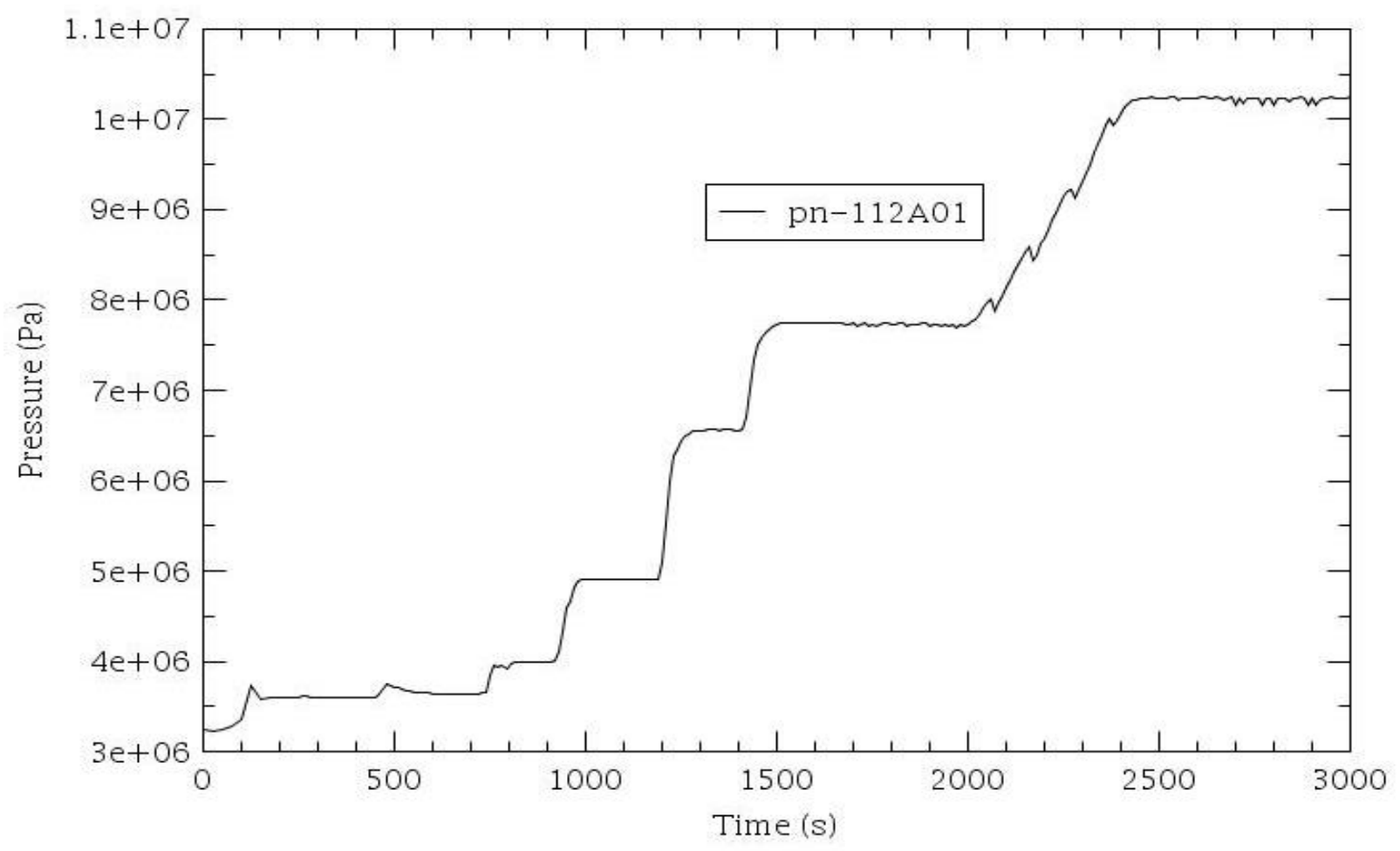

Figure 7-81. Pressure calculated for the $98 \mathrm{~kW}$ maximum power run. 


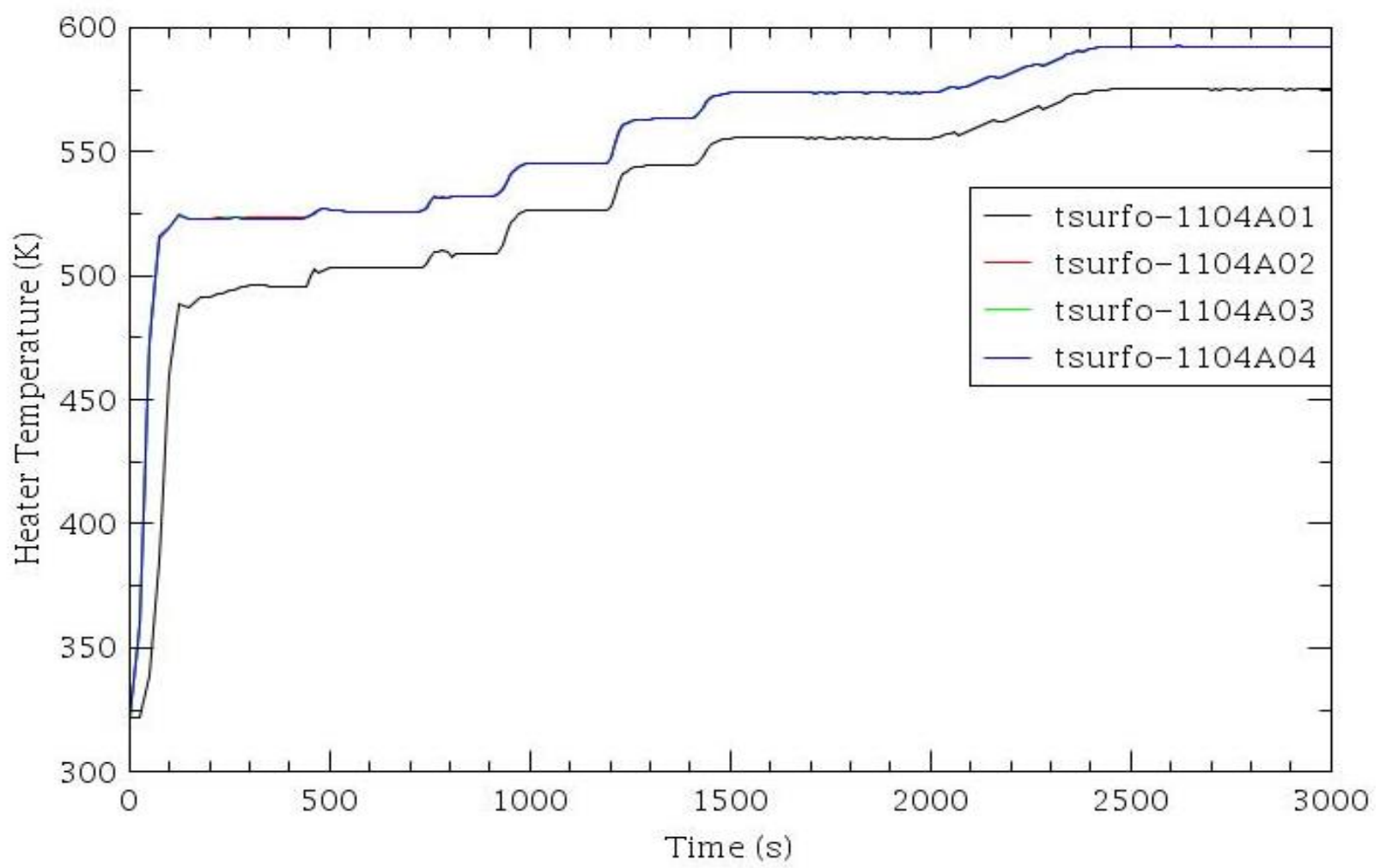

Figure 7-82. Heater surface temperatures calculated for the $98 \mathrm{~kW}$ maximum power run.

\subsection{CONDENSER PERFORMANCE}

The addition of an NC gas to the condenser of the TSTL degrades the effectiveness of the condenser, as the NC gas occupies portions of the condenser, and steam cannot be condensed in those NC gas-occupied portions. The condenser performs at its maximum capacity when there is only steam. The total heat input to the TS by the three heaters is removed by the primary coolant from both the condenser and the downcomer. The condenser should remove the majority of the heat, as condensation heat transfer is very efficient, and the condenser outside surface is significantly larger than the downcomer outside surface. Some heat is also removed from the condensed liquid circulating inside the downcomer. The TSTL experimental setup was not instrumented to separately measure the heat removed by the condenser and the downcomer. Temperatures of the primary coolant were measured at the entrance and exit of the primary system. This arrangement measures the total heat removed by the complete system (condenser and downcomer combined).

To evaluate the effects of NC gases on condenser performance, a series of TRACE calculations with different amounts of NC gases was completed. A calculation was performed first for pure steam conditions, and the results are shown in Figure 7-83 as the base/reference case, even if, as described in Section 7-3, experimental tests with pure steam could not reach the full $80 \mathrm{~kW}$ of power. Figure 7-83 shows the amount of heat removed by the condenser and by the downcomer as a function of time. The total power of $80 \mathrm{~kW}$ into the TS was entered in six steps over 1,000 s, as shown in Fig. 7-6. At the total power of $80 \mathrm{~kW}$, the condenser removes $51 \mathrm{~kW}$, while the downcomer removes $29 \mathrm{~kW}$, which is $36.3 \%$ of the total power, a very significant amount. Again, this is the case with only steam that results in the best performance of the condenser. The heat removed by the downcomer subcools the condensed water below its saturation temperature. The power input to one heater, with a maximum power of $26.667 \mathrm{~kW}$ 
after $1,000 \mathrm{~s}$, is also shown in this figure. When the tree heaters are added, the total input power to the system is $80 \mathrm{~kW}$ after $1,000 \mathrm{~s}$.

Figure 7-84 shows the calculated heat removed for test TS-140829-1, a helium high pressure test. In this calculation, the condenser removes only $37 \mathrm{~kW}$ of the total $80 \mathrm{~kW}$, while the downcomer removes the remaining $43 \mathrm{~kW}$, which is more than the condenser and $54 \%$ of the total power. This high heat removed by the downcomer results in large water subcooling. Large water subcooling was also measured in tests with large amounts of NC gases added.

Figure 7-85 shows heat removed by the condenser and the downcomer for different conditions, with increasing amounts of $\mathrm{NC}$ gases added. The maximum heat removed by the condenser is $51 \mathrm{~kW}$ for the theoretical case with pure steam, and the lowest value is $36 \mathrm{~kW}$ for the case with large amounts of helium added to the TS. The remaining heat (up to the total $80 \mathrm{~kW}$ ) will be removed by the downcomer, with values varying from $29 \mathrm{~kW}$ for pure steam to $44 \mathrm{~kW}$ with large amounts of helium added.

Since the water subcooling calculated by the TRACE code (and the liquid water temperature into the boiler) did not agree well with measured values (see Table 7.1), these results may not be totally accurate. TRACE calculated lower subcooling than the measured values, an indication that the TRACE code does not accurately calculate the heat removed by either the condenser or the downcomer or both. The actual heat removed by the downcomer may be larger than the values calculated by TRACE.

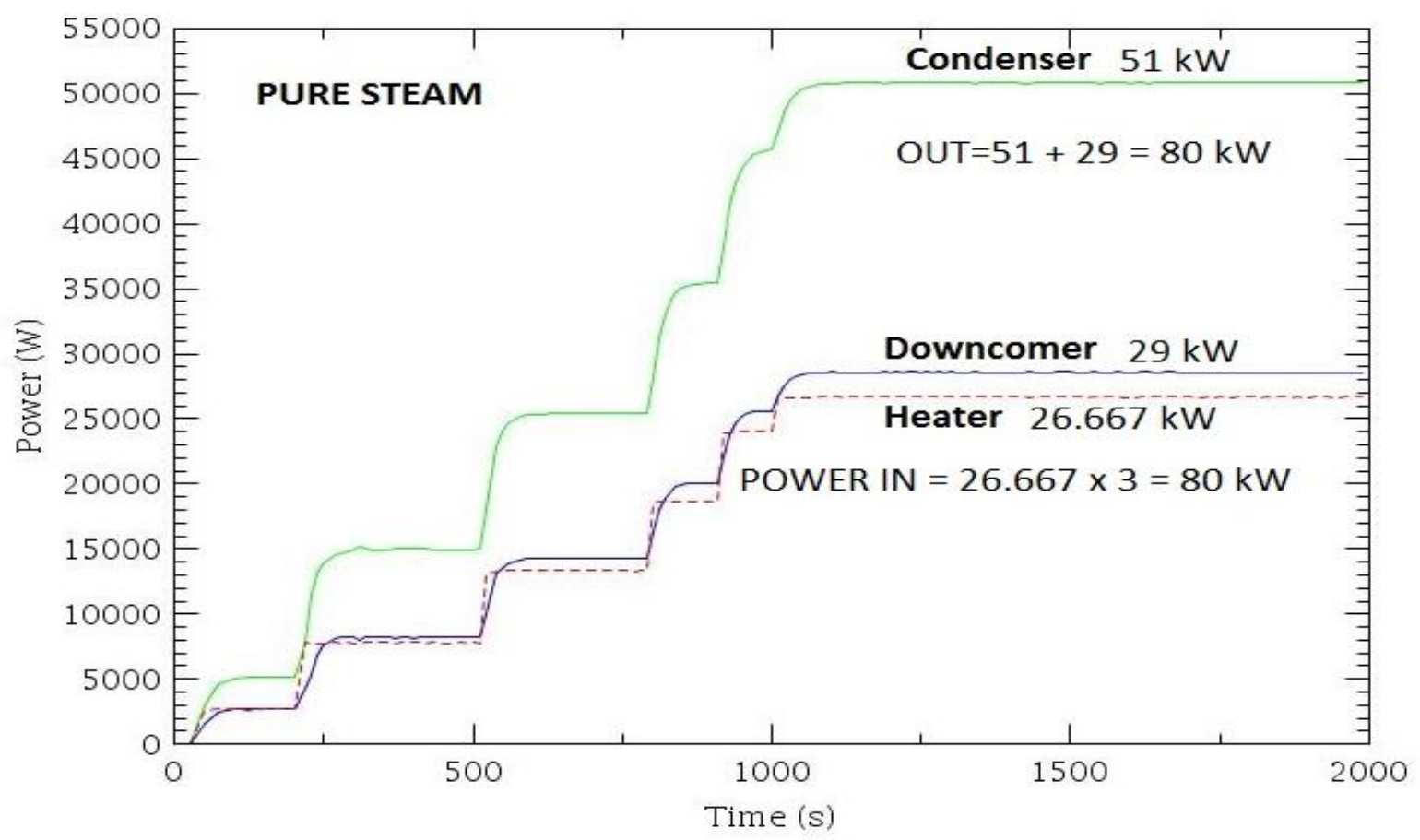

Figure 7-83. Heat removed by the condenser and downcomer for a case with pure steam. 


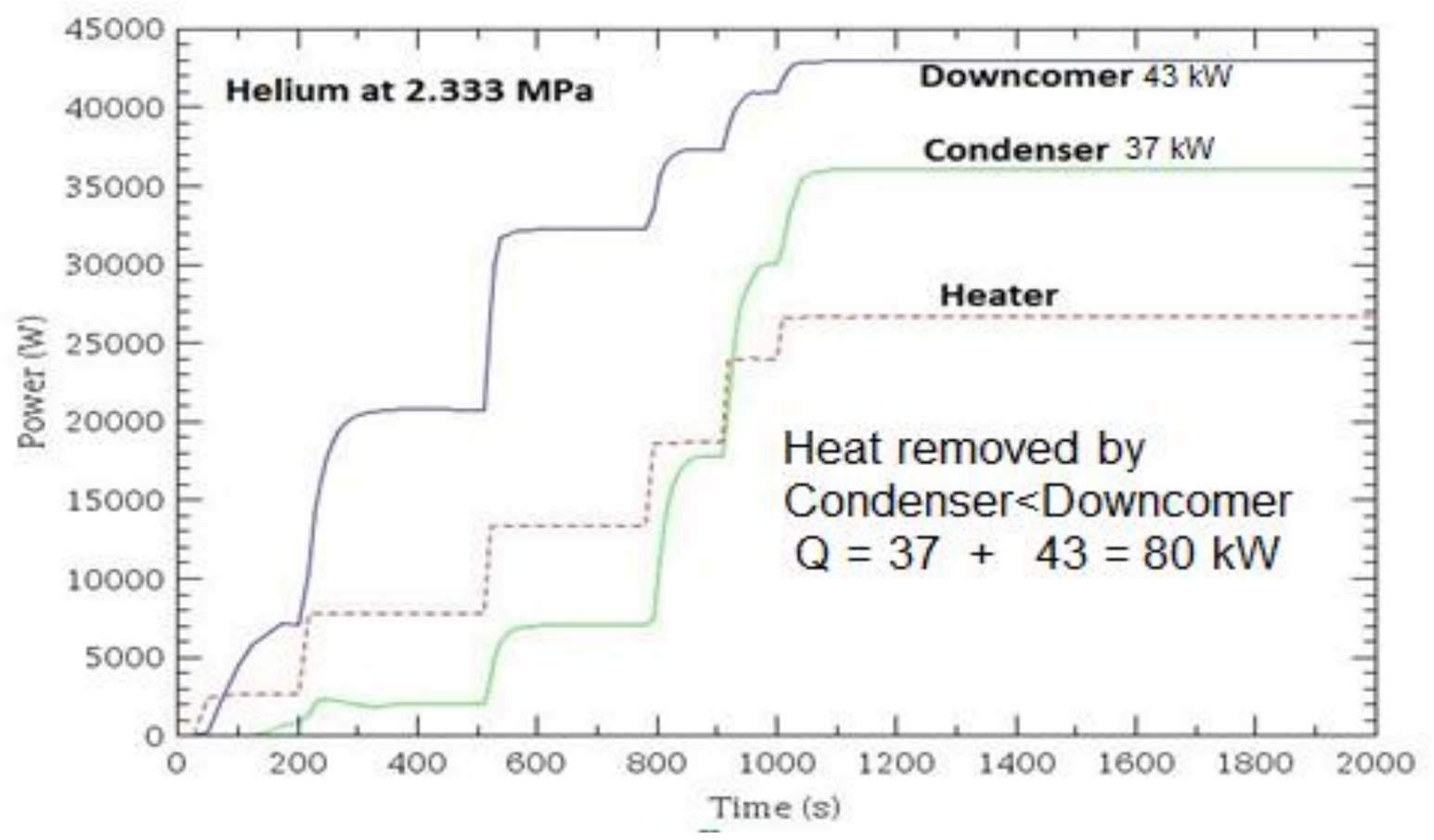

Figure 7-84. Heat removed by the condenser and downcomer with helium added.

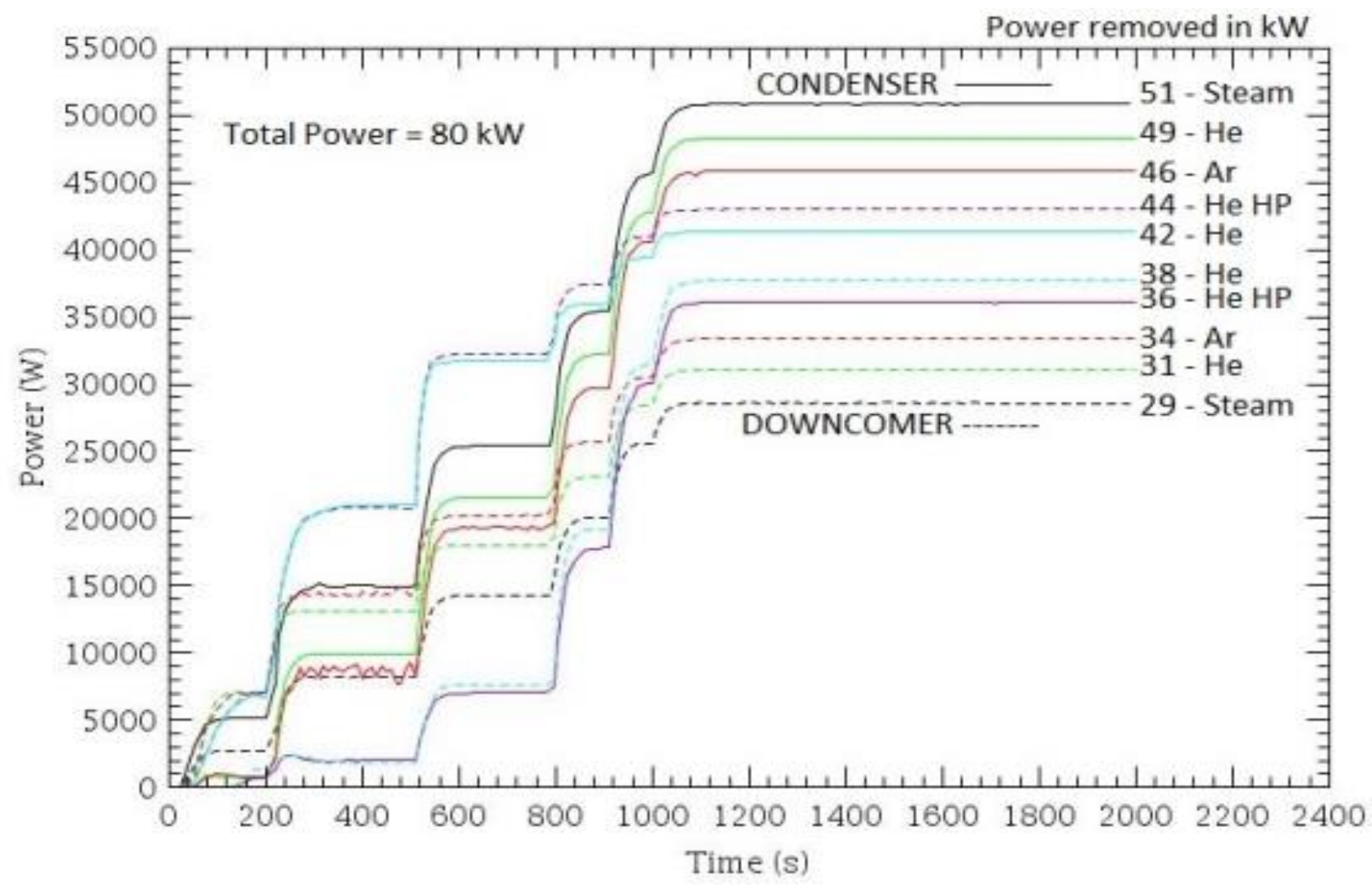

Figure 7-85. Heat removed by the condenser and downcomer for different cases analyzed. 


\subsection{RELAP5-3D AND TRACE DIFFERENCES}

As shown in Sections 7.2 and 7.4, the RELAP5-3D code calculated higher pressures and temperatures than the TRACE code for the same input conditions. This occurred with inputs with only steam (Fig. 7-6) and with inputs with NC gas (helium) added (Fig. 7-10). An investigation of the reasons for the different results has been completed. Each code employs different heat transfer coefficient logics for single phase natural and forced convection, for nucleate boiling, and for condensation. The boiling is under subcooled conditions, and the condensation is film-wise. The main cause for the different results is in the condensation, as the codes employ different condensation correlations.

TRACE calculates lower pressures than RELAP5-3D because it condenses vapor faster than RELAP53D. The heat transfer coefficients for condensation calculated by TRACE are significantly larger than those calculated by RELAP5-3D. Film condensation is predicted by both codes, but the heat transfer regime logic and the heat transfer correlations are different in each code. The RELAP5-3D code employs the Nusselt [13] or the Shah [14] correlation for laminar or turbulent film condensation, and it employs the Colburn-Hougen [15] correlation for NC gases. The TRACE code employs the Kuhn-SchrockPeterson [16] or Gnielinski [17] correlations of laminar or turbulent film condensation for conditions with either pure steam or NC gases added. The TRACE correlations calculate higher condensing rates than the RELAP5-3D correlations. TRACE calculations appear to agree well with the TSTL experimental data.

Table 7.2 compares values calculated by RELAP5-3D and TRACE at the full power of $80 \mathrm{~kW}$ for the run shown in Fig. 7-6, which was the run with pure steam. TRACE calculates larger heat transfer coefficients than RELAP5-3D for boiling and condensation regimes, with the main difference in the condensing heat transfer coefficients (h). TRACE calculates larger condensing $h$ (by a factor of 3 ) and lower pressure (by a factor of 2) than RELAP5-3D. RELAP5-3D requires twice as many condensing nodes as TRACE, but it still condenses less water than TRACE.

Table 7.2. RELAP5-3D and TRACE calculated results for only steam

\begin{tabular}{lcc}
\hline Variable & RELAP5-3D & TRACE \\
\hline Condensing $\mathrm{h}\left(\mathrm{W} / \mathrm{m}^{2} \mathrm{~K}\right)$ & $1,800-12,000$ & $\mathbf{1 2 , 0 0 0}-\mathbf{3 7 , 0 0 0}$ \\
Number of condensing nodes & 38 & 20 \\
Boiling $\mathrm{h}\left(\mathrm{W} / \mathrm{m}^{2} \mathrm{~K}\right)$ & $80,000-100,000$ & $100,000-120,000$ \\
Forced convection $\mathrm{h}\left(\mathrm{W} / \mathrm{m}^{2} \mathrm{~K}\right)$ & $11,000-18,000$ & $10,000-17,000$ \\
Liquid mass flow rate $(\mathrm{kg} / \mathrm{s})$ & 0.37 & 0.64 \\
Steam mass flow rate $(\mathrm{kg} / \mathrm{s})$ & 0.025 & 0.026 \\
$\Delta \mathrm{T}$ subcooling $(\mathrm{K})$ & 22 & 17 \\
System pressure $(\mathrm{MPa})$ & 3.75 & 1.84 \\
\hline
\end{tabular}




\section{SUMMARY AND CONCLUSIONS}

An extensive amount of experimental data was obtained from the TSTL, and extensive computer simulations were conducted to test the viability and performance of a two-phase thermosyphon for irradiation of fuels and materials in a research reactor. With this new facility, fuels and materials can be irradiated without concern for coolant contamination (e.g., from cladding failure from advanced fuel pins) or for specimen heat load. The specimens or fuels are irradiated inside a sealed container with its own internal coolant loop that will keep its integrity at very high operating pressures and temperatures.

The following conclusions are drawn:

Experimental Data. A total of 51 tests were completed, and a large amount of high-quality data has been obtained. Of the total 51 tests, 4 tests were run with pure steam, 12 tests with argon as the NC gas, and 35 tests with helium as the NC gas. A total of 10 tests were performed at subatmospheric pressure ( 4 of them with pure steam), one test was at a high power of $92.7 \mathrm{~kW}$, six tests were HFIR startups, and two tests were HFIR LOOPs. Final pressures up to $9.9 \mathrm{MPa}$, vapor temperatures up to $583 \mathrm{~K}\left(310^{\circ} \mathrm{C}\right)$, and heater temperatures above $600 \mathrm{~K}\left(327^{\circ} \mathrm{C}\right)$ have been reached in these tests. The collected data can be used for many purposes, including code benchmarking, as done in this report with the RELAP5-3D and the TRACE codes. The data also confirm the viability of the thermosyphon as a new irradiation facility to be installed in the HFIR with its own internal coolant loop. The experiments at very low initial pressures (vacuum or with a very low initial subatmospheric pressure) ended in CHF at low powers ( 10 kW total). By increasing the initial pressure to $16.7 \mathrm{kPa}$ with the addition of helium, the TSTL tolerated the full power of $80 \mathrm{~kW}$, and the heaters had no CHF occurrence.

Computer Code Selection. Two thermal hydraulic transient computer codes, RELAP5-3D and TRACE, were used to aid in the design of the TSTL, to perform pretest predictions, and to model the experiments in the TSTL. The results from the RELAP5-3D code were employed to design the facility. However, after comparison with experimental data, it was found that the RELAP5-3D code yielded very conservative, unrealistic results, with very high pressures and temperatures. Therefore, the TRACE code was selected as the code to model these experiments because it has shown good agreement with the data. The TRACE code has been able to model the TSTL boiling/condensing experiments very well, calculating pressures and temperatures that agreed with the experimental values. The RELAP5-3D code calculated unrealistic high pressures and temperatures that were well above the experimental values. The RELAP5-3D results are excessively conservative and unrealistic and cannot be used for best-estimate calculations.

CHF at low pressures. Starting with a very low initial condenser pressure (5.8 $\mathrm{kPa}$ at $\left.20^{\circ} \mathrm{C}\right)$, the TSTL repeatedly experienced a CHF event at $\sim 10 \mathrm{~kW}$ system power at the topmost thermocouple location. Neither the TRACE code nor the RELAP5-3D code was able to predict that CHF occurs at low system pressures and powers when pure steam/water is employed in the TSTL. To avoid this occurrence, higher initial pressures above $16.7 \mathrm{kPa}$ (by adding $\mathrm{NC}$ gases) are required to be able to reach the full $80 \mathrm{~kW}$ of power into the system without reaching temperature excursions in the heaters.

Temperature stratification. All tests using helium as the NC gas added showed a distinct temperature stratification inside the condenser, with low temperature helium at the upper elevations, and high temperature steam at the lower elevations of the condenser. As power increases, the demarcation line can be seen moving higher in the condenser. There appears to be very little mixing between the two gases. Tests with argon did not show this temperature stratification, and significant mixing occurred. The TRACE code was able to predict this behavior with either NC gas.

Condenser performance. The helium/steam stratification effect allows for some measure of control over the operating conditions of the thermosyphon. By increasing the initial helium pressure in the condenser, 
the condenser surface area available for condensation is reduced, which increases the operating pressure and temperature. This allows the designer to control the thermosyphon operating temperature by varying the condenser pressure. This could be done actively during an experiment. However, high pressure tests with large amounts of $\mathrm{NC}$ gases added result in more heat removed by the downcomer than by the condenser. High pressure tests also result in greater water subcooling than low pressure tests. Both experimental and calculated results show this trend.

Calculated liquid and vapor mass flow rates. Liquid and vapor mass flow rates were not measured in the experiments. The OFTF has measured flows at low pressures and temperatures. TRACE calculations have shown that high pressure tests ( $>1 \mathrm{MPa}$ initial pressure at zero power) yield lower calculated mass flow rates of liquid water and steam than low pressure tests $(<0.5 \mathrm{kPa}$ initial pressure) for the same power levels. The measured pressure differential $(\Delta \mathrm{P})$ across the entrance orifices is also lower in high pressure tests than in low pressure tests, and the same trend has been observed for the TRACE calculated $\triangle \mathrm{P}$. Larger orifice $\Delta$ Ps go together with larger liquid mass flow rates through the orifices. The mass flow rate of liquid water is controlled by the density difference between the downcomer and the boiler/evaporator. The vapor bubbles or voids in the boiler/evaporator are a function of the system power and pressure. At higher pressures, the bubbles are compressed and they are smaller, resulting in less buoyancy and lower liquid mass flow rates than at low pressures with larger bubbles and more buoyancy.

The amount of steam generated in the boiler/evaporator is a function of the system power (which is the same for most tests, with a final power of $80 \mathrm{~kW}$ ) and of the subcooling of the liquid water entering the boiler/evaporator (which varies with the tests). Large water subcooling has been measured and calculated for tests with high pressures and high amounts of NC gases added. This agrees with reduced condenser performance for high pressure tests with large amounts of $\mathrm{NC}$ gases. The downcomer removes more heat than the condenser, resulting in more water subcooling. Therefore, high pressure tests need more power for the highly subcooled water to become saturated than low pressure tests with less subcooled water. Consequently, there is less power left to generate steam, and lower amounts of steam are generated in high pressure tests than in low pressure tests. Since the TRACE code does not calculate the water subcooling accurately (the TRACE code under-calculates the subcooling), the calculated mass flow rates of steam generated are likely to be also with errors.

LOOP Transient. A LOOP transient was performed in the TSTL to match the same simulated transient in the HFIR. The experimental results show that the TSTL can manage heat removal throughout the transient without approaching any boiling limit on the external surface of the TS. In addition, the heater rods also remained sufficiently cool throughout the transient. This transient has also been modeled well by the TRACE code and appears to be a mild transient, despite the fact that the primary coolant flow is reduced to a much lower value ( $8 \%$ of the initial value) than the power value (to $21 \%$ of the initial value). The power reduction to $21 \%$ has been selected as the highest, most conservative value for the different materials that could be irradiated in the HFIR. Most likely, the power will be reduced to a value lower than $21 \%$, resulting in an even milder transient.

$130 \%$ Power. Per HFIR requirements, the system should be able to tolerate $130 \%$ of the nominal power under steady state conditions with the full primary coolant flow. The heaters of the TS could only reach a maximum power of $92.6 \mathrm{~kW}$ (116\% of the nominal power), which was tolerated by the TS (with NC gas added). The simulation with the TRACE code also agreed with the experimental values. Additional high power calculations were completed with the TRACE code to estimate the maximum power that the TS can tolerate. Calculations with helium added at high pressures resulted in CHF occurrence at power levels between $98 \mathrm{~kW}$ and $99 \mathrm{~kW}$. The calculation at the power of $98 \mathrm{~kW}$ was completed without CHF occurrence. The $98 \mathrm{~kW}$ power level is therefore the maximum power that the thermosyphon can tolerate safely. This indicates that, at least under the conditions specified in this run, the maximum nominal operating power is about $75 \mathrm{~kW}$, as $75 \mathrm{~kW} \times 1.3=97.5 \mathrm{~kW}<98 \mathrm{~kW}$. 
This maximum power limit is very dependent on the materials and conditions employed in the test and cannot be extrapolated directly to any other specimen (different materials) or to different input conditions such as axial power distribution, different geometry, $\mathrm{NC}$ gas, etc. A separate evaluation will be required for each specific case. 


\section{WORKS CITED}

[1] J. E. Deverall, Heat Pipe Thermal Control of Irradiation Capsules, LA-UR-73-1033, Los Alamos National Laboratory, 1973.

[2] J. E. Deverall and H. E. Watson, Temperature Control of Irradiation Experiments with Gascontrolled Heat Pipes, Los Alamos National Laboratory, 1973.

[3] E. S. Keddy and H. E. Martinez, "Development of High-Temperature Liquid-Metal Heat Pipes for Isothermal Irradiation Assemblies," Proceedings, Intersociety Energy Conversion Engineering Conference, 1982.

[4] E. Bojarsky, K. Muller and L. Schmidt, "Irradiation capsule with heat pipe successfully tested in the KNK II reactor Karlsruhe,” Journal of Nuclear Materials, vol. 139, no. 2, pp. 156-157, 1986.

[5] D. Paladino, R. Zboray, P. Benz and M. Andreani, "Three-gas mixture plume inducing mixing and stratification in a multi-compartment containment," Nuclear Engineering and Design, vol. 240, no. 2, pp. 210-220, 2010.

[6] J. L. McDuffee, RELAP5 Transient Analysis for a VXF Fuel Irradiation Facility, C-HFIR-2009003, Thermal Hydraulics \& Irradiation Engineering Group, Reactor \& Nuclear Systems Division, Oak Ridge National Laboratory, 2010.

[7] Idaho National Laboratory, RELAP5-3D Code Manuals, INEEL-EXT 98-00834, Idaho National Laboratory, 2012.

[8] US Nuclear Regulatory Commission, TRACE V5.0 Manuals, NRC ADAMS Accession Number ML120060403, 2012.

[9] J. J. Carbajo and J. L. McDuffee, "RELAP5 Model of a Two-Phase Thermosyphon Experimental Facility for Fuels and Materials Irradiation," in Trans. Am. Nucl. Soc. 108, Atlanta, Georgia, 2013.

[10] J. J. Carbajo, "Comparison of RELAP5-3D and TRACE Results for a Boiling/Condensing Experimental Facility," in Trans. Am. Nucl. Soc. 110, Reno, NV, 2014.

[11] D.C. Groeneveld et al, "The 1995 look-up table for critical heat flux in tubes, Nuclear Engineering and Design, vol. 163, pp 1-23, 1996.

[12] D.C. Groeneveld et al, "1986 AECL-UO Critical Heat Flux Lookup Table," Heat Transfer Engineering, vol. 1-2, pp. 46-62, 1986.

[13] W. Nusselt, "Die Oberlachenkondensation des Wasserdampfes," Zeitschrift Ver, Deutsch. Ing., vol. 60, pp. 541-546 and 569-575, 1916.

[14] M. Shah, "A General Correlation for Heat Transfer during Film Condensation inside Pipes," International Journal of Heat and Mass Transfer, vol. 22, pp. 547-556, 1979.

[15] A. Colburn and O. Hougen, "Design of cooler condensers for Mixtures of Vapors with Noncondensing Gases," Industrial and Engineering Chemistry, vol. 26, pp. 1178-1182, 1934.

[16] S. Kuhn, et. al, "Final Report on U.C. Berkeley Single Tube Condensation Studies," UCB-NE4201, University of California, Berkeley, 1994.

[17] V. Gnielinski, "New Equations flow Regime Heat and Mass Trasnfer in Turbulent Pipe and Channel Flow," Int. Chem. Eng., vol. 16, pp. 359-368, 1976. 
APPENDIX A. Thermosyphon Drawings 


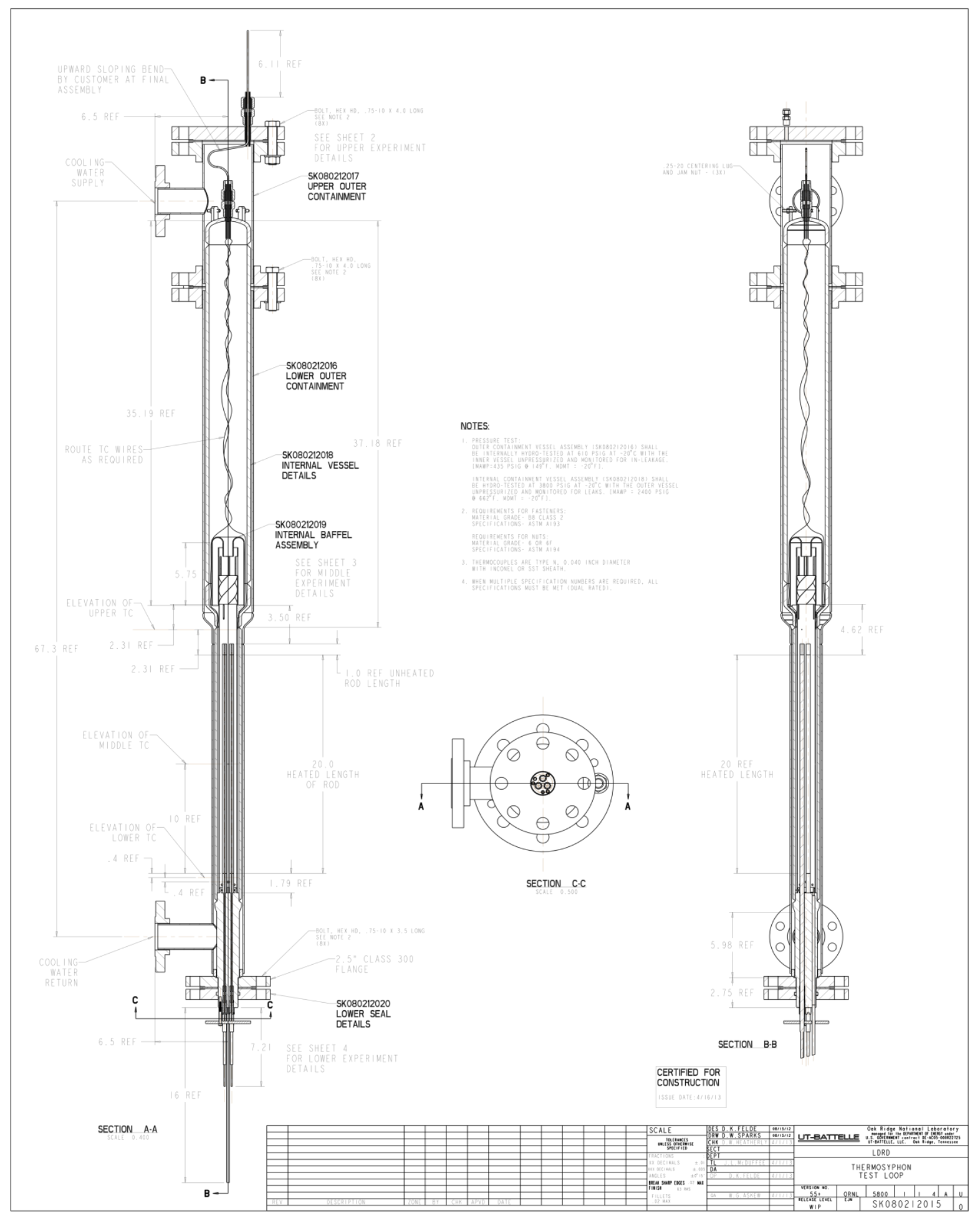

Figure A-1 Thermosyphon test assembly. 


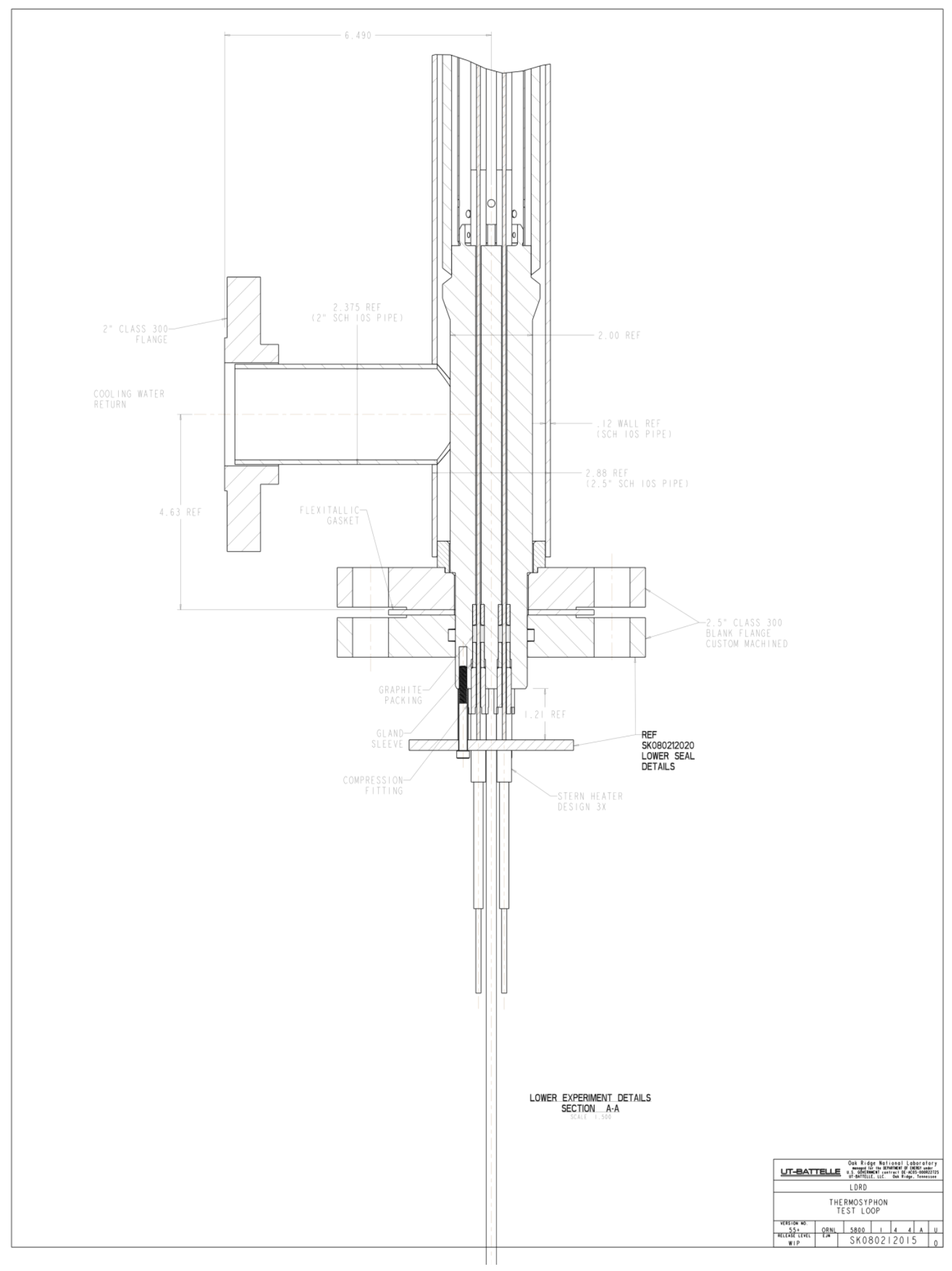

Figure A-2. Lower portion detail of the thermosyphon test assembly. 


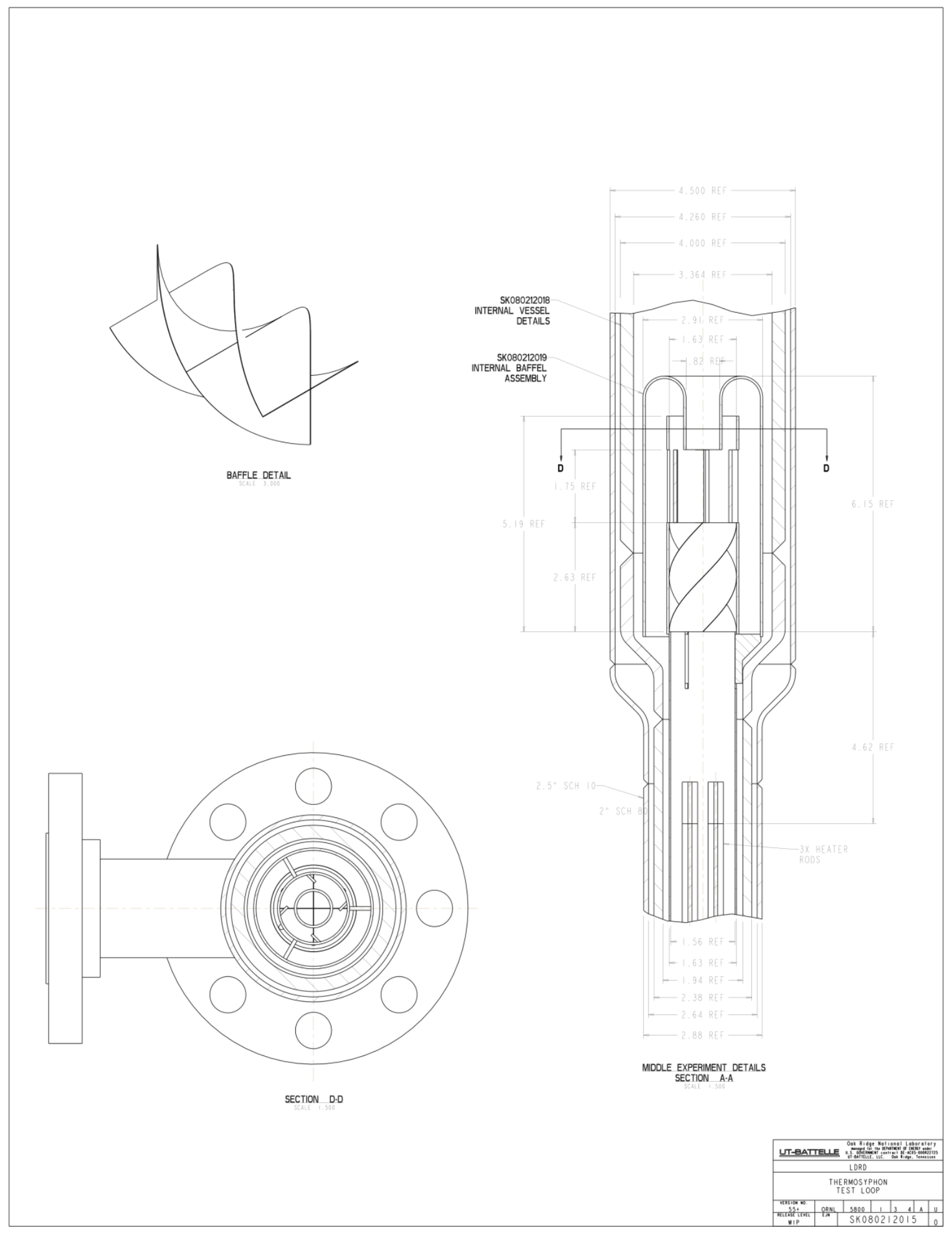

Figure A-3. Middle portion detail of the thermosyphon test assembly 


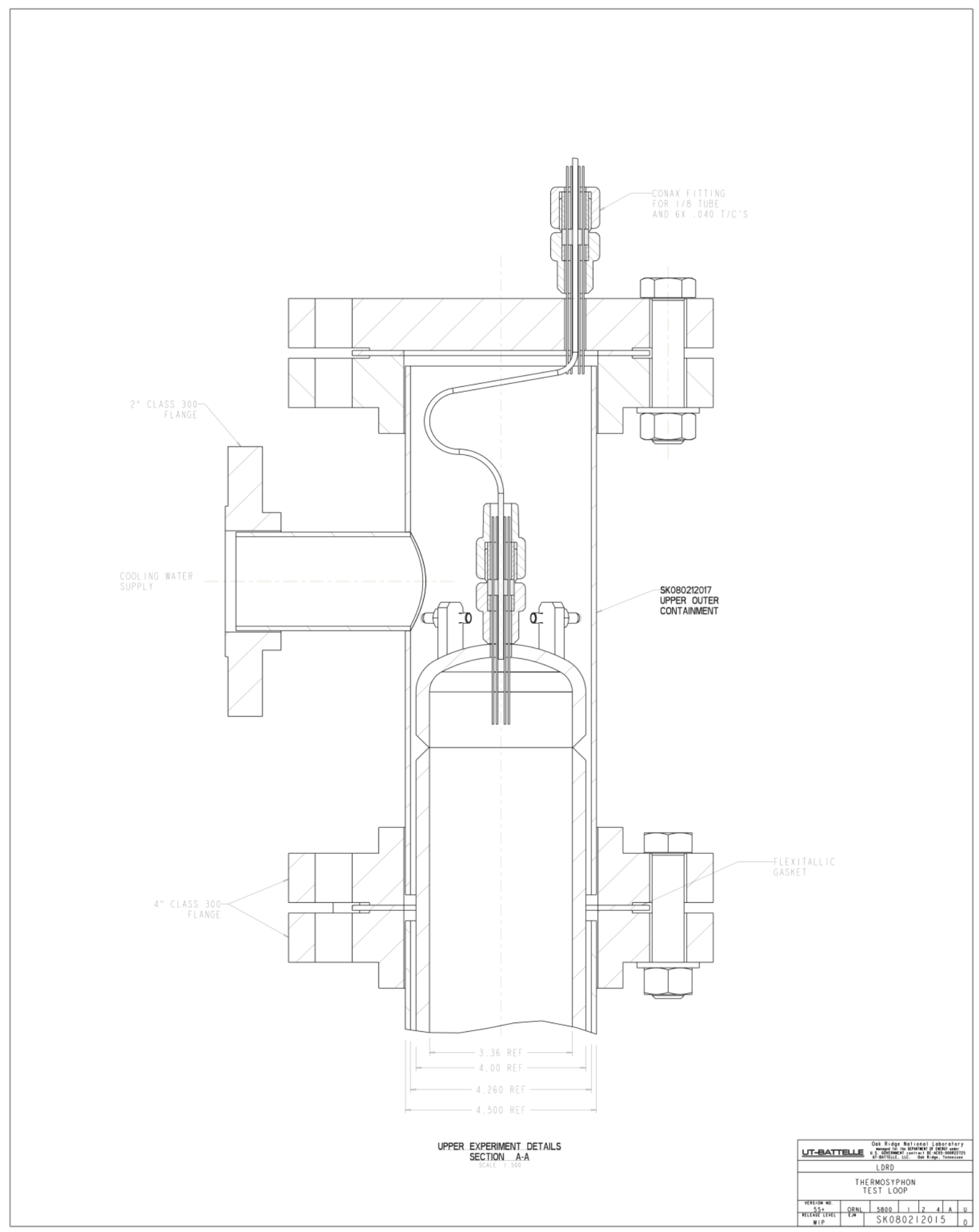

Figure A.4. Upper portion of the thermosyphon test assembly. 
